\title{
PORFLOW MODELING SUPPORTING THE FY13 SALTSTONE SPECIAL ANALYSIS
}

J. M. Jordan

G. P. Flach

MAY 2013

Savannah River National Laboratory

Savannah River Nuclear Solutions

Savannah River Site

Aiken, SC 29808

Prepared for the U.S. Department of Energy Under

Contract Number DE-AC09-08SR22470

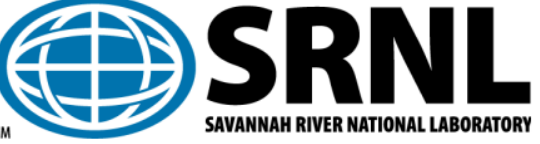




\section{DISCLAIMER}

This work was prepared under an agreement with and funded by the U.S. Government. Neither the U. S. Government or its employees, nor any of its contractors, subcontractors or their employees, makes any express or implied:

1. warranty or assumes any legal liability for the accuracy, completeness, or for the use or results of such use of any information, product, or process disclosed; or

2. representation that such use or results of such use would not infringe privately owned rights; or

3. endorsement or recommendation of any specifically identified commercial product, process, or service.

Any views and opinions of authors expressed in this work do not necessarily state or reflect those of the United States Government, or its contractors, or subcontractors.

Printed in the United States of America

Prepared for

U.S. Department of Energy 
Key Words:

Performance Assessment

Cementitious materials

Fractures

Oxidation

Retention:

Permanent

\title{
PORFLOW MODELING SUPPORTING THE FY13 SALTSTONE SPECIAL ANALYSIS
}

\author{
J. M. Jordan \\ G. P. Flach
}

MAY 2013

Savannah River National Laboratory

Savannah River Nuclear Solutions

Savannah River Site

Aiken, SC 29808 
SRNL-STI-2013-00280, REVISION 0

\section{REVIEWS AND APPROVALS}




\section{EXECUTIVE SUMMARY}

PORFLOW modeling supporting the concurrent Saltstone FY13 Special Analysis (SA) is described in this report. The present simulations are based on the 2009 Performance Assessment and subsequent modeling to support a response to NRC Request for Additional Information PA-8. Notable changes to the baseline PA-8 model include revised degradation of cementitious materials and associated hydraulic properties, inclusion of floor joints and roof support columns in model representations, and a revised Tc-99 shrinking-core model to implement combined redox and solubility controls. Also presented are new and further justifications for key model assumptions, and verification test cases for selected model attributes. Results are presented for the nominal value simulation case, a flow sensitivity parametric study, and Tc-99 transport sensitivity cases. Further discussion of PORFLOW model setup and simulation results is presented in the Saltstone FY13 SA, including dose results. 


\section{TABLE OF CONTENTS}

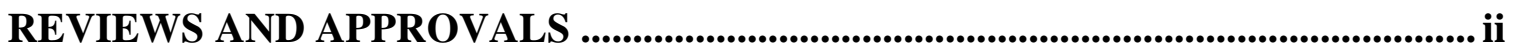

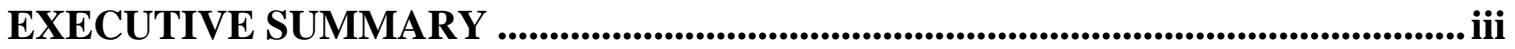

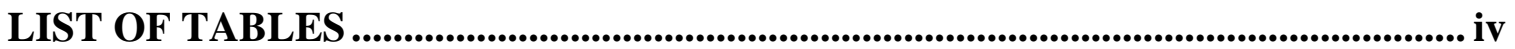

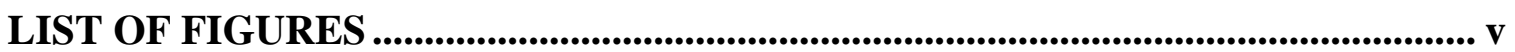

LIST OF ACRONYMS ......................................................................................... viii

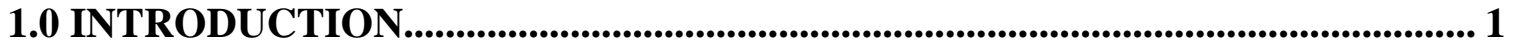

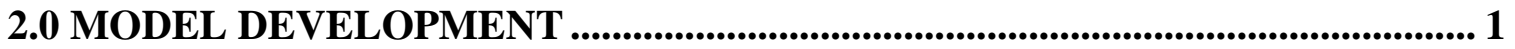

2.1 Degradation of Cementitious Materials ............................................................. 1

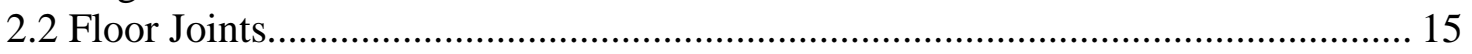

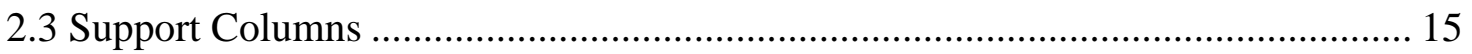

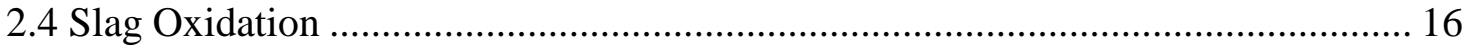

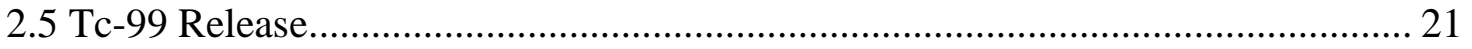

2.6 Alternative Explicit Fracture Representation.................................................... 25

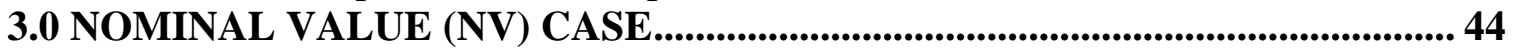

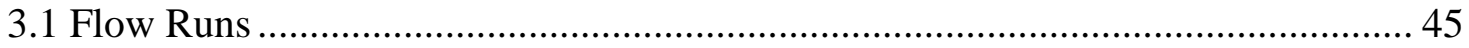

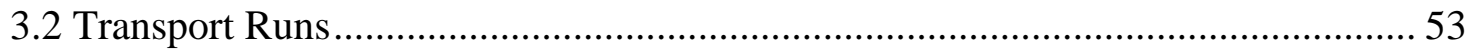

4.0 FLOW SENSITIVITY CASES..................................................................... 58

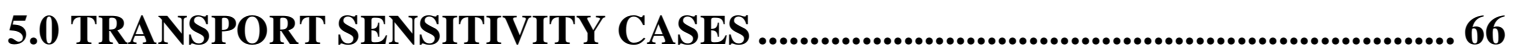

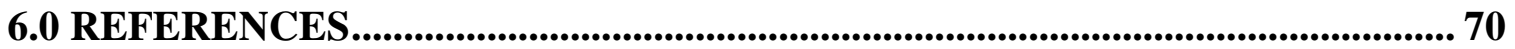

\section{LIST OF TABLES}

Table 2-1. Degradation analysis for SDU 2 concrete and saltstone

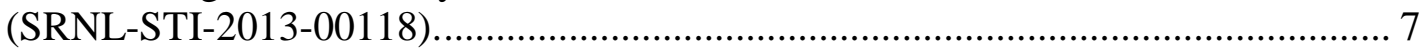

Table 2-2. Degradation analysis for SDU 4 concrete and saltstone

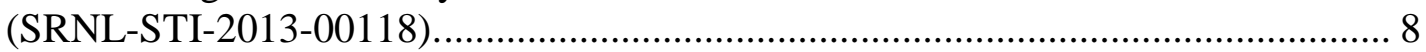

Table 2-3. Degradation analysis for SDU 1 concrete and saltstone (modified from

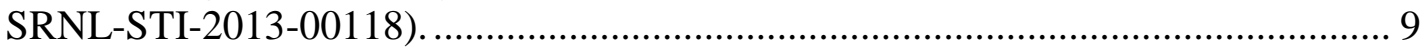

Table 2-4. Hydraulic parameters for SDU 2 cementitious materials and soils........... 10

Table 2-5. Technetium transport parameters recommended for cementitious materials; reproduced from Kaplan and $\mathrm{Li}(2013)$............................................................ 16

Table 2-6. Hydraulic parameters for Discrete Fracture and Equivalent Continuum Models. 31

Table 2-7. Damkohler numbers for various fracture spacings and infiltration rates.... 37

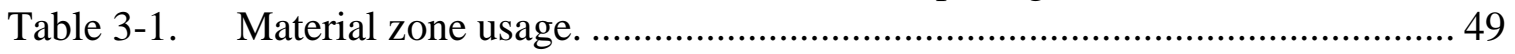

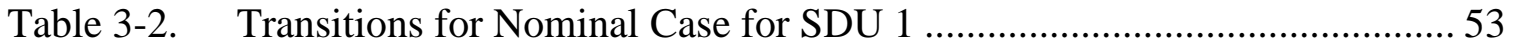

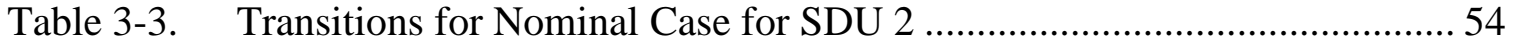

Table 3-4. Transitions for Nominal Case for SDU 4 .............................................. 55

Table 4-1. Vadose zone flow sensitivity cases...................................................... 59 


\section{LIST OF FIGURES}

Figure 2-1. Unsaturated hydraulic conductivity for intact SDU 2 concrete, intact grout,

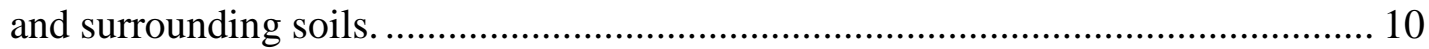

Figure 2-2. Example transitions of intact cementitious materials from intact to fullydegraded conditions represented by soils: (a) SDU 2 concrete and (b) grout. .......... 11

Figure 2-3. Alternative representations of a fractured medium; reproduced from Altman

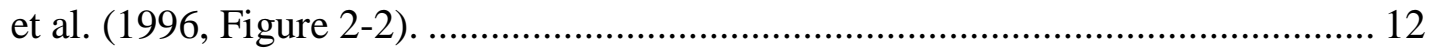

Figure 2-4. Alternative surrogate soils for blending to fully-degraded conditions. ...... 13

Figure 2-5. Partial blending (10.7\%) to gravel representing degradation to $5 \mathrm{mil}$

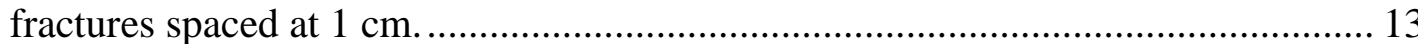

Figure 2-6. Infiltration rates compared to SDU 2 concrete and LVZ soil hydraulic

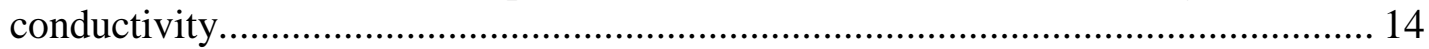

Figure 2-7. Degradation to selected fractured conditions using fracture properties based

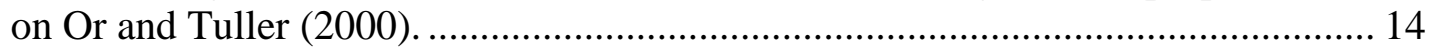

Figure 2-8. One-dimensional slag oxidation test: initial conditions........................... 19

Figure 2-9. One-dimensional slag oxidation test: conditions at 854 years................... 19

Figure 2-10. Two-dimensional slag oxidation test: initial conditions. ....................... 20

Figure 2-11. Two-dimensional slag oxidation test: conditions at 812 years. ............. 20

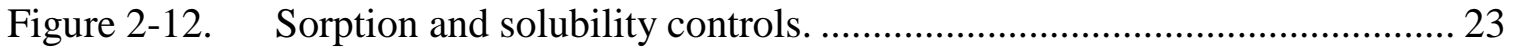

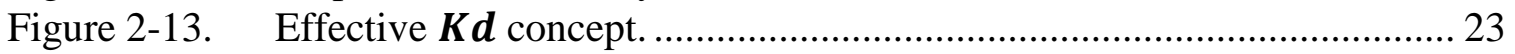

Figure 2-14. Weighting function between reduced and oxidized conditions. ............. 23

Figure 2-15. Test Case A for implementation of redox-solubility control: Tc-99 depleted before slag (solubility controls, no redox effect). .................................. 24

Figure 2-16. Test Case B for implementation of redox-solubility control: Case A at smaller timestep (increases accuracy)............................................................. 24

Figure 2-17. Test Case C for implementation of redox-solubility control: Tc-99 held up by solubility control until slag is exhausted, then concentration goes up orders of

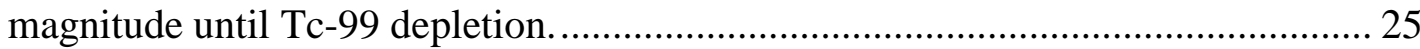

Figure 2-18. Explicit Fracture and Homogenized Fracture Models: a) schematic drawing showing material zones, and b) PORFLOW representations. .................... 30

Figure 2-19. Hydraulic characteristics of DFM and ECM materials......................... 31

Figure 2-20. Comparison of DFM and ECM flow simulations (1.0 meter fracture

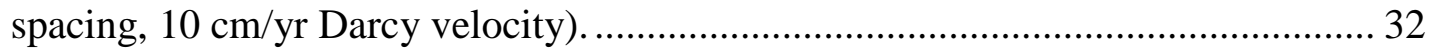

Figure 2-21. Comparison of inlet pressure head $(\mathrm{cm})$ for various infiltration rates and fracture spacings for DFM and ECM simulations.............................................. 32

Figure 2-22. Comparison of inlet pressure head $(\mathrm{cm})$ for various infiltration rates and fracture spacings for DFM and ECM simulations when the grout conductivity is reduced to $1.0 \mathrm{E}-10 \mathrm{~cm} / \mathrm{s}$.

Figure 2-23. Tracer release in DFM and ECM simulations 10 years for a 1.0 meter fracture spacing and $10 \mathrm{~cm} / \mathrm{yr}$ flow.

Figure 2-24. Tracer transport comparison for DFM and ECM simulations with a 1.0 meter fracture spacing and $10 \mathrm{~cm} / \mathrm{yr}$ flow: (a) flux, and (b) residual mass. ............. 34

Figure 2-25. Tracer transport comparison for DFM and ECM simulations for varying fracture spacings and a $10 \mathrm{~cm} / \mathrm{yr}$ flow rate. 
Figure 2-26. Tracer transport comparison for DFM and ECM simulations for a 1.0 meter fracture spacings and varying flow rates $(\mathrm{cm} / \mathrm{yr})$. ................................... 35

Figure 2-27. Tracer transport comparison for DFM and ECM simulations for a 0.3 meter fracture spacings and varying flow rates $(\mathrm{cm} / \mathrm{yr})$.................................. 36

Figure 2-28. Tracer transport comparison for DFM and ECM simulations for a 0.1

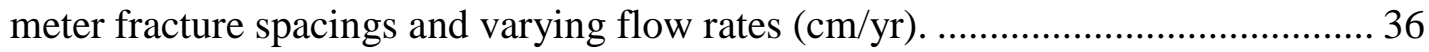

Figure 2-29. Initial conditions for slag oxidation and Tc-99 transport simulations. ... 37

Figure 2-30. DFM simulation of slag oxidation and Tc-99 transport: (a) concentrations

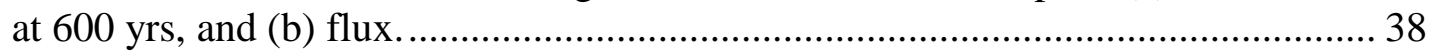

Figure 2-31. Cumulative release and average flux for DFM simulation of slag oxidation and Tc-99 transport

Figure 2-32. ECM simulation of slag oxidation and Tc-99 transport: (a) concentrations at 600 yrs, and (b) flux. 40

Figure 2-33. DFM simulation of slag oxidation and Tc-99 transport with 100x lower reduction capacities: (a) concentrations at 250 yrs, and (b) flux.

Figure 2-34. DFM simulation of slag oxidation and Tc-99 transport with 100x lower reduction capacities and no oxygen source in fracture: (a) concentrations at 250 yrs, and (b) flux.

Figure 2-35. ECM simulation of slag oxidation and Tc-99 transport with 100x lower reduction capacities: (a) concentrations at 250 yrs, and (b) flux........................... 43

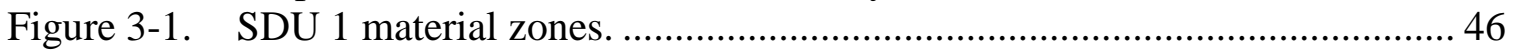

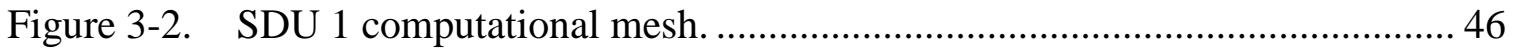

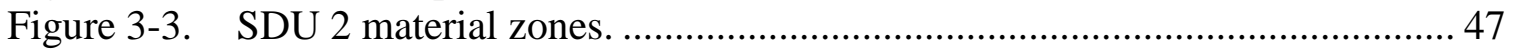

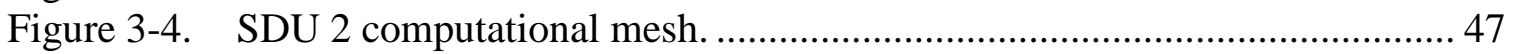

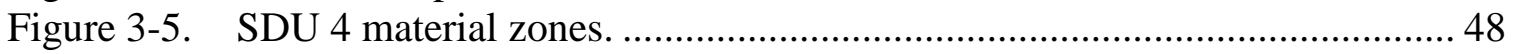

Figure 3-6. SDU 4 computational mesh. ................................................................ 48

Figure 3-7. Material property timeline for SDU 1 and nominal (NV) case. ................ 50

Figure 3-8. Material property timeline for SDU 2 and nominal (NV) case. ................ 50

Figure 3-9. Material property timeline for SDU 4 and nominal (NV) case. ................ 51

Figure 3-10. SDU 1 flow rates for nominal (NV) case......................................... 51

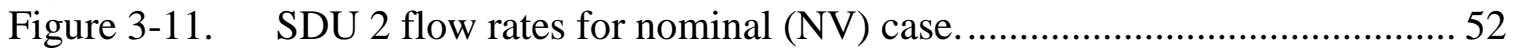

Figure 3-12. SDU 4 flow rates for nominal (NV) case............................................ 52

Figure 3-13. Flux for Tc-99 for nominal (NV) case for SDU 1................................ 56

Figure 3-14. Flux for Tc-99 for nominal (NV) case for SDU 2............................... 56

Figure 3-15. Flux for Tc-99 for nominal (NV) case for SDU 4............................... 57

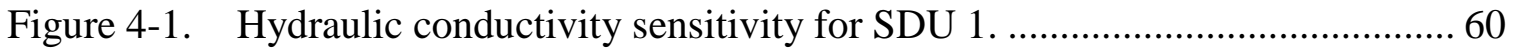

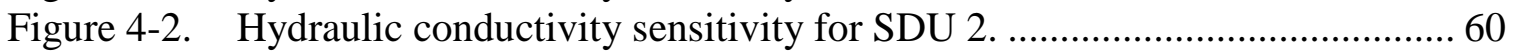

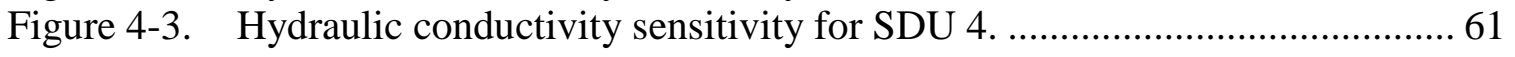

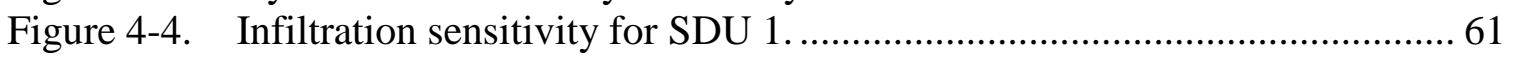

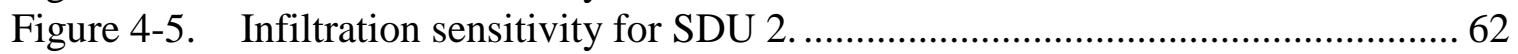

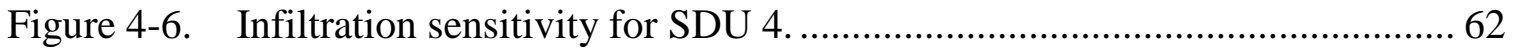

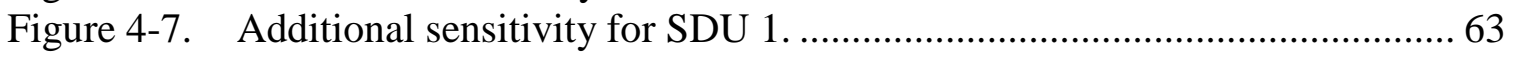

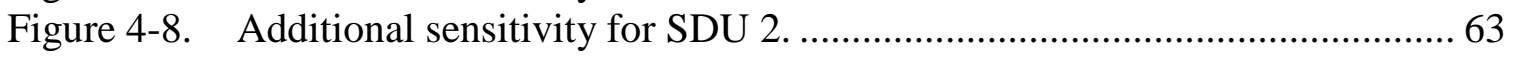

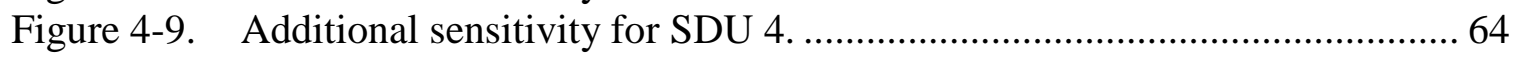

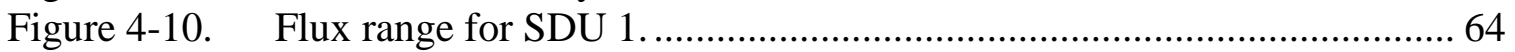

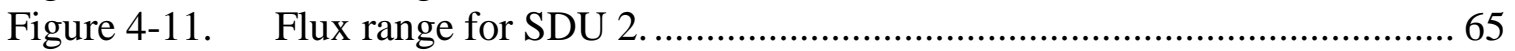




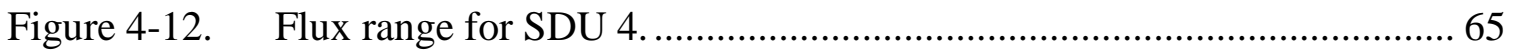

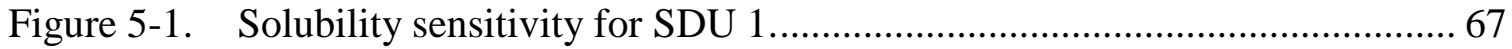

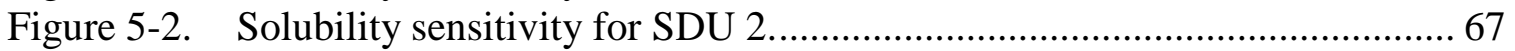

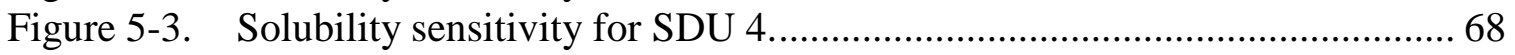

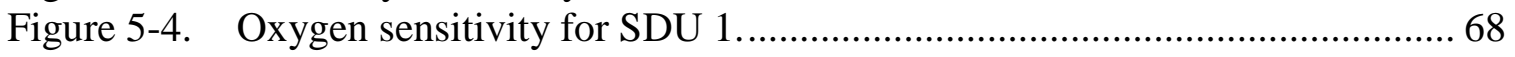

Figure 5-5. Oxygen sensitivity for SDU 2................................................................ 69

Figure 5-6. Oxygen sensitivity for SDU 4.................................................................. 69 


\section{LIST OF ACRONYMS}

$\begin{array}{ll}\text { BE } & \text { Best Estimate } \\ \text { CE } & \text { Conservative Estimate } \\ \text { DFM } & \text { Discrete Fracture Model } \\ \text { DOE } & \text { Department of Energy } \\ \text { ECM } & \text { Equivalent Continuum Model } \\ \text { GCL } & \text { Geosynthetic Clay Liner } \\ \text { HDPE } & \text { High Density Polyethylene } \\ \text { LVZ } & \text { Lower Vadose Zone } \\ \text { MCC } & \text { Moisture Characteristic Curve } \\ \text { NRC } & \text { Nuclear Regulatory Commission } \\ \text { NV } & \text { Nominal Value } \\ \text { PA } & \text { Performance Assessment } \\ \text { RAI } & \text { Request for Additional Information } \\ \text { SA } & \text { Special Analysis } \\ \text { SDU } & \text { Saltstone Disposal Unit } \\ \text { SRS } & \text { Savannah River Site } \\ \text { SRR } & \text { Savannah River Remediation } \\ \text { SRNL } & \text { Savannah River National Laboratory }\end{array}$




\subsection{INTRODUCTION}

PORFLOW related analyses supporting the Saltstone FY13 Special Analysis (SA) (SRR 2013) described herein are based on the 2009 Performance Assessment (PA) (SRR 2009, Flach et al. 2009) and subsequent modeling to support a response to NRC Request for Additional Information (RAI) PA-8 (SRR 2011, Flach 2011). FY13 SA differences from the RAI PA-8 analysis are defined by SRR (2013) and Sheppard (2013). Notable changes to the nominal RAI PA-8 model include revised degradation of cementitious materials (Flach and Smith 2013) and associated hydraulic properties, and a revised Tc-99 shrinking-core model to implement combined redox and solubility controls. These new Saltstone model developments are discussed in the next section, followed by a cursory presentation of nominal value, flow sensitivity, and transport sensitivity simulation results. Further discussion of PORFLOW model setup and simulation results is presented in the FY13 SA (SRR 2013), including dose results.

\subsection{MODEL DEVELOPMENT}

This section describes model development required to implement FY13 SA changes to the RAI PA-8 analysis in PORFLOW simulations in the areas of: a) degradation of cementitious materials, b) hydraulic properties of degraded materials, c) representation of floor joints and support columns, and d) combined redox and solubility controls on Tc-99 release. Also presented are new or further justifications for key model assumptions, and verification and validation test cases for selected model attribtutes.

\subsection{Degradation of Cementitious Materials}

Flach and Smith (2013) considered degradation of Saltstone cementitious materials through sulfate attack, carbonation-influenced corrosion of embedded steel, and decalcification, and estimated the elapsed times at which full damage might occur under best estimate (BE), nominal value (NV), and conservative estimate (CE) conditions. For Saltstone Disposal Unit (SDU) 2 and SDU 4, the degradation times for various disposal unit components are reproduced from SRNL-STI-2013-00118 in Table 2-1 and Table $2-2$, respectively. For SDU 1, modeling was performed using preliminary degradation times based on carbonation rates for SDU 4 roof concrete. Although the analysis was later refined to use carbonation rates specific to SDU 1 roof concrete, the resulting degradation times were observed to be practically the same as the earlier results. The latter values were retained for PORFLOW analysis and are provided in Table 2-3. In these tables the "column" degradation times refer to the first pair of $2 \mathrm{ft}$ grid segments at the top and bottom of columns. Subsequent column segments degrade in succession at the frequency indicated by the "column degradation” times.

The physical form of degradation from sulfate attack and carbonation (causing accelerated steel corrosion) is presumed to be small-scale cracking resulting from internal stresses. For decalcification, porosity and average pore size are presumed to increase as the binders are dissolved away. Thus the hydraulic properties of degraded materials are 
expected to evolve due to physical changes occurring from roughly the pore to decimeter scale. The exact morphology of a concrete or grout at its end-state is not known, but a fully-degraded material is assumed to be no more permeable than the soil adjoining it. In numerical simulations each cementitious material degrades exactly to the adjoining soil, which makes the concrete or grout no longer a hydraulic barrier compared to the surrounding environment. The transition from an intact low-permeability material to a fully-degraded soil-like material is assumed to occur smoothly over the degradation time periods presented in Table 2-1 through Table 2-3.

To avoid abrupt changes in properties through time, linear weighting is chosen to smoothly blend hydraulic properties between an intact initial matrix and a soil surrogate for the end-state. Letting $f$ and $F$ represent the fractions of the final (soil) and initial (matrix) states, respectively, the blending fractions satisfy the equation:

$$
f+F=1
$$

The soil fraction $f$, which can also be interpreted as a degradation factor, varies between 0 and 1 according to the piecewise linear function:

$$
f(t)=\max \left[0, \min \left(1, \frac{t-t_{1}}{t_{2}-t_{1}}\right)\right]
$$

where $t_{1}$ and $t_{2}$ are the degradation start and end times, respectively, from Table 2-1 through Table 2-3. The composite porosity $\left[\mathrm{cm}^{3}\right.$ void $/ \mathrm{cm}^{3}$ total] is:

$$
n=f n_{s}+F n_{m}
$$

where $n_{s}$ and $n_{m}$ are the porosities of the soil and matrix, respectively. Using the same subscripting convention, the saturated hydraulic conductivity $[\mathrm{cm} / \mathrm{s}]$ of the blended material is:

$$
K=f K_{s}+F K_{m}
$$

The saturation $\left[\mathrm{cm}^{3}\right.$ liquid $/ \mathrm{cm}^{3}$ void] function of the blended material is:

$$
S(\psi)=\frac{f n_{S} S_{S}(\psi)+F n_{m} S_{m}(\psi)}{n}
$$

where $\psi$ is suction (negative pressure) head [cm]. The relative permeability [-] function becomes:

$$
k_{r}(\psi)=\frac{f k_{r s}[S(\psi)] K_{S}+F k_{r m}[S(\psi)] K_{m}}{K}
$$

and the unsaturated conductivity [cm/s] of the blended material is $k_{r}(\psi) K$.

The water retention curve for the blended material represented by Equation (2.5) is presented with suction head as the independent variable, the usual convention. However, the relative permeability curve is also presented as a direct function of suction head, 
rather than the usual choice of saturation, to more clearly illustrate how unsaturated conductivity defined by $k_{r}(\psi) K$ varies with the primary flow variable, pressure head $(-\psi)$. That is, rather than viewing unsaturated conductivity variation for the blended material through the separate functions $k_{r}(S)$ and $S(\psi)$, the confounding intermediate variable $S$ is eliminated between the water retention and conventional relative permeability curves to achieve the single characteristic curve $k_{r}(\psi)$.

The blending process is most conveniently conducted using analytic expressions for the water retention and relative permeability curves of the intact and soil materials, as opposed to tabular data that may not share the same suction head values $\left(\psi_{i}\right)$. For this purpose, van Genuchten (1980) / Mualem (1976) functions can be established directly or indirectly from Phifer et al. (2006) for the cementitious materials and soils of interest. The van Genuchten (1980) water retention function is:

$$
S_{e}=\frac{s-S_{r}}{1-S_{r}}=\frac{\theta-\theta_{r}}{\theta_{s}-\theta_{r}}=\left[\frac{1}{1+(\alpha \psi)^{n}}\right]^{m}
$$

where $\theta$ is water content $\left[\mathrm{cm}^{3}\right.$ liquid $/ \mathrm{cm}^{3}$ total], the subscripts $e, r$, and $s$ refer to effective, residual, and saturated conditions, respectively. The model parameters are $S_{r}$ (or $\theta_{s}$ and $\theta_{r}$ ), $\alpha, n$, and $m$. The relative permeability function is given by:

$$
k_{r}=S_{e}^{1 / 2}\left[1-\left(1-S_{e}^{1 / m}\right)^{m}\right]^{2}
$$

For the Mualem (1976) conductivity model:

$$
m=1-1 / n
$$

leaving $S_{r}, \alpha$, and $n$ as the independent model parameters.

Intact concretes exhibit a high air entry pressure compared to the soil suction levels encountered in the Saltstone application, approximately $-\infty<\psi<1500 \mathrm{~cm}$ (Flach and Smith 2013), such that these materials are expected to be saturated over the suction range of interest. Thus any set of characteristic curves having a relative permeability of 1.0 for $0<\psi<1500 \mathrm{~cm}$ is an adequate choice for the intact state. For this modeling effort, the high-quality concrete parameters given in Table 6-8 of WSRC-STI-2006-00198 are selected and provided in Table 2-4. Unsaturated hydraulic conductivity for SDU 2 concrete, intact grout, and surrounding soils is plotted in Figure 2-1. For grouts, the moisture characteristic curve data presented in Dixon (2011, Table B.2) for Room Temperature Cure $\left(20^{\circ} \mathrm{C}\right)$ ARP/MCU Saltstone have been specified (Sheppard 2013). These tabular data are well fit by the van Genuchten (1980) parameters listed in Table 2-4 as shown by Figure 2-1. Backfill and Lower Vadose Zone (LVZ) soils surround SDUs. Tabular data for these soils of interest are provided by Phifer et al. (2006, Table 519 “Lower Vadose Zone” and Table 5-21 “Control Compacted Backfill”). These data are presented in Figure 2-1 along with van Genuchten (1980) fits using the RETC software. The resulting parameters are listed in Table 2-4. 
Figure 2-2 illustrates example transitions from intact SDU 2 cementitious materials to fully-degraded conditions resembling the adjacent soils. Figure 2-2 (a) is representative of the SDU 2 floor concrete residing on top of LVZ soil, while Figure 2-2 (b) applies to saltstone grout alongside and under backfilled soil. Within the suction head range of interest $(-\infty<\psi<1500 \mathrm{~cm})$ degradation to a soil condition always produces higher unsaturated conductivities than the intact material values.

Transitioning completely to a soil is conceptually most clearly consistent with degradation by decalcification, where the assumptions are that porosity and pore size increase but internal stresses are not present that would produce a fractured medium. Linear blending of properties is consistent with the concept of parallel flow through distinct intact and fully-degraded regions that vary in proportion, and results in the intermediate conductivity variations that are two-tiered (Figure 2-2). In this manner the partially-degraded cementitious materials resemble a soil with a bimodal pore size distribution, that is, both micro- and macro-porosity (Durner 1994, Simunek et al. 2003, Priesack and Durner 2006). Alternative (non-linear) weighting schemes are mathematically possible, but lacking a specific physical driver, were rejected in favor of simple linear averaging.

For degradation by sulfate attack and carbonation-influenced steel corrosion, presumably resulting in an increasingly fractured medium, several alternative representations of degraded conditions could be adopted as shown in Figure 2-3 reproduced from Altman et al. (1996). The chosen blending process falls under the "Equivalent Matrix and Fracture Continuum” representation depicted in Figure 2-3, or Equivalent Continuum Model (ECM) in short. The ECM is most appropriate for steady-state flow conditions and smaller scale fractures, such that local equilibrium is achieved between fractures and matrix. The former conditions are generally expected for Saltstone cementitious materials degrading by sulfate attack and carbonation and lying several feet below the ground surface.

Within the ECM framework, blending approaches other than a 100\% transition to soil could be adopted following Peters and Klavetter (1988) among others (Simunek et al. 2003). Pruess (1998) notes that "recent theoretical and experimental work suggests that relative permeability and capillary pressure behavior of fractures is similar to that of highly permeable media with intergranular porosity (Pruess and Tsang, 1990; Firoozabadi and Hauge, 1990; Persoff and Pruess, 1995). Accordingly, we used the customary van Genuchten correlations, with parameters chosen as for coarse sands”. Thus high-permeability granular materials are reasonable surrogates for natural fractures with rough surfaces and/or infilled with granular material.

Figure 2-4 shows the results of alternatively blending intact SDU 2 concrete with the "Gravel” and "Sand” materials from Phifer et al. (2006) while preserving the saturated conductivity of LVZ soil. "Sand" is shorthand for sandy native sediments at the Savannah River Site, which contain up to $25 \%$ fines under the chosen classification. Thus the "Sand" material from Phifer et al. (2006) has a lower saturated conductivity than a clean coarse-grained sand, and could be questioned as a surrogate for high-permeability fractures. Nonetheless both materials have a higher saturated conductivity than Backfill, 
and the volume fraction $(b)$ of higher-permeability material needed to achieve the same saturated hydraulic conductivity as Backfill for the fully-degraded concrete is less than $100 \%$. The specific fractions of Gravel and Sand used in Figure 2-4 are 0.06\% and $32.5 \%$, respectively. Considering the tiny fraction of total volume occupied by fractures, Gravel is viewed as the more appropriate surrogate material for fractures. Blending with Gravel produces a more pronounced two-tiered curve, which is consistent with the ease with which fractures are dewatered through tension in the adjoining matrix (Wang and Narasimhan 1985). Blending to $100 \%$ LVZ soil is observed to produce higher unsaturated conductivities within the suction head range of interest $(-\infty<\psi<1500 \mathrm{~cm})$ than blending with the two higher permeability materials. In this sense, the choice of LVZ (or Backfill) soil is conservative relative to the other candidate blending materials.

Another ECM approach is to match the saturated conductivity of a concrete-gravel blend to that of a fractured medium with specified attributes, principally fracture aperture $b$ and spacing $B$. For this exercise, gravel from Phifer et al. (2006) is again considered to be a reasonable surrogate for fractures. The saturated conductivity of a saturated fracture is (e.g. Wang and Narasimhan 1985):

$$
K_{f}=\frac{\rho g b^{2}}{12 \eta}
$$

where $\rho$ is liquid density $\left[\mathrm{kg} / \mathrm{m}^{3}\right], g$ is gravitational acceleration $\left[\mathrm{m} / \mathrm{s}^{2}\right], b$ is fracture aperture $[\mathrm{m}]$, and $\eta$ is liquid viscosity $[\mathrm{kg} / \mathrm{m}-\mathrm{s}]$. The effective conductivity of the fractured porous matrix is:

$$
K=\frac{b K_{f}+B K_{m}}{b+B} \approx \frac{b}{b+B} K_{f}=f K_{f}
$$

where the contribution of the low-permeability matrix is assumed to be negligible and $f=b /(b+B)$. As an example, the effective saturated conductivity of a lowpermeability porous medium with $5 \mathrm{mil}(0.127 \mathrm{~mm})$ fractures spaced at $1 \mathrm{~cm}$ is $1.65 \mathrm{E}-02$ $\mathrm{cm} / \mathrm{s}$. The fraction of gravel required to produce this same saturated conductivity is 10.7\% using Equation (2.4). Unsaturated conductivity for this concrete-gravel blend, which is representative of a severely damaged concrete, is shown in Figure 2-5.

Compared to LVZ soil, the concrete-gravel blend exhibits higher conductivity for saturated and near-saturated conditions, but lower conductivity for suction heads over the approximate range $50<\psi<5000 \mathrm{~cm}$. The suction range of interest for Saltstone was stated earlier to be $-\infty<\psi<1500 \mathrm{~cm}$ (Flach and Smith 2013), but this range can be further refined by comparing expected infiltration rates to conductivity. The hydraulic head gradient in vadose zone soil tends to be close to unity, such that infiltration and unsaturated conductivity are approximately the same per Darcy’s law. Figure 2-6 compares LVZ soil and backfill conductivity to various infiltration rates in the same units $(\mathrm{cm} / \mathrm{s})$. The intersection of these curves occurs over the range $50<\psi<500 \mathrm{~cm}$, consistent with numerical model simulations. Over this range and for the chosen fracture attributes, the choice of $100 \% \mathrm{LVZ}$ soil for the fully-degraded condition is conservative relative to a concrete-gravel blend. 
Or and Tuller (2000) present a direct method for defining fracture hydraulic properties based on an idealized fracture geometry. These derived fracture properties can be used instead of properties from a surrogate granular material in an ECM model. Following Flach et al. (2009, Section 3.7), Figure 2-7 presents example ECM curves for two conditions: a) 5 mil $(0.127 \mathrm{~mm})$ fractures spaced at $1 \mathrm{~cm}$ (as considered in Figure 2-5), and b) $50 \mathrm{mil}(1.27 \mathrm{~mm})$ fractures spaced at $10 \mathrm{~cm}$. Within the suction head range of most interest $(50<\psi<500 \mathrm{~cm}$ ), conductivities based on Or and Tuller (2000) are lower than both the concrete-gravel blend and LVZ soil. This observation further supports LVZ soil as a conservative-tending choice for fully-degraded concrete. The same conclusion applies for $100 \%$ Backfill as the selection for fully-degraded grout.

The exact morphologies of fully-degraded SDU concrete and grout are not known, which precludes precise specification of hydraulic properties. The ECM alternatives presented in Figure 2-4, Figure 2-5, and Figure 2-7 appear to be non-conservative relative to blending to $100 \% \mathrm{LVZ}$ or Backfill soil in that unsaturated conductivities of the alternatives are lower in the suction head range of most interest, $50<\psi<500 \mathrm{~cm}$. Thus, in lieu of better characterization of the future physical state of degraded SDU cementitious materials, blending to $100 \% \mathrm{LVZ}$ and Backfill soils is considered a reasonable choice for SDU steady-state flow modeling. 
Table 2-1. Degradation analysis for SDU 2 concrete and saltstone (SRNL-STI-2013-00118).

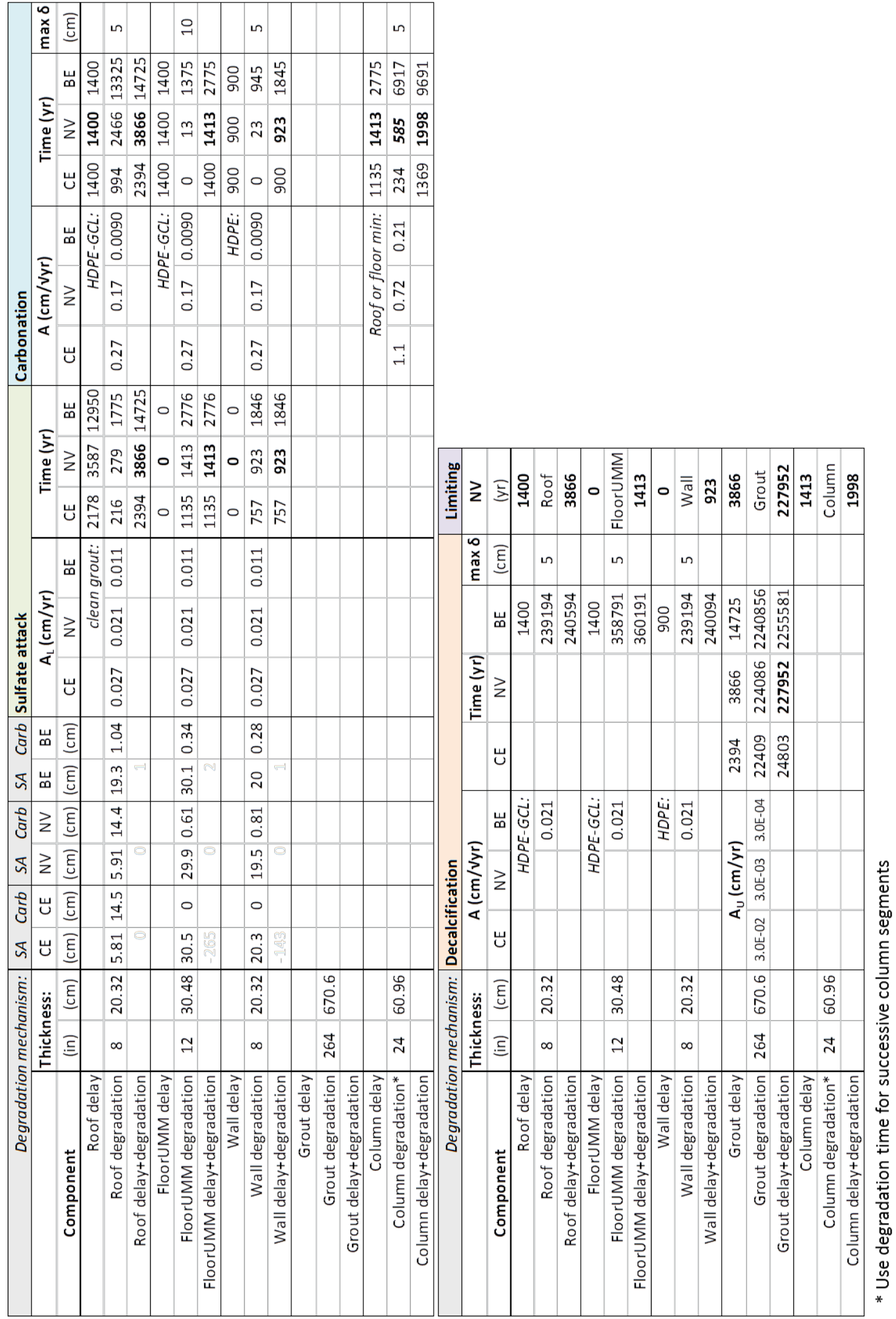


Table 2-2. Degradation analysis for SDU 4 concrete and saltstone (SRNL-STI-2013-00118).

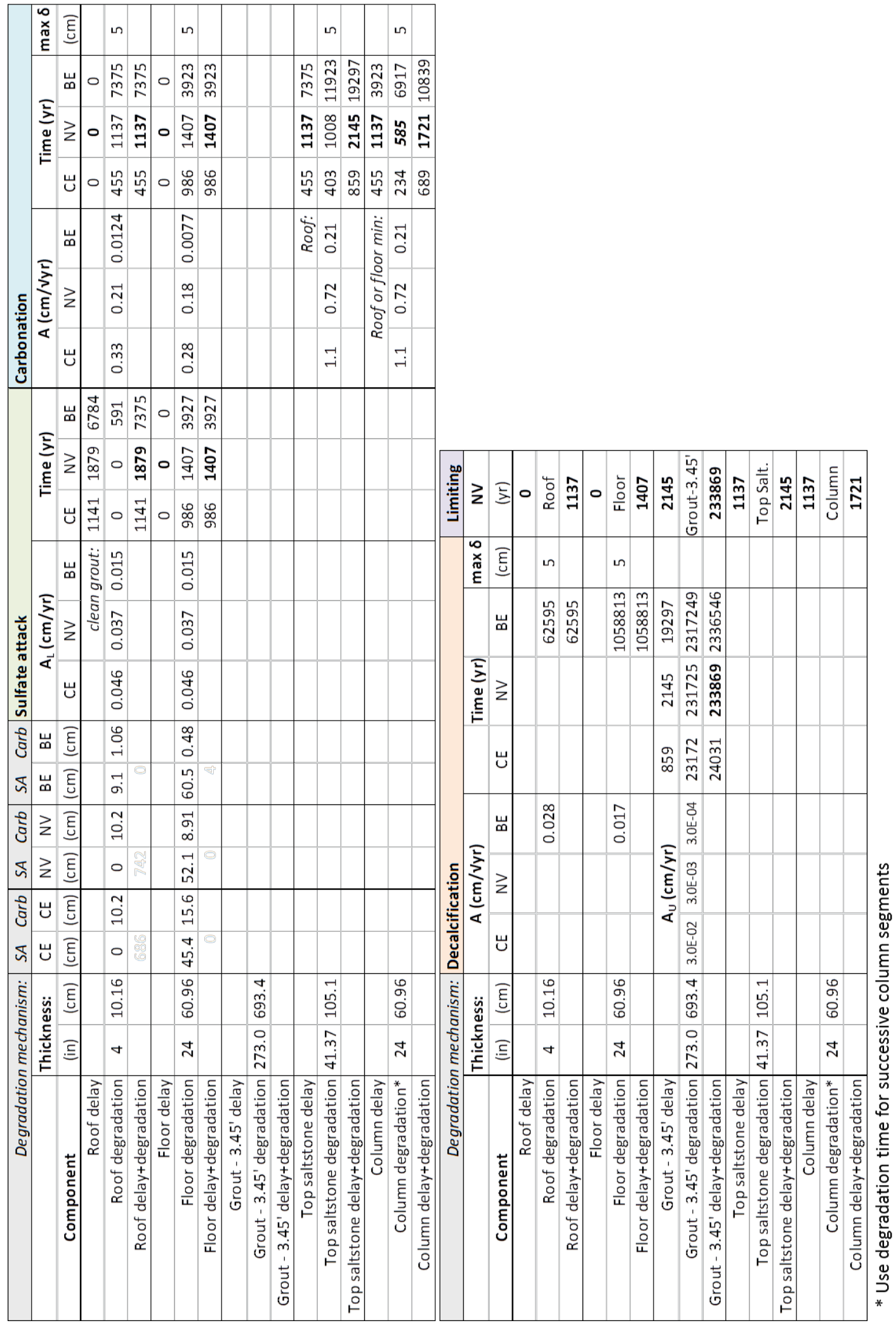


Table 2-3. Degradation analysis for SDU 1 concrete and saltstone (modified from SRNL-STI-2013-00118).

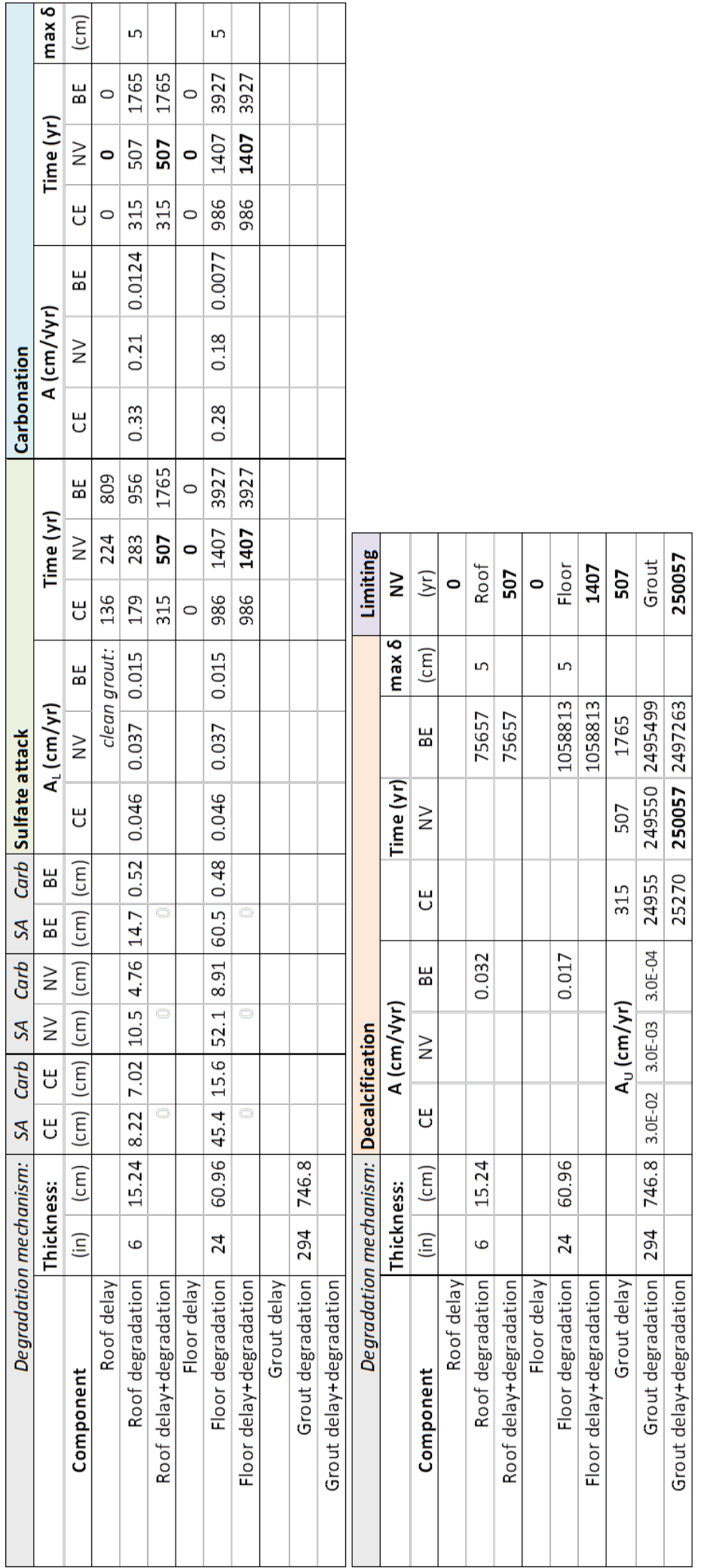


Table 2-4. Hydraulic parameters for SDU 2 cementitious materials and soils.

\begin{tabular}{|c|c|c|c|c|}
\hline Parameter & $\begin{array}{c}\text { Intact } \\
\text { concrete }\end{array}$ & Intact grout & Backfill soil & $\begin{array}{c}\text { Lower } \\
\text { Vadose } \\
\text { Zone (LVZ) } \\
\text { soil }\end{array}$ \\
\hline$\theta_{s}$ & 0.082 & 0.58 & 0.35 & 0.39 \\
\hline$\theta_{r}$ & 0 & 0 & 0.10062 & 0.14014 \\
\hline$S_{r}$ & 0 & 0 & 0.2875 & 0.3593 \\
\hline$\alpha\left(\mathrm{cm}^{-1}\right)$ & $2.0856 \mathrm{E}-06$ & $1.9994 \mathrm{E}-05$ & 0.01464 & 0.01257 \\
\hline$n$, van Genuchten $(1980)$ & 1.9433 & 1.51012 & 1.22727 & 1.39358 \\
\hline$K_{v}(\mathrm{~cm} / \mathrm{s})$ & $9.3 \mathrm{E}-11$ & $6.4 \mathrm{E}-09$ & $4.1 \mathrm{E}-05$ & $9.1 \mathrm{E}-05$ \\
\hline$n$, porosity & 0.11 & 0.58 & 0.35 & 0.39 \\
\hline
\end{tabular}

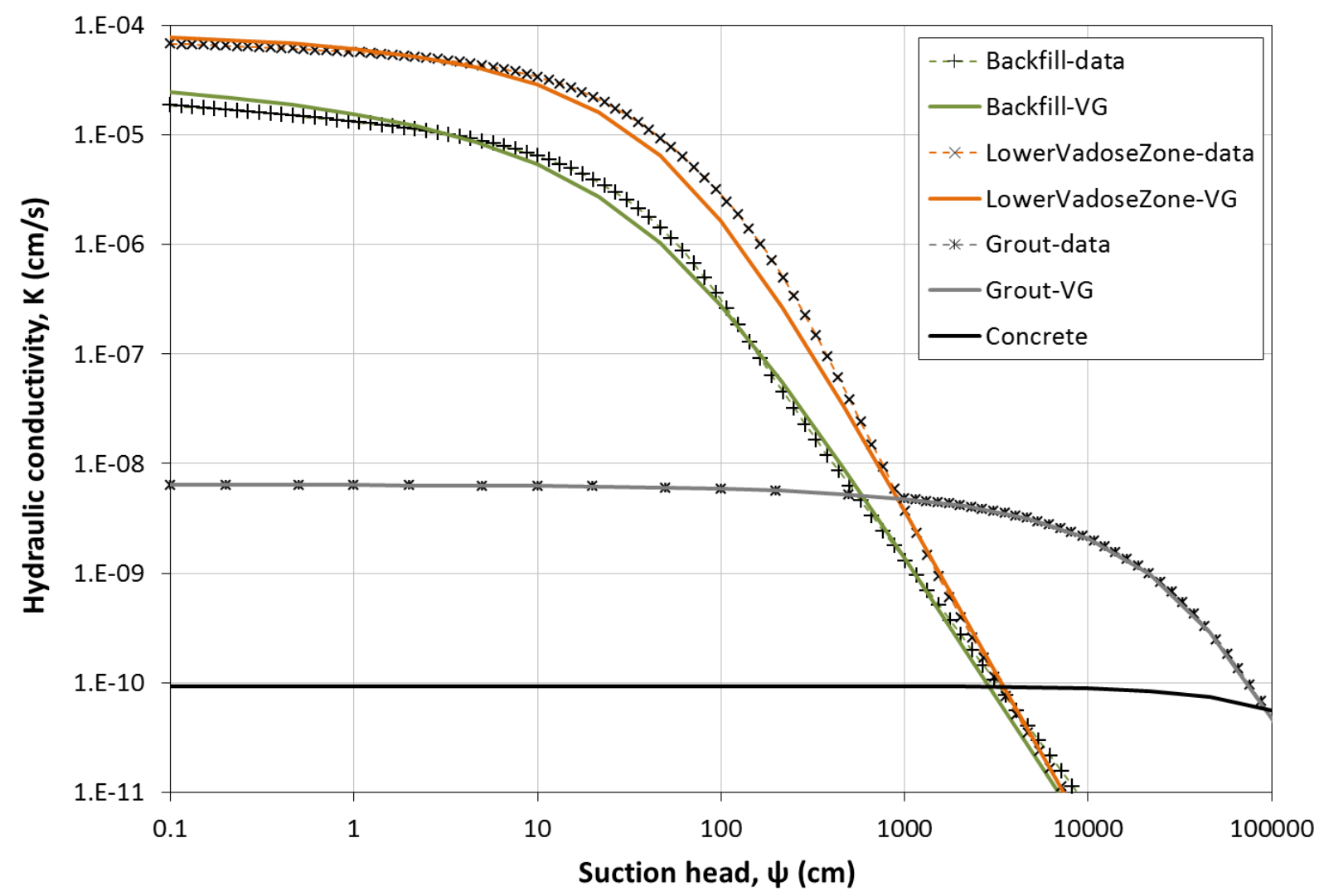

Figure 2-1. Unsaturated hydraulic conductivity for intact SDU 2 concrete, intact grout, and surrounding soils. 
SRNL-STI-2013-00280, REVISION 0

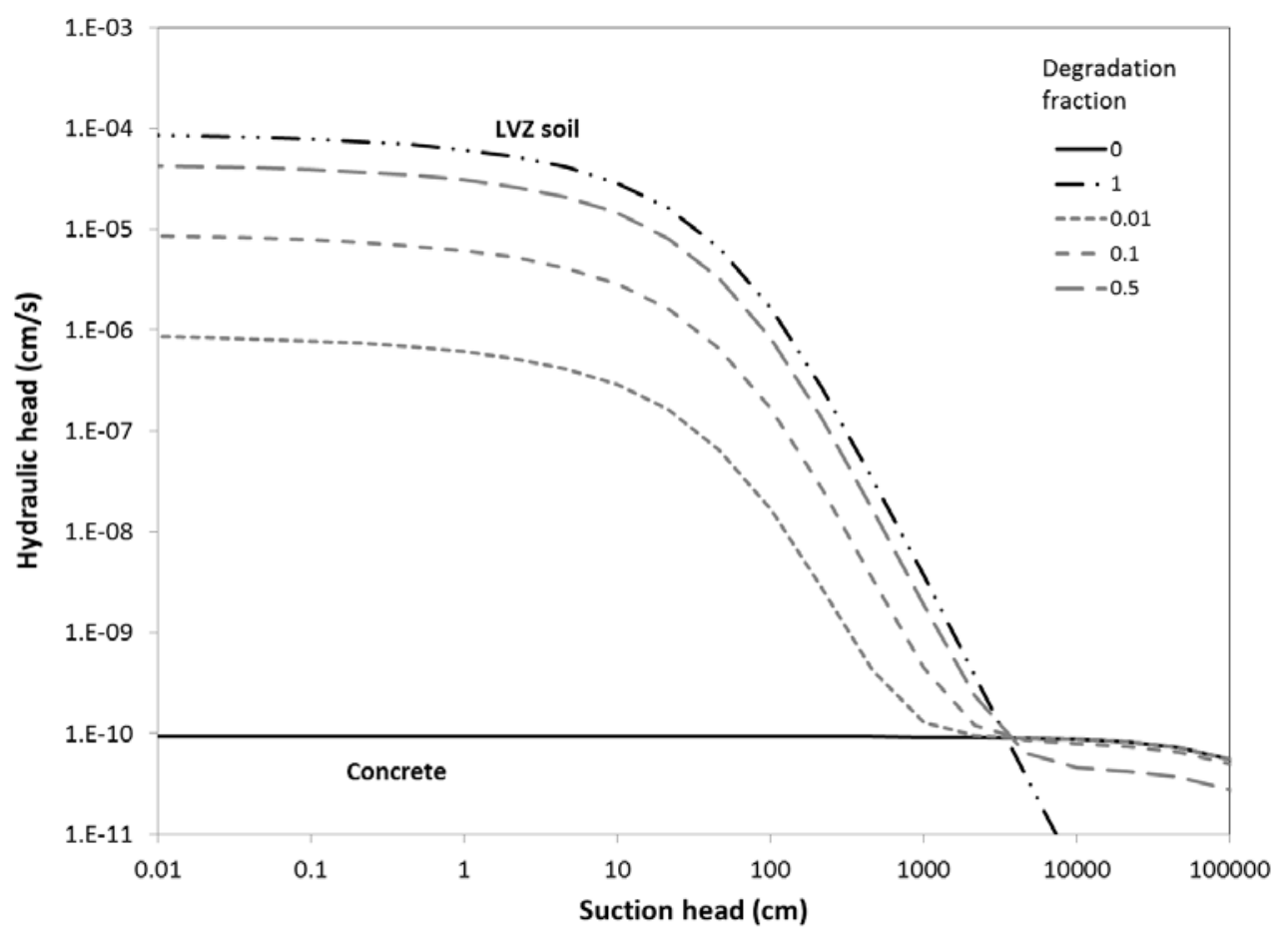

(a)

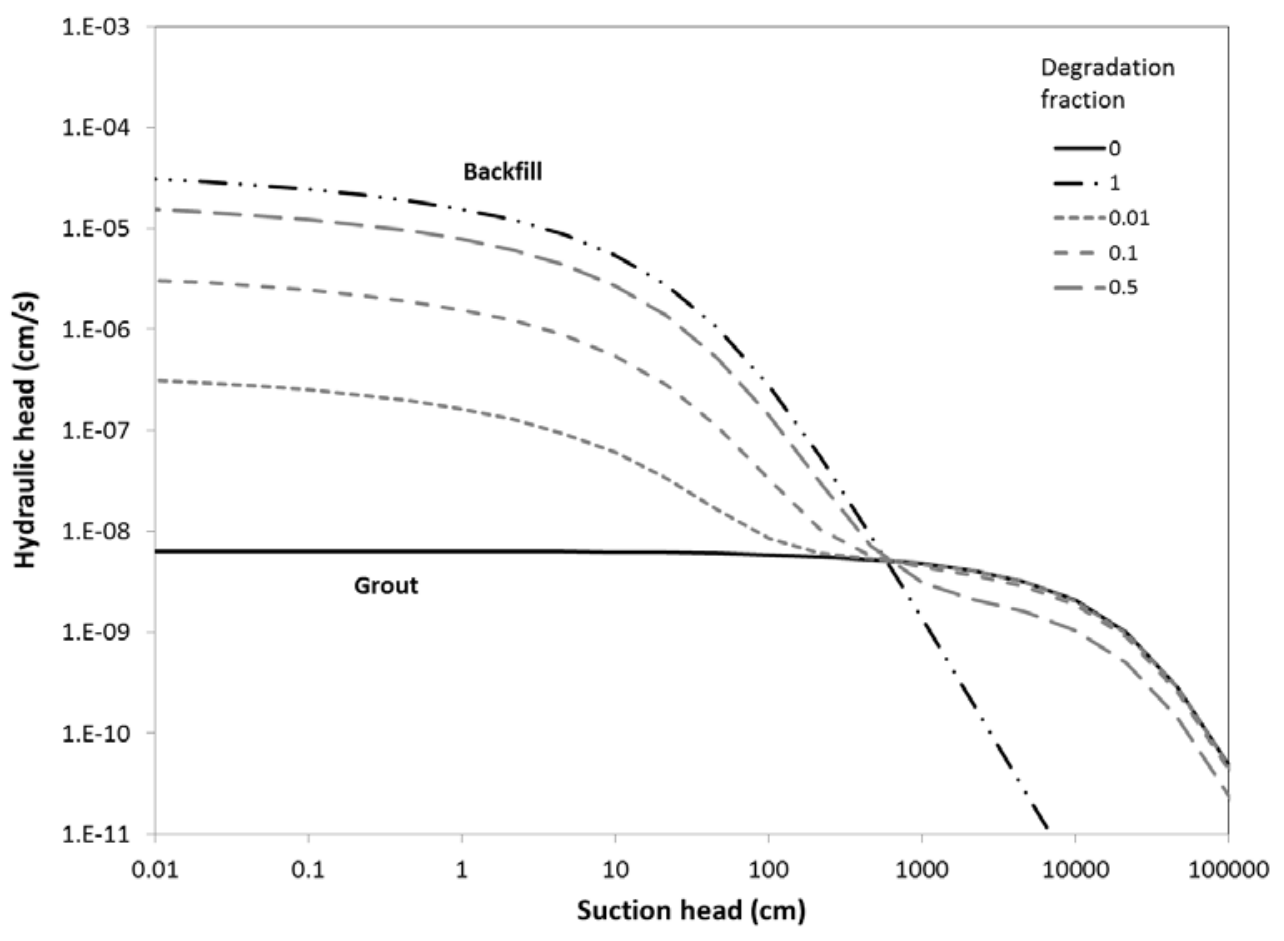

(b)

Figure 2-2. Example transitions of intact cementitious materials from intact to fully-degraded conditions represented by soils: (a) SDU 2 concrete and (b) grout. 
REPRESENTATION

Equivalent Single Continuum

EQUIVALENT POROUS MEDIUM

COMPOSITE POROSITY (EQUIVALENT CONTINUUM)

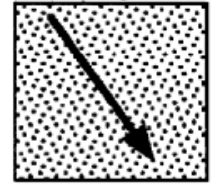

Equivalent Matrix and Fracture Continuum
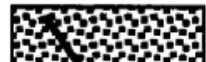

(n)

Equivalent Matrix

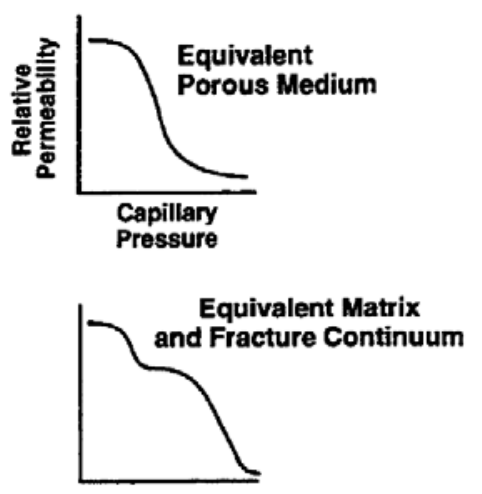

DUAL POROSITY
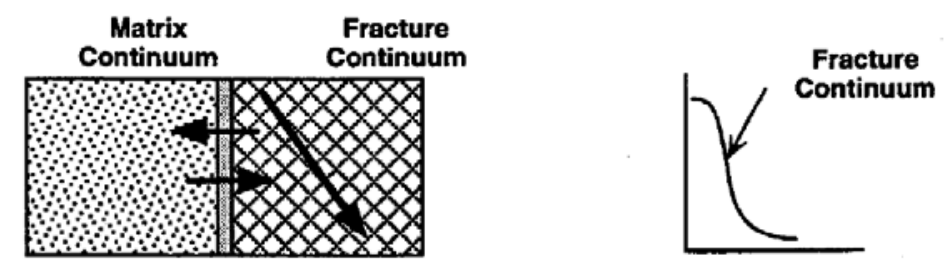

DUAL

PERMEABILITY
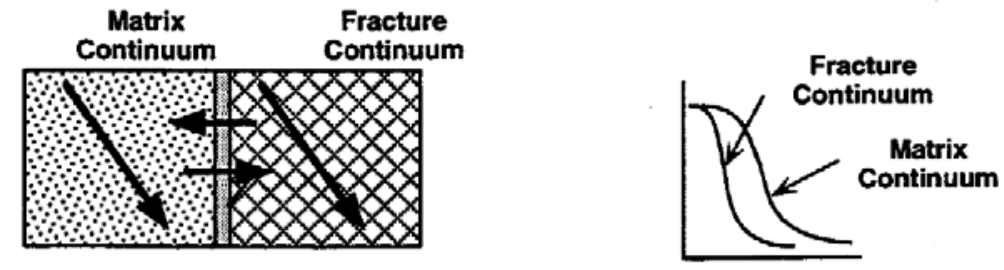

DISCRETE FRACTURES

WITHOUT MATRIX
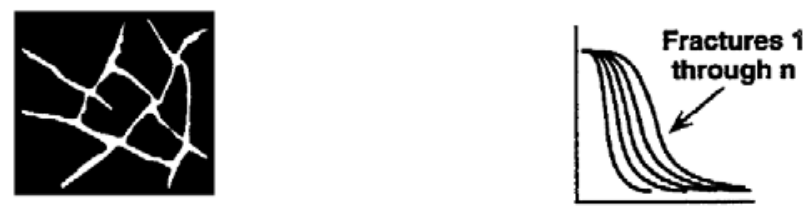

DISCRETE FRACTURES WITH MATRIX
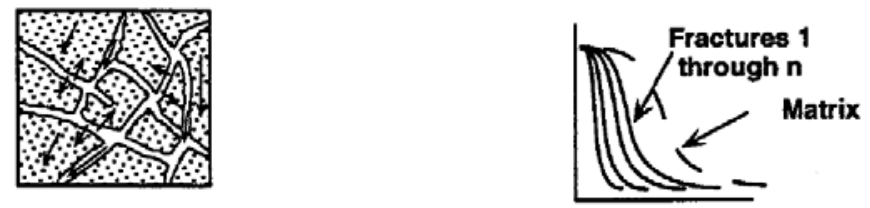

Figure 2-3. Alternative representations of a fractured medium; reproduced from Altman et al. (1996, Figure 2-2). 
SRNL-STI-2013-00280, REVISION 0

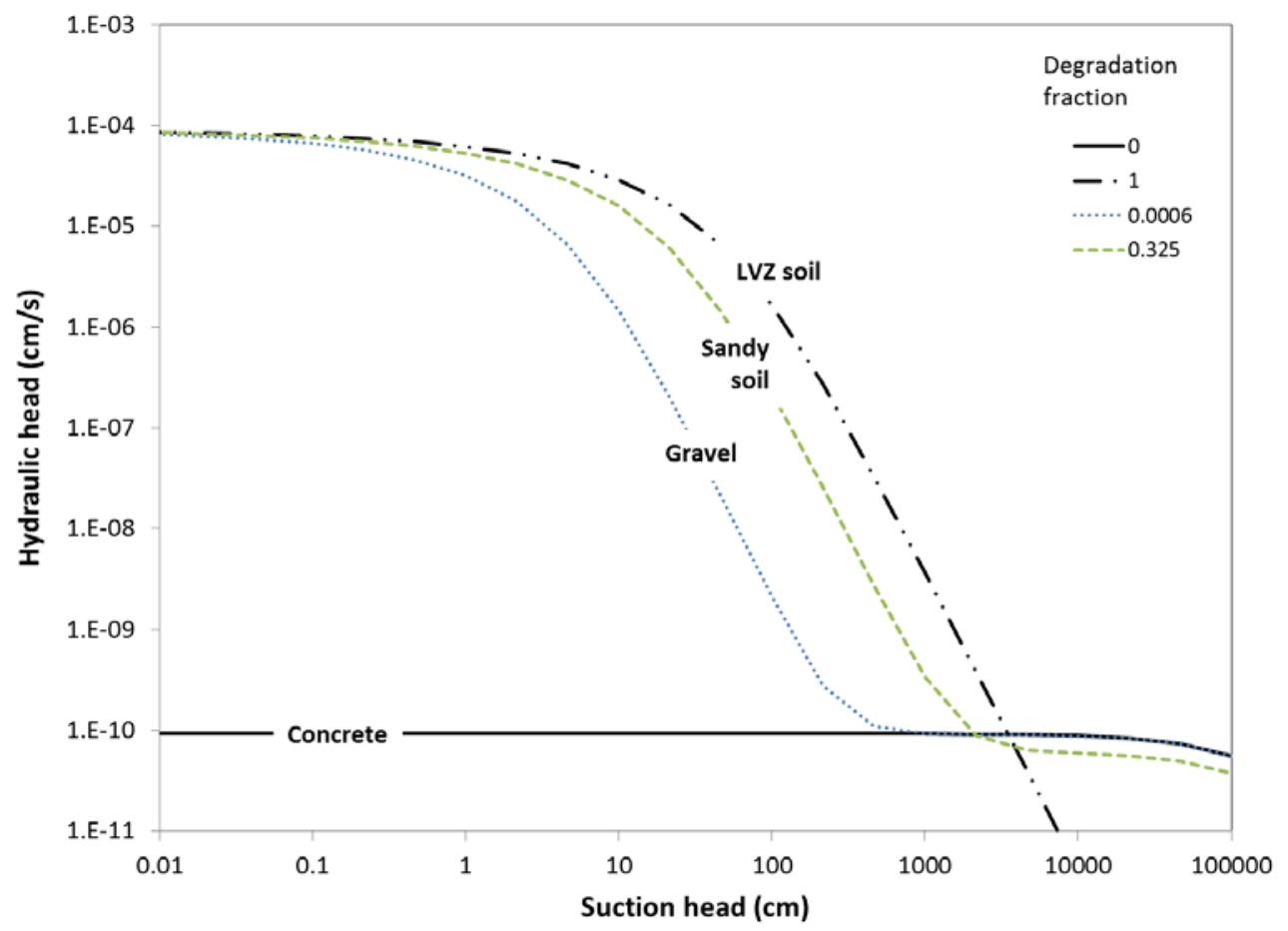

Figure 2-4. Alternative surrogate soils for blending to fully-degraded conditions.

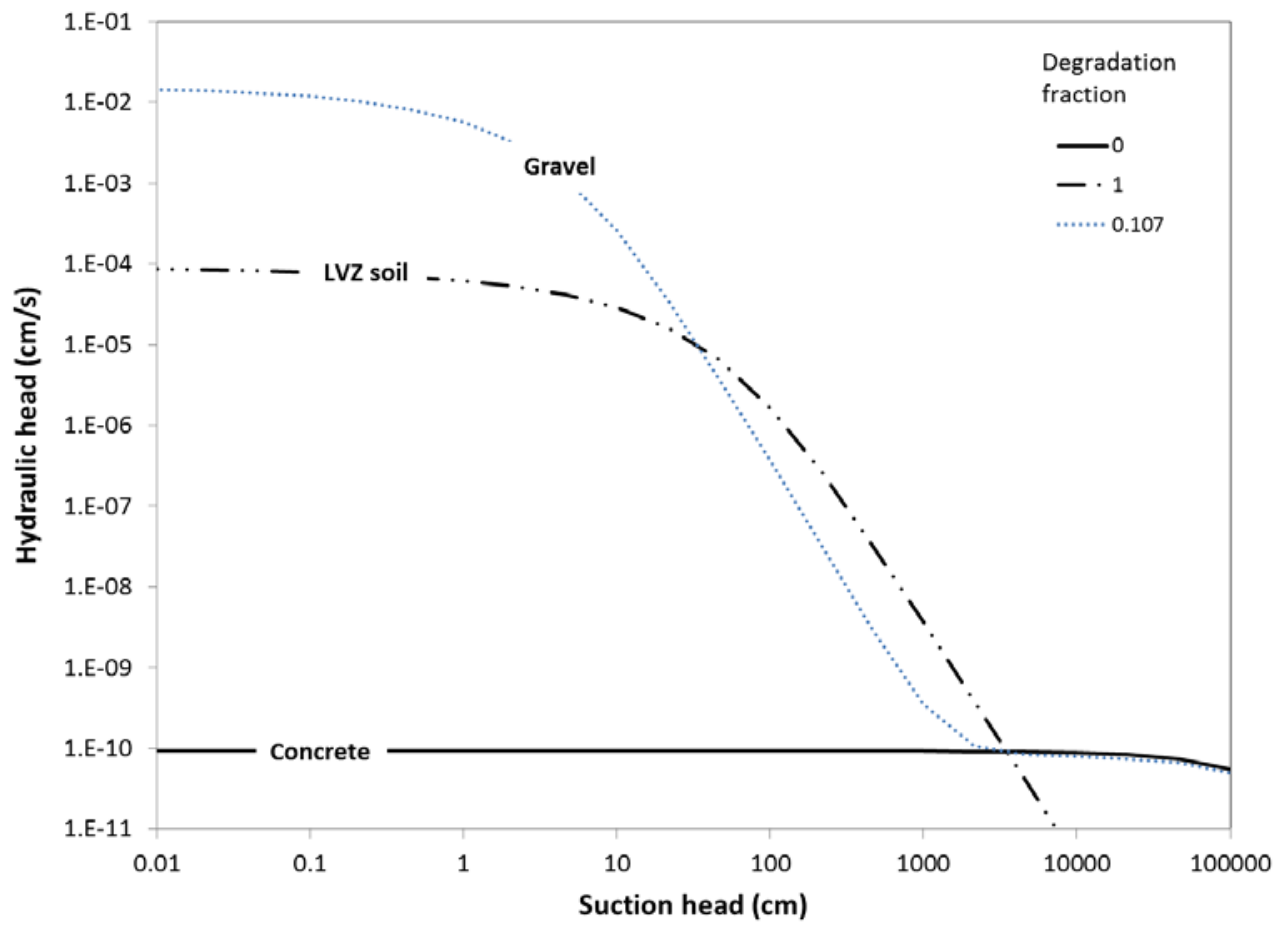

Figure 2-5. Partial blending (10.7\%) to gravel representing degradation to 5 mil fractures spaced at $1 \mathrm{~cm}$. 
SRNL-STI-2013-00280, REVISION 0

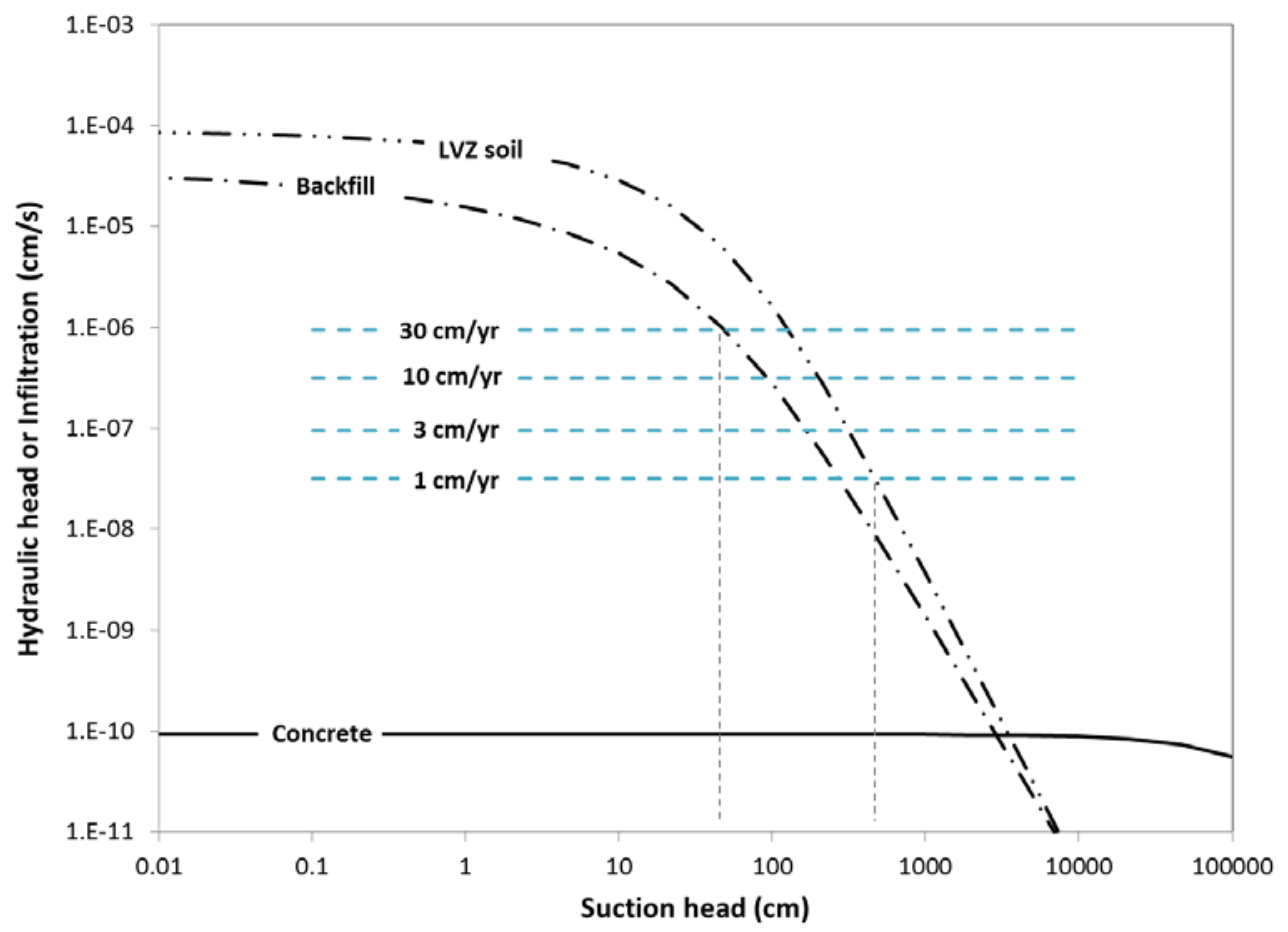

Figure 2-6. Infiltration rates compared to SDU 2 concrete and LVZ soil hydraulic conductivity.

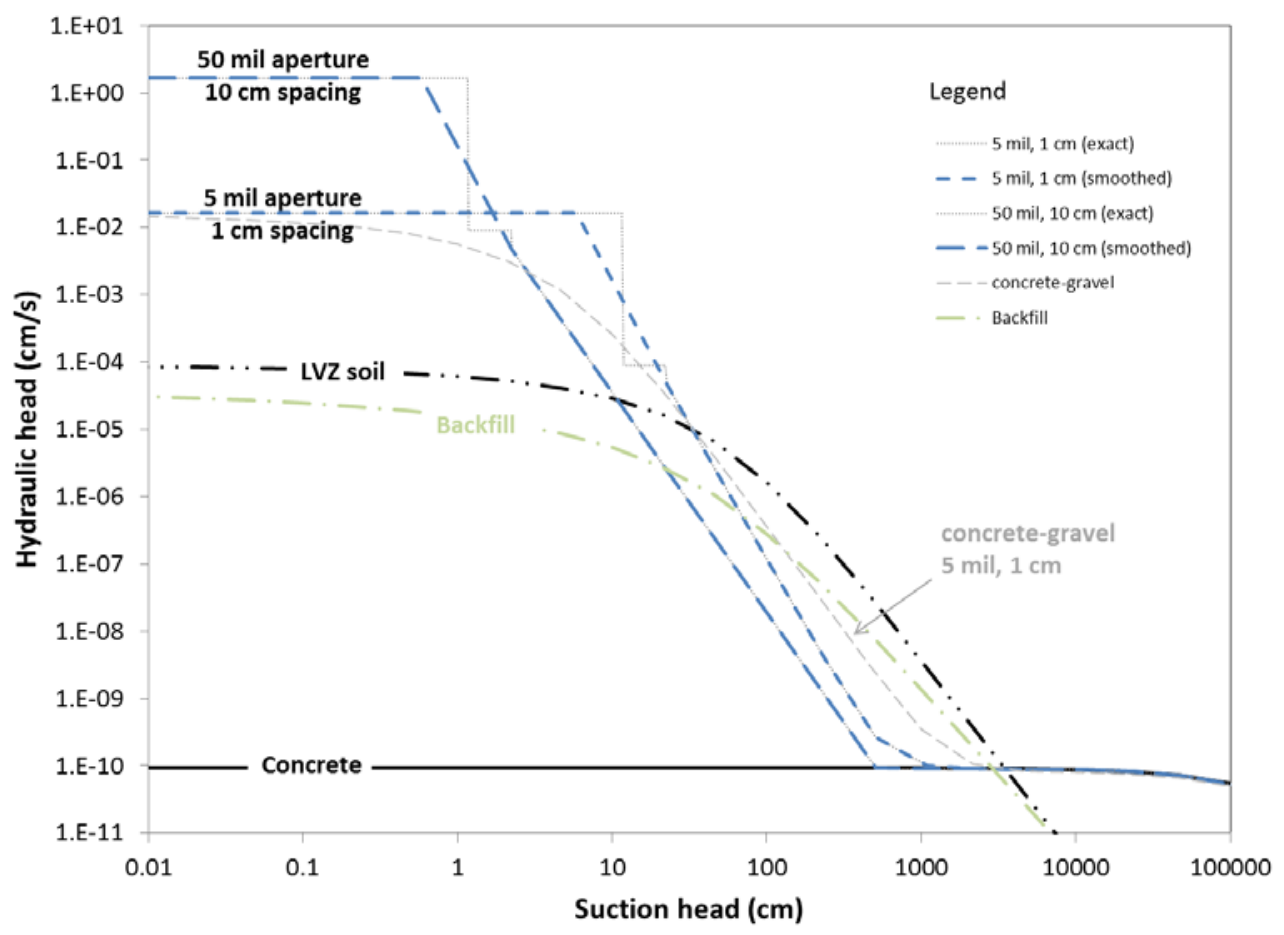

Figure 2-7. Degradation to selected fractured conditions using fracture properties based on Or and Tuller (2000). 


\subsection{Floor Joints}

Construction joints and water stops are present in the SDU 4 design. These joints and water stops are assumed to represent leak paths in the design. The total length of joints for SDU 4 is 8,818 feet. SDU 4 is 600 feet in length, so 15 joints running through the length of the disposal unit were added to the 2D model. Joints are similarly found in the SDU 1 design with a total of 5,012 linear feet. SDU 1 is 600 feet in length, so 8 joints running through the length of the disposal unit were added to the $2 \mathrm{D}$ model. The SDU $1 / 4$ joints were modeled as 2 inch bands of gravel extending through the floor of each disposal unit, and evenly spaced across the 2D model width. As described in SRNL-STI2012-00445, the 2 inch section of gravel equates to an open gap of $0.455 \mathrm{~mm}$ with respect to saturated hydraulic conductivity. Watertight structures are designed with a gap of less than $0.2 \mathrm{~mm}$, so an equivalent gap size of $0.455 \mathrm{~mm}$ is reasonable and provides a convenient modeling dimension.

The SDU2 design does not have joints within the floor, but a similar potential leak path exists at the joint between the wall and floor. These joints are modeled in the same manner as the SDU 1/4 floor joints.

\subsection{Support Columns}

The SDU 4 design contains 9 10-inch diameter roof support columns per disposal cell, arranged in a 3x3 grid. In the 2D model, a single 2-inch wide gap was created and sized to the extent feasible to match the surface area and volume of the physical columns in total. This 2-inch wide column, from a 3D perspective is a 2-inch wide section running the entire 600 feet length of the disposal unit. The 2-inch by 600 feet column has a greater surface area and volume when compared to the physical dimensions of the individual columns. The column in the model is centered in the cell. The SDU 1 design does not have columns.

The SDU 2 design contains 48 roof supported columns, each with a 14-inch diameter. For the 2D model, a single column was sized and located to match the surface area and volume of the physical columns. From a 3D perspective, this single column forms an annular ring.

The columns in both the SDU 2 and SDU 4 models are subdivided into approximately 2 foot vertical sections along the height of the columns. These sections are degraded in sequence starting simultaneously from the top and bottom of the column following Table 2-1 and Table 2-2.

The physical columns do not appreciably affect lateral flow past the columns through grout. In the 2D model representations, the column can affect lateral flow because the feature creates distinct inner and outer grout zones separated by the column. To preclude the $2 \mathrm{D}$ columns becoming a barrier to lateral flow, the initial properties are set to those of the surrounding grout. 


\subsection{Slag Oxidation}

Tc-99 mobility varies strongly with redox conditions: under reducing conditions technetium release from moderately-aged cementitious materials is limited by a solubility of 1.e-8 mol/L, whereas for oxidized conditions in the same material technetium release is controlled by sorption with a distribution coefficient $\left(K_{d}\right)$ equal to $0.8 \mathrm{~mL} / \mathrm{g}$ (Kaplan and Li 2013; Sheppard 2013). Table 2-5 provides technetium transport parameters for a range of redox and $\mathrm{pH}$ conditions.

Table 2-5. Technetium transport parameters recommended for cementitious materials; reproduced from Kaplan and Li (2013).

\begin{tabular}{|c|c|c|c|}
\hline $\begin{array}{l}\text { Cementitious } \\
\text { Material }\end{array}$ & $\begin{array}{l}\text { Young Cement } \\
\mathbf{1}^{\text {st }} \text { Stage } \\
(\mathrm{pH} \sim \mathbf{1 2})\end{array}$ & $\begin{array}{l}\text { Moderately-aged Cement } \\
\mathbf{2}^{\text {nd }} \text { Stage } \\
\text { (pH } \sim \mathbf{1 0 . 5})\end{array}$ & $\begin{array}{l}\text { Aged Cement } \\
3^{\text {rd }} \text { Stage } \\
(\mathrm{pH} \sim 5.5)\end{array}$ \\
\hline Reduced & $6 \times 10^{-7} \mathrm{~mol} /$ L solubility $^{(\mathrm{a})}$ & $1 \times 10^{-8} \mathrm{~mol} / \mathrm{L}$ solubility ${ }^{(\mathrm{a}, \mathrm{d})}$ & $0.5 \mathrm{~mL} / \mathrm{g} \mathrm{K}_{\mathrm{d}}^{(\mathrm{c})}$ \\
\hline Oxidized & $0.8 \mathrm{~mL} / \mathrm{g} \mathrm{K}_{\mathrm{d}}^{(b)}$ & $0.8 \mathrm{~mL} / \mathrm{g} \mathrm{K}_{\mathrm{d}}^{(\mathrm{b}, \mathrm{d})}$ & $0.5 \mathrm{~mL} / \mathrm{g} \mathrm{K}_{\mathrm{d}}^{(\mathrm{b}, \mathrm{d})}$ \\
\hline \multicolumn{4}{|c|}{$\begin{array}{l}\text { (a) This work } \\
\text { (b) Kaplan (2010) } \\
\text { (c) }\end{array}$} \\
\hline
\end{tabular}

By design SDU grouts and concretes, except SDU 1 and 4 roof concrete, contain ground blast furnace slag to create reducing conditions that hinder Tc-99 release from the waste form and transport through cementitious barriers. The reducing capacities of SDU grout and concrete recommended for transport modeling are 0.607 and $0.178 \mathrm{meq} \mathrm{e}-\mathrm{g}$, respectively (Sheppard 2013, Table 3).

These reducing capacities are consumed by dissolved oxygen entering the system through infiltrating liquid. Intact SDU cementitious materials are expected to be fully saturated once buried under a facility closure cap, precluding oxidation by gas-phase transport of oxygen through the porous media; the possibility of gas-phase oxygen transport through fractured cementitious materials is considered later in sensitivity cases. Soils surrounding disposal units will generally be unsaturated, such that soil moisture will be in contact with gas-phase oxygen. The concentration of dissolved oxygen in soil moisture is assumed to be fixed at its solubility limit, 1.06 meq e-/L (Kaplan and Hang 2003, Table 3).

Slag oxidation via infiltrating dissolved oxygen is modeled with PORFLOW by defining liquid-phase oxygen $(C 2)$ and solid-phase slag (C3) concentrations and associated mass balance transport equations ( $C$ is reserved for Tc-99 concentration). Oxygen and slag are depleted by the sink (negative source) terms expressed in PORFLOW parlance as:

SOURce for C2:REACtion type: $-1 .{ }^{\star}$ RATE

SOURce for C3:REACtion type: $-1 .{ }^{*}$ RATE

where the reaction rate is proportional to $C 2$ and $C 3$ through the command: 
The reaction rate coefficient (1.e+6) is sufficiently high that the reaction is practically instantaneous, that is, slag and oxygen react immediately upon contact in model simulations. The condition of soil moisture being saturated with dissolved oxygen is implemented by specifying a (practically) non-depleting, solubility-limited, source of oxygen in all soil zones through PORFLOW commands of the form:

$$
\text { SOUR C2 ID=SOIL SOLU } 1.06 \mathrm{E}-3 \quad 1 . \mathrm{E}+19
$$

where 1.06E-3 is the solubility limit (oxygen concentration)[meq e-/mL], and 1.E+19 [meq e-] is the source amount (practically infinite).

Appendix A presents a simple verification test case for slag oxidation involving advective flow into a single computational cell with a volume of $1.0 \mathrm{~mL}$. For the chosen material properties and boundary conditions, the calculated time for complete oxidation is 118 years. PORFLOW simulations with a timestep of 0.01 yr produced the same result.

Appendix B defines a more sophisticated series of slag oxidation tests involving a onedimensional column nominally composed of soil, concrete, grout, concrete, and soil layers. Figure 2-8 illustrates the initial conditions for Test 3 in which slag is present in all three cementitious material layers. Although the focus of the simulation is slag oxidation, Tc-99 transport is also simulated. Preliminary simulations indicated larger than expected mass balance errors for the slag species (C3). Time step reductions to $\Delta t \leq 0.025 \mathrm{yr}$ improved results. Alternative matrix solvers (e.g. MATRix LUDE) and convergence criteria had little or no effect, with the exception of "convergence for SPECies in coupled mode" which produced different simulation results as indicated in Appendix B. More than two iterations (the default) created a significant mass sink for slag. Simulations with and without "Convergence for SPECies in couPled mode" produced similar discrepancies with respect to the analytic slag depletion times, in the range of $\pm 10 \%$. Although larger than anticipated, this level of mass balance error was deemed acceptable considering other Performance Assessment uncertainties. Subsequent simulations were performed with no species coupling. Figure 2-9 illustrates PORFLOW simulation results at $854 \mathrm{yr}$ for Test 3 (and no species coupling). According to the handcalculation all slag should be consumed at this time; instead, some slag remains in the very bottom of the grout section and the bottom concrete. As indicated in the Appendix B table, slag is instead exhausted at $\sim 920 \mathrm{yr}$ in the PORFLOW simulation.

The preceding test case involves one-dimensional advective-dominated flow and dissolved oxygen transport. Another test case was devised to verify slag oxidation when dissolved oxygen is transported by advection and diffusion. The geometry is identical to that depicted in Figure 2-8, however, the cementitious material zones are assigned a low permeability, except for a narrow high-permeability channel in the center. The widths of the model domain and fast-flow path are 1.0 meter and 2.0 centimeters, respectively. Appendix C presents the problem specification in further detail and Figure 2-10 illustrates the initial conditions. 
An analytic solution for slag oxidation by diffusion of dissolved oxygen is (Smith and Walton 1993; Painter and Pabalan 2009; Flach 2011, Equation (14)) :

$$
\delta(t)=\left[\frac{2 n D_{e} c_{O x}}{r_{O x} \rho_{b}} t\right]^{1 / 2}
$$

where $\delta$ is penetration depth [cm], $n$ is porosity $\left[\mathrm{cm}^{3}\right.$ void / $\mathrm{cm}^{3}$ total], $D_{e}$ is the effective diffusion coefficient $\left[\mathrm{cm}^{2} / \mathrm{s}\right], c_{O X}$ is the dissolved oxygen concentration at the exposure surface [meq e-/mL], $t$ is elapsed time [s], $r_{O x}$ is reducing capacity [meq e-/g], and $\rho_{b}$ is bulk density $\left[\mathrm{g} / \mathrm{cm}^{3}\right.$ total]. For the parameter values specified in Appendix C, which pertain to the middle grout section, the time required to consume slag is 812 years. Figure 2-11 shows the corresponding PORFLOW simulation results. In the middle grout region, nearly all of the slag has been consumed, in close agreement with the analytic solution. The slag initially in the upper and lower concrete sections has not yet been exhausted because of the higher bulk density of concrete compared to grout. 
SRNL-STI-2013-00280, REVISION 0

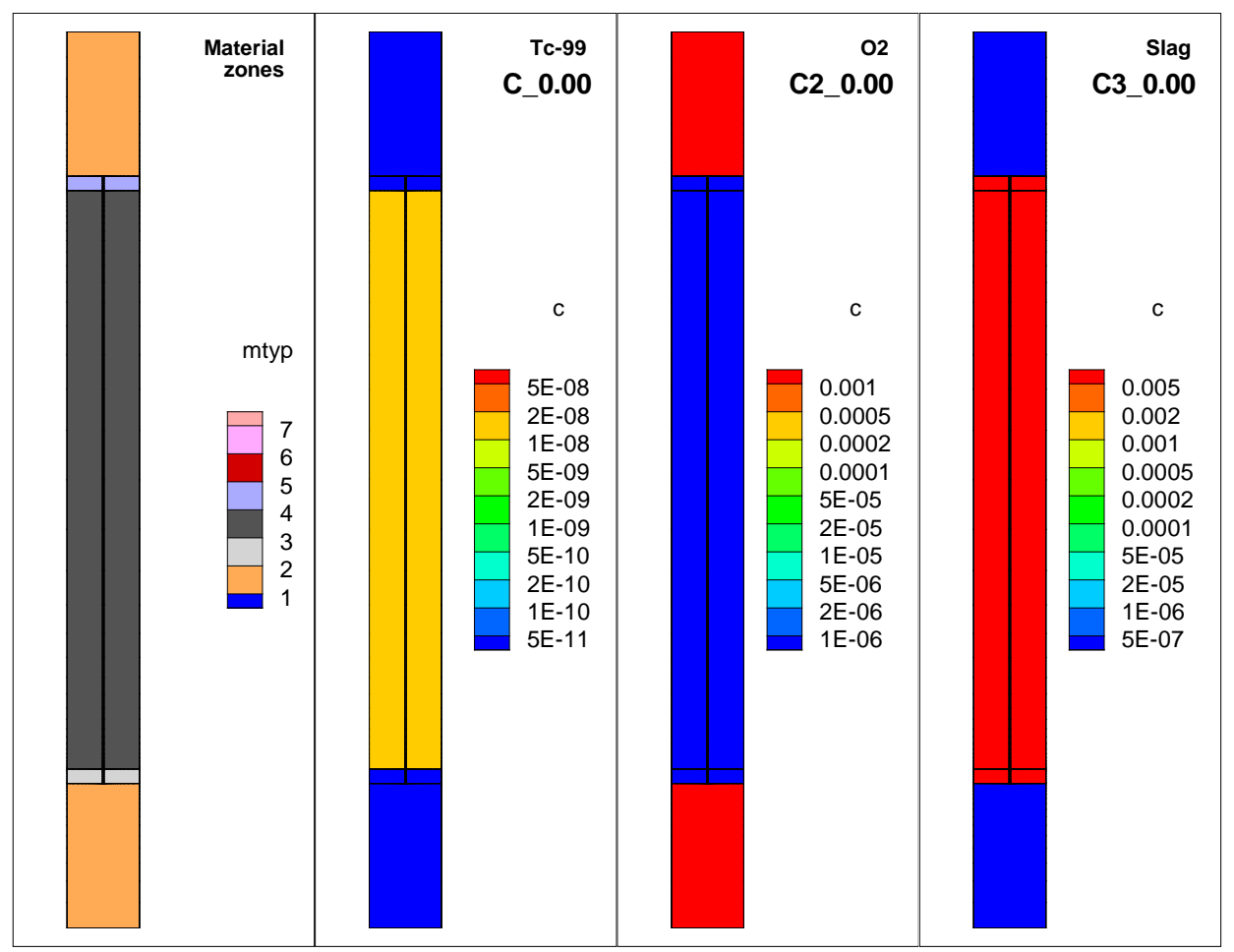

Figure 2-8. One-dimensional slag oxidation test: initial conditions.

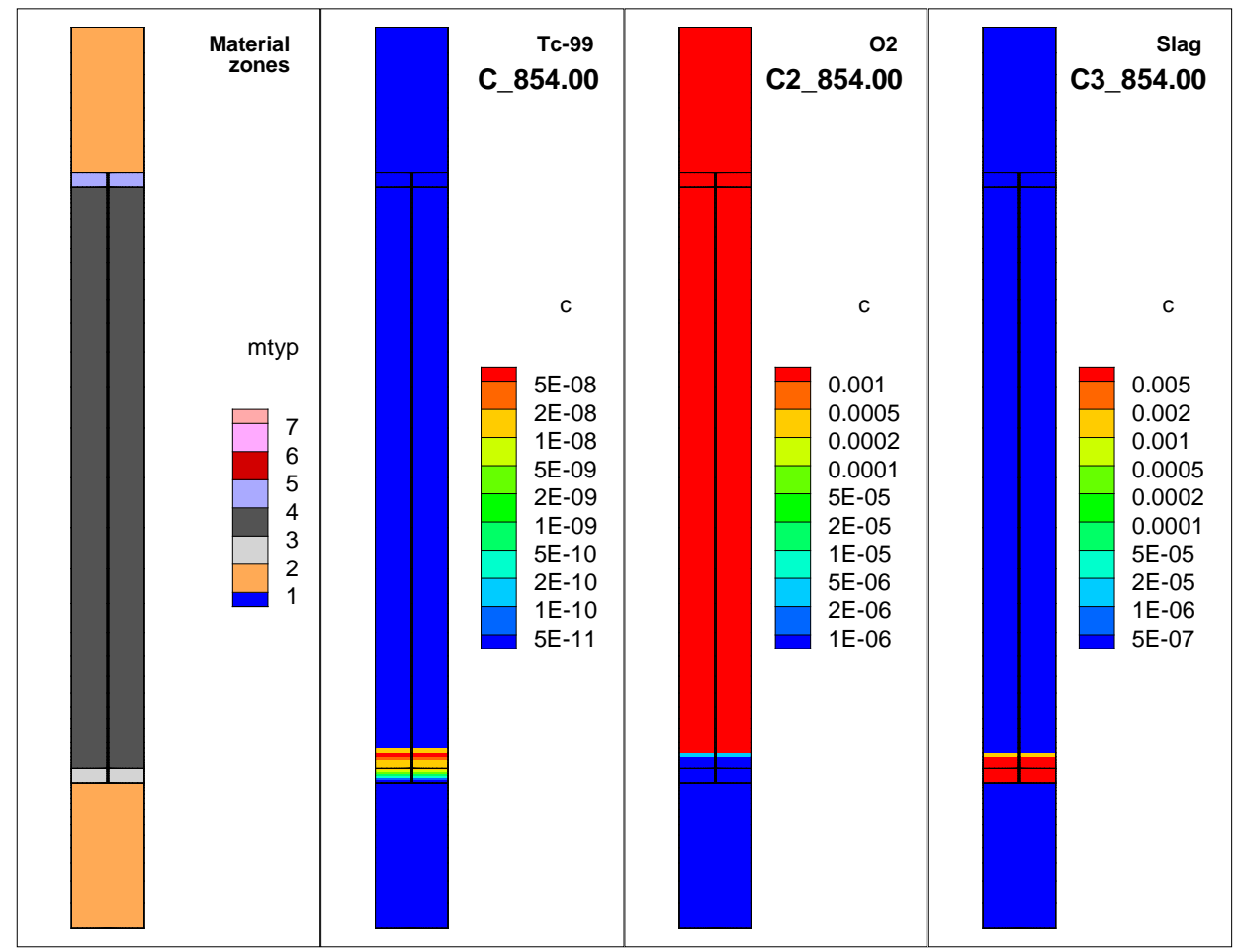

Figure 2-9. One-dimensional slag oxidation test: conditions at 854 years. 
SRNL-STI-2013-00280, REVISION 0

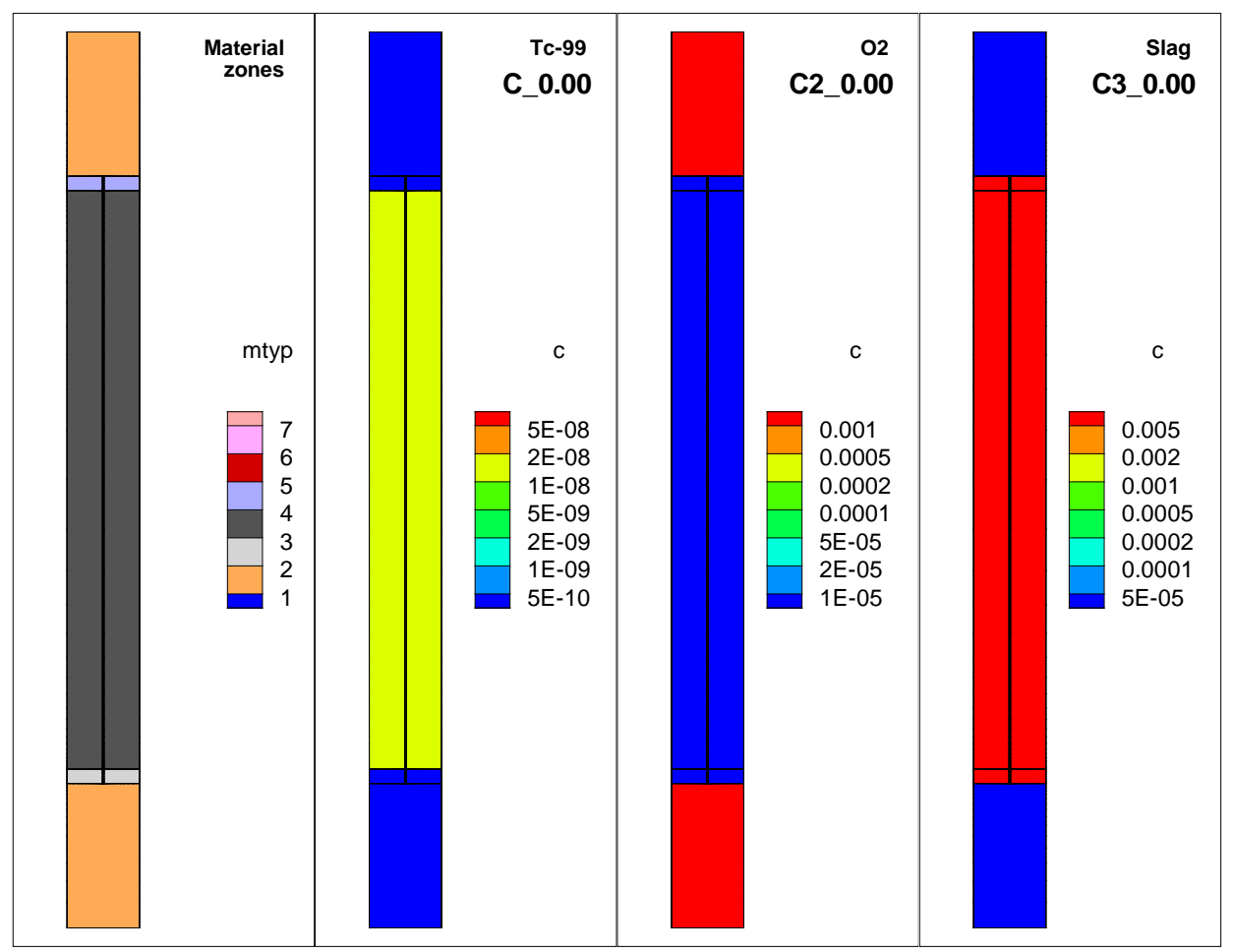

Figure 2-10. Two-dimensional slag oxidation test: initial conditions.

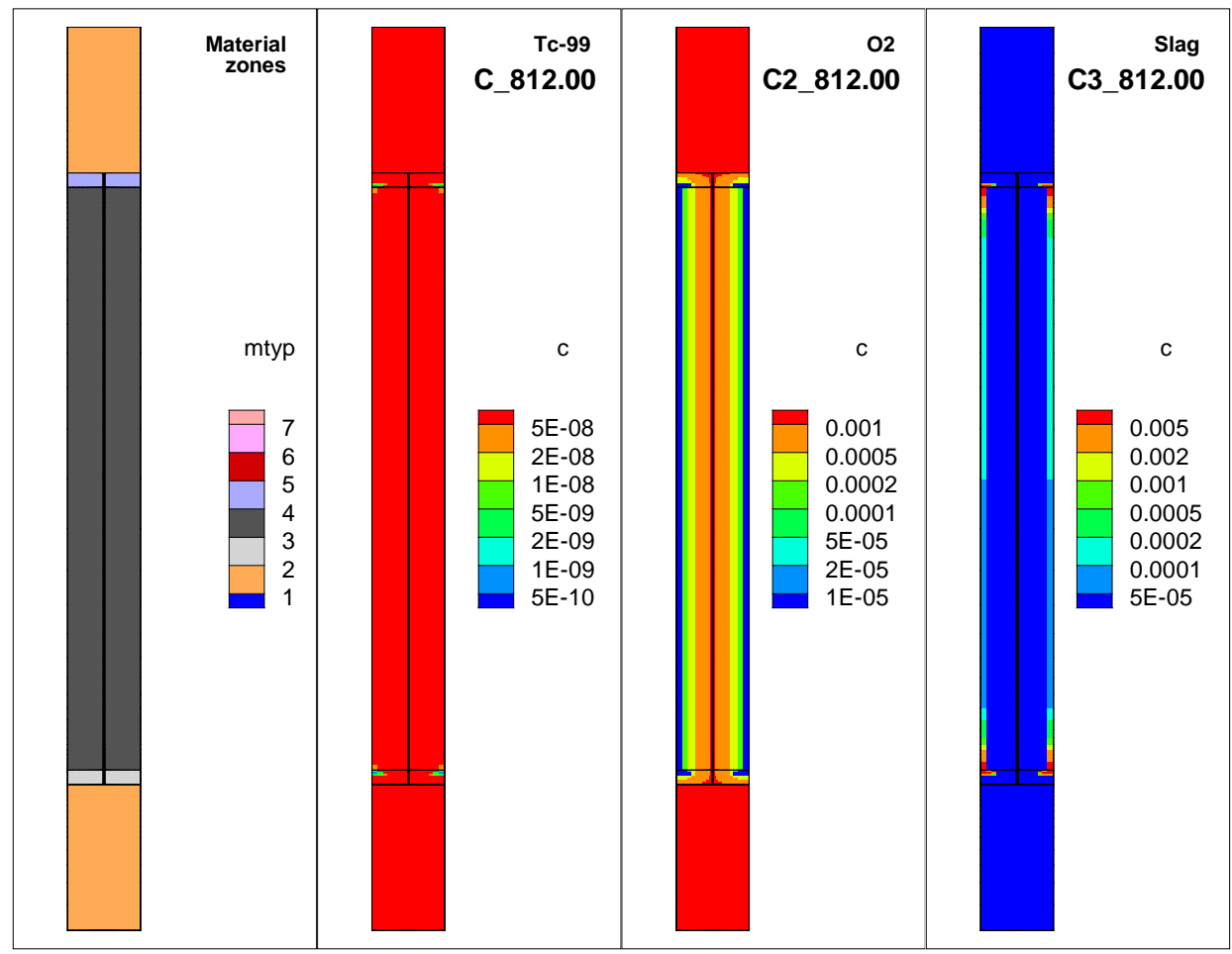

Figure 2-11. Two-dimensional slag oxidation test: conditions at 812 years. 


\subsection{Tc-99 Release}

The specifications in Table 2-5 imply a dual dependence of Tc-99 solute transport on the redox state and solid-phase concentration of Tc-99, the latter from the solubility limit. In PORFLOW simulations reducing conditions are assumed when slag is present, i.e., $C 3>0$. Solubility control can be implemented in PORFLOW using the option:

\section{DISTribution coefficient from fluid and solid concentrations}

which allows the user to specify an arbitrary relationship between the liquid and solid phase concentrations through tabular data. A three data-point example of solubility control is shown in Figure 2-12 where $C_{\ell}$ is liquid concentration $[\mathrm{mol} / \mathrm{mL}]$ and $C_{s}$ is solid concentration [mol/g]. Linear sorption is indicated between points (1) and (2) ( $K_{d} \equiv C_{s} / C_{\ell}$ $[\mathrm{mL} / \mathrm{g}])$. The flat portion between points (2) and (3) is the solubility limit on liquid concentration. PORFLOW also allows a univariate variation of sorption coefficient, which could be used to vary $K_{d}$ with $C 3$ (redox conditions). However, solubility and redox controls cannot be simultaneously implemented with these methods. This software limitation can be overcome by creating user-defined variables in PORFLOW to implement a $K_{d}$ function that is more sophisticated than the built-in code options. The desired $K_{d}$ function is derived first, followed by a discussion of PORFLOW implementation.

Table 2-5 indicates a $K_{d}$ variation between 0.5 and $0.8 \mathrm{~mL} / \mathrm{g}$ under oxidized conditions. To simplify matters, the lower value is used regardless of $\mathrm{pH}$ for oxidized conditions:

$$
K_{d}=K_{d, O x}=0.5 \mathrm{~mL} / \mathrm{g}
$$

In practice the transition from reduced to oxidized conditions occurs before the transition from moderate to aged $\mathrm{pH}$ conditions; therefore the $K_{d}$ function need not address reducing+aged conditions. Under reducing conditions and solubility controls, the inverse slope between points (1) and (2) (Figure 2-12) is somewhat arbitrarily set to:

$$
K_{d}=K_{d, R e}=0.01 \mathrm{~mL} / \mathrm{g}
$$

which maintains the liquid concentration at the solubility limit until the solid concentration is very low. Between points (2) and (3) (Figure 2-12) an effective $K_{d}$ value (Figure 2-13) can be computed from total mass and solubility as:

$$
K_{d}^{e f f} \equiv \frac{C_{s}}{C_{\ell}}=\frac{m_{s} / V \rho_{b}}{C_{s o l}}=\frac{m-m_{\ell}}{V \rho_{b} C_{s o l}}=\frac{m-V n S C_{s o l}}{V \rho_{b} C_{s o l}}=\frac{m / v^{-n S C_{s o l}}}{\rho_{b} C_{s o l}}
$$

where $m_{s}$ is species mass partitioned to the solid [mol], $V$ is total volume $\left[\mathrm{cm}^{3}\right], \rho_{b}$ is bulk solid density [g/ $\mathrm{cm}^{3}$ total], $C_{\text {sol }}$ is solubility [mol $\left./ \mathrm{mL}\right], m$ is total species mass [mol], $m_{\ell}$ is dissolved species mass [mol], $n$ is porosity $\left[\mathrm{cm}^{3}\right.$ void $/ \mathrm{cm}^{3}$ total], and $S$ is liquid saturation $\left[\mathrm{cm}^{3}\right.$ liquid $/ \mathrm{cm}^{3}$ void]. If Equation (2.15) is briefly applied during a computational timestep, then liquid-solid partitioning varies about the same initial condition (red dot), but along a line with slope $1 / K_{d}{ }^{\text {eff }}$ instead of horizontally. Provided 
Equation (2.15) is updated each timestep, liquid-solid partitioning will not deviate far from solubility control. The whole range of reduced conditions between points (1) and (3) can be covered by the composite function:

$$
K_{d}=\max \left[K_{d, R e}, K_{d}^{e f f}\right]=\max \left[K_{d, R e}, \frac{m / V^{-n S C_{s o l}}}{\rho_{b} C_{s o l}}\right]
$$

Furthermore, the transition between reduced and oxidized conditions can be handled by combining Equations (2.13) and (2.16) as:

$$
K_{d}=\left(1-x_{O x}^{p}\right) \cdot \max \left[K_{d, R e} \frac{m / V^{-n S C_{s o l}}}{\rho_{b} C_{s o l}}\right]+x_{O x} p \cdot K_{d, O x}
$$

where $p \gg 1$ and the oxidized fraction is defined by:

$$
x_{O x} \equiv 1-\frac{C_{\text {slag }}}{C_{\text {slag }, 0}}
$$

and $C_{\text {slag }}$ and $C_{\text {slag, } 0}$ are the current and initial slag concentrations [meq e-/g]. A value of 25 was selected for the power on $x_{O x}$; the resulting weighting function is shown in Figure $2-14$.

Appendix D provides a snippet from an FY13 SA input file that highlights the PORFLOW commands used to implement Equations (2.17) and (2.18). Appendix E defines three test cases. Case A tests implementation of solubility control using Equation (2.16); results are plotted in Figure 2-15. Case B illustrates greater accuracy when a smaller timestep is used (Figure 2-16). Case $C$ tests combined redox and solubility control through Equations (2.17) and (2.18) (Figure 2-17). 


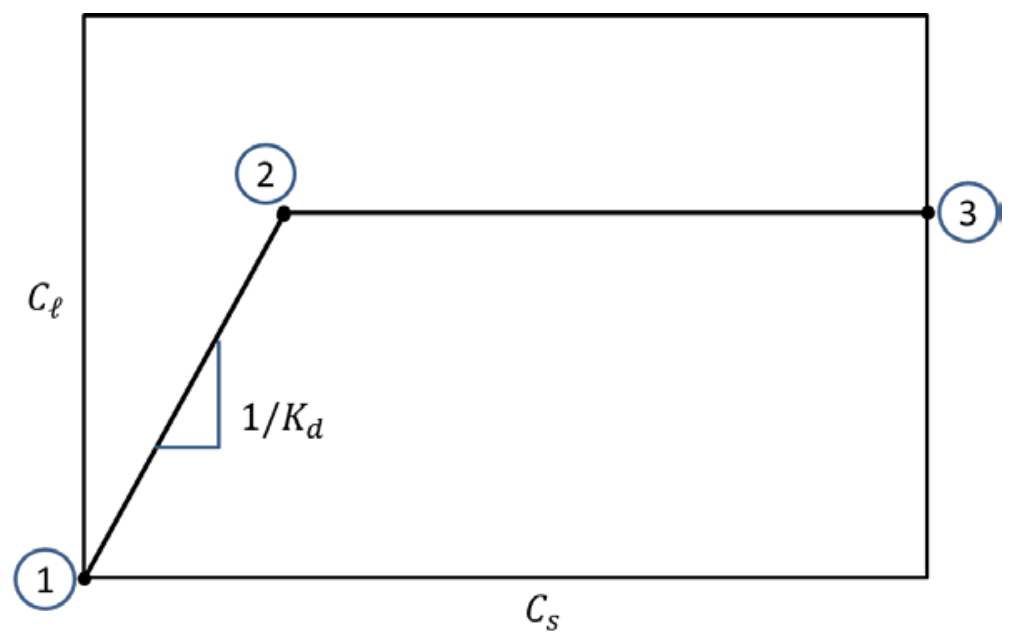

Figure 2-12. Sorption and solubility controls.

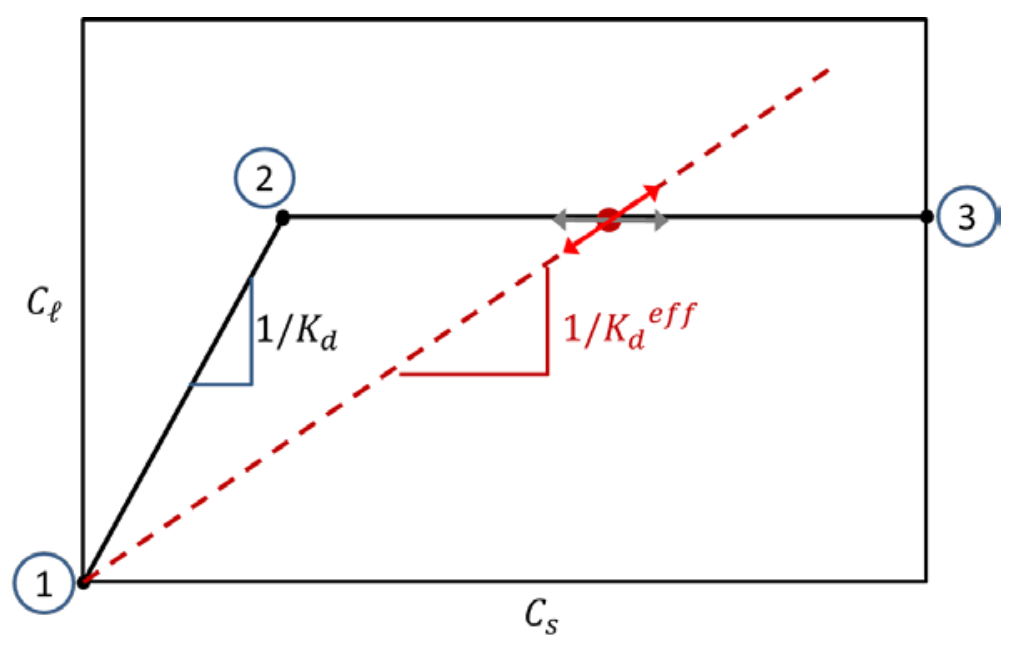

Figure 2-13. Effective $K_{d}$ concept.

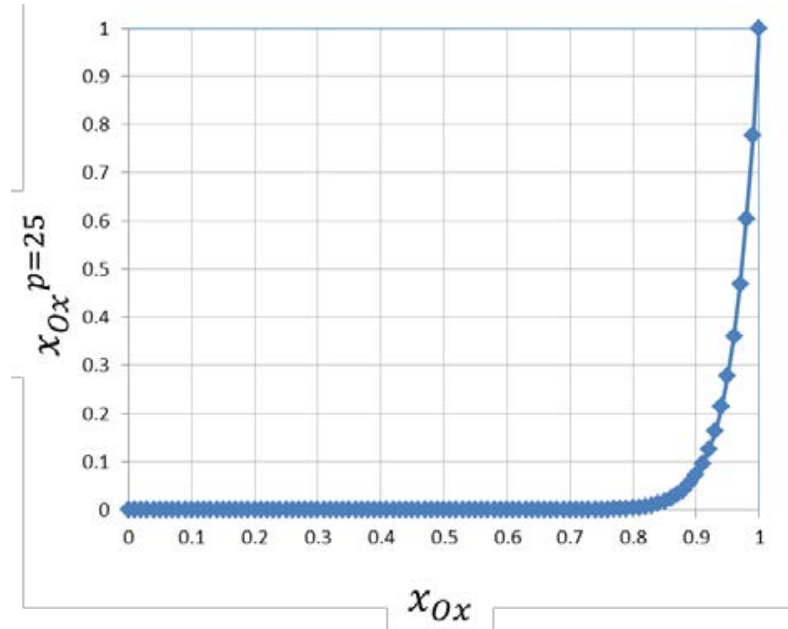

Figure 2-14. Weighting function between reduced and oxidized conditions. 
SRNL-STI-2013-00280, REVISION 0

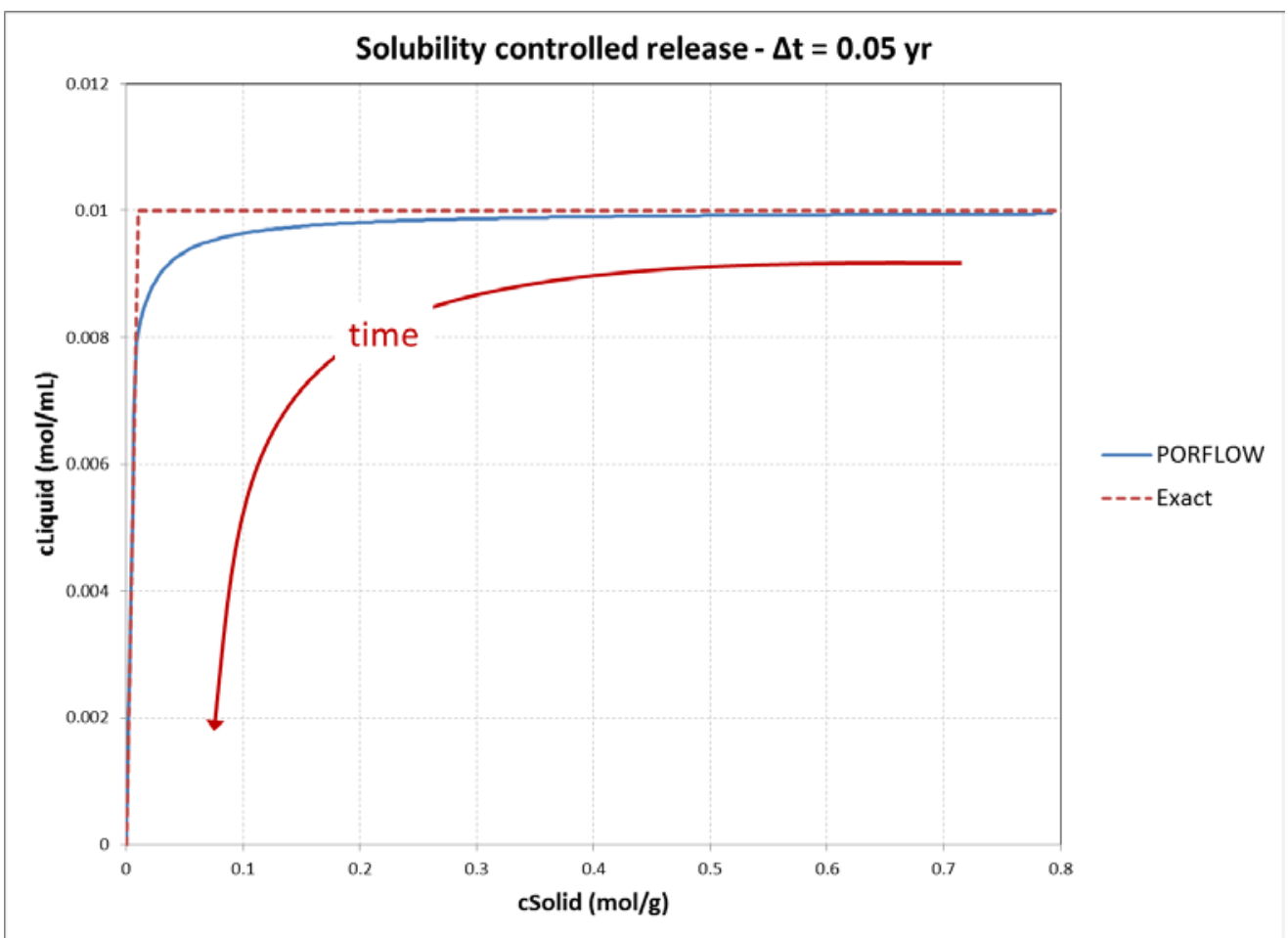

Figure 2-15. Test Case A for implementation of redox-solubility control: Tc-99 depleted before slag (solubility controls, no redox effect).

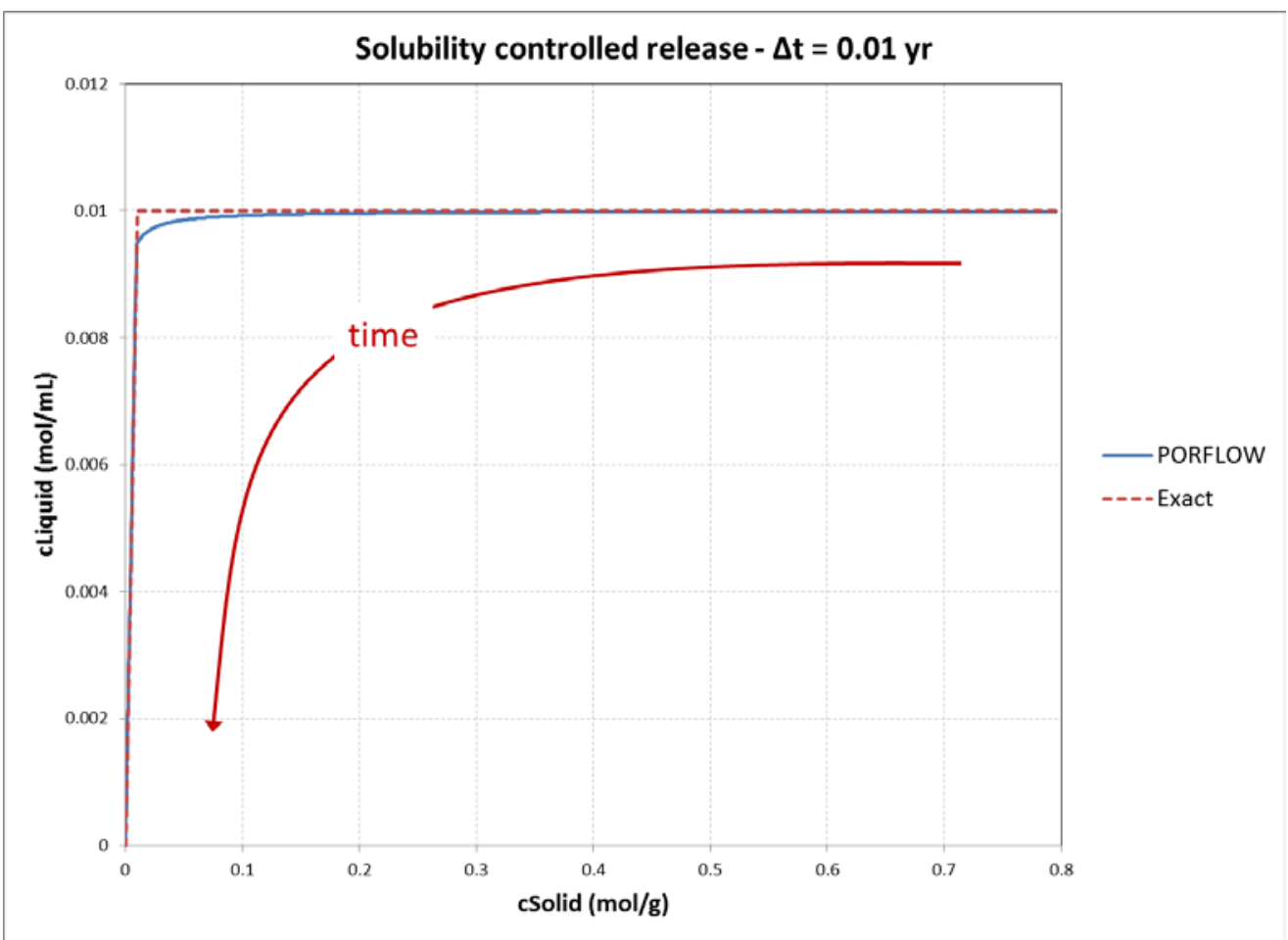

Figure 2-16. Test Case B for implementation of redox-solubility control: Case A at smaller timestep (increases accuracy). 


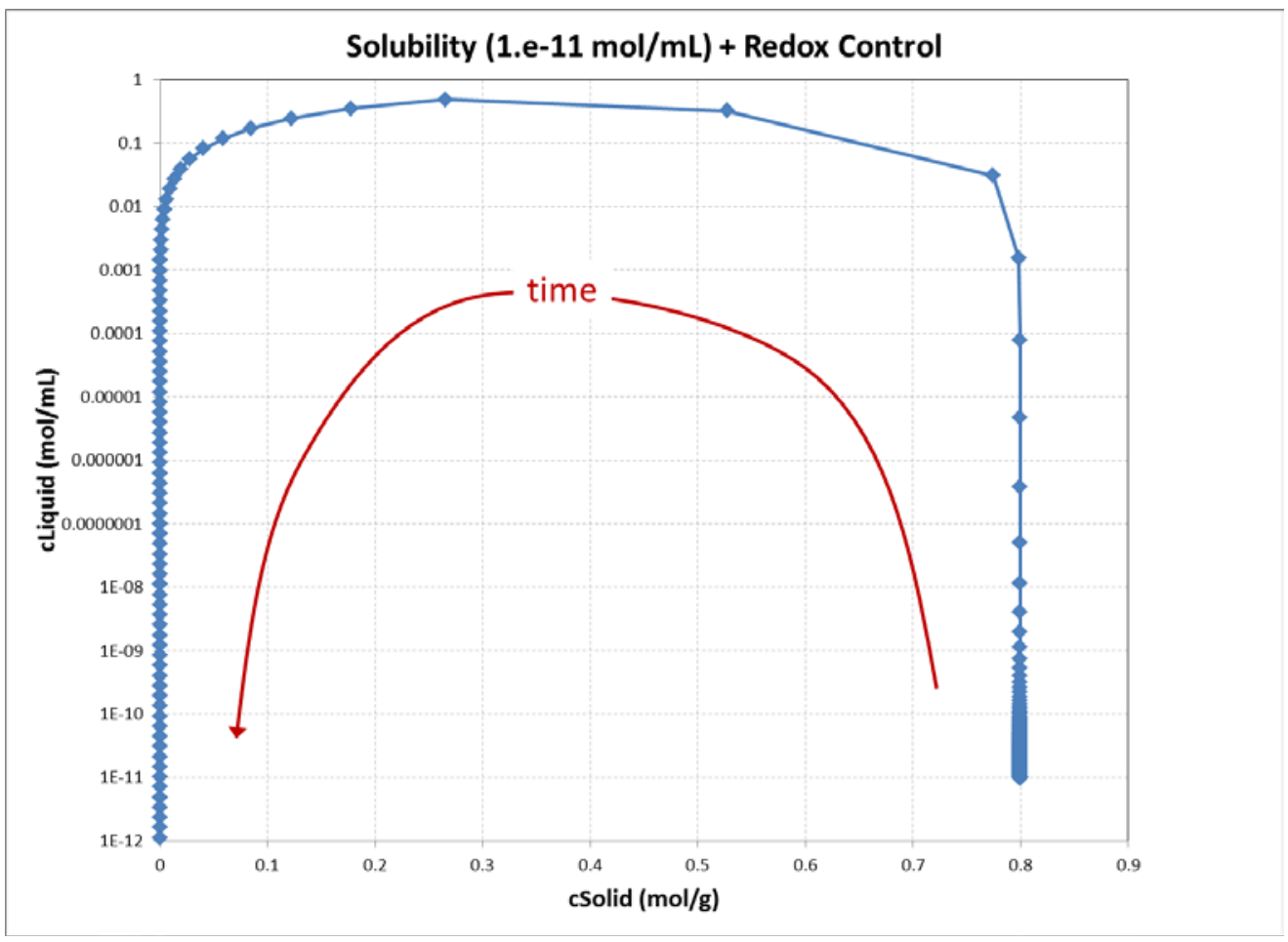

Figure 2-17. Test Case C for implementation of redox-solubility control: Tc-99 held up by solubility control until slag is exhausted, then concentration goes up orders of magnitude until Tc-99 depletion.

\subsection{Alternative Explicit Fracture Representation}

As discussed in Section 2.1, SDU cementitious materials are expected to physically degrade from multiple phenomena. Physical degradation may take the form of cracking, depending on the material and primary degradation mode. For this situation, a discrete fracture model (DFM, Figure 2-3) can be considered as an alternative to the Equivalent Continuum Model (ECM) chosen for FY13 SA modeling. This section compares the ECM with the alternative DFM representation with respect to a) spatial-average, steadystate Darcy flow, b) solute transport with retardation due to sorption alone (non-Tc species), and c) slag oxidation and Tc transport.

\section{Darcy flow}

Figure 2-18 illustrates a vertical fracture-matrix pair that will serve as a representative analog for predominantly downward flow and transport through a degraded SDU with fully-penetrating fractures. The fracture spacing is 1.0 meter (centerline to centerline) and a $2.0 \mathrm{~cm}$ gravel-filled seam is used as a surrogate (Pruess 1998) for a physical fracture with smaller aperture. The additional cases of 0.3 and 0.1 meter fracture spacing will also be considered. Concrete and grout are assigned saturated conductivities of 1.0E-10 and $1.0 \mathrm{E}-08 \mathrm{~cm} / \mathrm{s}$, respectively. The high-quality concrete van Genuchten (1980) parameters given in Table 6-8 of Phifer et al. (2006) are selected for both materials following the logic discussed in Section 2.1. For the soil above and below the concrete and grout layers, 
the "Sand" material from Phifer et al. (2006) is chosen. The hydraulic characteristics of the various materials are summarized in Table 2-6. Gravel occupying the concrete and grout fracture zones is assigned the porosity of the adjoining matrix, in anticipation of follow-on transport simulations which could otherwise be impacted by a change of porosity. Figure 2-19 illustrates the hydraulic characteristics of the materials used in the DFM representation as solid lines. For the ECM approach, composite materials are created by blending the cementitious materials with gravel by volume proportion; these blended ECM properties are depicted in Figure 2-19 with dashed lines. For steady-state flow simulations, pressure head at the bottom boundary is set to zero and infiltration (Darcy velocity) at the top boundary is imposed at various rates.

Figure 2-20 compares simulated pressure head and saturation for the the DFM and ECM models for a 1.0 meter fracture spacing and $10 \mathrm{~cm} / \mathrm{yr}$ infiltration rate. The two solutions are observed to be very similar. Figure 2-21 compares inlet pressure head between the two conceptual models for fracture spacings of 1.0, 0.3, and 0.1 meters and a wide range of infiltration rates. At the two smaller fracture spacings, the DFM and ECM results practically overlap. A small discrepancy is observed for the 1.0 meter spacing results, possible due to two-dimensional flows in soil around the inlet and outlet of the fast-flow path that is not accounted for in the ECM. These comparisons demonstrate that the ECM accurately reproduces the spatial-average, steady-state, Darcy velocity in the DFM representation.

The saturated conductivity of the grout in the above simulations is $1.0 \mathrm{E}-08 \mathrm{~cm} / \mathrm{s}$ or 0.32 $\mathrm{cm} / \mathrm{yr}$, which means that the material can accept an infiltration rate of $0.32 \mathrm{~cm} / \mathrm{yr}$ under unit gradient conditions. Additional simulations were performed with a grout saturated conductivity of $1.0 \mathrm{E}-10 \mathrm{~cm} / \mathrm{s}$ or $0.0032 \mathrm{~cm} / \mathrm{yr}$, which forces more flow through the fracture at low flowrates. Figure 2-22 compares inlet pressure head for the DFM and ECM models. Again, excellent agreement is observed between the two modeling approaches.

\section{$\underline{\text { Solute transport }}$}

Radionuclide transport in the FY13 SA is controlled by advection, diffusion/dispersion, retardation, and first-order decay/ingrowth. Tc-99 is also dependent on a shrinking core slag oxidation model and solubility, and considered separately in the following subsection. Retardation due to sorption affects the time scale of solute transport but not the behavior of solute breakthrough at a downgradient point in terms of non-dimensional time; thus consideration of a non-sorbing tracer species is sufficient to examine the fundamental differences between the DFM and ECM constructs (e.g. Flach 2012). Furthermore the discrete fracture and equivalent continuum models differ in their treatment of advection and dispersion, so radionuclude decay will be ignored going forward. For solute transport simulations the grout conductivity is set to $1.0 \mathrm{E}-10 \mathrm{~cm} / \mathrm{s}$ to minimize advection in the DFM grout zone, and the effective diffusion coefficient for the grout is set to $1.0 \mathrm{E}-07 \mathrm{~cm}^{2} / \mathrm{s}$.

Figure 2-23 is a snapshot the DFM and ECM simulations at 10 years for a fracture spacing of 1.0 meters and an infiltration of $10 \mathrm{~cm} / \mathrm{yr}$. Lateral diffusion into the fracture 
zone is evident in the DFM simulation, whereas the ECM simulation shows a uniform flushing front. Not surprisingly, Figure 2-24 indicates different transport behavior between the two models. Compared to the ECM, the DFM has a lower peak flux and a much longer trailing flux due to diffusion-limited transport from the interior of the matrix into the fracture. Heavy plume tailing in this and other analogous contexts has been widely discussed in the literature (e.g., Haggerty et al. 2000, Zinn and Harvey 2003, Haggerty et al. 2004). Figure 2-25 shows breakthrough curves for 1.0, 0.3, and $0.1 \mathrm{~m}$ fracture spacings and a $10 \mathrm{~cm} / \mathrm{yr}$ flow rate. As the fracture becomes smaller better agreement is observed between the DFM and ECM. Figure 2-26 through Figure 2-28 compare breakthrough curves for flowrates ranging from 0.001 to $100 \mathrm{~cm} / \mathrm{yr}$ and fracture spacings of 1.0, 0.3, and 0.1 meters, respectively. Improved agreement between the DFM and ECM breakthrough curves is observed for smaller fracture spacings and flow rates.

The reason is that the time scale for diffusion through the matrix becomes shorter relative to the time scale for advection for slower flow and smaller diffusion distances, such that the matrix and fracture are in closer equilibrium. At complete equilibrium, the two model representations produce identical breakthrough curves, despite their notably different flow fields (e.g., Haggerty et al. 2004, Flach 2012). The ECM is observed to reproduce the breakthrough behavior of the DFM for flow rates up to $10 \mathrm{~cm} / \mathrm{yr}$ (and somewhat higher) for fracture spacings up to $0.3 \mathrm{~m}(1 \mathrm{ft})$. At a fracture spacing of $1.0 \mathrm{~m}$, the ECM exhibits good agreement with the DFM for flow rates up to about $1 \mathrm{~cm} / \mathrm{yr}$. At higher flow rates the ECM produces a peak flux that is higher than the DFM peak. These comparisons indicate that the ECM approach selected for FY13 SA analysis is either a good approximation to, or is conservative relative to, the alternative DFM approach for general solute transport, depending on fracture spacing and flow rate.

The conditions required for approximate equilibrium between the fracture and matrix zones can be identified by quantitatively examining the timescales for diffusion and advection (Haggerty et al. 2004, Flach 2012). The time scale for solute diffusion from matrix to fracture is:

$$
t_{d}=\frac{W^{2}}{D_{e}}
$$

where $W$ is the diffusion distance [cm], and $D_{e}$ is the effective diffusion coefficient of the matrix $\left[\mathrm{cm}^{2} / \mathrm{s}\right]$. The appropriate timescale for advection is the "mean solute residence time” (Haggerty et al. 2004) defined as:

$$
t_{a}=\frac{L}{v}
$$

where $L$ is the advection distance $[\mathrm{cm}]$, and $v=U / n$ is average pore velocity [cm/s] $(U$ $=$ Darcy velocity, $n=$ porosity). The average pore velocity is the rate of total flow through the system divided by total area and porosity. Thus the mean solute residence time $\left(t_{a}\right)$ is the time for solute travel through the system when the flow is uniform. The mean solute residence time is the same for both the DFM and ECM. 
The ratio of the longitudinal advection and lateral diffusion timescales is a nondimensional Damkohler number:

$$
D a=\frac{t_{a}}{t_{d}}=\frac{L D_{e}}{W^{2} v}
$$

Equilibrium conditions are expected when $D a \gg 1$. Approximate equilibrium occurs for $D a \sim 1$ and somewhat higher values. That is, the ECM will produce solute transport results equal or similar to the DFM when $D a \geq \sim 1$. Table 2-7 presents Damkohler numbers for various fracture spacings and flow rates. Damkohler numbers greater than or equal to one are highlighted. For a fracture spacing of $0.1 \mathrm{~m}$, Table 2-7 implies good agreement between ECM and DFM transport simulations for the selected flow rates, which was indeed observed in Figure 2-28. For a fracture spacing of $0.3 \mathrm{~m}$, good agreement is expected for infiltrations up to at least $1 \mathrm{~cm} / \mathrm{yr}$, but not at $10 \mathrm{~cm} / \mathrm{yr}$, which is consistent with Figure 2-27. At a $1.0 \mathrm{~m}$ spacing the ECM is predicted to match the DFM for Darcy velocities less than $1 \mathrm{~cm} / \mathrm{yr}$ in agreement with Figure 2-26. The ECM is less accurate at higher flows, but conservatively overpredicts the peak flux.

\section{$\underline{\text { Slag oxidation and Tc-99 transport }}$}

In FY13 SA simulations, Tc-99 transport is coupled to a shrinking-core slag oxidation submodel and controlled by a solubility of 1.0E-08 mol/L under reducing conditions (Table 2-5). These additional influences motivate a separate evaluation of Tc-99 beyond the preceding generic consideration of solute transport. Initial conditions for DFM and ECM simulations are depicted in Figure 2-29. The fracture spacing is 1.0 meters and the thickness is a unit centimeter. The infiltration rate is fixed at $10 \mathrm{~cm} / \mathrm{yr}$. The grout and concrete reduction capacities ( slag concentrations) are set to 0.607 and 0.178 meq e-/g (Sheppard 2013). The initial inventory of Tc-99 is set to $2.56 \mathrm{E}-03 \mathrm{~mol}$, which is equivalent in waste density to the 538 Ci SDU 2 inventory in the FY13 SA.

Using Equation (2.12), the time required to completely oxidize the grout by lateral diffusion is 49,309 years. For Tc-99 release at the solubility limit (flow · area · solubility $=1.0 \mathrm{E}-08 \mathrm{~mol} / \mathrm{yr}$ ), the inventory would last about 256,000 years. Figure $2-30$ presents short-term DFM simulation results. The flux is observed to track the solubility limit (1.0E-08 mol/yr) except for occasional spikes that correspond to discrete grid cells becoming oxidized. These spikes are an artifact of numerical modeling; the actual flux would vary more smoothly and lie above $1.0 \mathrm{E}-08 \mathrm{~mol} / \mathrm{yr}$. Figure $2-31$ shows the average flux computed as the cumulative release through 600 years divided by 600 years. The average flux is $4.8 \mathrm{E}-08 \mathrm{~mol} / \mathrm{yr}$. Figure 2-32 illustrates the corresponding ECM results. Here the Tc-99 flux is precisely controlled by the solubility limit. The time required to completely oxidize the grout by advective inflow in the ECM is 47,656 years. Because of the long times required to either completely oxidize the grout and/or deplete the Tc-99 inventory at the solubility flux in both models, similar flux levels are expected well into the future.

To accelerate slag oxidation and Tc-99 release for demonstration purposes, the above simulations were repeated with the reduction capacities lowered by $100 x$. The grout then becomes completely oxidized at 493 years for the DFM and 477 years for the ECM. 
Figure 2-33 presents the DFM results when the fracture zone contains a non-depleting internal source of oxygen (as with the previous DFM simulation) to account for gasphase oxygen in the unsaturated fracture. Now the flux is roughly 100x higher, presumably because of a 100x faster oxidation rate. Again the oscillations are numerical artifacts, and the true flux would be closer to a running time-average. Figure 2-34 presents results for a simulation without the internal oxygen source, such that the oxygen supply is constrained to that available from infiltrating water. Initially slag oxidation and Tc-99 release are slowed because of the limited oxygen supply. However, by 150 years the fluxes in Figure 2-33 and Figure 2-34 are similar in magnitude. Figure 2-35 illustrates comparable ECM results. Here the flux is constant at the solubility-controlled level until all cementitious materials are oxidized, when the remaining inventory releases as a sharp pulse. Oxidation in the ECM occurs as a downward moving front. Tc-99 released behind the front is captured in the reducing region just ahead of the oxidation front, creating a concentrated source. The peak concentration for the ECM is roughly two orders of magnitude larger than the highest flux from the DFM, and occurs late in time.

These observations indicate that the peak ECM flux for Tc-99 will be conservative compared to the DFM. However, the time period of investigation must be sufficiently long to avoid a non-conservative focus only on earlier release rates. 


\section{Fractured Media Representations}
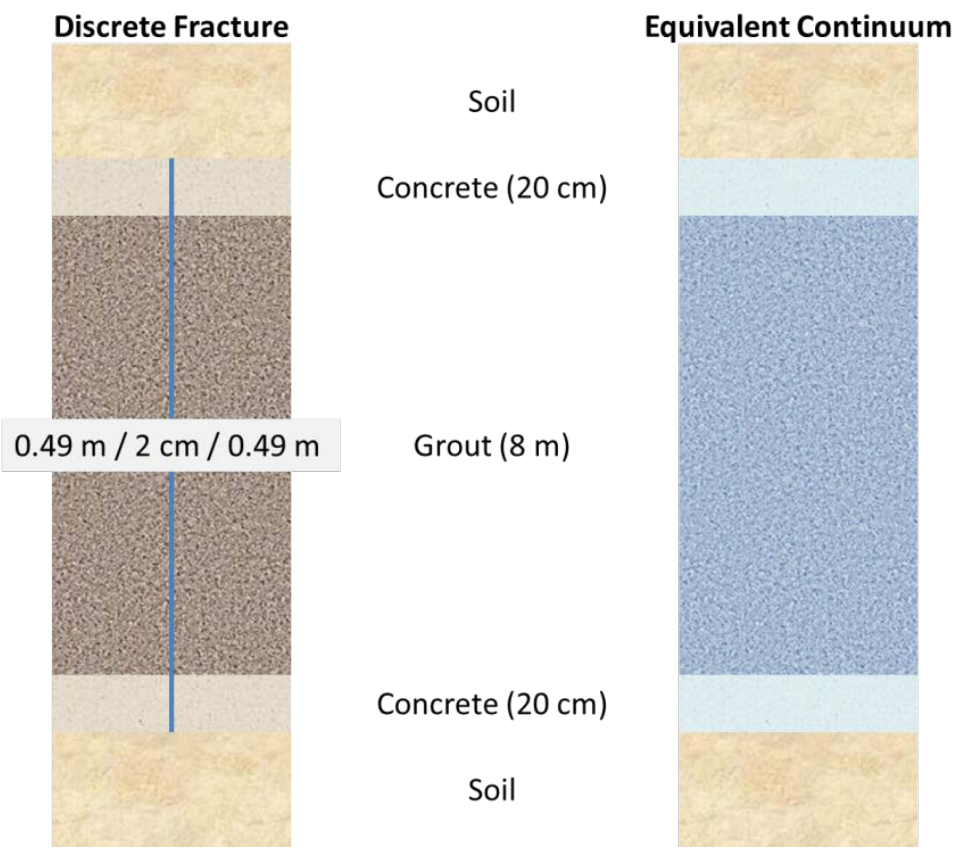

(a)

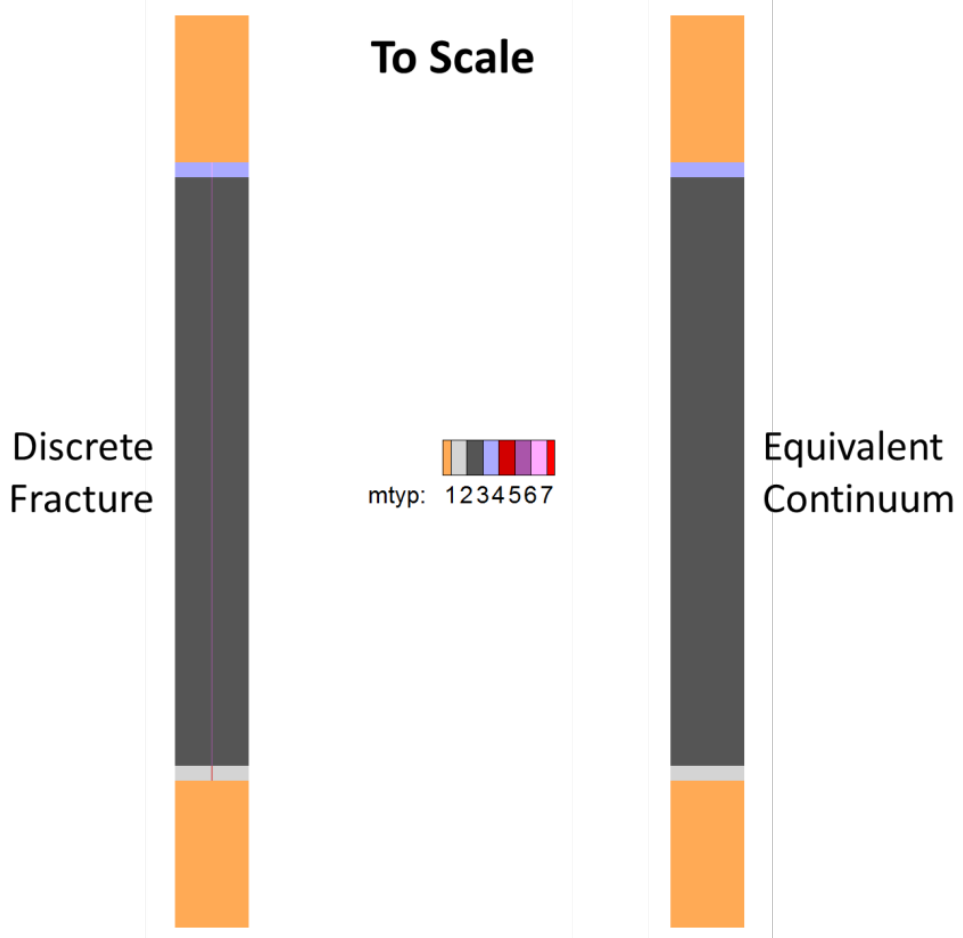

(b)

Figure 2-18. Explicit Fracture and Homogenized Fracture Models: a) schematic drawing showing material zones, and b) PORFLOW representations. 
Table 2-6. Hydraulic parameters for Discrete Fracture and Equivalent Continuum Models.

\begin{tabular}{|c|c|c|c|c|c|}
\hline Parameter & $\begin{array}{c}\text { Intact } \\
\text { concrete }\end{array}$ & $\begin{array}{c}\text { Intact } \\
\text { grout }\end{array}$ & $\begin{array}{c}\text { Gravel } \\
\text { surrogate } \\
\text { for } \\
\text { concrete } \\
\text { fracture }\end{array}$ & $\begin{array}{c}\text { Gravel } \\
\text { surrogate } \\
\text { for grout } \\
\text { fracture }\end{array}$ & Soil \\
\hline$\theta_{s}$ & 0.082 & 0.58 & 0.29843 & 0.29843 & 0.38103 \\
\hline$\theta_{r}$ & 0 & 0 & 0.01564 & 0.01564 & 0.1349 \\
\hline$S_{r}$ & 0 & 0 & 0.0524 & 0.0524 & 0.3540 \\
\hline$\alpha\left(\mathrm{cm}^{-1}\right)$ & $2.0856 \mathrm{E}-06$ & $1.9994 \mathrm{E}-05$ & 0.14266 & 0.14266 & 0.02954 \\
\hline$n$, van Genuchten & 1.9433 & 1.51012 & 1.45746 & 1.45746 & 1.40995 \\
\hline$(1980)$ & & & & & \\
\hline$K_{v}(\mathrm{~cm} / \mathrm{s})$ & $9.3 \mathrm{E}-11$ & $6.4 \mathrm{E}-09$ & $1.5 \mathrm{E}-01$ & $1.5 \mathrm{E}-01$ & $5.0 \mathrm{E}-04$ \\
\hline$n$, porosity & 0.12 & 0.58 & 0.12 & 0.58 & 0.38 \\
\hline
\end{tabular}

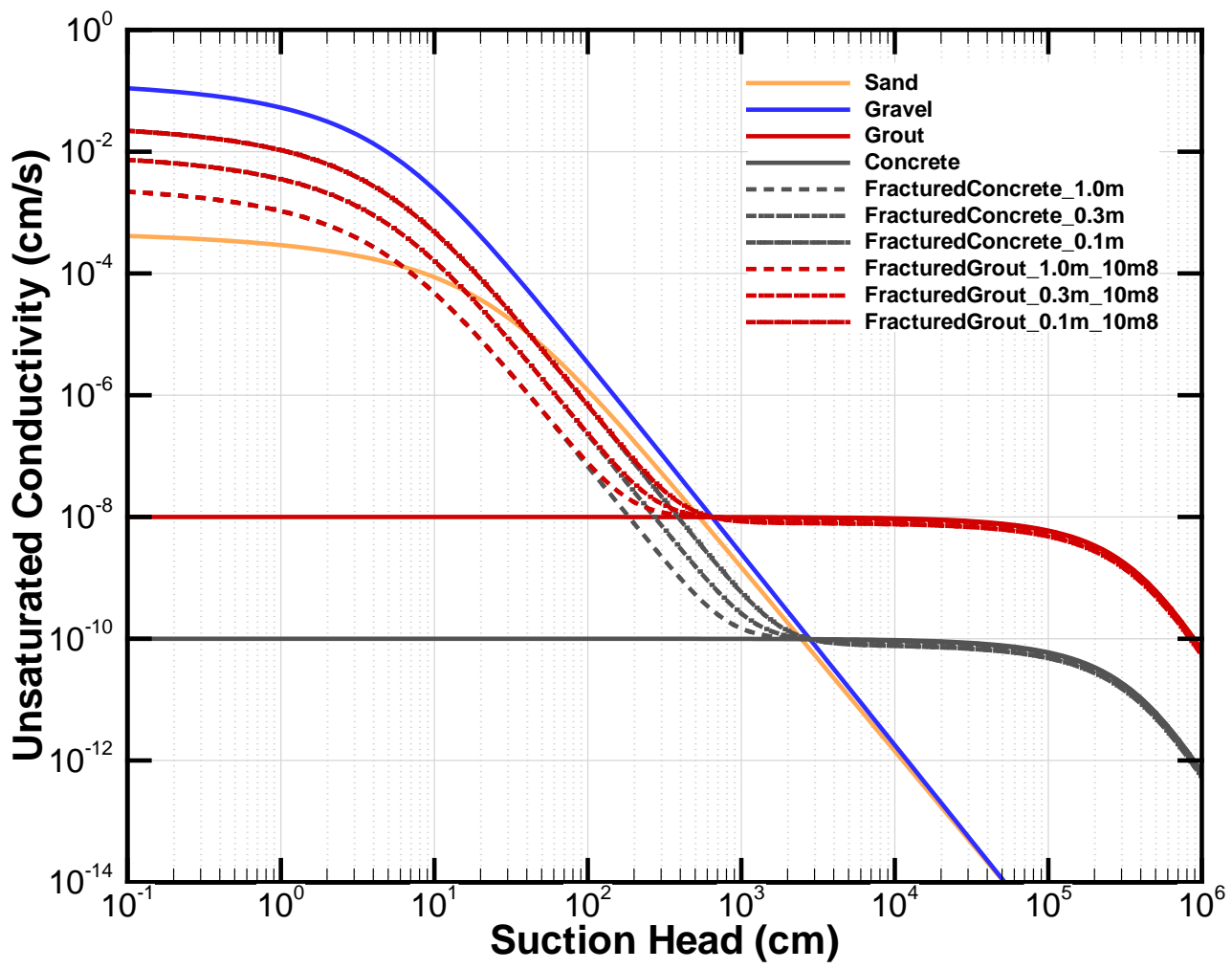

Figure 2-19. Hydraulic characteristics of DFM and ECM materials. 


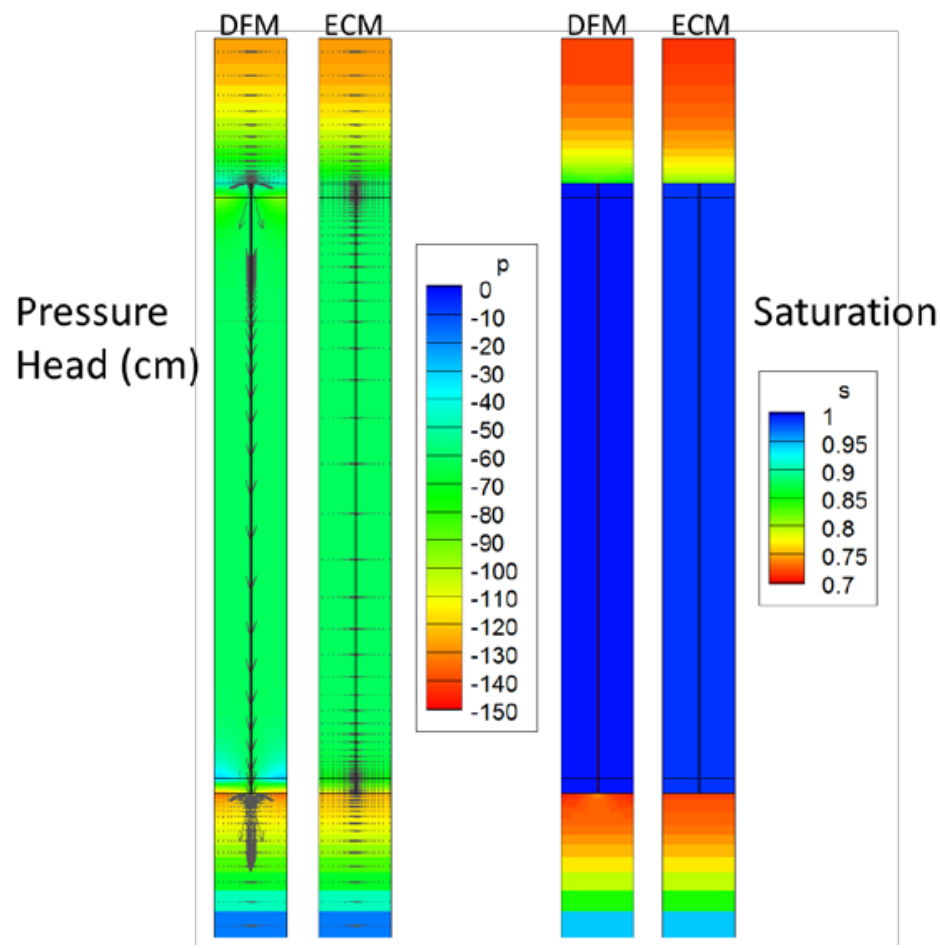

Figure 2-20. Comparison of DFM and ECM flow simulations (1.0 meter fracture spacing, $10 \mathrm{~cm} / \mathrm{yr}$ Darcy velocity).

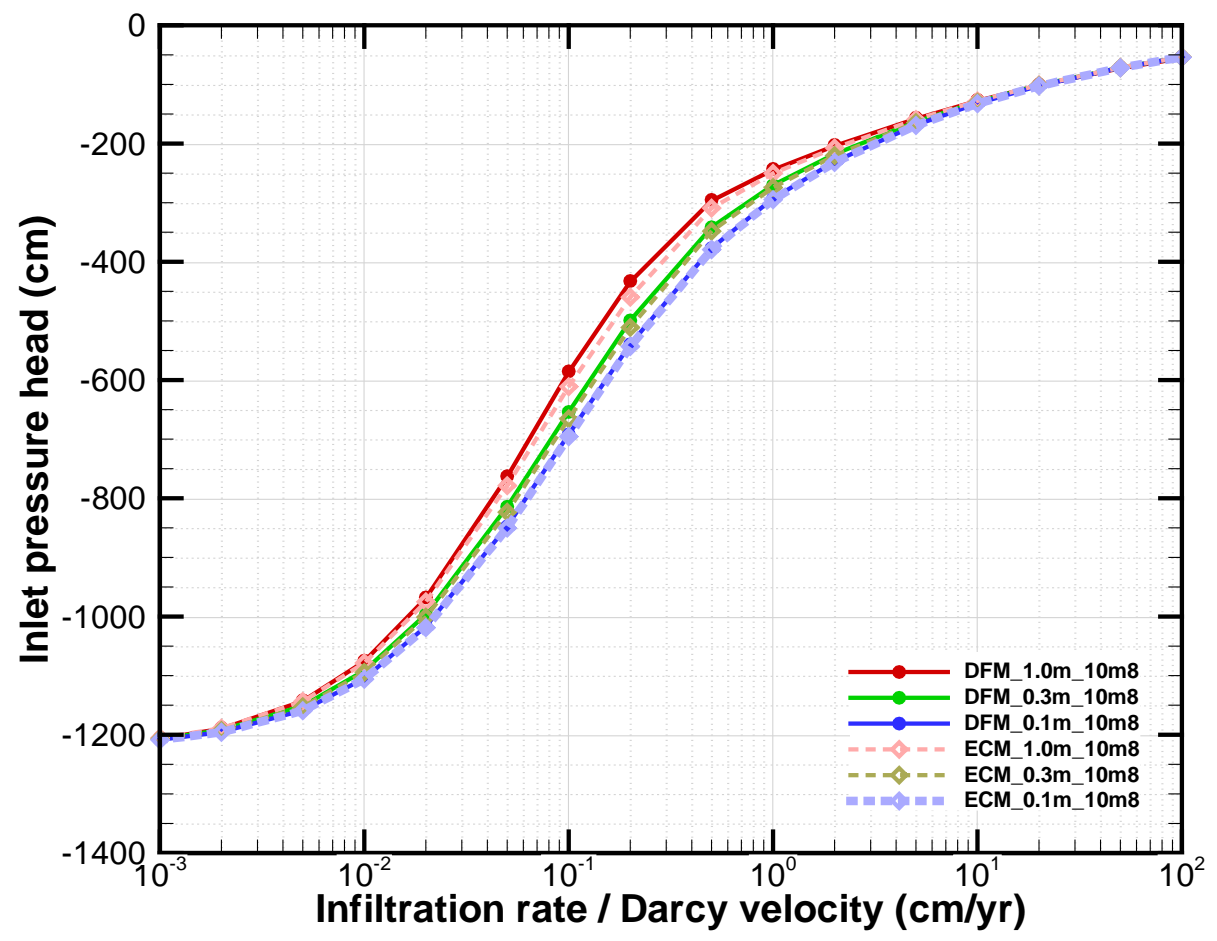

Figure 2-21. Comparison of inlet pressure head $(\mathrm{cm})$ for various infiltration rates and fracture spacings for DFM and ECM simulations. 


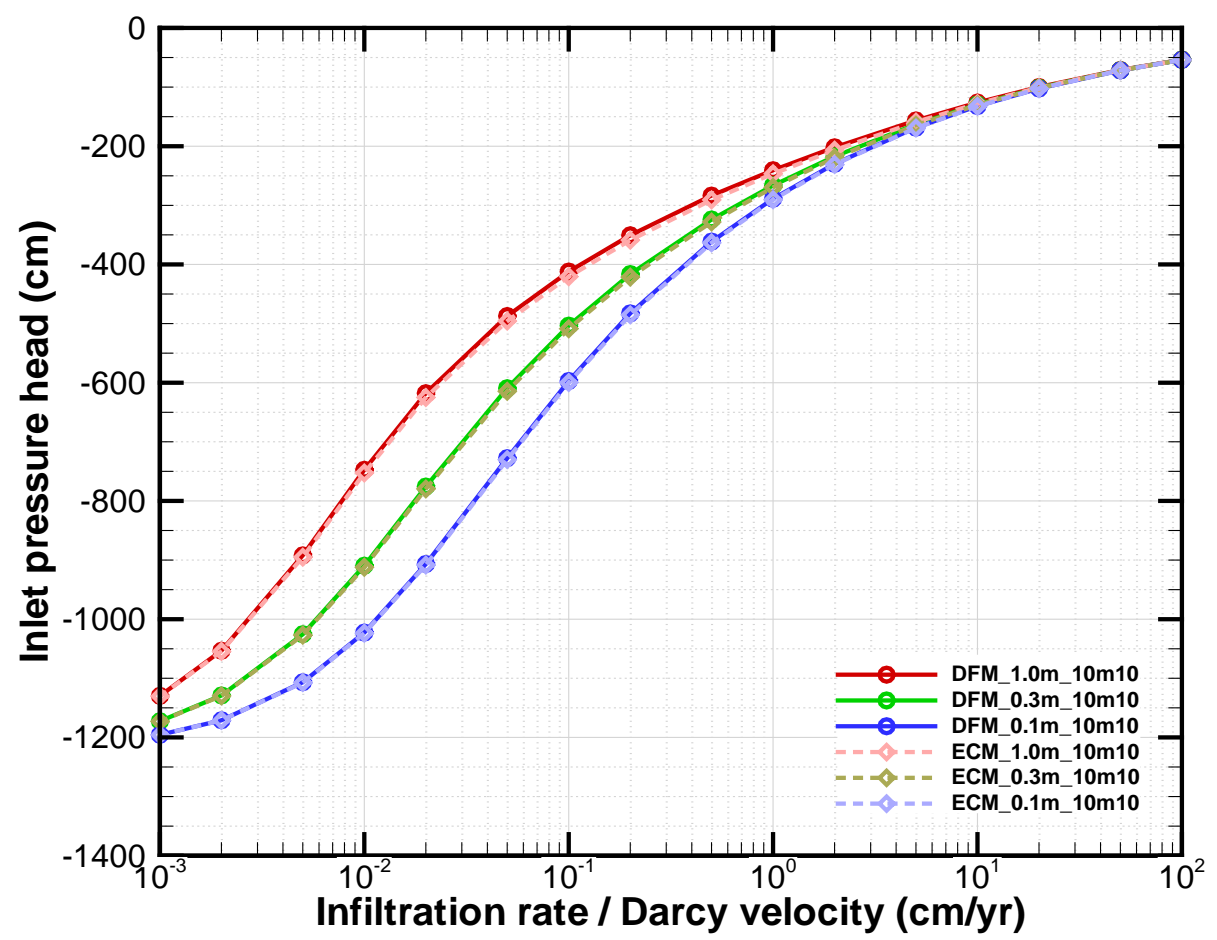

Figure 2-22. Comparison of inlet pressure head $(\mathrm{cm})$ for various infiltration rates and fracture spacings for DFM and ECM simulations when the grout conductivity is reduced to $1.0 \mathrm{E}-10 \mathrm{~cm} / \mathrm{s}$.

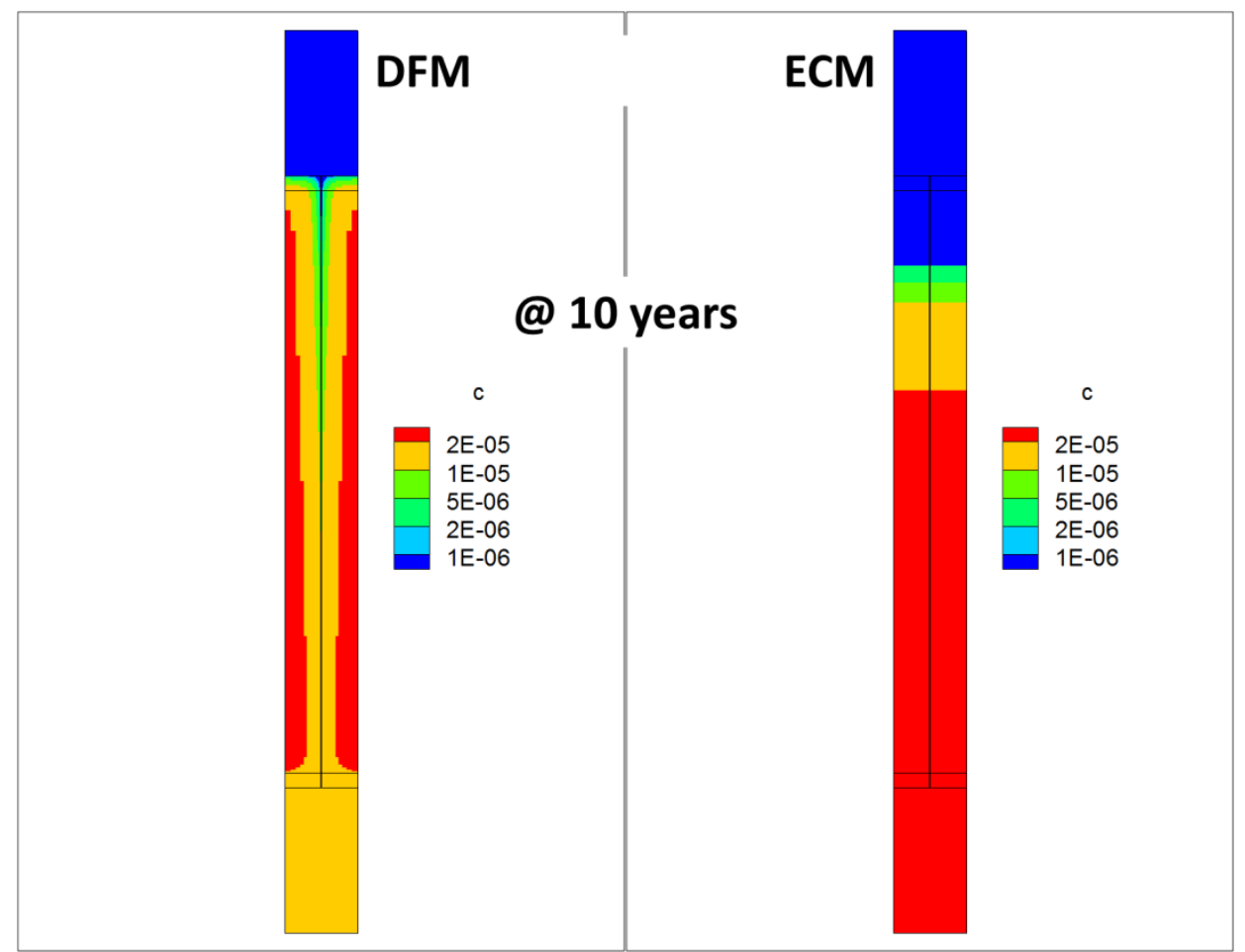

Figure 2-23. Tracer release in DFM and ECM simulations 10 years for a 1.0 meter fracture spacing and $10 \mathrm{~cm} / \mathrm{yr}$ flow. 


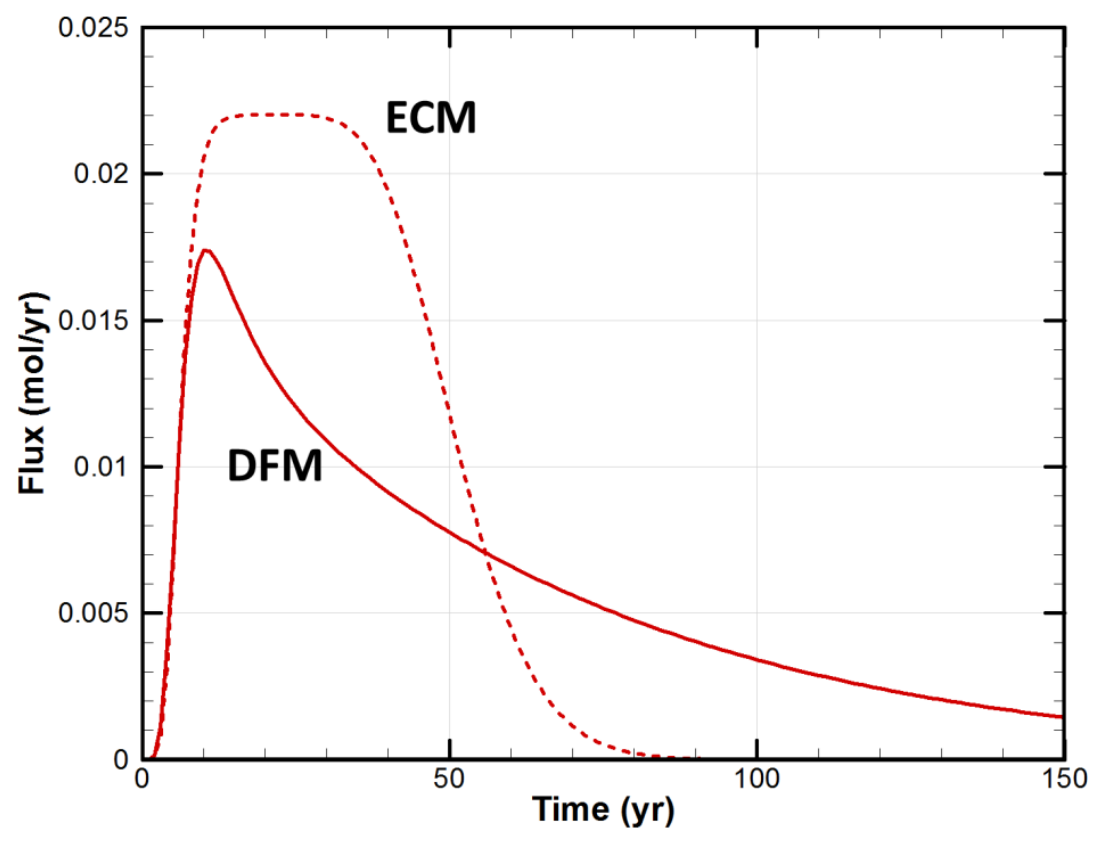

(a)

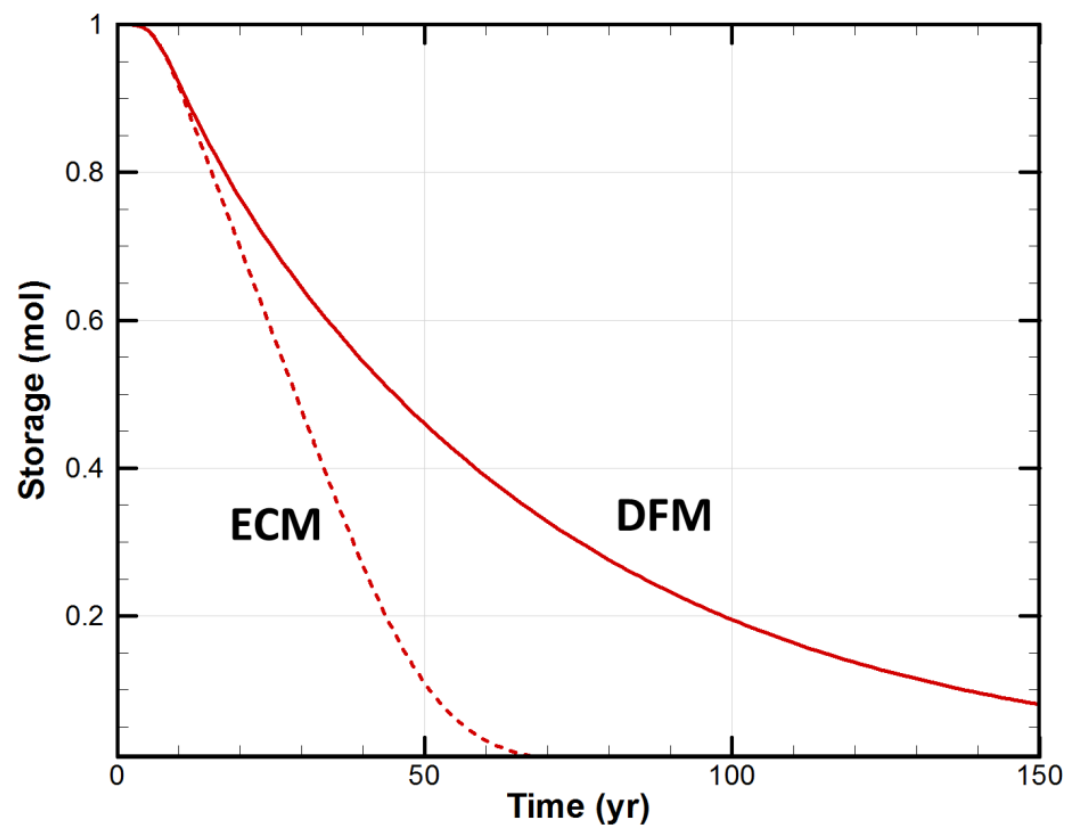

(b)

Figure 2-24. Tracer transport comparison for DFM and ECM simulations with a 1.0 meter fracture spacing and $10 \mathrm{~cm} / \mathrm{yr}$ flow: (a) flux, and (b) residual mass. 


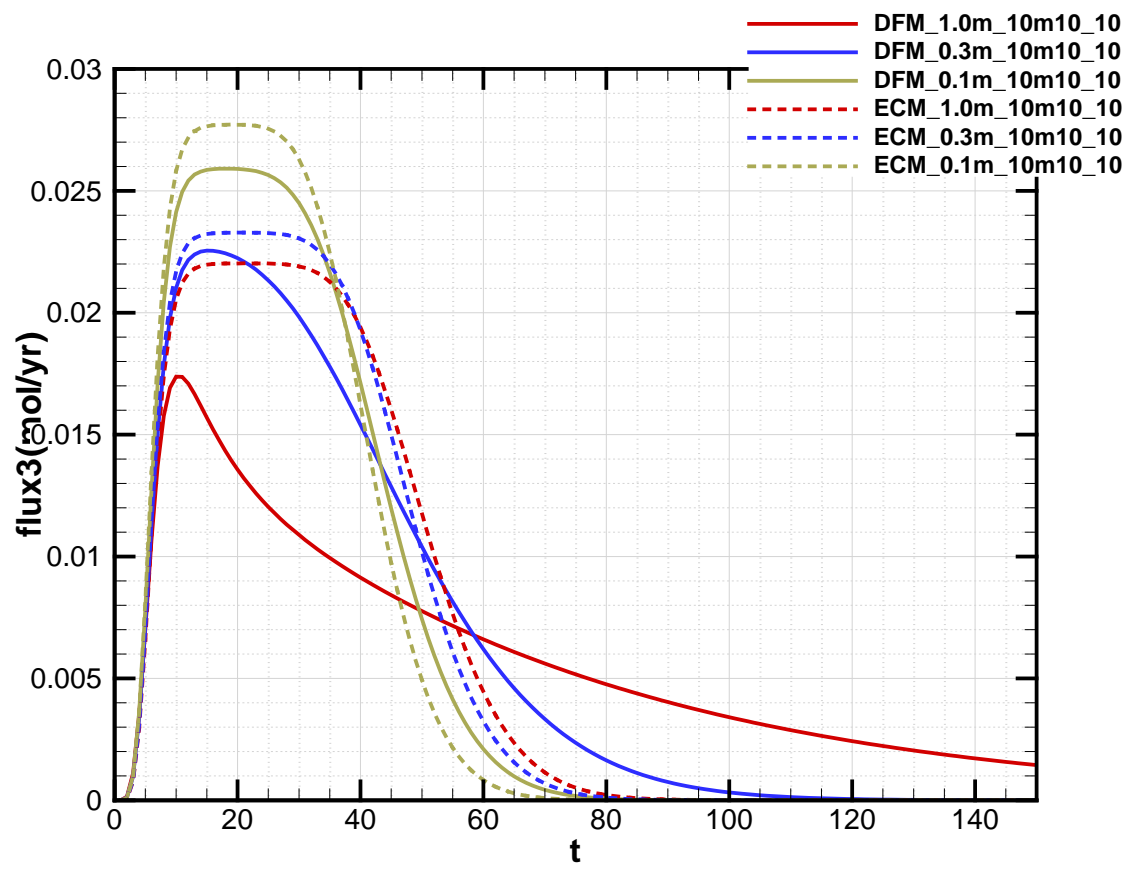

Figure 2-25. Tracer transport comparison for DFM and ECM simulations for varying fracture spacings and a $10 \mathrm{~cm} / \mathrm{yr}$ flow rate.

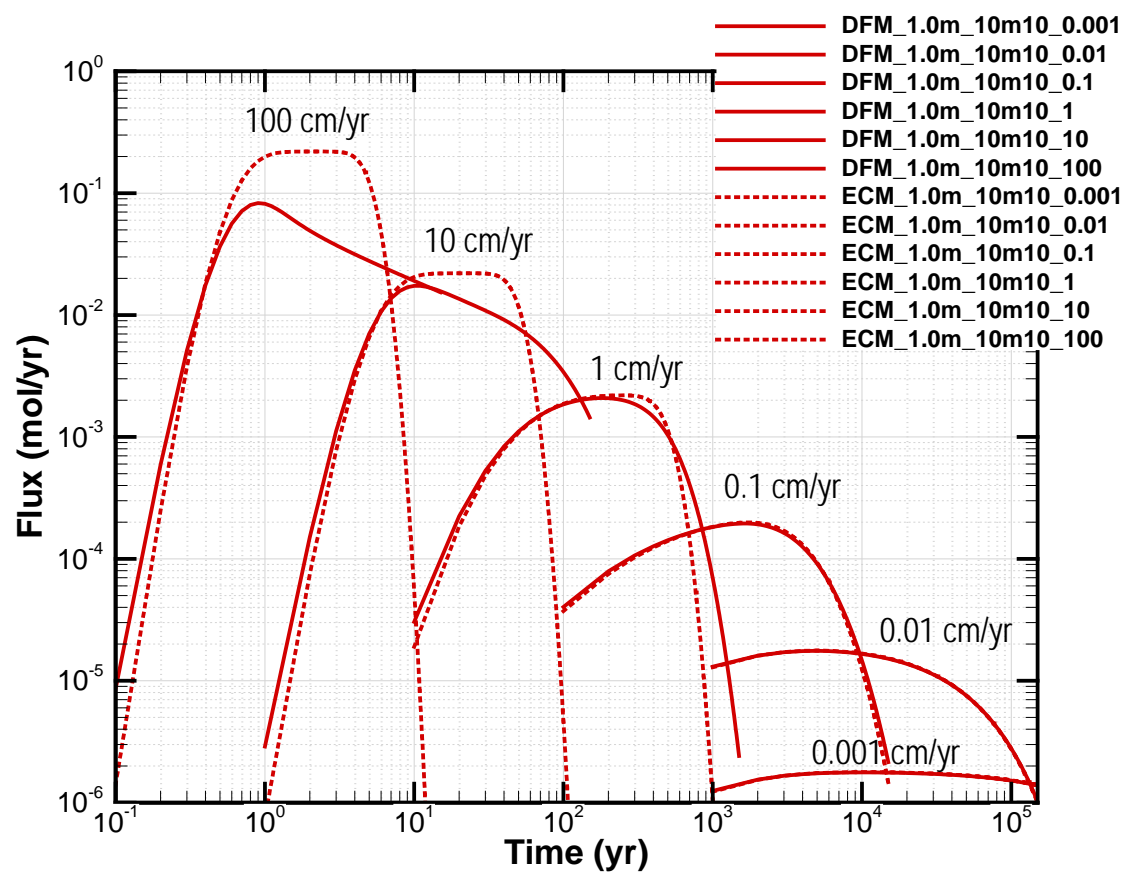

Figure 2-26. Tracer transport comparison for DFM and ECM simulations for a 1.0 meter fracture spacings and varying flow rates $(\mathrm{cm} / \mathrm{yr})$. 


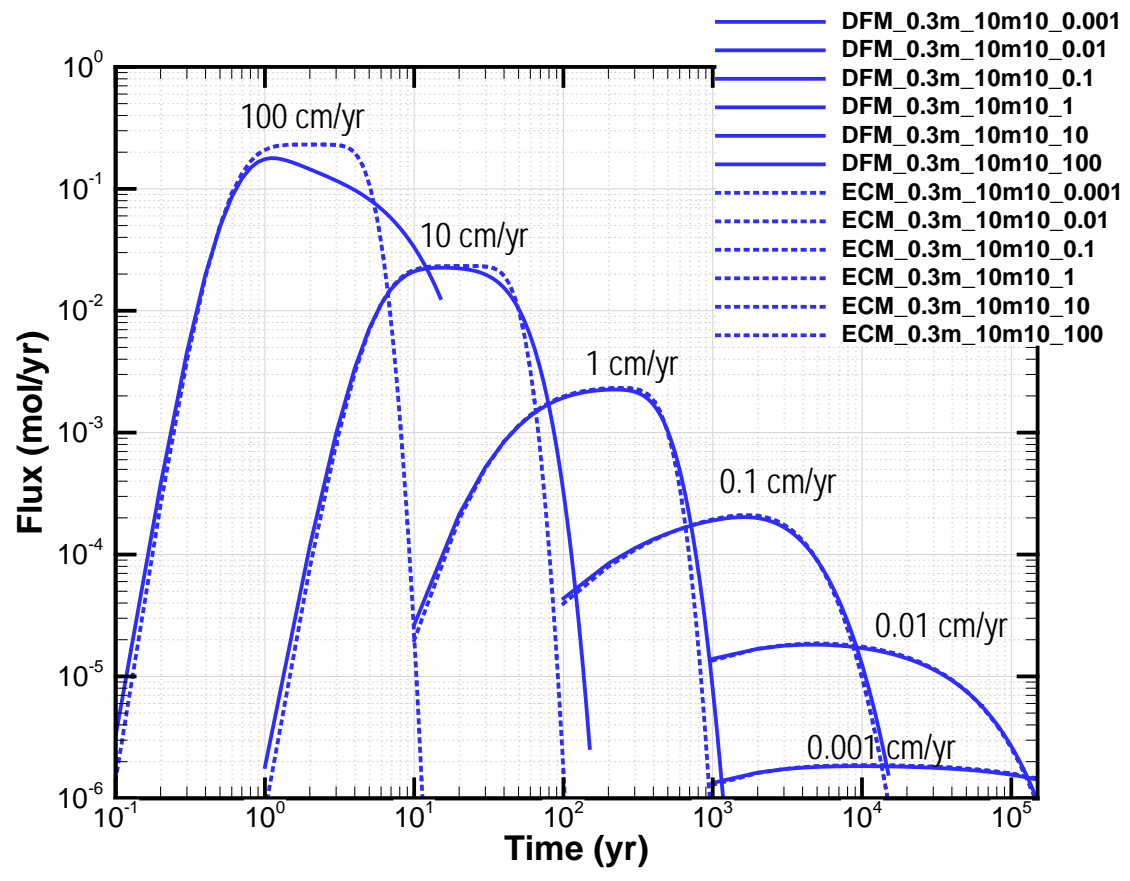

Figure 2-27. Tracer transport comparison for DFM and ECM simulations for a 0.3 meter fracture spacings and varying flow rates $(\mathrm{cm} / \mathrm{yr})$.

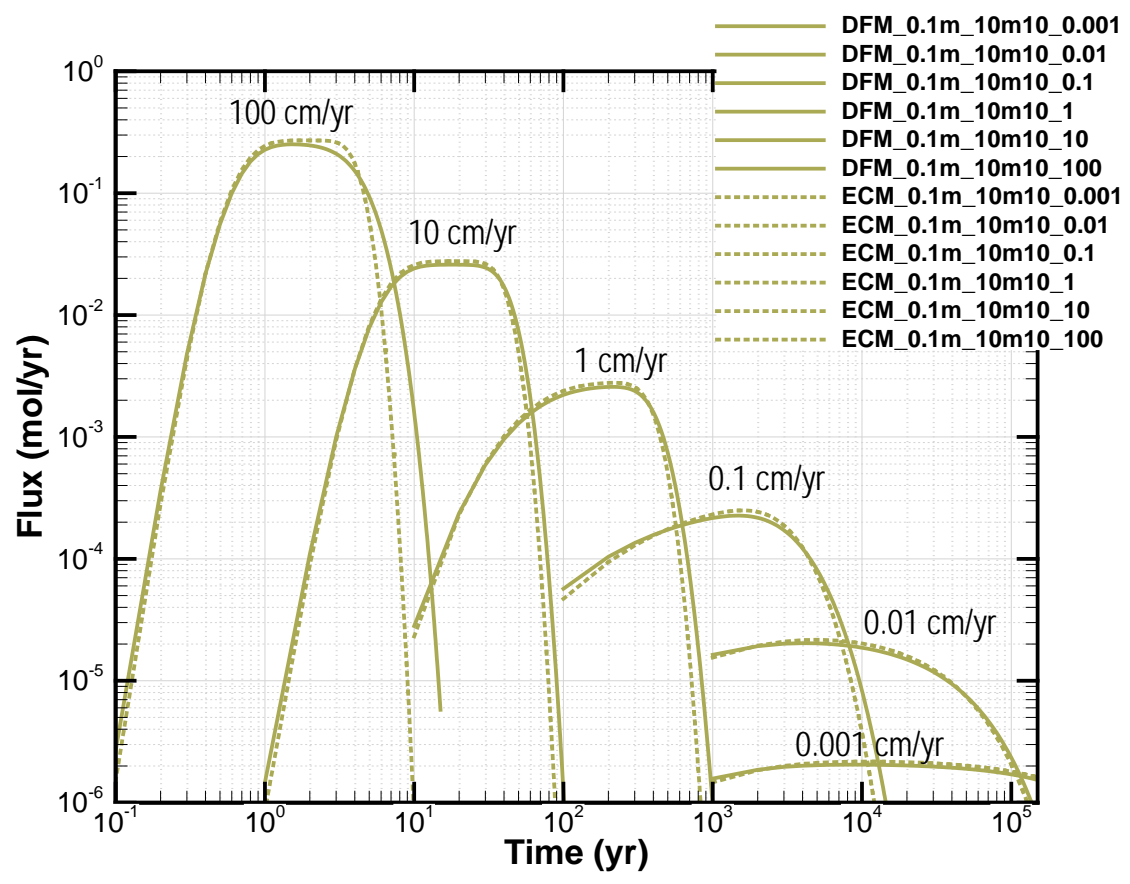

Figure 2-28. Tracer transport comparison for DFM and ECM simulations for a 0.1 meter fracture spacings and varying flow rates $(\mathrm{cm} / \mathrm{yr})$. 
Table 2-7. Damkohler numbers for various fracture spacings and infiltration rates.

\begin{tabular}{|c|c|c|c|c|c|c|c|c|c|c|c|c|c|}
\hline \multirow{2}{*}{$\begin{array}{c}\text { Damkohler No. } \\
\mathrm{Da}=\mathrm{t}_{\mathrm{a}} / \mathrm{t}_{\mathrm{d}}\end{array}$} & \multicolumn{3}{|c|}{ Longitudinal Advection } & \multirow[b]{2}{*}{0.02} & \multirow[b]{2}{*}{0.05} & \multirow[b]{2}{*}{0.1} & \multirow[b]{2}{*}{0.2} & \multirow[b]{2}{*}{0.5} & \multirow[b]{2}{*}{1} & \multirow[b]{2}{*}{2} & \multirow[b]{2}{*}{5} & \multirow[b]{2}{*}{10} & \multirow[b]{2}{*}{20} \\
\hline & $\mathrm{L}=8 \mathrm{~m}$ & $\mathrm{U}, \mathrm{cm} / \mathrm{yr}:$ & 0.01 & & & & & & & & & & \\
\hline $\mathrm{De}=1.0 \mathrm{E}-07 \mathrm{~cm} 2 / \mathrm{s}$ & $\mathrm{n}=0.58$ & $t_{a}(y r):$ & 46400 & 23200 & 9280 & 4640 & 2320 & 928 & 464 & 232 & 92.8 & 46.4 & 23.2 \\
\hline Lateral Diffusion & $t_{d}(y r):$ & & & & & & & & & & & & \\
\hline $2 \mathrm{~W}=0.1 \mathrm{~m}^{*}$ & 8 & & 5853 & 2927 & 1171 & 585 & 293 & 117 & 59 & 29 & 12 & 5.9 & 2.9 \\
\hline $0.2 \mathrm{~m}$ & 32 & & 1463 & 732 & 293 & 146 & 73 & 29 & 15 & 7.3 & 2.9 & 1.5 & 0.73 \\
\hline $0.3 \mathrm{~m}$ & 71 & & 650 & 325 & 130 & 65 & 33 & 13 & 6.5 & 3.3 & 1.3 & 0.65 & 0.33 \\
\hline $0.5 \mathrm{~m}$ & 198 & & 234 & 117 & 47 & 23 & 12 & 4.7 & 2.3 & 1.2 & 0.47 & 0.23 & 0.12 \\
\hline $0.7 \mathrm{~m}$ & 388 & & 119 & 60 & 24 & 12 & 6.0 & 2.4 & 1.2 & 0.60 & 0.24 & 0.12 & 0.060 \\
\hline $1 \mathrm{~m}$ & 793 & & 59 & 29 & 12 & 5.9 & 2.9 & 1.2 & 0.59 & 0.29 & 0.12 & 0.059 & 0.029 \\
\hline $2 \mathrm{~m}$ & 3171 & & 15 & 7.3 & 2.9 & 1.5 & 0.73 & 0.29 & 0.15 & 0.073 & 0.029 & 0.015 & 0.007 \\
\hline $3 \mathrm{~m}$ & 7135 & & 6.5 & 3.3 & 1.3 & 0.65 & 0.33 & 0.13 & 0.065 & 0.033 & 0.013 & 0.007 & 0.003 \\
\hline $5 \mathrm{~m}$ & 19819 & & 2.3 & 1.2 & 0.47 & 0.23 & 0.12 & 0.047 & 0.023 & 0.012 & 0.005 & 0.002 & 0.001 \\
\hline $7 \mathrm{~m}$ & 38844 & & 1.2 & 0.60 & 0.24 & 0.12 & 0.060 & 0.024 & 0.012 & 0.006 & 0.002 & 0.001 & 0.001 \\
\hline $10 \mathrm{~m}$ & 79274 & & 0.59 & 0.29 & 0.12 & 0.059 & 0.029 & 0.012 & 0.006 & 0.003 & 0.001 & 0.001 & 0.0003 \\
\hline * fracture spacing & & & & & & & & & & & & & \\
\hline
\end{tabular}

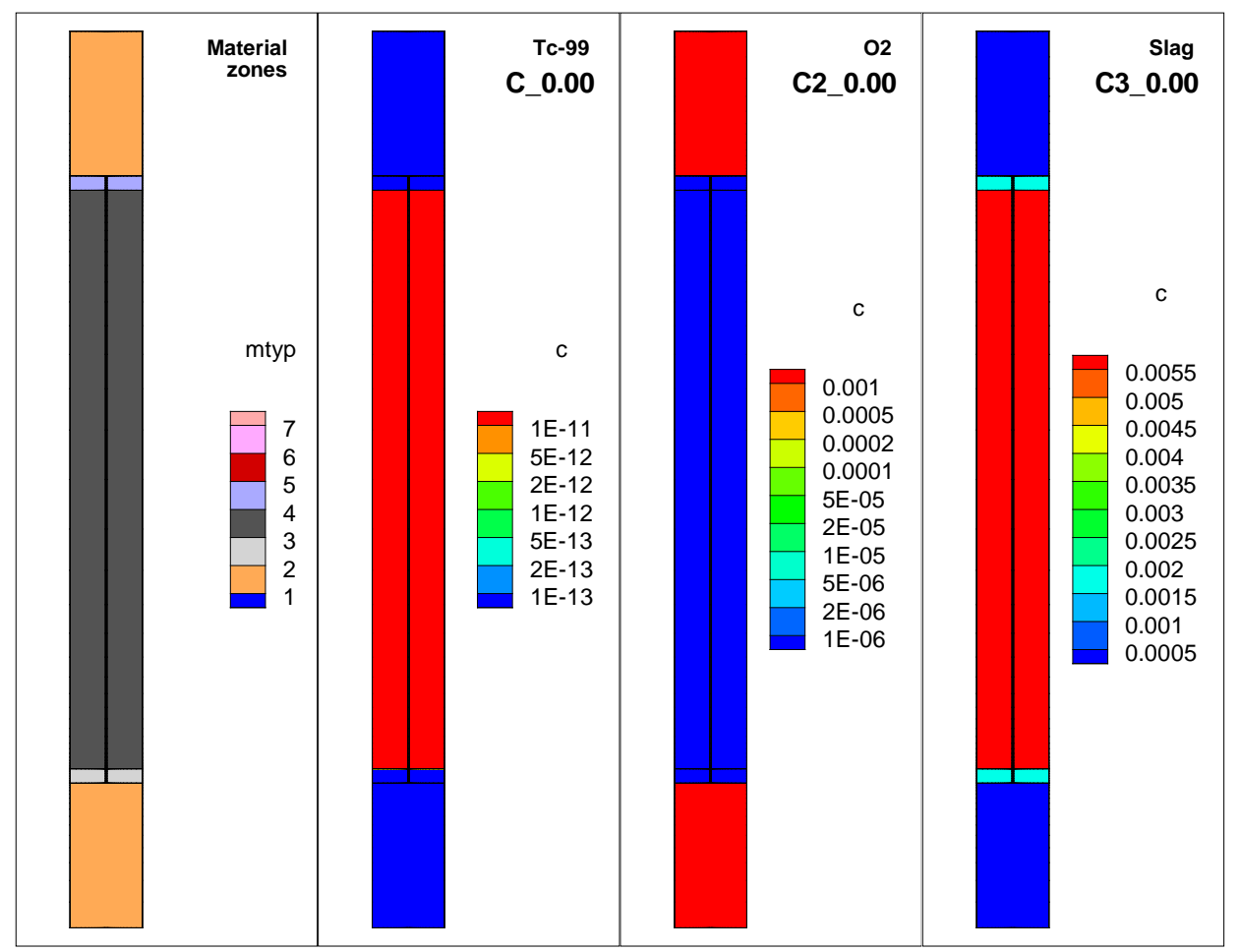

Figure 2-29. Initial conditions for slag oxidation and Tc-99 transport simulations. 
SRNL-STI-2013-00280, REVISION 0

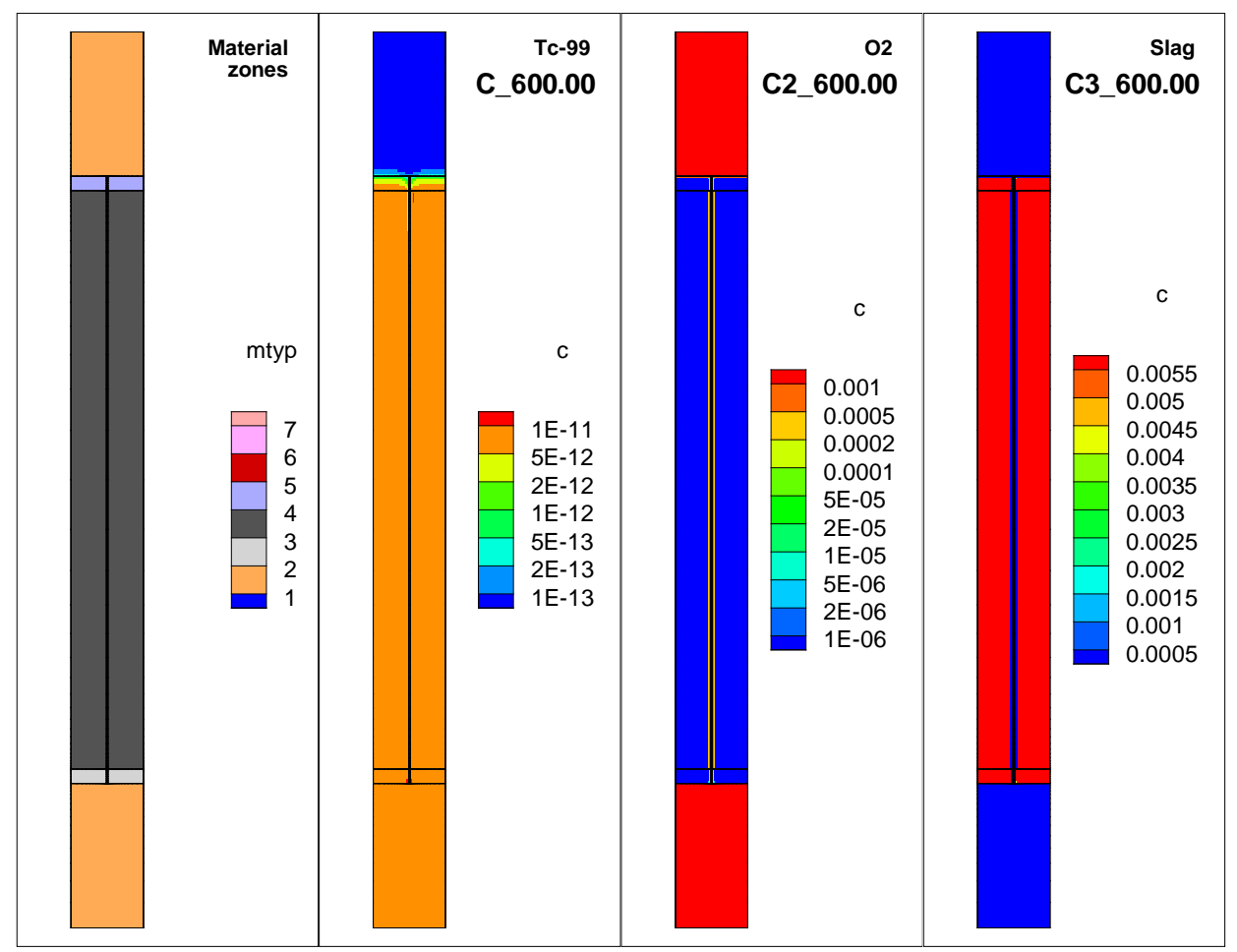

(a)

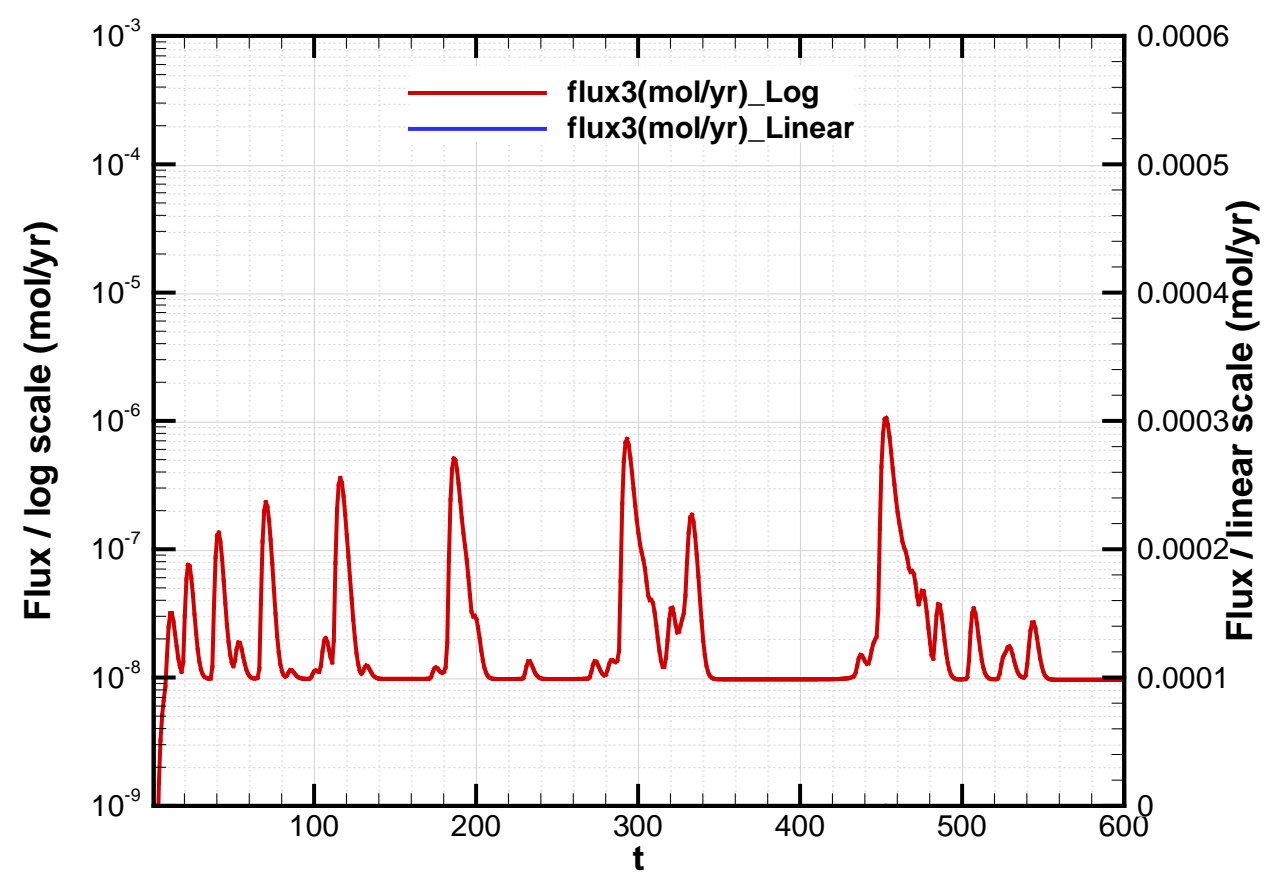

(b)

Figure 2-30. DFM simulation of slag oxidation and Tc-99 transport: (a) concentrations at 600 yrs, and (b) flux. 
SRNL-STI-2013-00280, REVISION 0

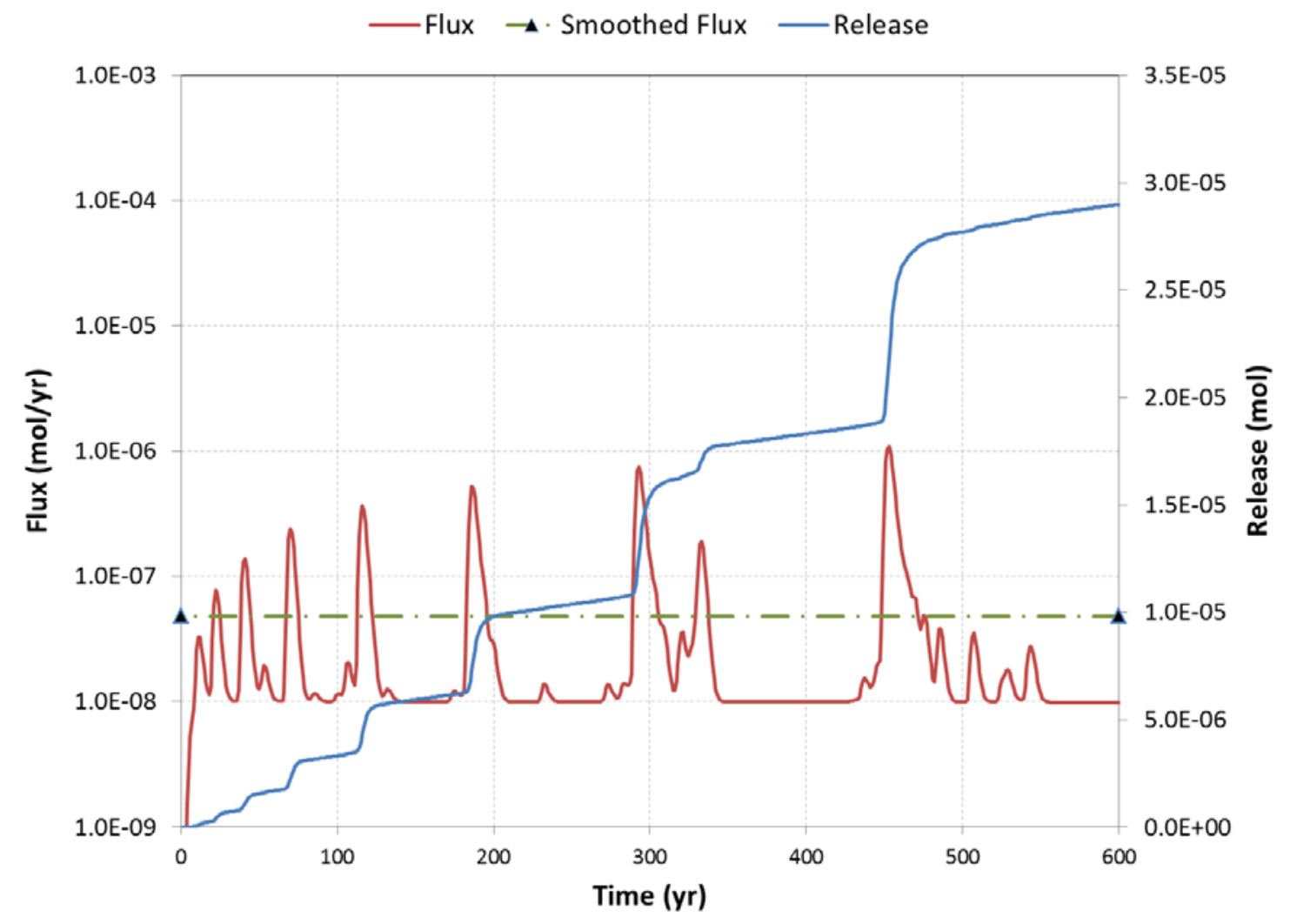

Figure 2-31. Cumulative release and average flux for DFM simulation of slag oxidation and Tc-99 transport. 
SRNL-STI-2013-00280, REVISION 0

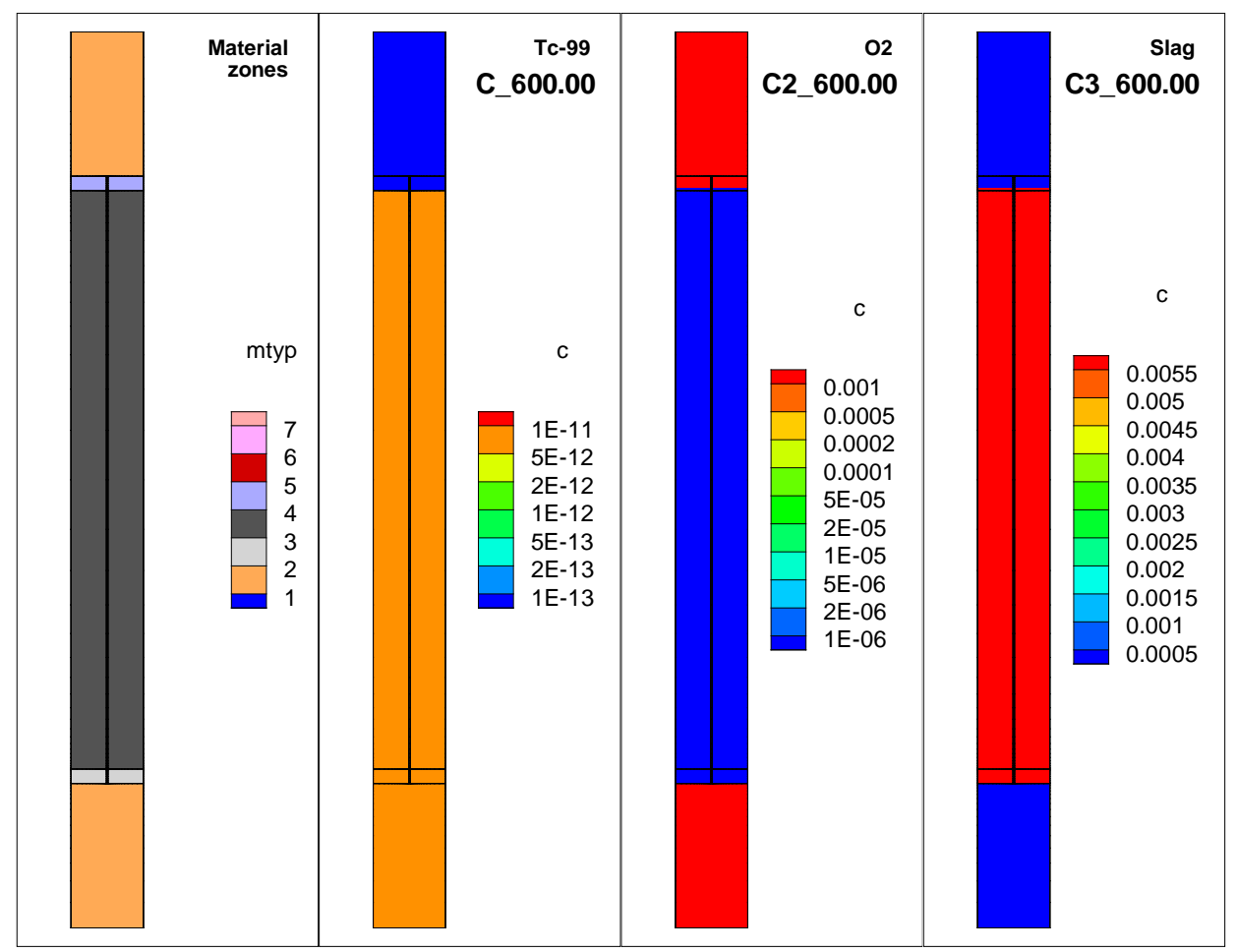

(a)

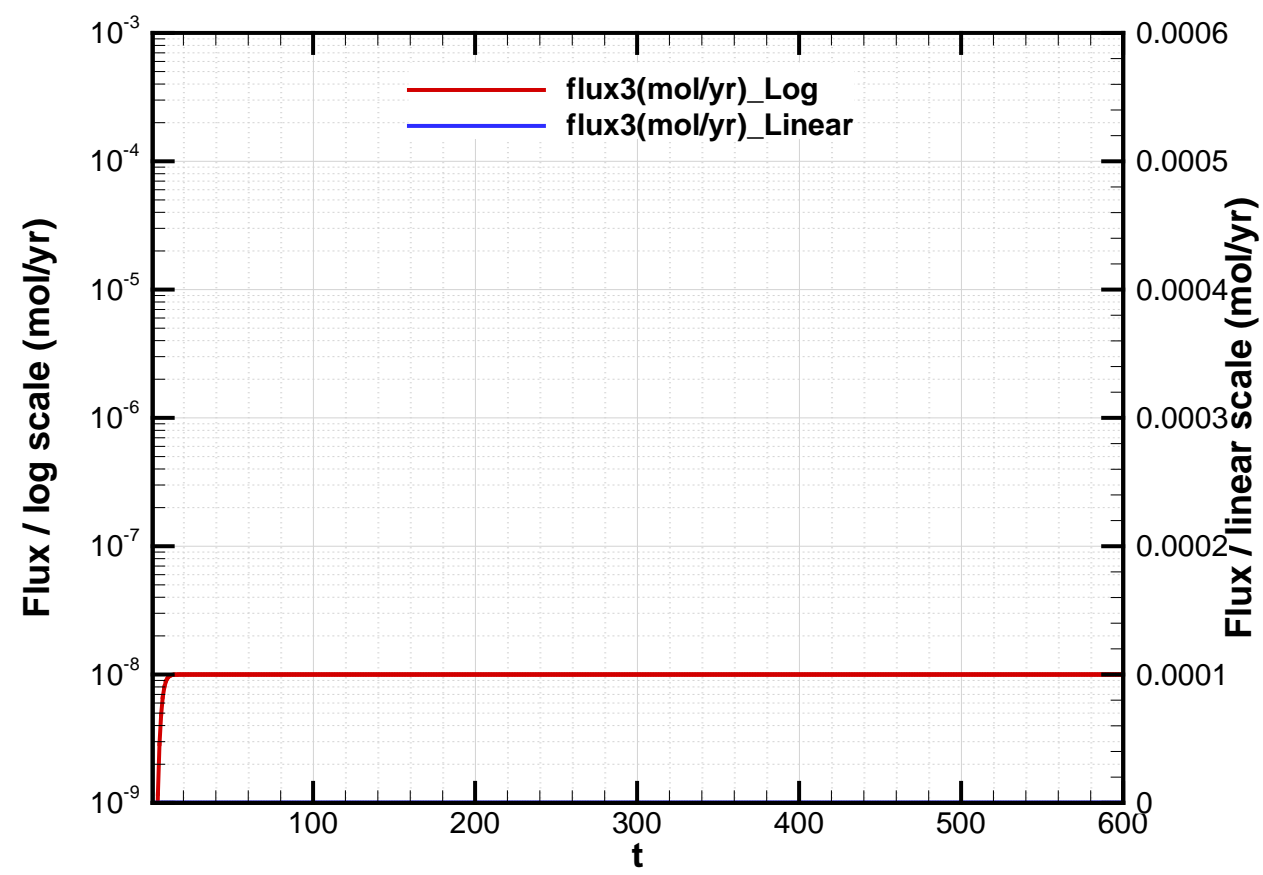

(b)

Figure 2-32. ECM simulation of slag oxidation and Tc-99 transport: (a) concentrations at 600 yrs, and (b) flux. 
SRNL-STI-2013-00280, REVISION 0

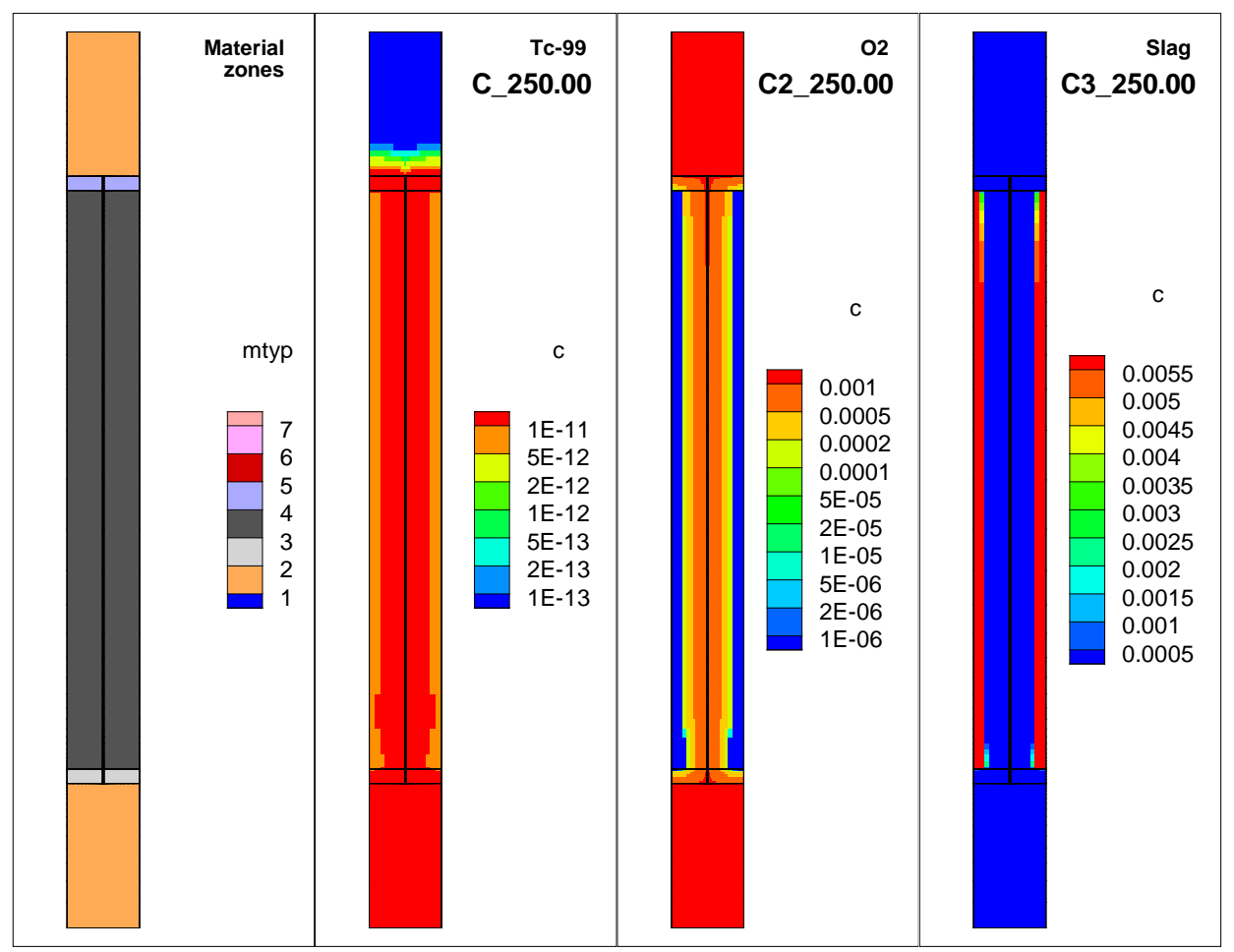

(a)

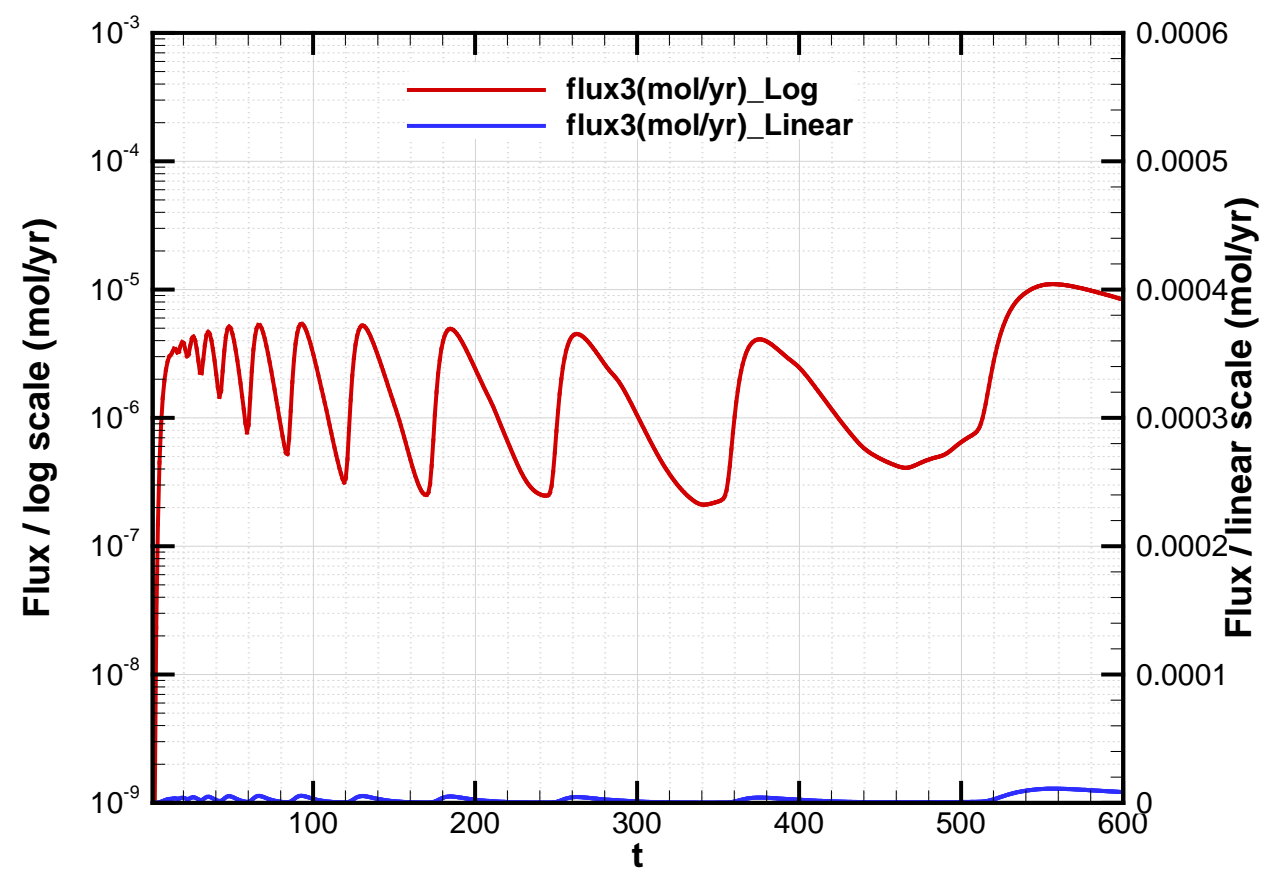

(b)

Figure 2-33. DFM simulation of slag oxidation and Tc-99 transport with 100x lower reduction capacities: (a) concentrations at 250 yrs, and (b) flux. 
SRNL-STI-2013-00280, REVISION 0

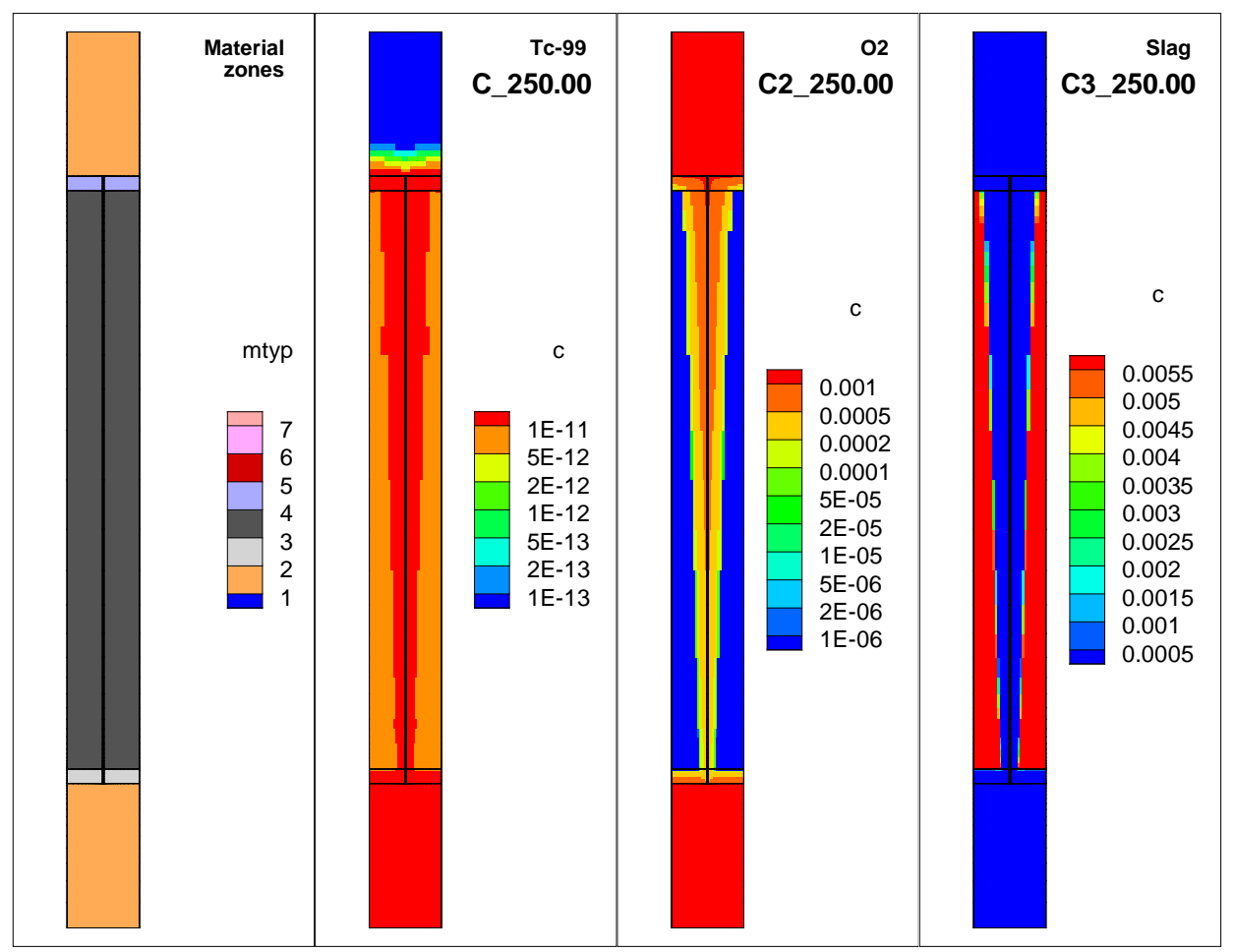

(a)

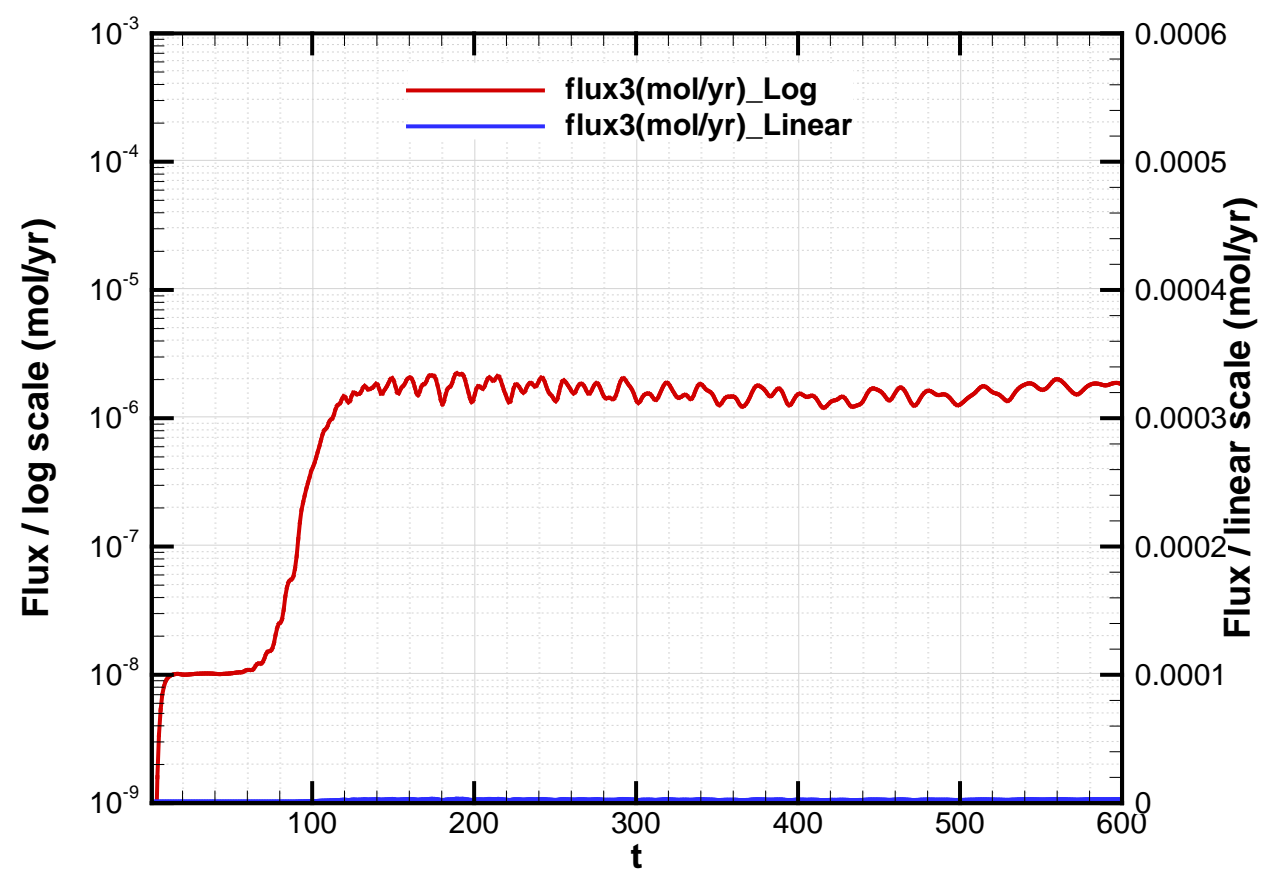

(b)

Figure 2-34. DFM simulation of slag oxidation and Tc-99 transport with 100x lower reduction capacities and no oxygen source in fracture: (a) concentrations at 250 yrs, and (b) flux. 
SRNL-STI-2013-00280, REVISION 0

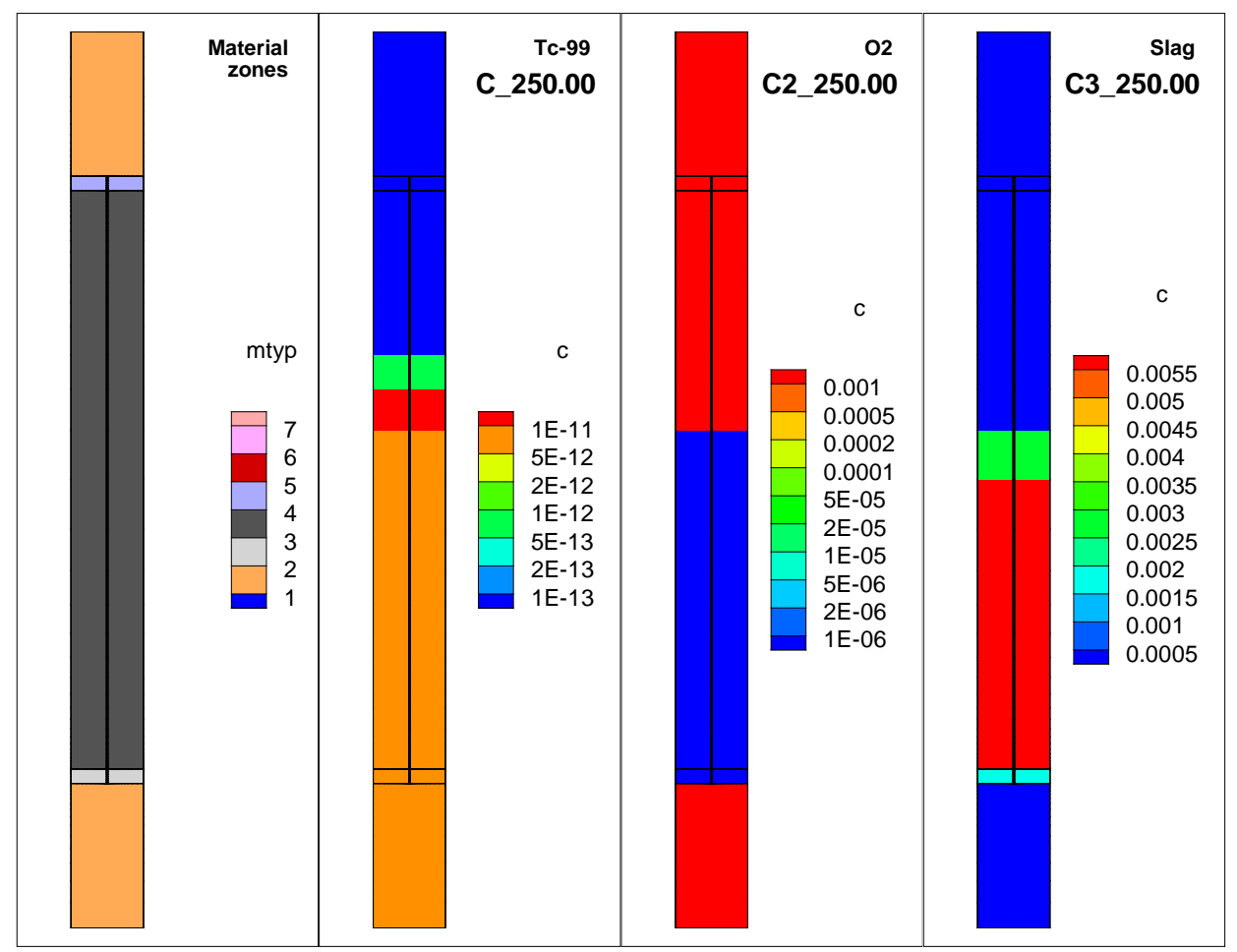

(a)

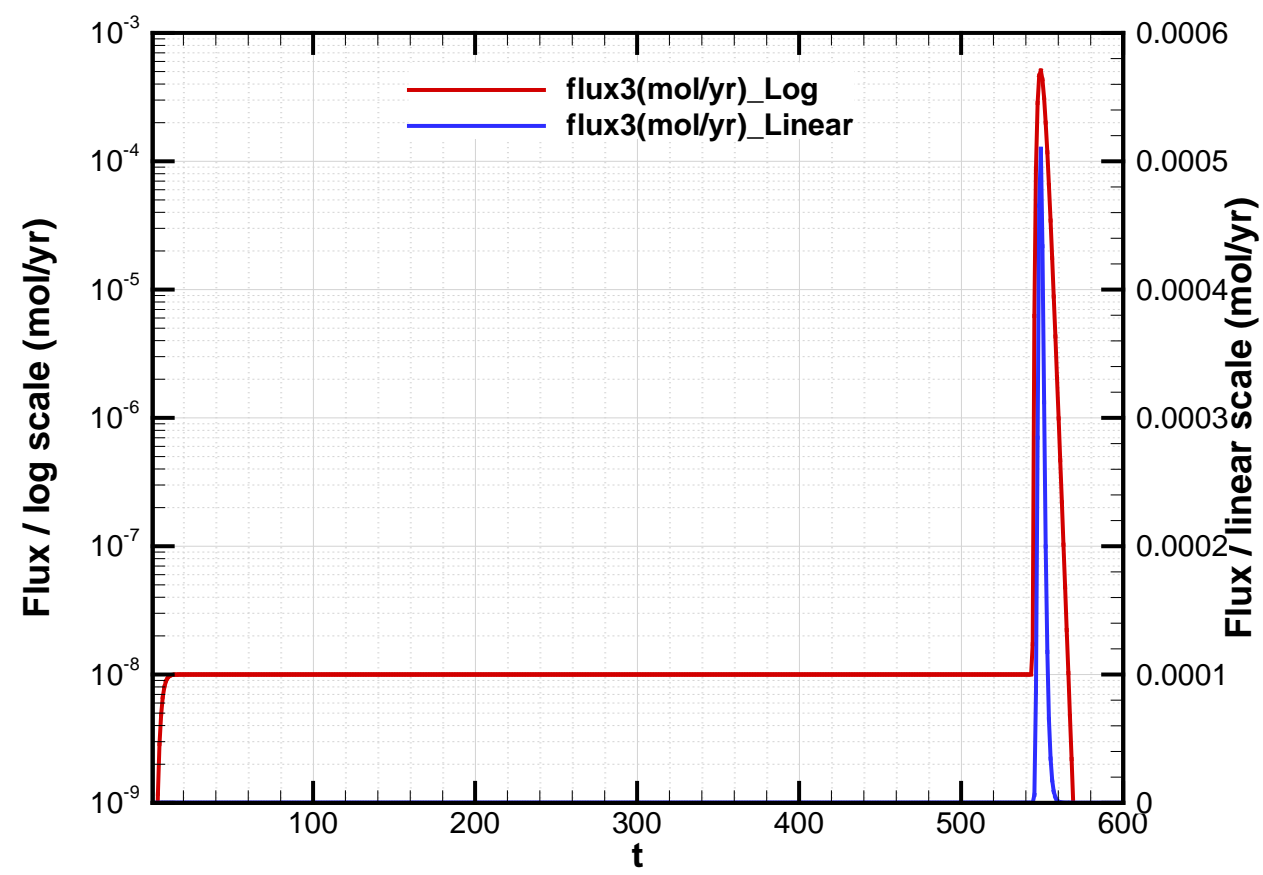

(b)

Figure 2-35. ECM simulation of slag oxidation and Tc-99 transport with 100x lower reduction capacities: (a) concentrations at 250 yrs, and (b) flux. 


\subsection{NOMINAL VALUE (NV) CASE}

As mentioned in the Introduction section, PORFLOW analyses supporting the Saltstone FY13 SA are based on the 2009 PA (SRR 2009, Flach et al. 2009), subsequent modeling to support a response to NRC RAI PA-8 (SRR 2011, Flach 2011), and perturbations to RAI PA-8 analysis defined by SRR (2013) and Sheppard (2013). Design checking of PORFLOW related analyses has been documented separately by Smith et al. (2013).

The sizable length to width aspect ratio of SDU 1 and 4 and the axisymmetric nature of SDU 2 are amenable to computationally efficient two-dimensional modeling. For the existing rectangular disposal units, a representative 2D cross-section was modeled, taking advantage of symmetry about the centerline and using Cartesian coordinates. For SDU 2, the model was created using a radial slice and cylindrical coordinates, assuming axisymmetric conditions. Figure 3-1 through Figure 3-6 illustrate the material zones and computational mesh chosen for each disposal unit type.

The disposal units are modeled in 2D numerical grids that reflect the actual dimensions of engineered materials, except in the case of the HDPE and HDPE/GCL liners and hypothetical fast flow paths. The 100 mil (0.1 inch) HDPE and 300 mil (0.3 inch) HDPE/GCL are modeled as being 1.0" thick to avoid numerical difficulties. Hydraulic conductivity perpendicular to these layers is increased by 10x and 3.33x respectively, in order to preserve the physical leakance of the materials. Sheet drain (SDU 2, 4) and crack (SDU 1, 4) features are modeled as being 2.0 inch thick. Equivalent columns and floor joints dimensions were also used.

The model grids are divided up into different material zones. Material properties as assigned based on the zonal name definitions. Some material zones that were used in prior saltstone modeling, such as the COLUMN zone, are not used for this modeling. The previous COLUMN zone was divided into 2-foot sections and replaced with the zones FF_GROUT1, FF_GROUT2, FF_GROUT3, etc. The full list of material zone names and their usage in the different models are listed in Table 3-1.

For each time interval, material properties are generally assigned to a material zone by specifying a material from a palette, and two time-dependent multipliers to the base value. The value used for a time interval is the base value times two time dependent factors, averaged over the time period. The factors are defined by linear interpolation of discrete data pairs. By convention, the first factor is used to change property values due to degradation. The second factor is used to correct for differences between physical and model geometry (e.g. HDPE thickness discussed above). Often both factors are 1.0 (e.g backfilled soil). A different approach is taken for cementitious materials that are assigned blended properties: the blending fractions are based on the midpoint time of each time period rather than an average across the time period. Key material properties and their degradation through time are shown in Figure 3-7 through Figure 3-9.

A few deviations from the modeling specifications (Sheppard 2013; SRR 2009, 2011, 2013; Flach et al. 2009) occurred in PORFLOW implementations. The most notable 
differences are the SDU 2 upper mudmat and SDU 1/4 wall components being initialized to an oxidized state for non-Tc transport simulations; however, these components are in a reduced condition at time zero, as intended, for Tc-99 transport simulations. Many species are insensitive to redox conditions. I-129 and Ra-226 are redox sensitive and follow-on runs with the SDU 2 upper mudmat having a reduced state at time zero were made. Little impact to water table flux was observed. Other discrepancies were less significant and noted by Smith et al. (2013).

\subsection{Flow Runs}

The flow cases were run as a series of steady state runs, to avoid the computational cost of fully transient simulations. The time periods for steady-state simulation were chosen to align with key material property changes where feasible, thus minimizing the number of property transitions occurring within time periods. The flow simulations were run out 100,000 years. The flowrates for various key zones are plotted in Figure 3-10 through Figure 3-12.

At the outset of the flow simulation for SDU 1, the sand drain sheds much of the flow away from the disposal unit. There is also high flow through the external wall, which is fully degraded at time zero in the model. As materials begin to degrade, flow increases through the disposal unit interior, especially through the joints. For SDU 2, flow increases initially through the column as it fails more quickly than the saltstone. This creates a faster flow path through the system. For SDU 4, there is high initial flow through the wall as it, like SDU 1, begins in a degraded state. As various segments of the column fail, there is much higher flow through these regions. As time progresses and saltstone begins to degrade, the flow becomes more uniform.

Further results and discussion are contained in the FY13 SA (SRR 2013), in particular doses and their significance to performance measures. 
SRNL-STI-2013-00280, REVISION 0

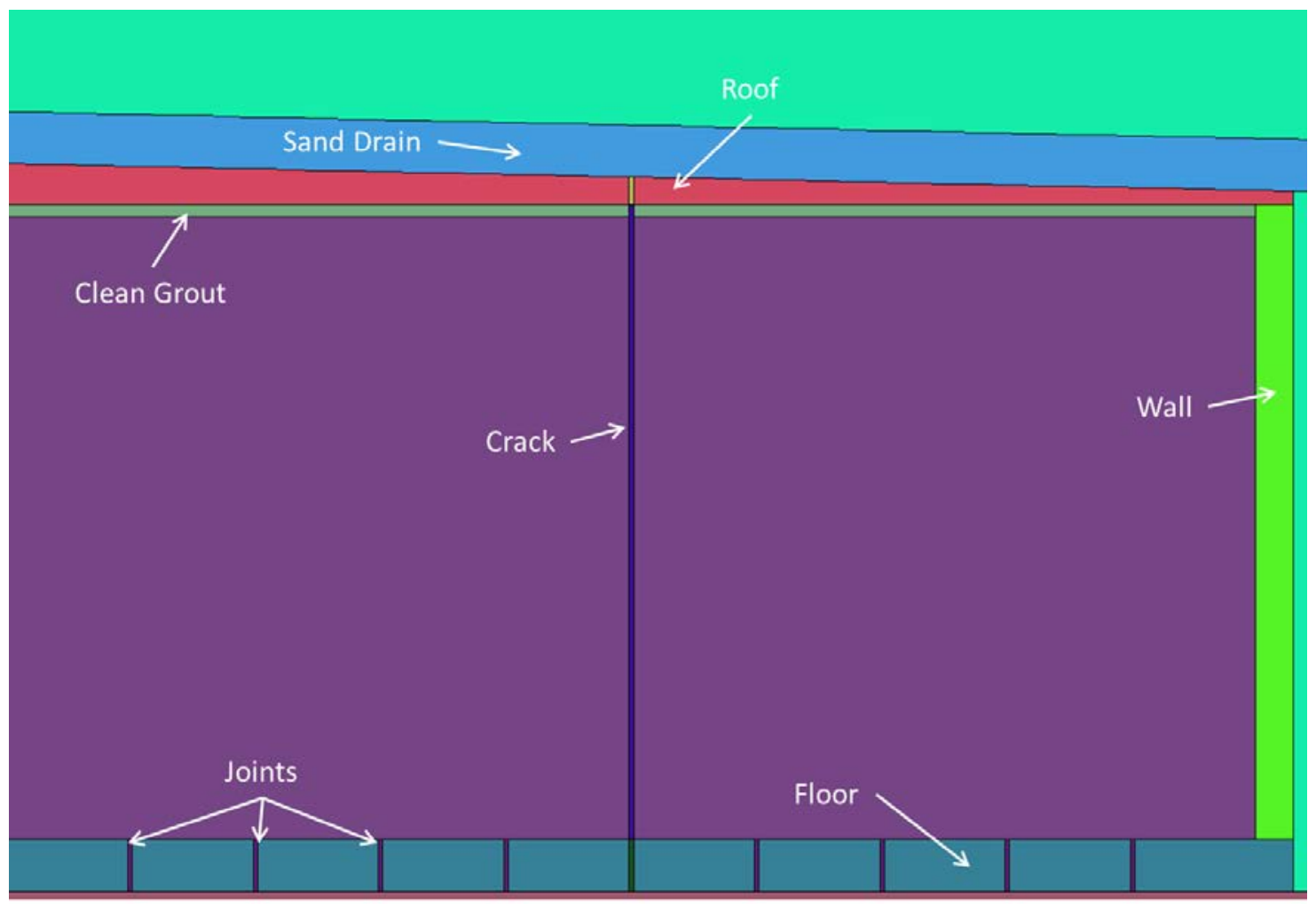

Figure 3-1. SDU 1 material zones.

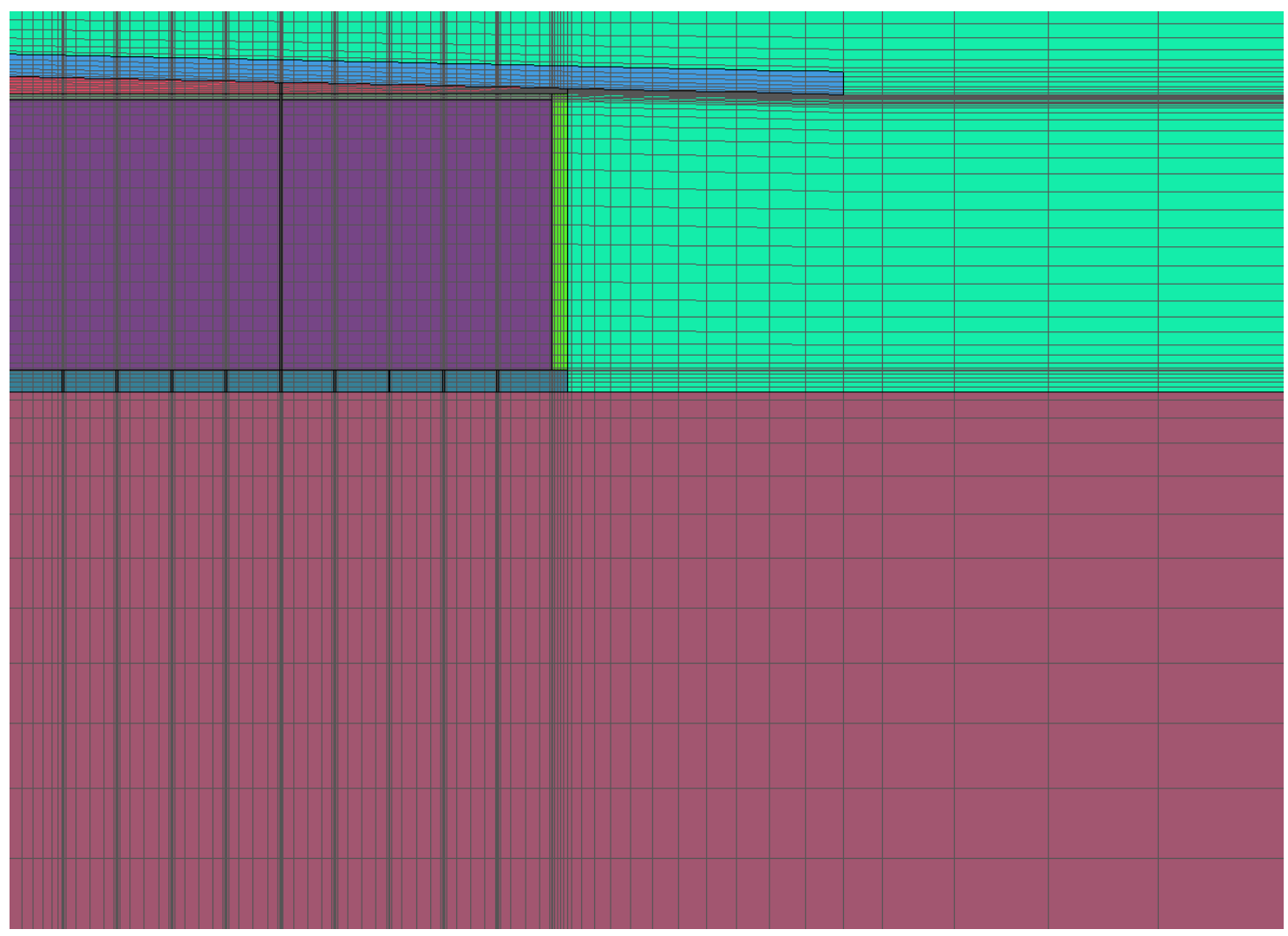

Figure 3-2. SDU 1 computational mesh. 
SRNL-STI-2013-00280, REVISION 0

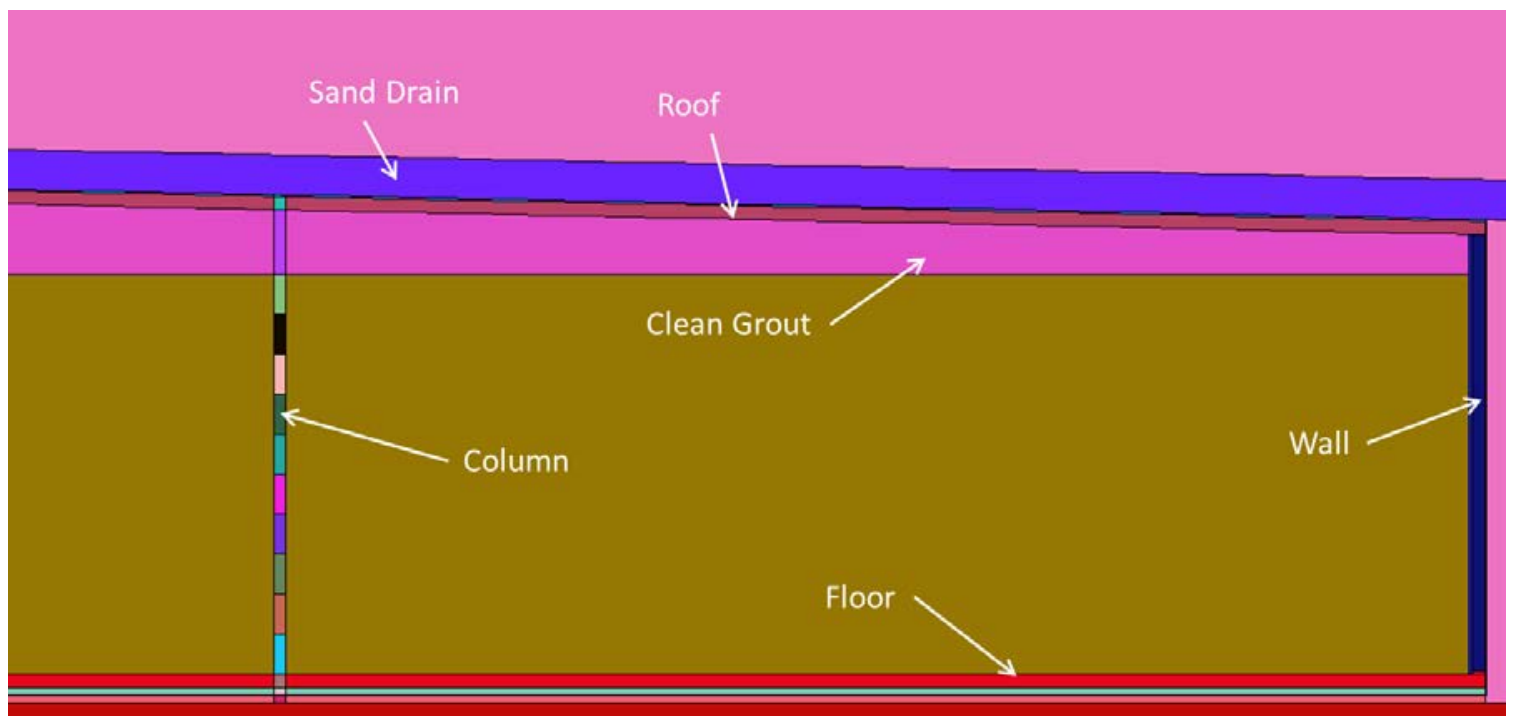

Figure 3-3. SDU 2 material zones.

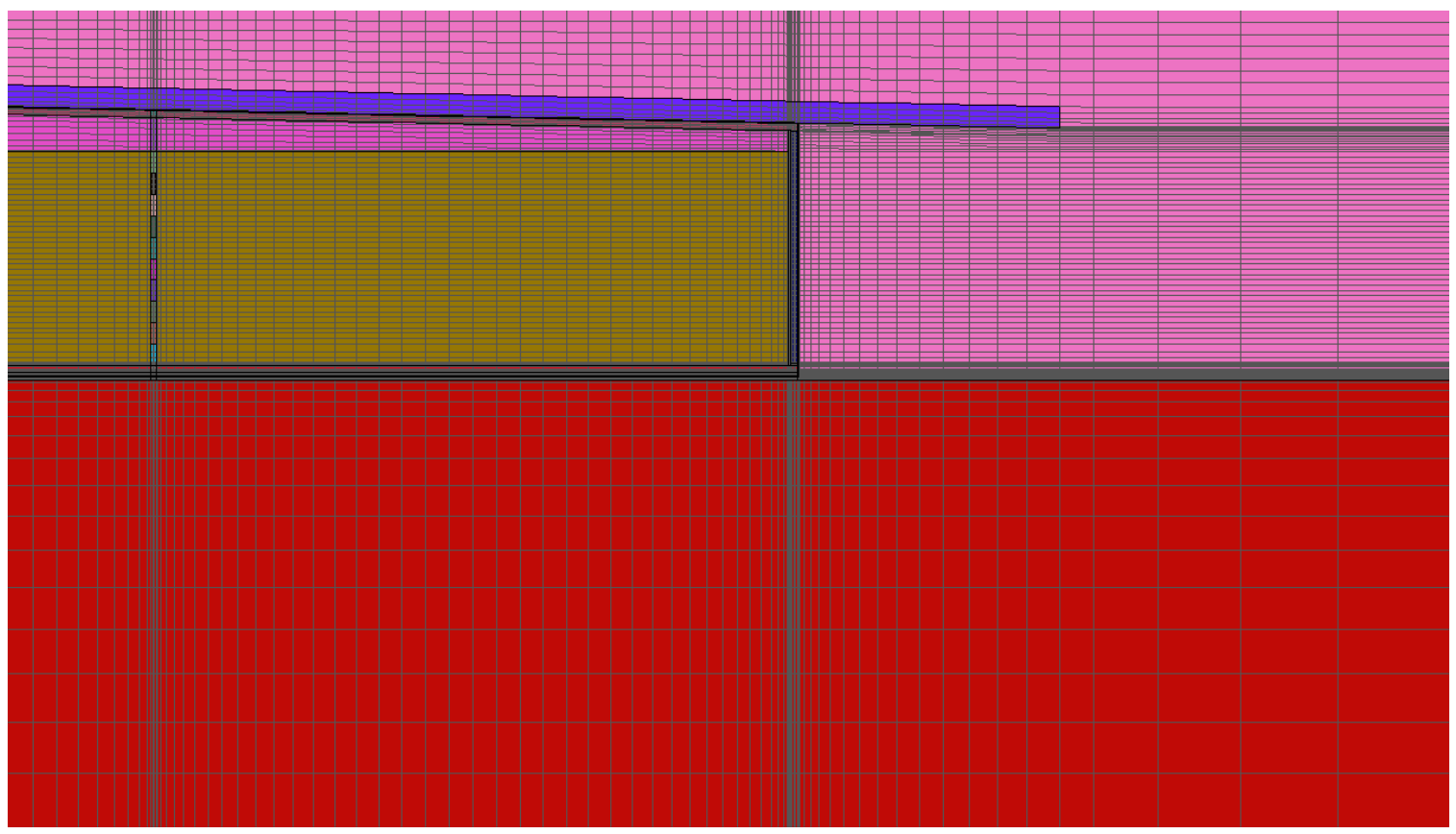

Figure 3-4. SDU 2 computational mesh. 


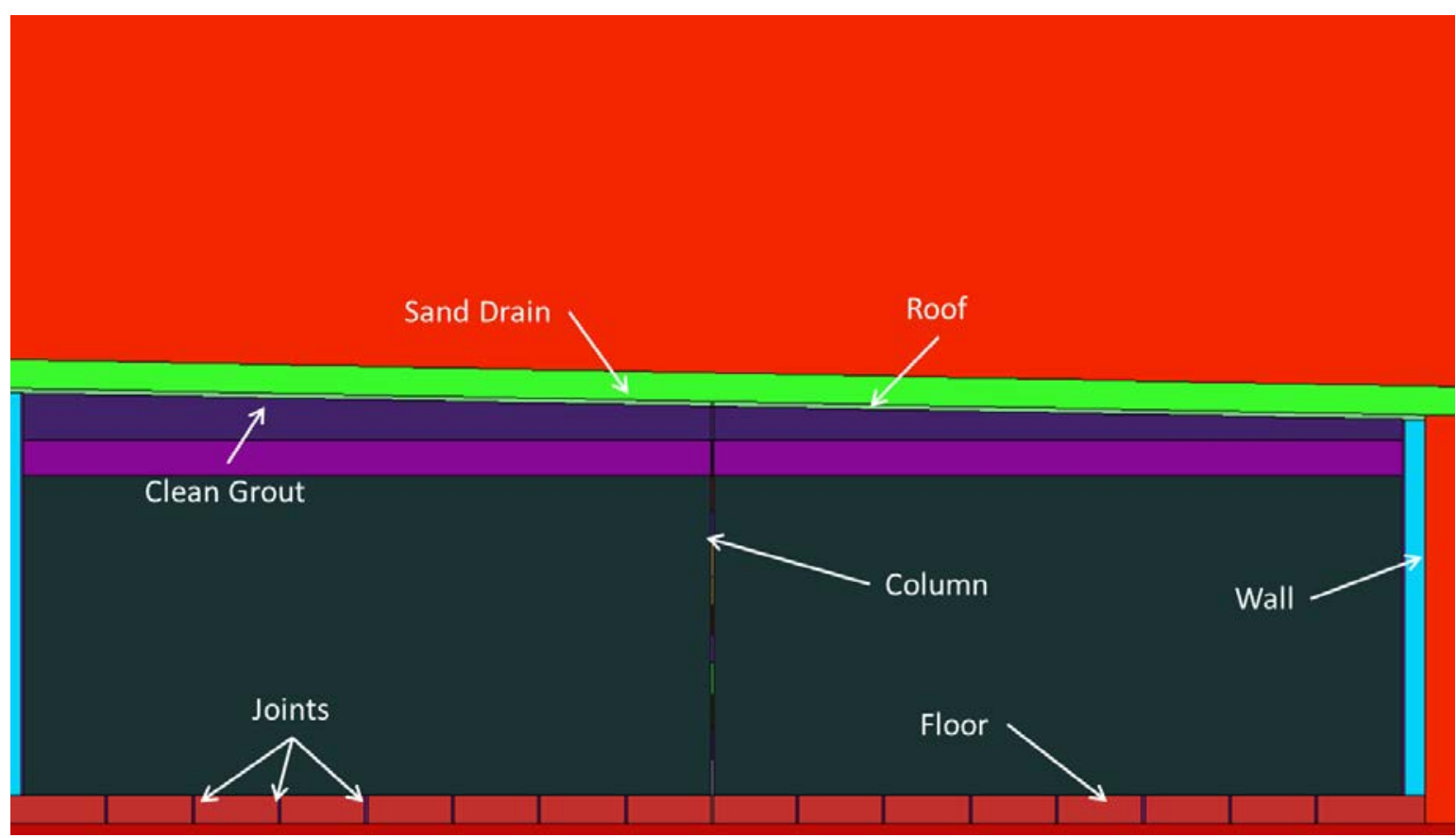

Figure 3-5. SDU 4 material zones.

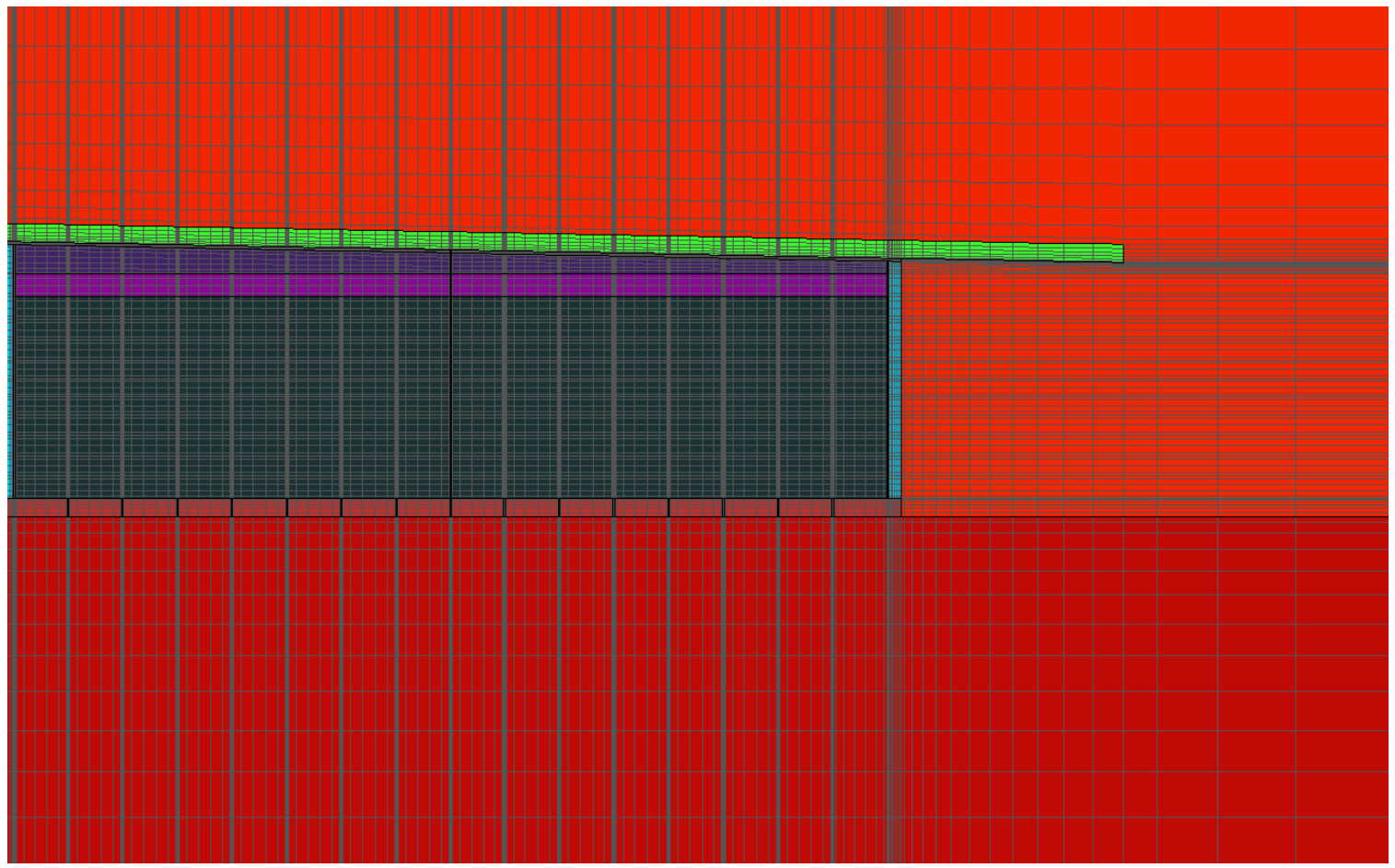

Figure 3-6. SDU 4 computational mesh. 
Table 3-1. Material zone usage.

\begin{tabular}{|c|c|c|c|}
\hline Zone Name & SDU 1 & SDU 2 & SDU 4 \\
\hline NATIVE_SOIL & $\mathrm{X}$ & $\mathrm{X}$ & $\mathrm{X}$ \\
\hline BACKFILL & $\mathrm{X}$ & $x$ & $\mathrm{X}$ \\
\hline LOWER_MUD_MAT & & $x$ & \\
\hline SHOT_CRETE & \multicolumn{3}{|c|}{ Not Used } \\
\hline UPPER_MUD_MAT & & $x$ & \\
\hline FLOOR & $x$ & $x$ & $x$ \\
\hline SALTSTONE & $x$ & $x$ & $x$ \\
\hline CLEAN_GROUT & & $x$ & $x$ \\
\hline HDPE & & $x$ & \\
\hline SHEET_DRAIN & & $x$ & $x$ \\
\hline WALL & $x$ & $x$ & $x$ \\
\hline DIAPHRAGM & \multicolumn{3}{|c|}{ Not Used } \\
\hline FLOOR_HDPE_GCL & & $x$ & \\
\hline ROOF & $x$ & $x$ & $x$ \\
\hline ROOF_HDPE_GCL & & $x$ & \\
\hline SAND_DRAIN & $x$ & $x$ & $x$ \\
\hline CRACK & $x$ & & \\
\hline COLUMN & \multicolumn{3}{|c|}{ Not Used } \\
\hline JOINT & $x$ & $x$ & $x$ \\
\hline FF_ROOF & $x$ & $x$ & $x$ \\
\hline FF_GROUT1 & & $x$ & $\mathrm{x}$ \\
\hline FF_GROUT2 & & $x$ & $x$ \\
\hline FF_GROUT3 & & $x$ & $\mathrm{x}$ \\
\hline FF_GROUT4 & & $x$ & $\mathrm{x}$ \\
\hline FF_GROUT5 & & $x$ & $\mathrm{X}$ \\
\hline FF_GROUT6 & & $x$ & $x$ \\
\hline FF_GROUT7 & & $x$ & $x$ \\
\hline FF_GROUT8 & & $x$ & $x$ \\
\hline FF_GROUT9 & & $x$ & $x$ \\
\hline FF_GROUT10 & & $x$ & $x$ \\
\hline FF_GROUT11 & & $x$ & $x$ \\
\hline FF_GROUT12 & & & $x$ \\
\hline FF_GROUT13 & \multicolumn{3}{|c|}{ Not Used } \\
\hline FF_FLOOR & $x$ & $\mathrm{X}$ & $\mathrm{X}$ \\
\hline COL_BOTTOM & \multicolumn{3}{|c|}{ Not Used } \\
\hline OX_CRACK & \multicolumn{3}{|c|}{ Not Used } \\
\hline TOP_SALTSTONE & & & $x$ \\
\hline FF_ROOF_HDPE & & $x$ & \\
\hline FF_FLOOR_HDPE & & $x$ & \\
\hline FF_LOWER_MUD & & $\mathrm{X}$ & \\
\hline FF_UPPER_MUD & & $\mathrm{X}$ & \\
\hline
\end{tabular}




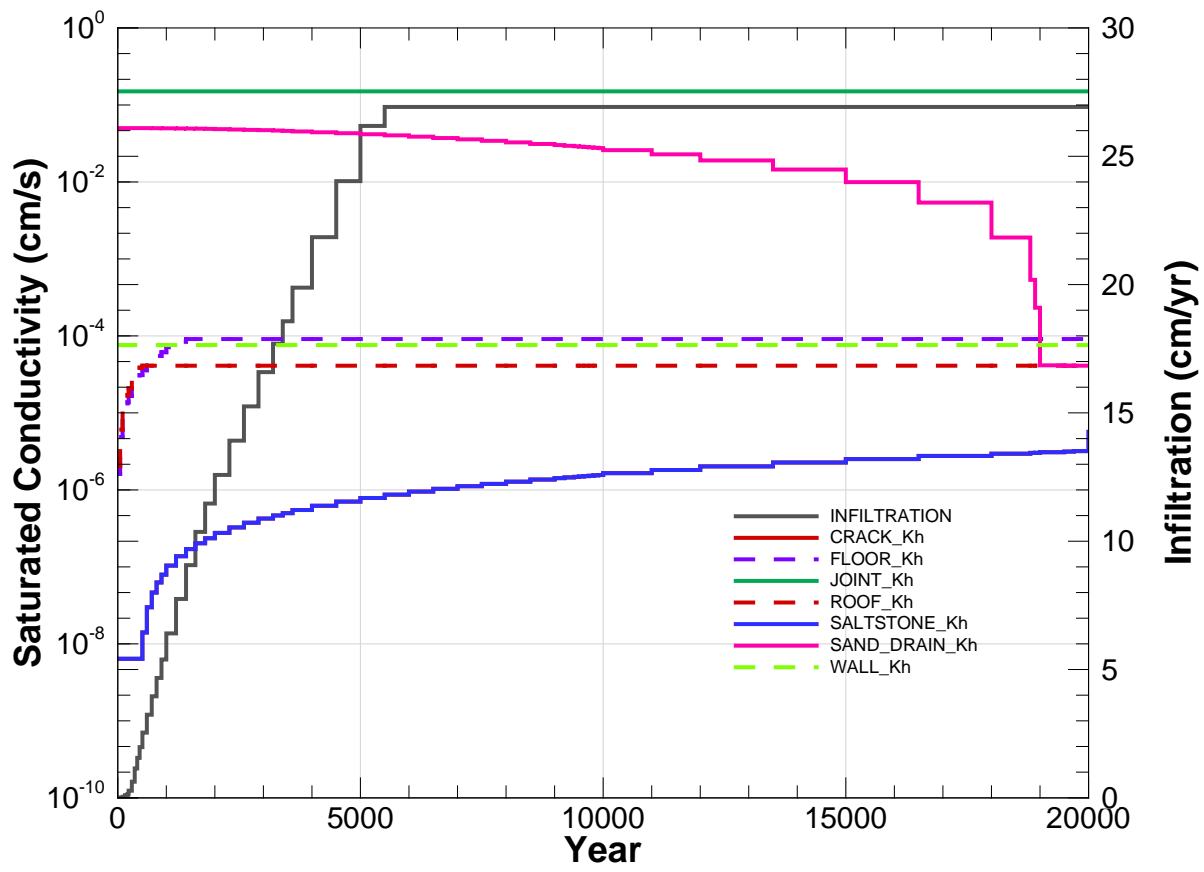

Figure 3-7. Material property timeline for SDU 1 and nominal (NV) case.

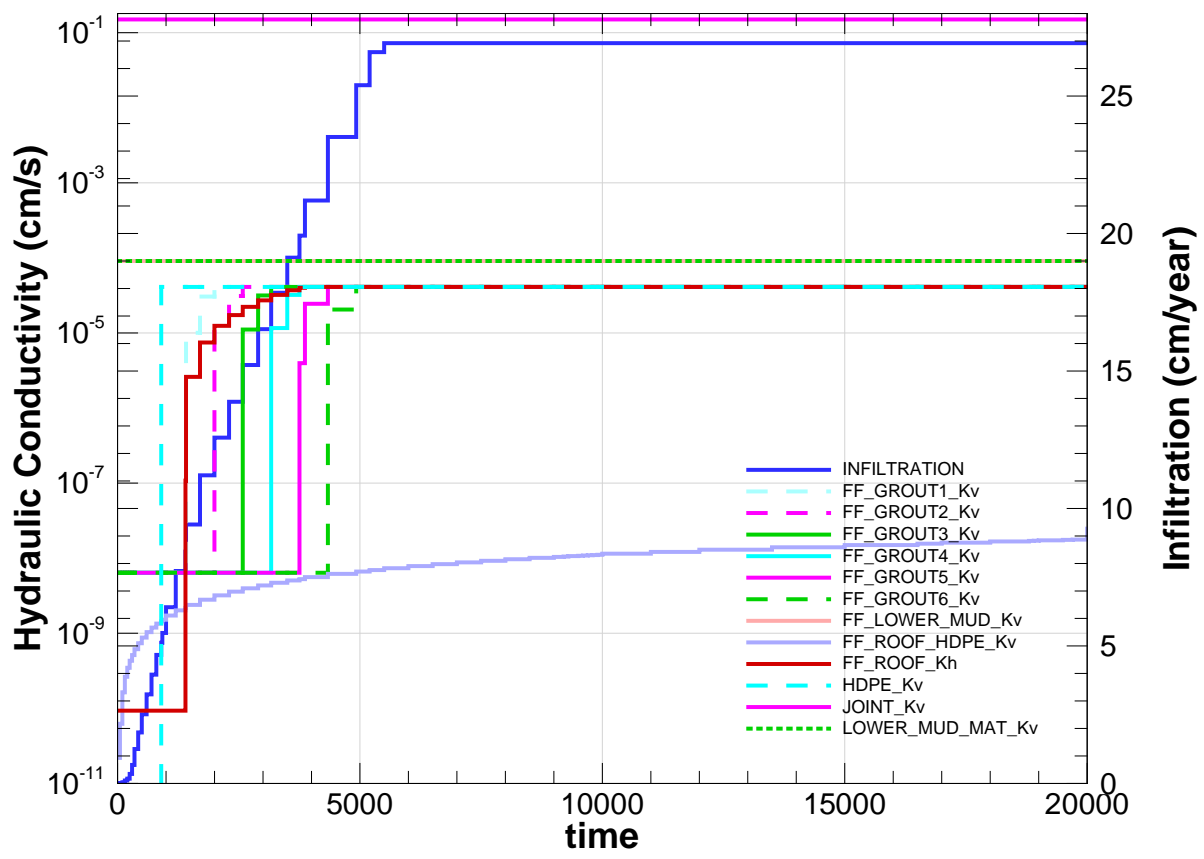

Figure 3-8. Material property timeline for SDU 2 and nominal (NV) case. 


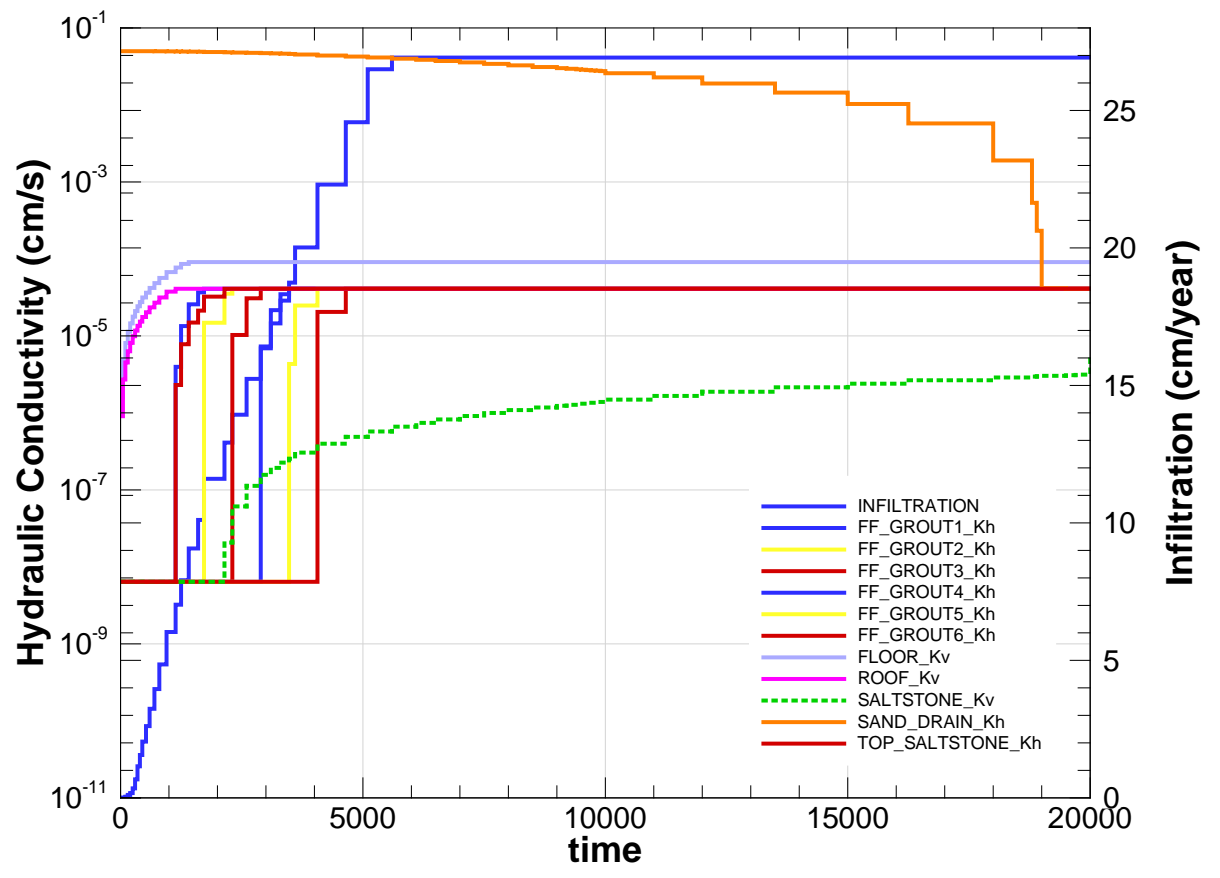

Figure 3-9. Material property timeline for SDU 4 and nominal (NV) case.

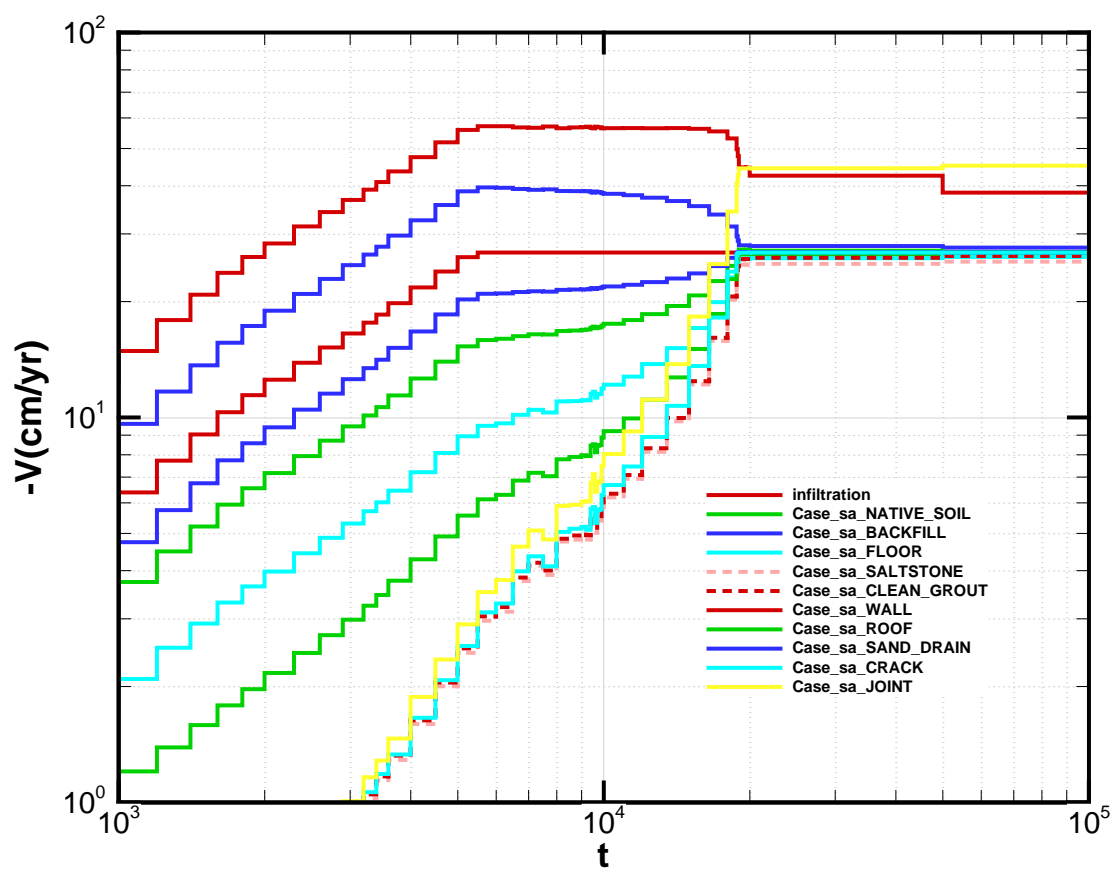

Figure 3-10. SDU 1 flow rates for nominal (NV) case. 


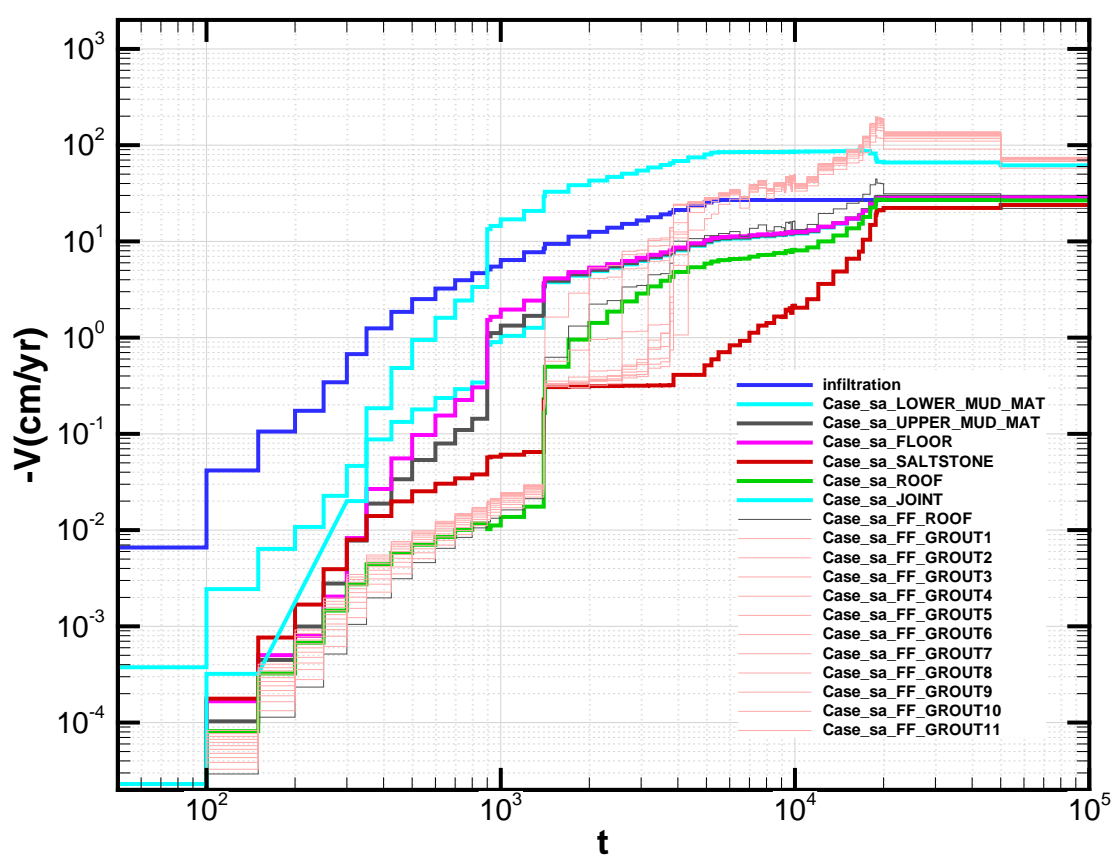

Figure 3-11. SDU 2 flow rates for nominal (NV) case.

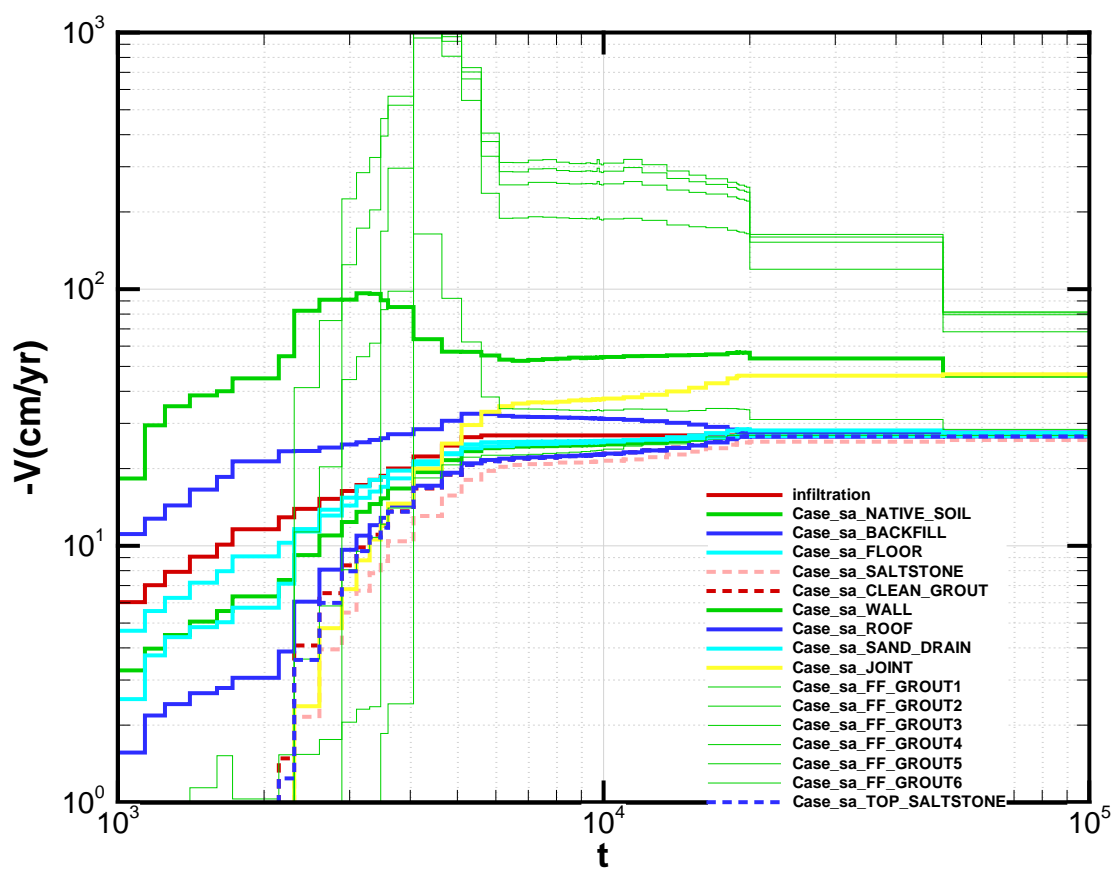

Figure 3-12. SDU 4 flow rates for nominal (NV) case. 


\subsection{Transport Runs}

Flow cases were evaluated and the pore volumes counted to determine the chemical transition times for the different material zones. These transition times, from reducing moderate to oxidized moderate and from oxidized moderate to oxidized aged, trigger changes in $K_{d}$ within cementitious material zones for the transport runs. For soils, the Eh transition time is not applicable and the $\mathrm{pH}$ transition time refers to a switch from cement leachate impacted $K_{d}$ to non-leachate $K_{d}$ based on the chemical state of saltstone from which contaminant species originate. All species use these Eh and $\mathrm{pH}$ transition times except for Tc-99, for which a transition from reduced-moderate to oxidized-aged conditions is based on the shrinking core model presented in Section 2.5. The relevant transition times for the different disposal units are shown in Table 3-2 through Table 3-4.

The flux to the water table, which corresponds to the bottom of the model domain, was determined for each set of species. Of particular note due to its importance in terms of dose is Tc-99. As discussed, the analysis for Tc-99 uses a shrinking core model which also allows solubility to be taken into account. For SDU 1 and SDU 2, there is a steady increase in Tc-99 throughout the 20,000 year time period. For SDU 4, the flux to the water table plateaus around 5,000 years and starts to drop off around 16,000 years. This represents the solubility limit being reached and then the Tc-99 being depleted. Flux plots for Tc-99 for the different disposal units are shown in Figure 3-13 through Figure 3-15.

Further results and discussion are contained in the FY13 SA (SRR 2013), in particular doses and their significance to performance measures.

Table 3-2. Transitions for Nominal Case for SDU 1

\begin{tabular}{|l|r|r|}
\hline Zone & Eh-Transition & pH-Transition \\
\hline BACKFILL: & $\mathrm{NA}$ & $1 \mathrm{E}+49$ \\
\hline CLEAN_GROUT: & 7036 & 17383 \\
\hline CRACK: & 33882 & $1 \mathrm{E}+49$ \\
\hline FF_FLOOR: & 7035 & 9624 \\
\hline FF_ROOF: & 6857 & 9001 \\
\hline FLOOR: & 7035 & 9624 \\
\hline NATIVE_SOIL: & $\mathrm{NA}$ & $1 \mathrm{E}+49$ \\
\hline ROOF: & $\mathrm{NA}$ & 9001 \\
\hline SALTSTONE: & 33882 & $1 \mathrm{E}+49$ \\
\hline WALL: & 14707 & 22312 \\
\hline
\end{tabular}


Table 3-3. Transitions for Nominal Case for SDU 2

\begin{tabular}{|l|r|r|}
\hline Zone & Eh-Transition & pH-Transition \\
\hline BACKFILL: & 17576 & $1 \mathrm{E}+49$ \\
\hline CLEAN_GROUT: & 5540 & 35293 \\
\hline FF_FLOOR: & 5819 & 7468 \\
\hline FF_GROUT1: & 5755 & 17362 \\
\hline FF_GROUT10: & 5954 & 13599 \\
\hline FF_GROUT11: & 4929 & 13798 \\
\hline FF_GROUT2: & 5050 & 13800 \\
\hline FF_GROUT3: & 5207 & 13734 \\
\hline FF_GROUT4: & 5400 & 13695 \\
\hline FF_GROUT5: & 5753 & 13677 \\
\hline FF_GROUT6: & 5685 & 13740 \\
\hline FF_GROUT7: & 5653 & 13636 \\
\hline FF_GROUT8: & 5675 & 13566 \\
\hline FF_GROUT9: & $\mathrm{NA}$ & 13549 \\
\hline FF_LOWER_MUD: & 7579 & 6979 \\
\hline FF_ROOF: & 3802 & 9655 \\
\hline FF_UPPER_MUD: & 5540 & 5091 \\
\hline FLOOR: & $\mathrm{NA}$ & 7468 \\
\hline LOWER_MUD_MAT: & $\mathrm{NA}$ & 6979 \\
\hline NATIVE_SOIL: & 3579 & $1 \mathrm{E}+49$ \\
\hline ROOF: & 33064 & 9655 \\
\hline SALTSTONE: & 33064 & $1 \mathrm{E}+49$ \\
\hline SHEET_DRAIN: & 5935 & 5091 \\
\hline UPPER_MUD_MAT: & & 8431 \\
\hline WALL: & N & \\
\hline
\end{tabular}


Table 3-4. Transitions for Nominal Case for SDU 4

\begin{tabular}{|l|r|r|}
\hline Zone & Eh-Transition & pH-Transition \\
\hline BACKFILL: & 5773 & $1 \mathrm{E}+49$ \\
\hline CLEAN_GROUT: & 4488 & 22857 \\
\hline FF_FLOOR: & 1959 & 5544 \\
\hline FF_GROUT1: & 3028 & 17053 \\
\hline FF_GROUT10: & 2923 & 4200 \\
\hline FF_GROUT11: & 2942 & 4158 \\
\hline FF_GROUT12: & 2079 & 4185 \\
\hline FF_GROUT2: & 2925 & 3754 \\
\hline FF_GROUT3: & 3101 & 3981 \\
\hline FF_GROUT4: & 3602 & 4015 \\
\hline FF_GROUT5: & 4094 & 4232 \\
\hline FF_GROUT6: & 4105 & 4441 \\
\hline FF_GROUT7: & 3725 & 4476 \\
\hline FF_GROUT8: & 3384 & 4340 \\
\hline FF_GROUT9: & NA & 4282 \\
\hline FF_ROOF: & 4488 & 3218 \\
\hline FLOOR: & NA & 5544 \\
\hline NATIVE_SOIL: & NA & $1 \mathrm{E}+49$ \\
\hline ROOF: & 23840 & 3218 \\
\hline SALTSTONE: & 23840 & $1 \mathrm{E}+49$ \\
\hline SHEET_DRAIN: & 5930 & $1 \mathrm{E}+49$ \\
\hline TOP_SALTSTONE: & 10330 & 23961 \\
\hline WALL: & & 17688 \\
\hline
\end{tabular}


SRNL-STI-2013-00280, REVISION 0

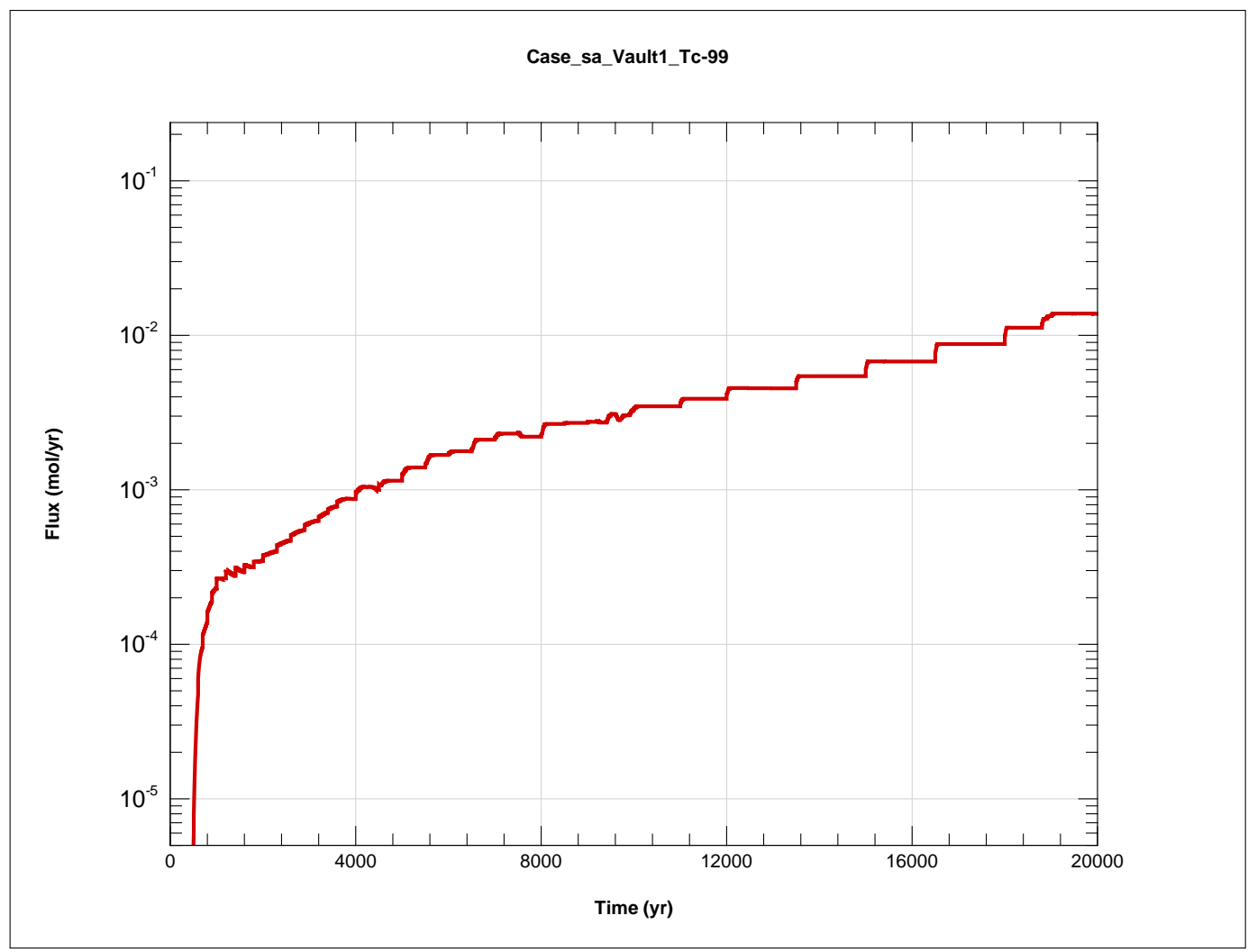

Figure 3-13. Flux for Tc-99 for nominal (NV) case for SDU 1.

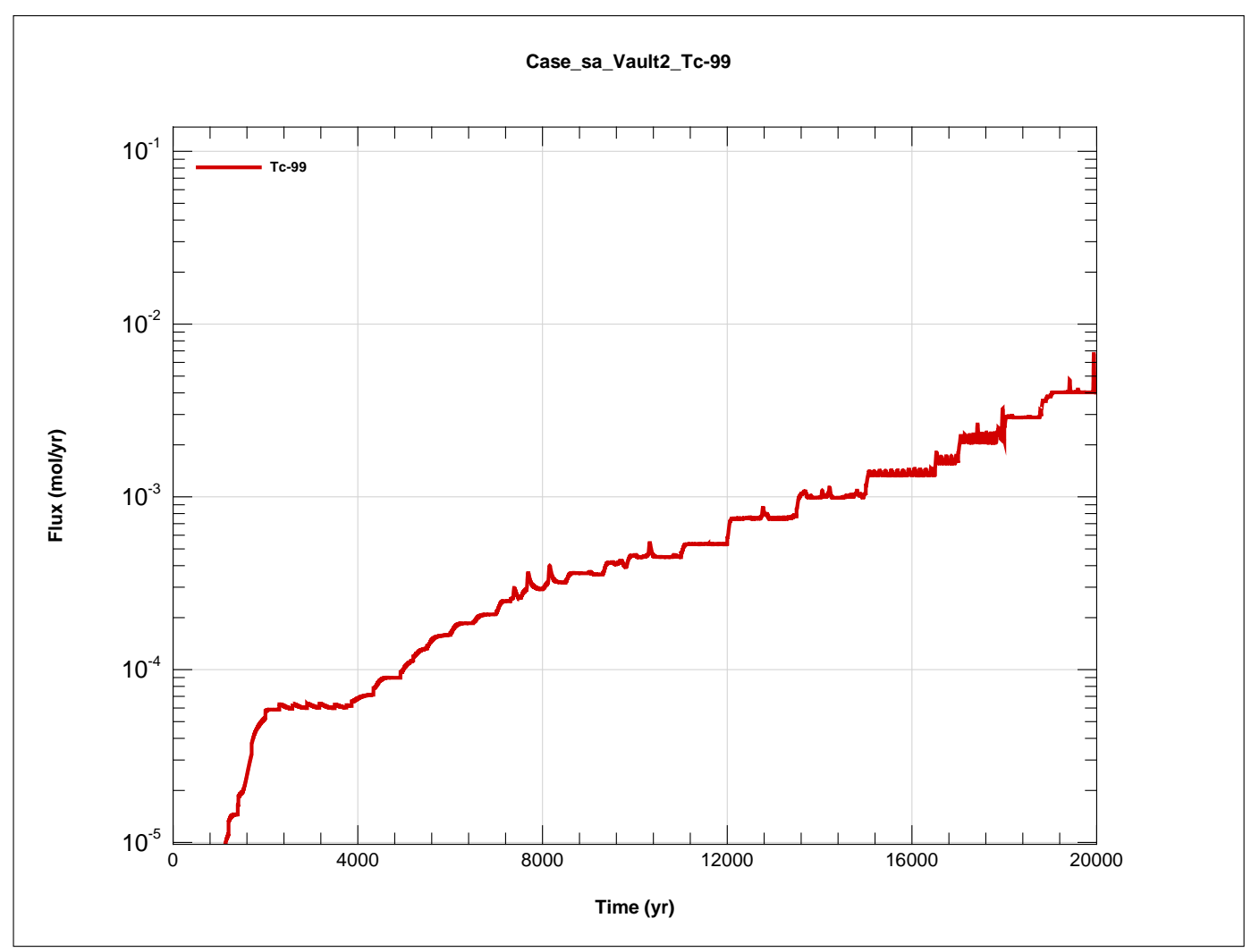

Figure 3-14. Flux for Tc-99 for nominal (NV) case for SDU 2. 
SRNL-STI-2013-00280, REVISION 0

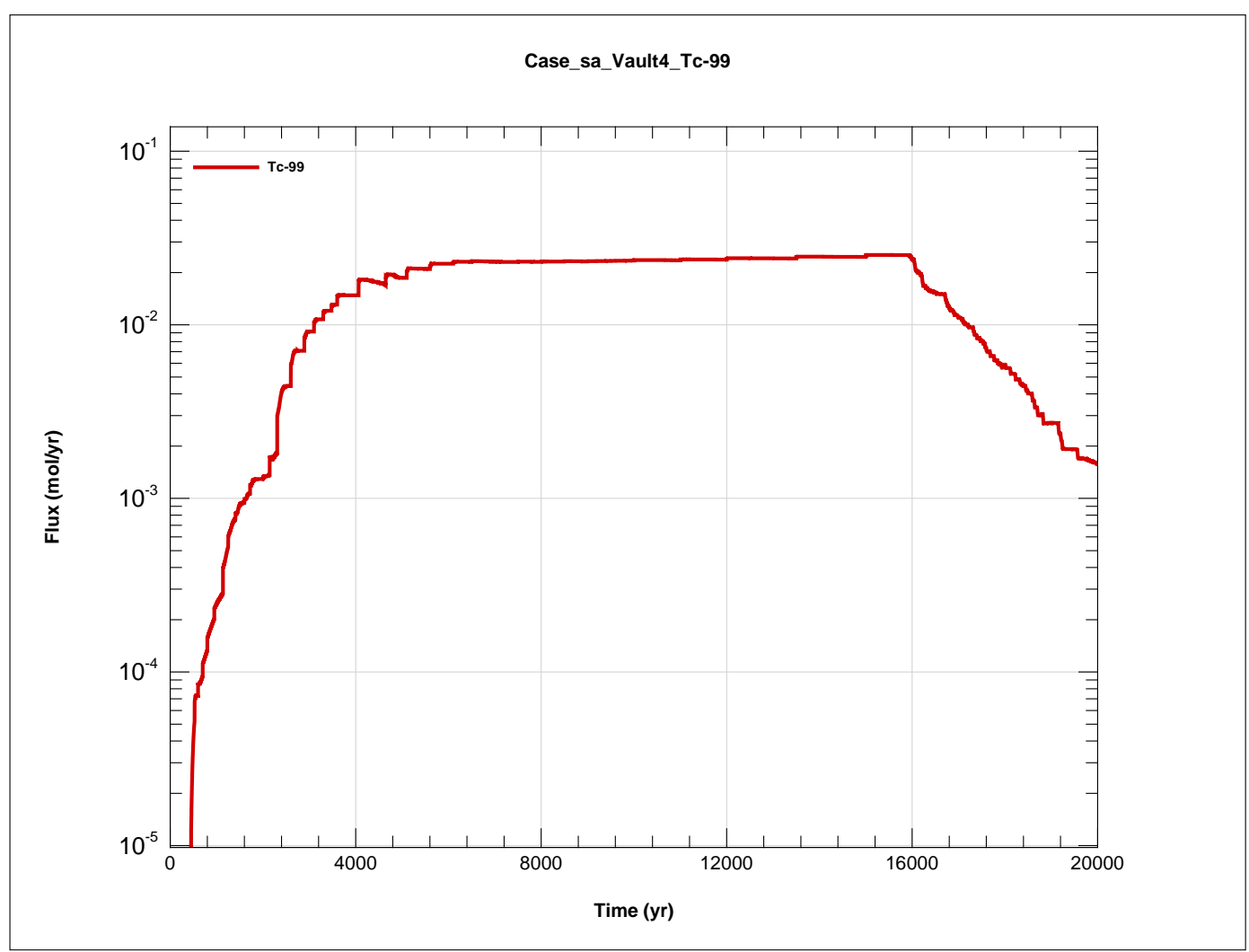

Figure 3-15. Flux for Tc-99 for nominal (NV) case for SDU 4. 


\subsection{FLOW SENSITIVITY CASES}

Probabilistic uncertainty and sensitivity analysis for the FY13 SA using GoldSim was conducted in parallel to PORFLOW modeling. The GoldSim system model includes vadose zone and aquifer transport submodels, but does not simulate multi-dimensional vadose zone flow because of the complexities of time-varying material properties and solution of the non-linear Richards (unsaturated flow) equation. Instead, GoldSim imports PORFLOW vadose zone flow fields generated for the nominal case and several additional flow sensitivity cases defined by Sheppard (2013, Table 9) and listed in Table 4-1. Further results and discussion are provided in the FY13 SA (SRR 2013).

The first three parametric runs examined the impact of the initial saltstone hydraulic conductivity, where the F-1 case is the same as the nominal case. Corresponding Tc-99 flux results for the different disposal units are presented in Figure 4-1 through Figure 4-3. While initial conductivity impacts the Tc-99 release prior to 4,000 years, the impact on the maximum Tc-99 flux for SDU 4 is minimal because the peak release is solubility limited. For SDU 1, the nominal case is not solubility limited. However, for the run with the higher initial hydraulic conductivity, F-2, the release becomes solubility limited. SDU 2 exhibits similar behavior in that the higher initial hydraulic conductivity case becomes solubility limited. Due to the discretization of the model, pulses are present as Tc-99 contained in individual cells is released.

A second variable that was evaluated in the sensitivity cases was the infiltration rate. The three cases, F-1, F-13, and F-25 represent the nominal, maximum, and minimum cases with only infiltration rate varying. The results are typical to what would be expected, with the higher infiltration rate leading to a higher and earlier release as well as an earlier depletion of the Tc-99 for SDU 1 and SDU 4. The flux comparison plots are shown in Figure 4-4 through Figure 4-6.

The other two variables that were examined were the cementitious degradation rate and the moisture characteristic curves (MCCs) used for the joint material. Case F-1 uses nominal value (NV) settings while F-4 uses best estimate (BE) values. The difference between F-1 and F-7 is that F-1 uses the MCC for gravel for the joint material and F-7 uses an MCC with a relative permeability of 1 . As shown in all of the graphs, the choice of MCCs has a minimal impact on the results. The best estimate degradation rates lead to a much lower flux to the water table for all disposal units. The flux comparison plots are shown in Figure 4-7 through Figure 4-9.

The combination of high hydraulic conductivity, nominal cemititious degradation rate, and maximum infiltration rate represents what should be at the high end in terms of flux, F-14. The opposite combination, F-36, represents what should be at the low in in terms of flux. The range of fluxes for F-1, F-14, and F-36 are presented in Figure 4-10 through Figure 4-12.

Further results and discussion are provided in the FY13 SA (SRR 2013). 
Table 4-1. Vadose zone flow sensitivity cases.

\begin{tabular}{|c|c|c|c|c|}
\hline Case & $\begin{array}{c}\text { Infiltration } \\
\text { Rate }\end{array}$ & $\begin{array}{c}\text { Cementitious } \\
\text { Degradation Rate }\end{array}$ & $\begin{array}{c}\text { Initial Saltstone } \\
\text { Saturated Hydraulic } \\
\text { Conductivity (cm/sec) }\end{array}$ & $\begin{array}{c}\text { MCC for } \\
\text { Joint }\end{array}$ \\
\hline F-1 & Average & Nominal & $6.4 \mathrm{E}-09$ & Gravel \\
\hline F-2 & Average & Nominal & $4.5 \mathrm{E}-07$ & Gravel \\
\hline F-3 & Average & Nominal & $3.9 \mathrm{E}-10$ & Gravel \\
\hline F-4 & Average & $\mathrm{BE}$ & 6.4E-09 & Gravel \\
\hline F-5 & Average & $\mathrm{BE}$ & 4.5E-07 & Gravel \\
\hline F-6 & Average & $\mathrm{BE}$ & $3.9 \mathrm{E}-10$ & Gravel \\
\hline F-7 & Average & Nominal & $6.4 \mathrm{E}-09$ & Rel Per $=1$ \\
\hline F-8 & Average & Nominal & $4.5 \mathrm{E}-07$ & Rel Per $=1$ \\
\hline F-9 & Average & Nominal & $3.9 \mathrm{E}-10$ & Rel Per $=1$ \\
\hline F-10 & Average & $\mathrm{BE}$ & 6.4E-09 & Rel Per $=1$ \\
\hline F-11 & Average & $\mathrm{BE}$ & 4.5E-07 & Rel Per $=1$ \\
\hline F-12 & Average & $\mathrm{BE}$ & $3.9 \mathrm{E}-10$ & Rel Per $=1$ \\
\hline F-13 & Maximum & Nominal & $6.4 \mathrm{E}-09$ & Gravel \\
\hline F-14 & Maximum & Nominal & $4.5 \mathrm{E}-07$ & Gravel \\
\hline F-15 & Maximum & Nominal & $3.9 \mathrm{E}-10$ & Gravel \\
\hline F-16 & Maximum & $\mathrm{BE}$ & $6.4 \mathrm{E}-09$ & Gravel \\
\hline F-17 & Maximum & $\mathrm{BE}$ & 4.5E-07 & Gravel \\
\hline F-18 & Maximum & $\mathrm{BE}$ & $3.9 \mathrm{E}-10$ & Gravel \\
\hline F-19 & Maximum & Nominal & $6.4 \mathrm{E}-09$ & Rel Per $=1$ \\
\hline F-20 & Maximum & Nominal & 4.5E-07 & Rel Per $=1$ \\
\hline F-21 & Maximum & Nominal & 3.9E-10 & Rel Per $=1$ \\
\hline F-22 & Maximum & $\mathrm{BE}$ & $6.4 \mathrm{E}-09$ & Rel Per $=1$ \\
\hline $\mathrm{F}-23$ & Maximum & $\mathrm{BE}$ & 4.5E-07 & Rel Per $=1$ \\
\hline F-24 & Maximum & $\mathrm{BE}$ & $3.9 \mathrm{E}-10$ & Rel Per $=1$ \\
\hline F-25 & Minimum & Nominal & 6.4E-09 & Gravel \\
\hline F-26 & Minimum & Nominal & 4.5E-07 & Gravel \\
\hline F-27 & Minimum & Nominal & $3.9 \mathrm{E}-10$ & Gravel \\
\hline F-28 & Minimum & $\mathrm{BE}$ & $6.4 \mathrm{E}-09$ & Gravel \\
\hline F-29 & Minimum & $\mathrm{BE}$ & 4.5E-07 & Gravel \\
\hline F-30 & Minimum & $\mathrm{BE}$ & $3.9 \mathrm{E}-10$ & Gravel \\
\hline F-31 & Minimum & Nominal & 6.4E-09 & Rel Per $=1$ \\
\hline F-32 & Minimum & Nominal & 4.5E-07 & Rel Per $=1$ \\
\hline F-33 & Minimum & Nominal & $3.9 \mathrm{E}-10$ & Rel Per $=1$ \\
\hline F-34 & Minimum & $\mathrm{BE}$ & $6.4 \mathrm{E}-09$ & Rel Per $=1$ \\
\hline F-35 & Minimum & $\mathrm{BE}$ & 4.5E-07 & Rel Per $=1$ \\
\hline F-36 & Minimum & $\mathrm{BE}$ & $3.9 \mathrm{E}-10$ & Rel Per $=1$ \\
\hline F-37 & \multicolumn{4}{|c|}{ Same as F-1 but with a roof slop of $1.5 \%$ (SDU-2 only) } \\
\hline F-38 & \multicolumn{4}{|c|}{ Same as F-1 but with a roof slop of $2.5 \%$ (SDU-2 only) } \\
\hline
\end{tabular}


SRNL-STI-2013-00280, REVISION 0

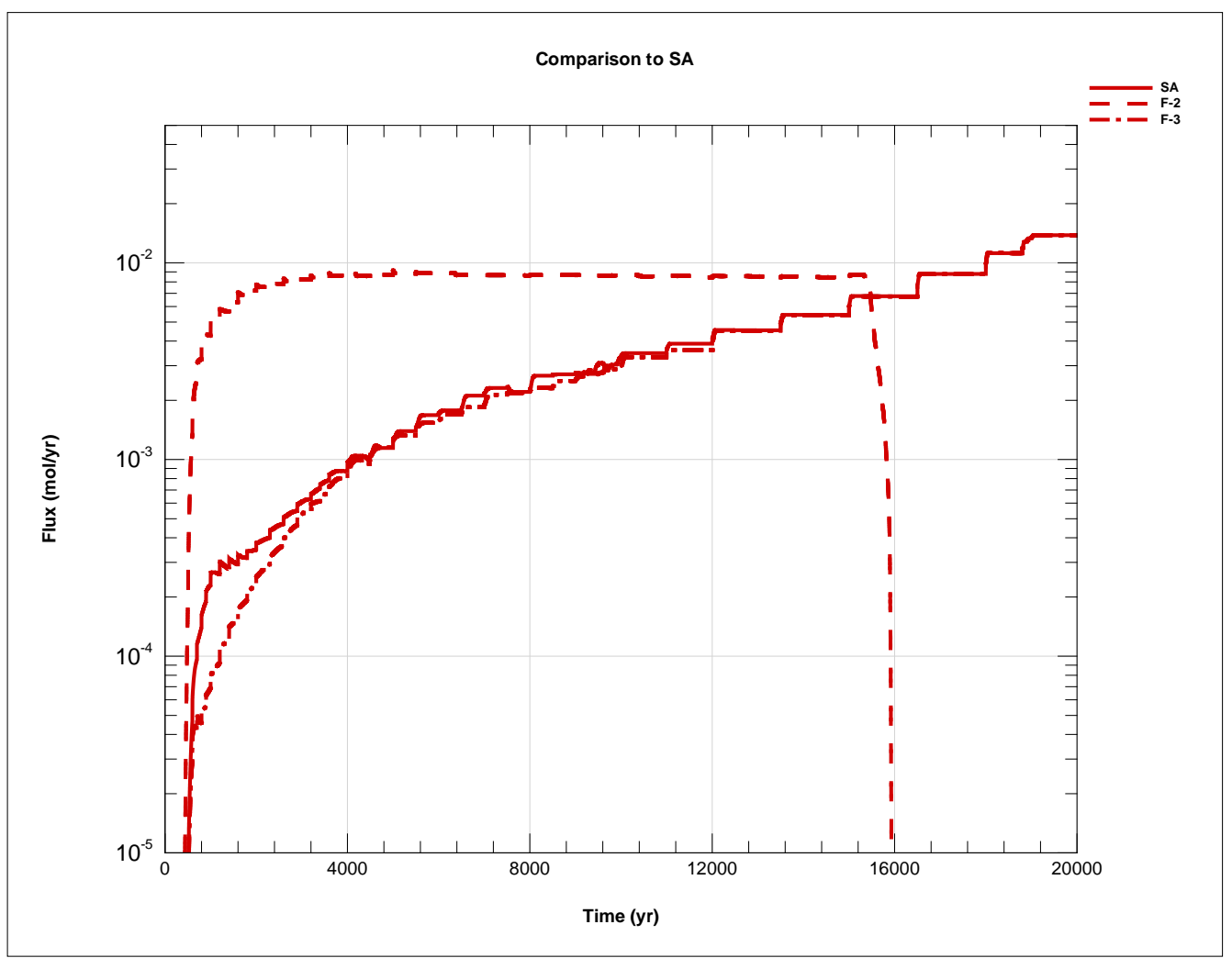

Figure 4-1. Hydraulic conductivity sensitivity for SDU 1.

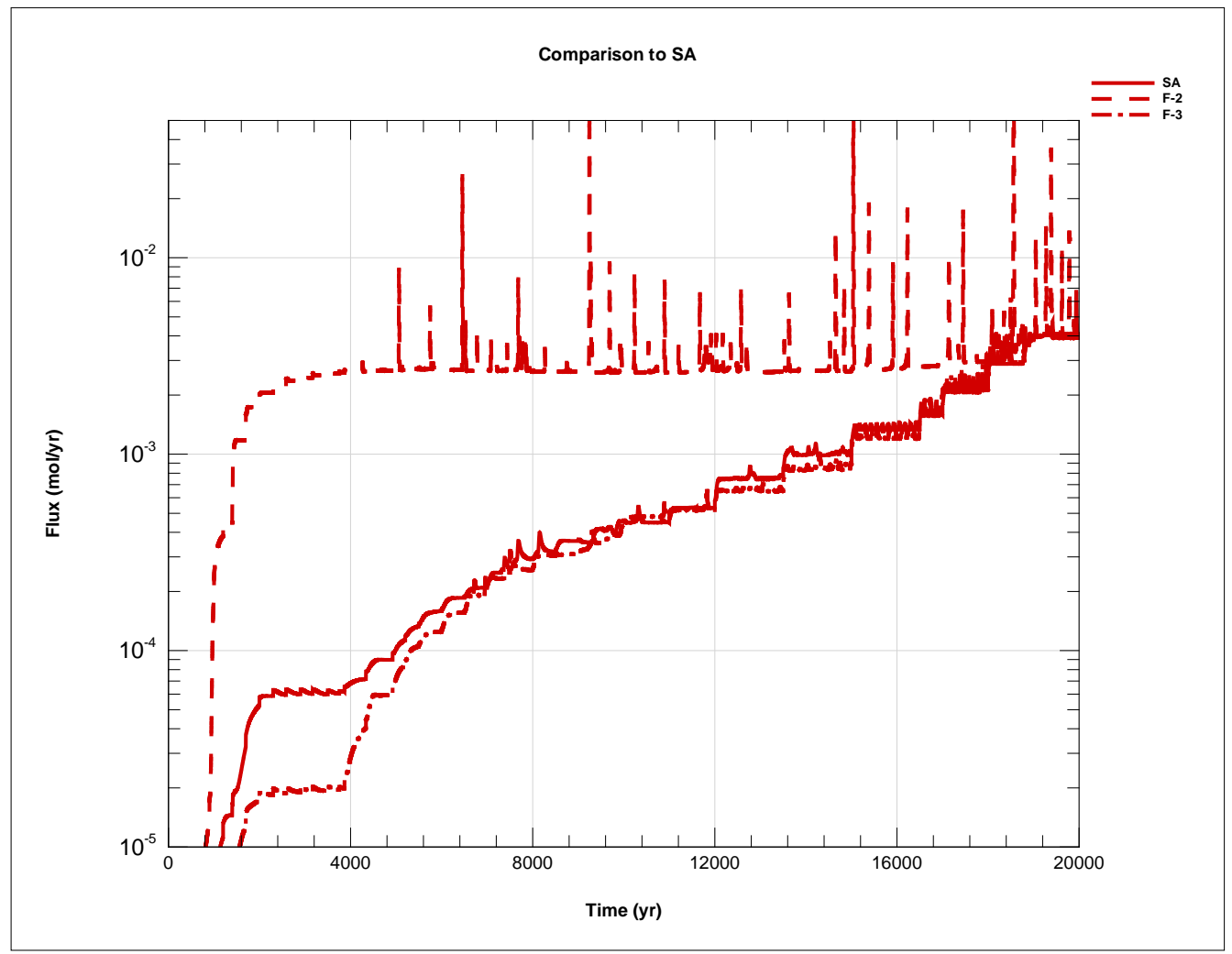

Figure 4-2. Hydraulic conductivity sensitivity for SDU 2. 
SRNL-STI-2013-00280, REVISION 0

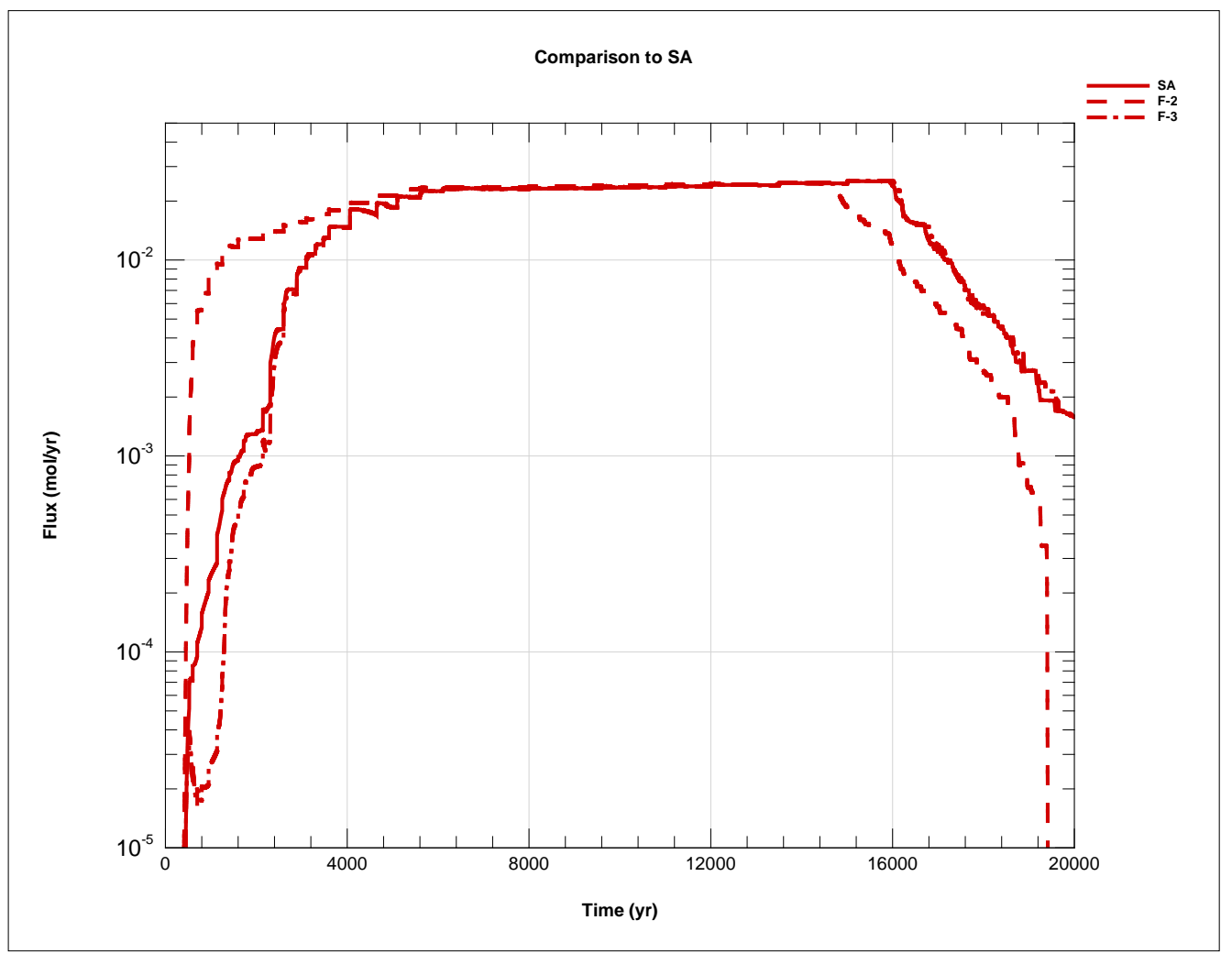

Figure 4-3. Hydraulic conductivity sensitivity for SDU 4.

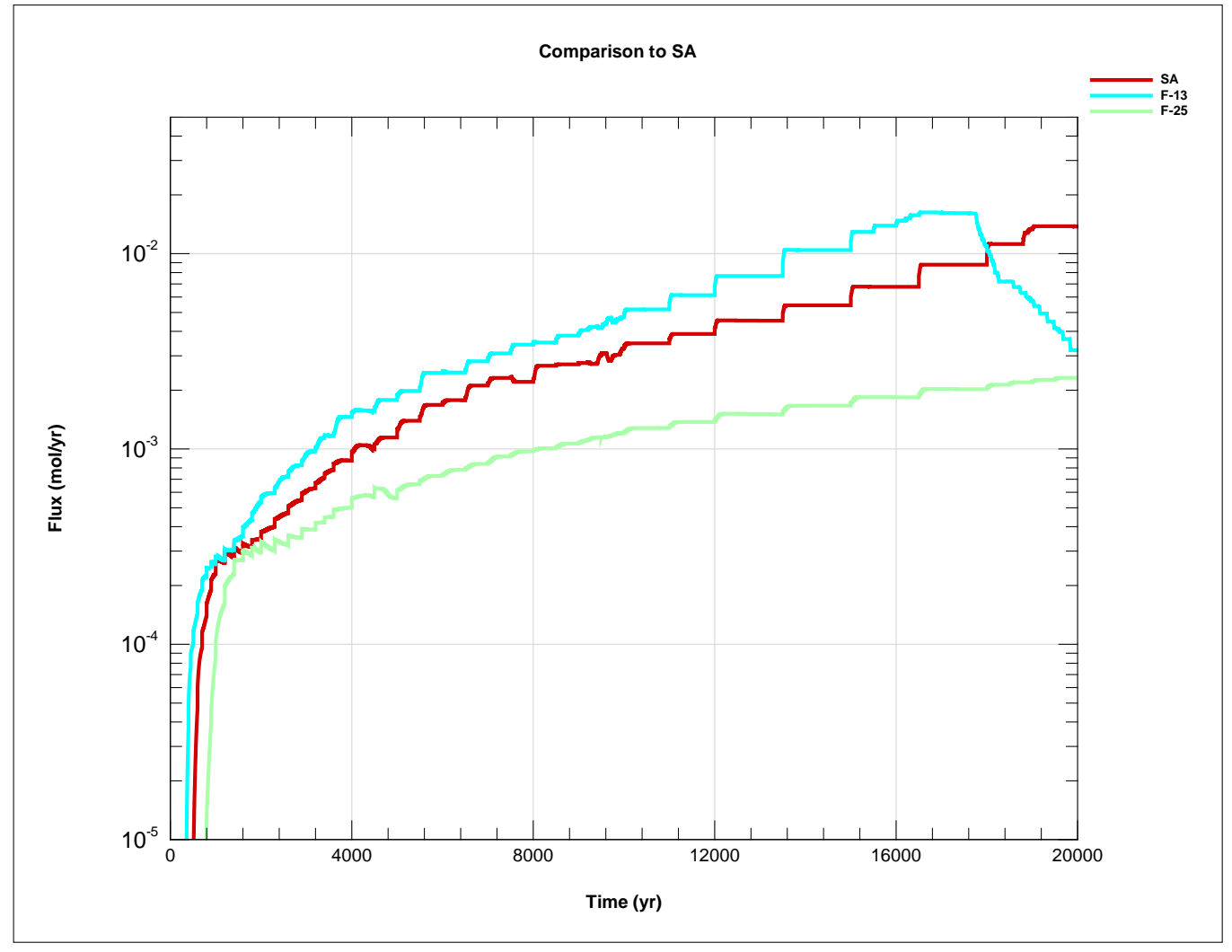

Figure 4-4. Infiltration sensitivity for SDU 1. 
SRNL-STI-2013-00280, REVISION 0

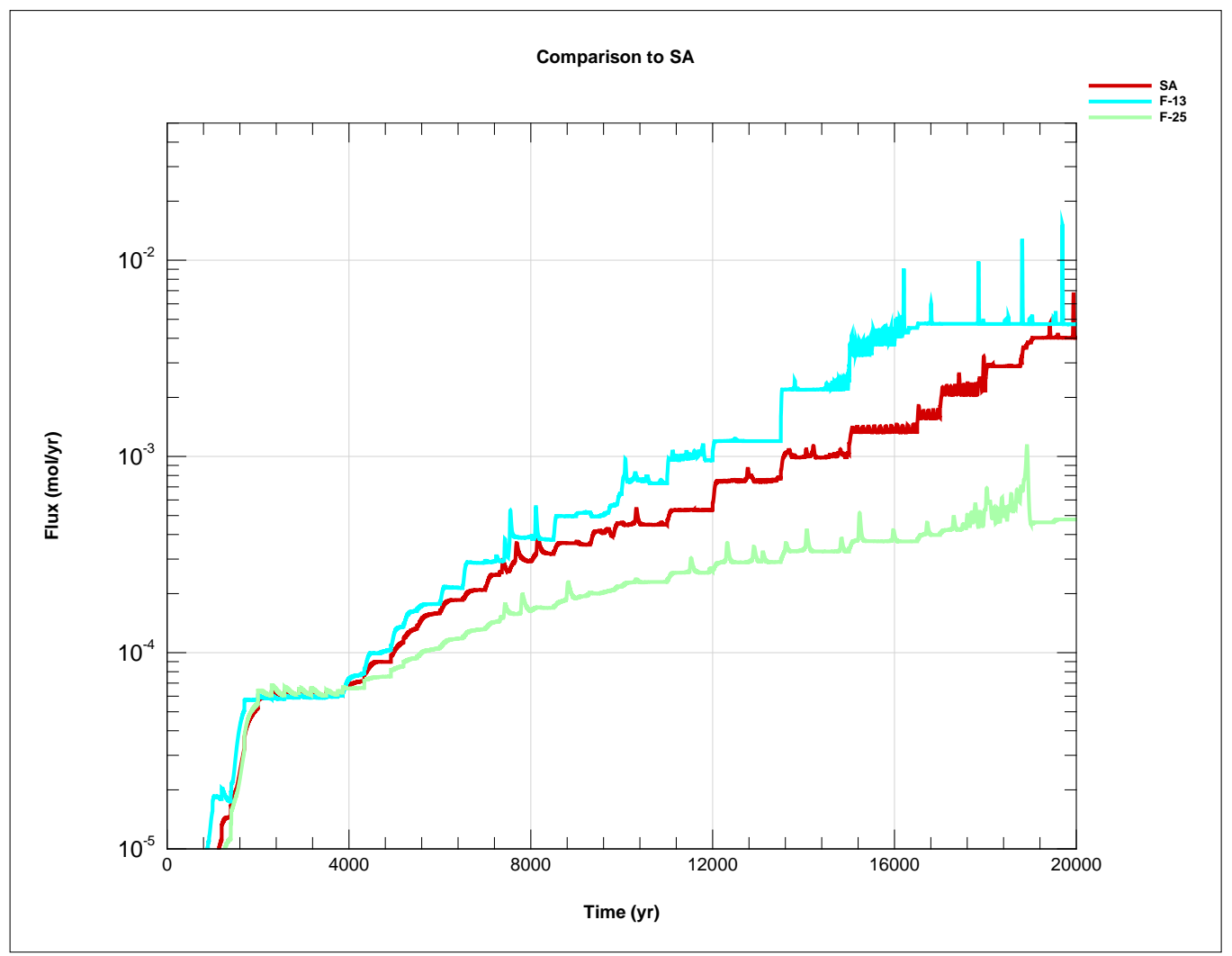

Figure 4-5. Infiltration sensitivity for SDU 2.

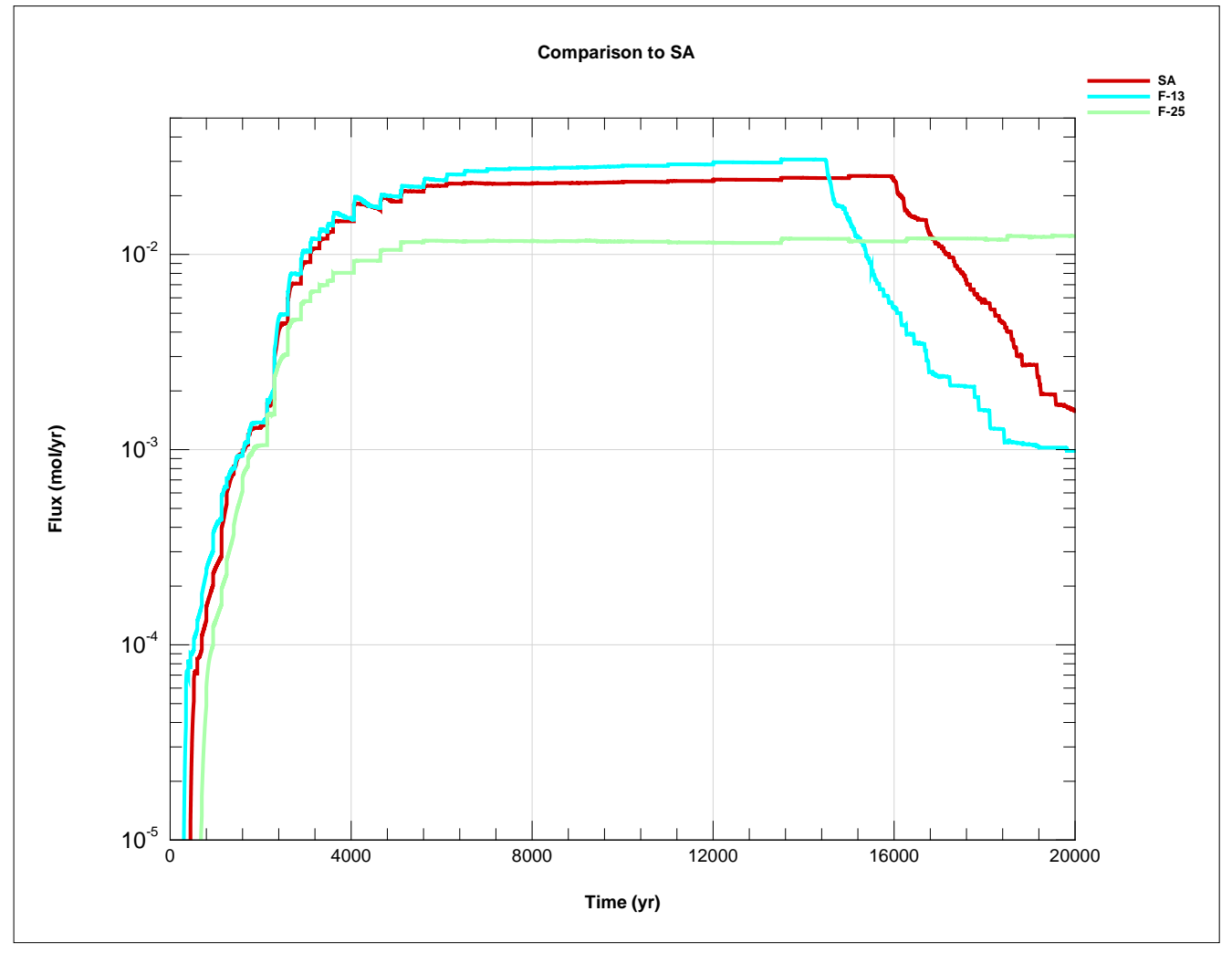

Figure 4-6. Infiltration sensitivity for SDU 4. 
SRNL-STI-2013-00280, REVISION 0

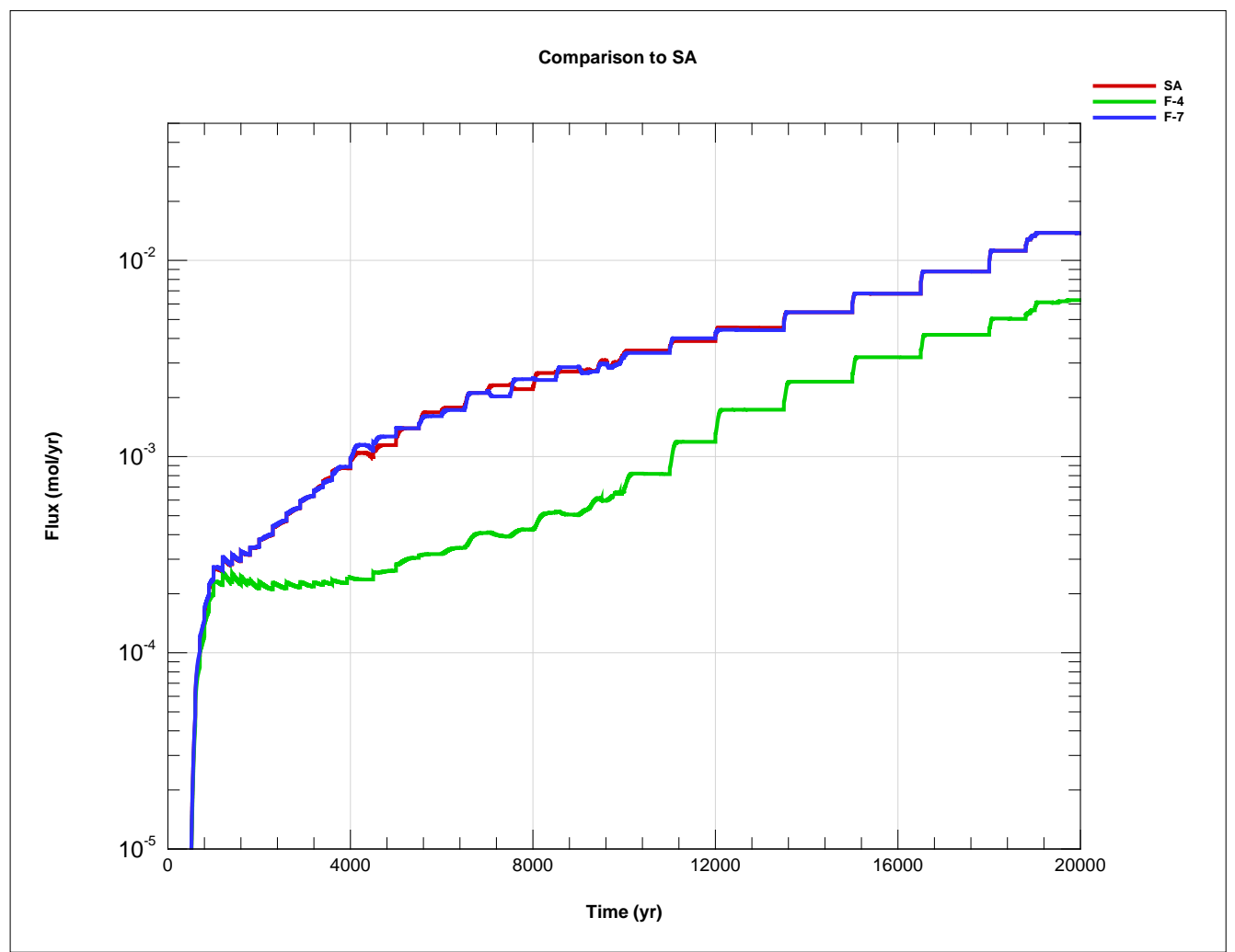

Figure 4-7. Additional sensitivity for SDU 1.

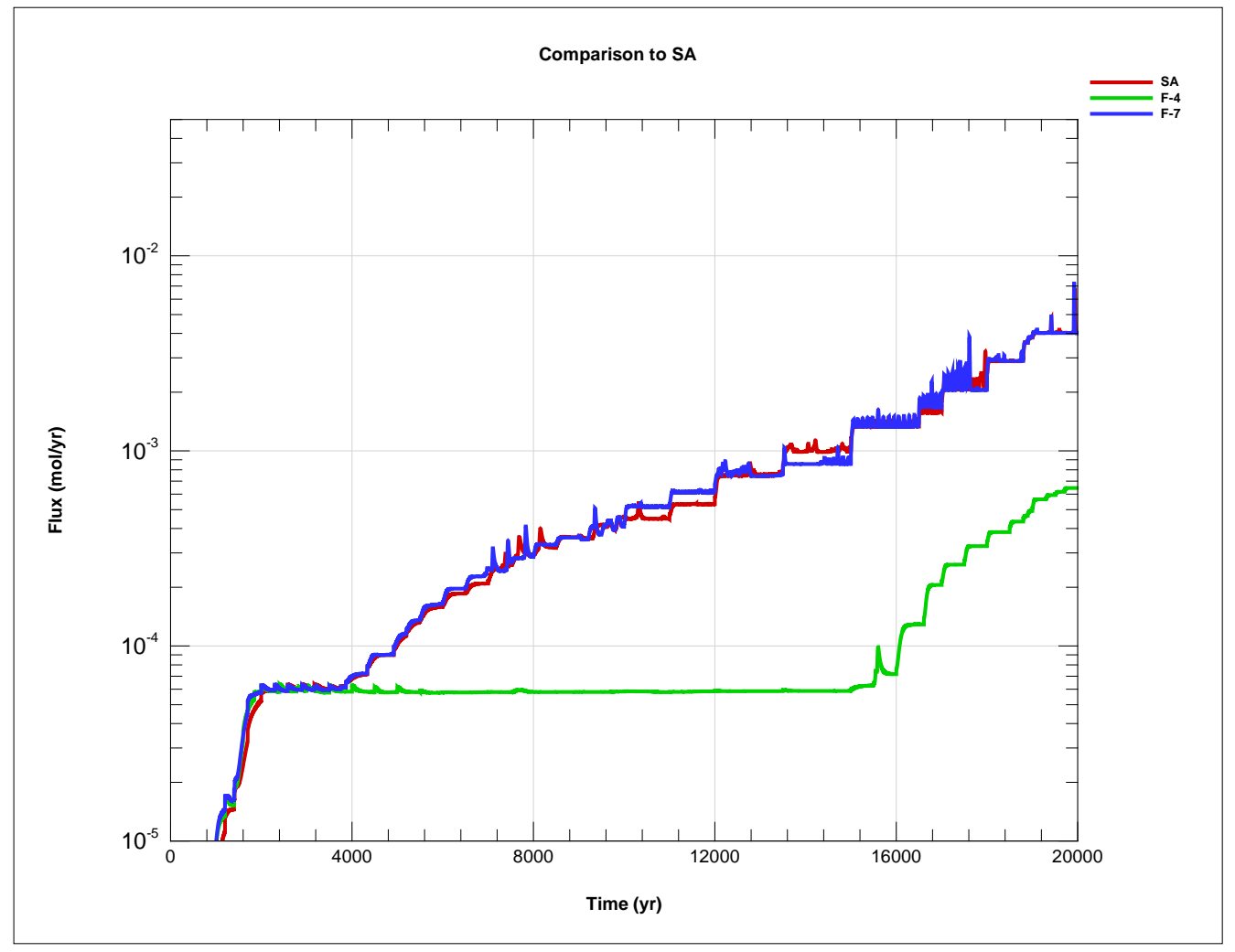

Figure 4-8. Additional sensitivity for SDU 2. 
SRNL-STI-2013-00280, REVISION 0

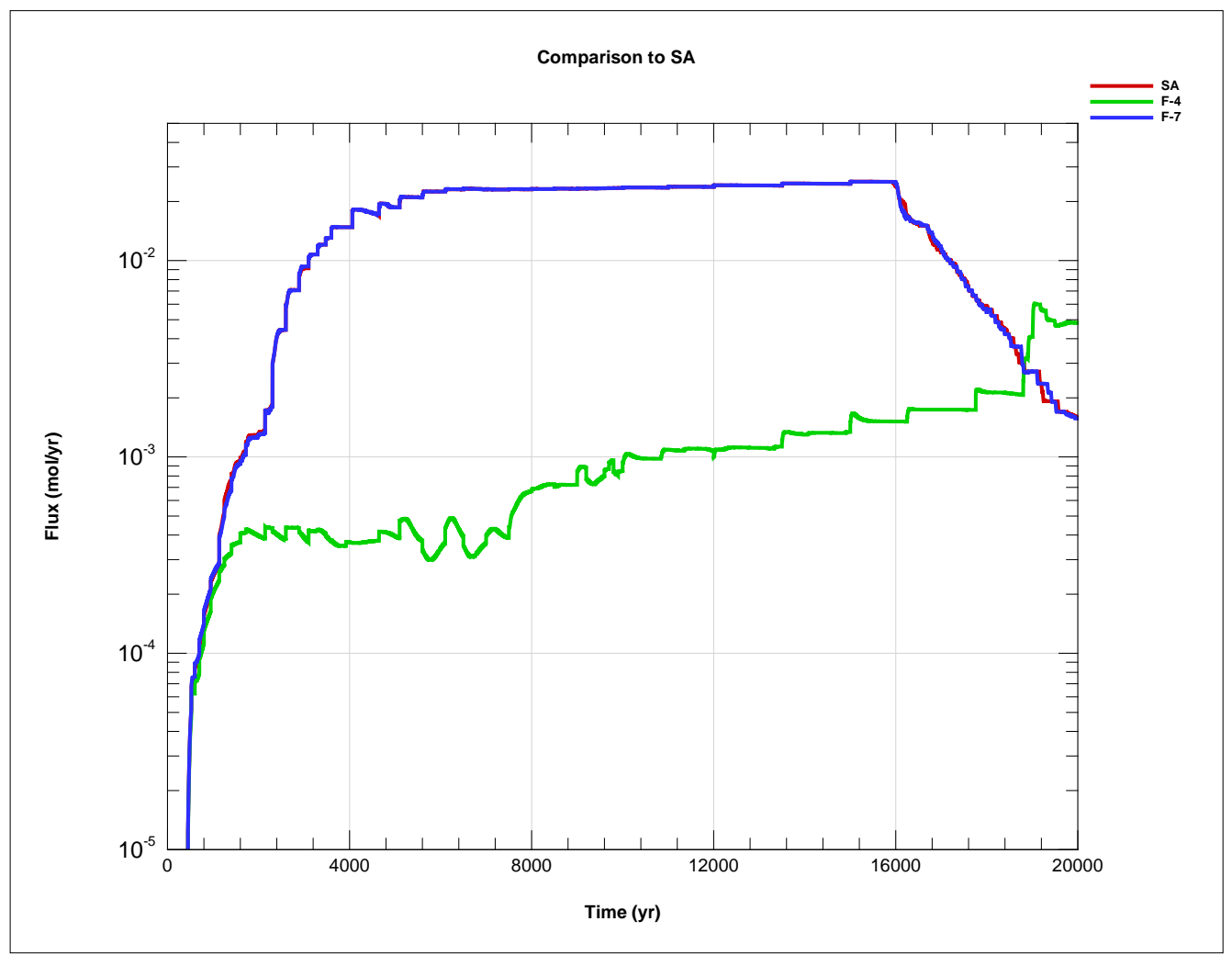

Figure 4-9. Additional sensitivity for SDU 4.

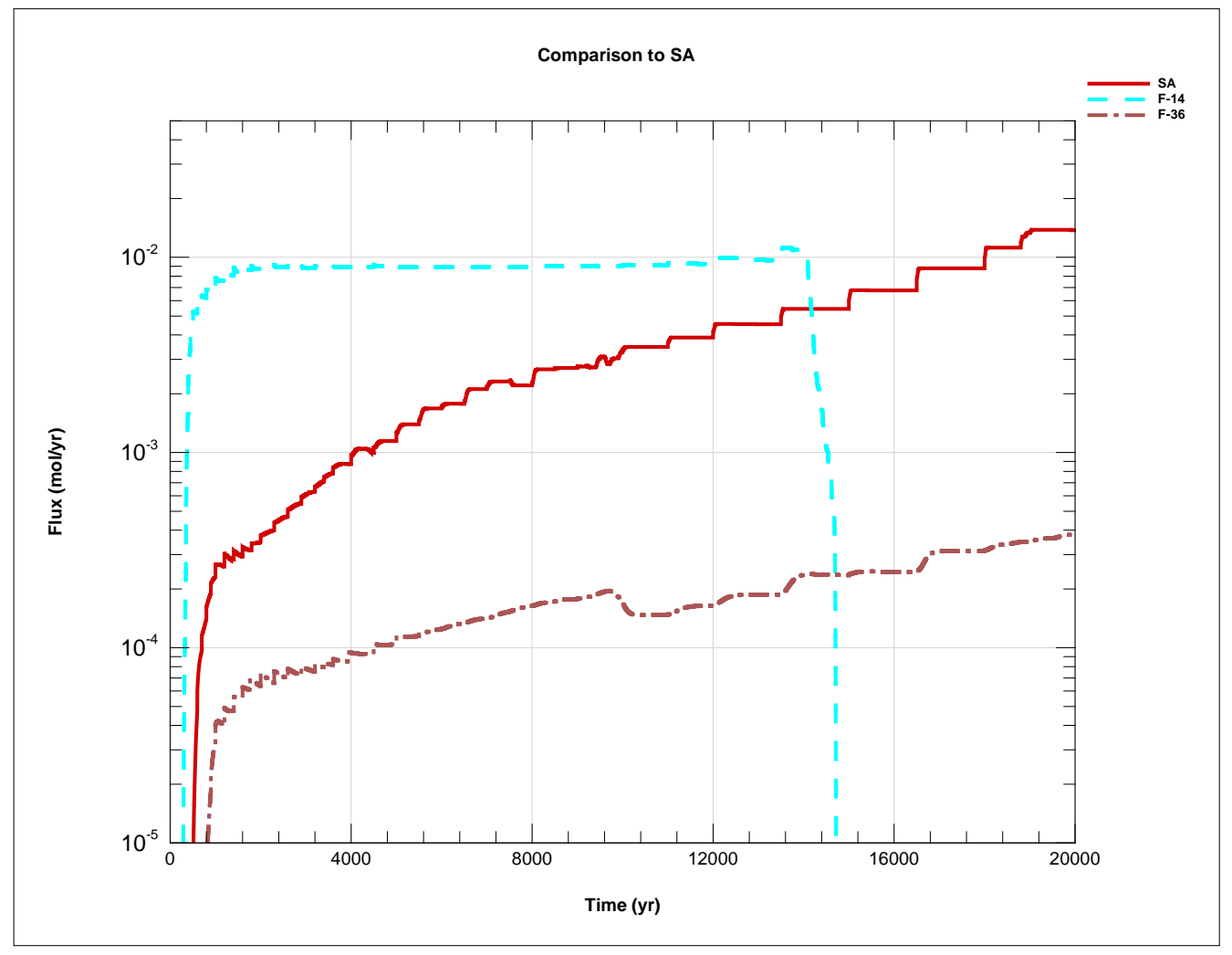

Figure 4-10. Flux range for SDU 1. 
SRNL-STI-2013-00280, REVISION 0

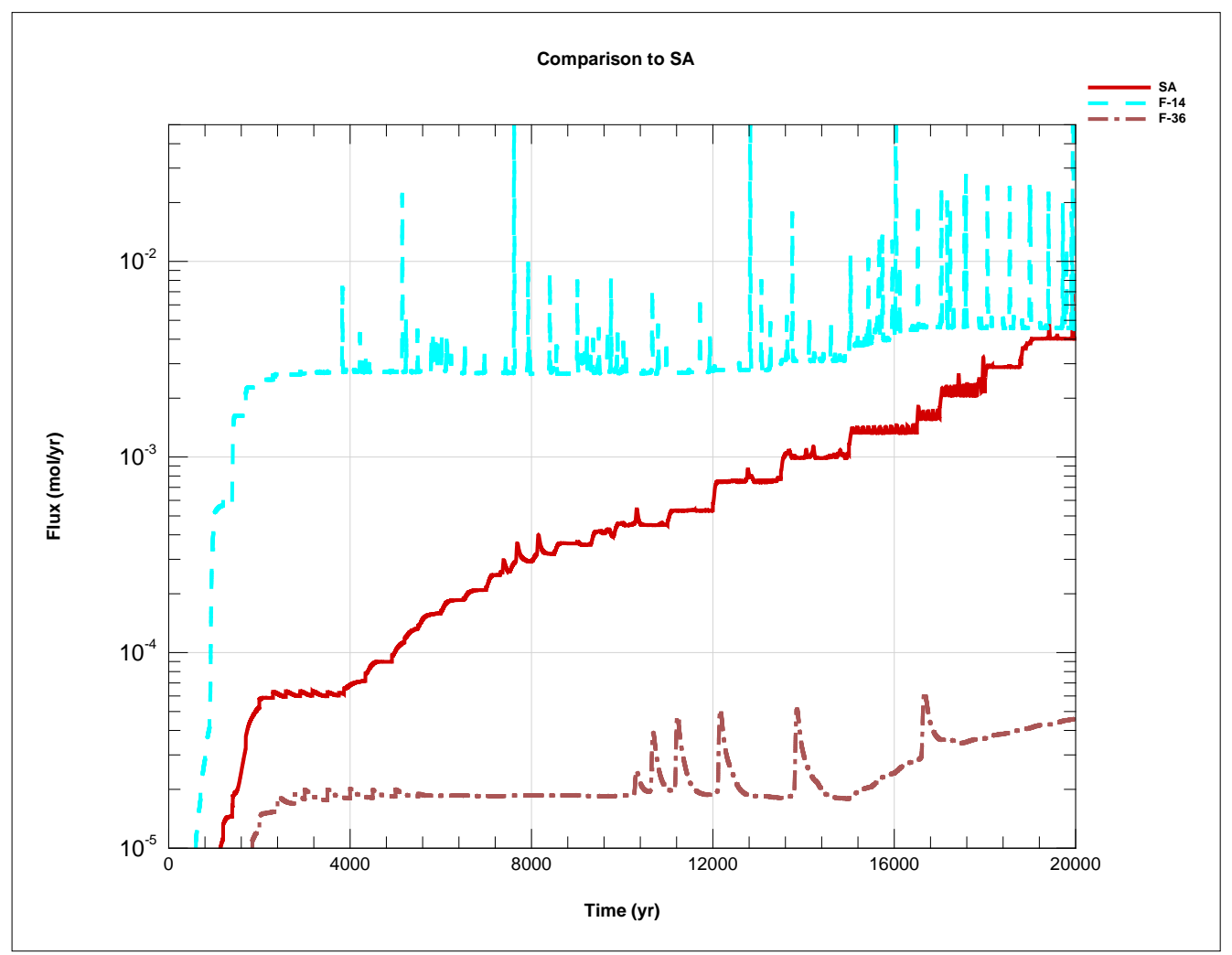

Figure 4-11. Flux range for SDU 2.

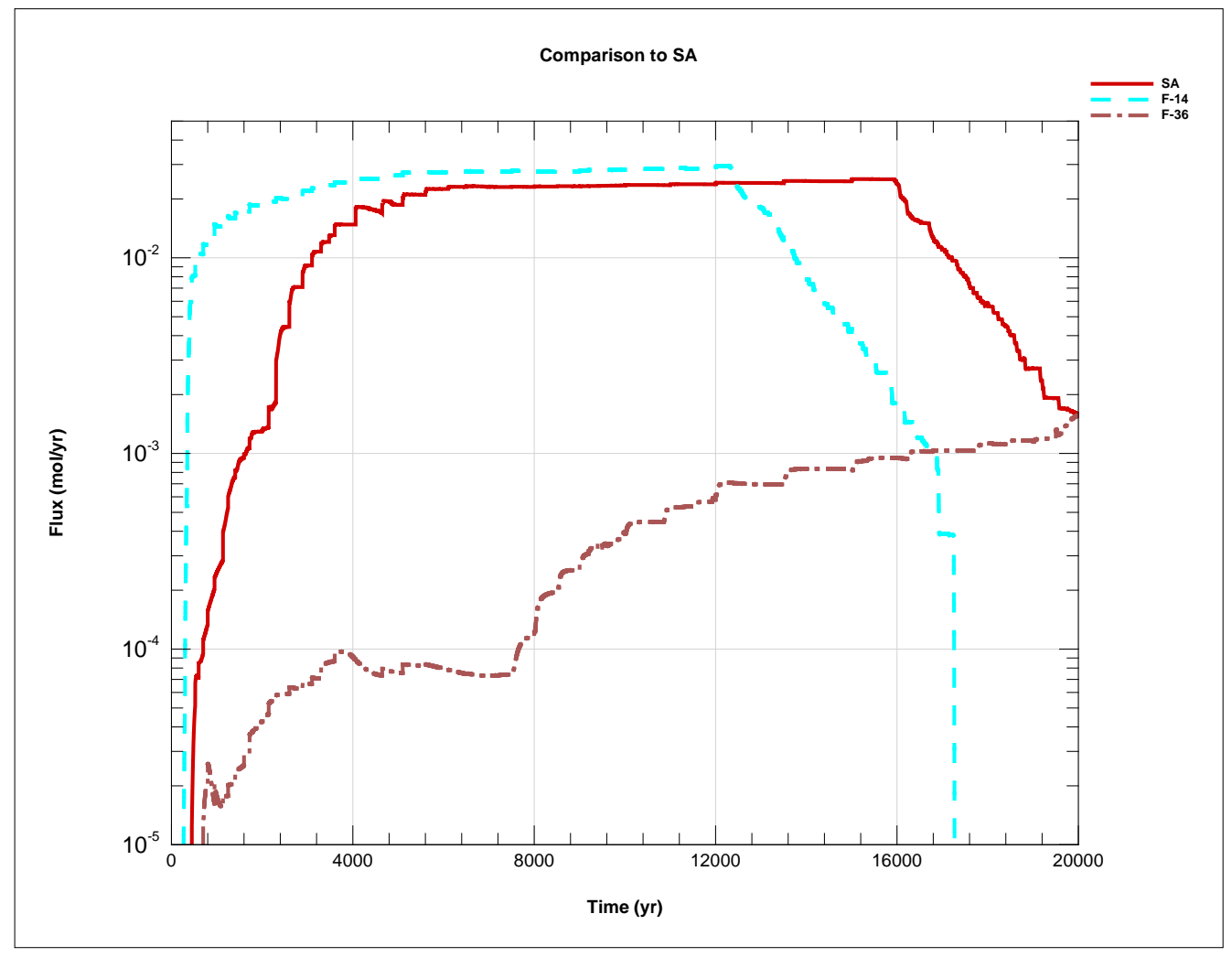

Figure 4-12. Flux range for SDU 4. 


\subsection{TRANSPORT SENSITIVITY CASES}

Among those radionuclides making a significant contribution to dose in the nominal simulation, the largest transport modeling biases and uncertainties are associated with Tc-99. Therefore further PORFLOW transport sensitivity analysis focused on alternative conceptual model and parameter settings for Tc-99. The following sensitivity cases were considered:

1) Tc solubility: $1.0 \mathrm{E}-08,1.0 \mathrm{E}-09$, and $1.0 \mathrm{E}-07 \mathrm{~mol} / \mathrm{L}$

2) Internal non-depleting oxygen sources (simulating fracture zones that expose saltstone to gas-phase oxygen): $1,2,5,10$, and $20 \%$ coverage

3) Oxidized concrete from time zero

4) Sensitivity settings in item 1) w/oxidized concrete

5) Sensitivity settings in item 2) w/oxidized concrete

6) Sensitivity settings in item 1) w/oxidized concrete for flow sensitivity cases F-1, $4,5,14,15,16,17,25,26,28,29$, and 30.

Selected water table flux results from these simulations are presented in this report.

Results from the oxidized Case 3) showed almost no impact when compared to the nominal case. The results for Case 4) are presented in Figure 5-1 through Figure 5-3. The nominal case, labeled "case SA" in these figures, has a solubility of $1.0 \mathrm{E}-08 \mathrm{~mol} / \mathrm{L}$; the labels "sol1" and "sol3" are used to denote 1.0E-07 and 1.0E-09 mol/L respectively. The higher solubility values have a dramatic effect on the flux to the water table, particularly for SDU 4, where most of the Tc-99 is out of the containment system by 7,000 years.

Sensitivity groups 2) and 5) consider the impact of potential fractures that are dewatered and expose saltstone to gas-phase oxygen at internal fracture surfaces. In PORFLOW modeling this conceptual model is implemented by randomly placing non-depleting oxygen sources within certain percentages of grid cells representing saltstone. These sources have the effect of immediately oxidizing slag and Tc-99 within assigned cells, and causing accelerated oxidation of surrounding cells. The results of sensitivity Case 5) are presented in Figure 5-4 through Figure 5-6. The labels "ox1" through "ox5" denote oxygen source densities of 1, 2, 5, 10 and $20 \%$ respectively. As expected, the greater the percentage of internal oxygen sources, the greater the impact on Tc-99 flux at the water table. In addition, the impact is greatest for SDU 4.

Further discussion of transport sensitivity can be found in the FY13 SA (SRR 2013). 


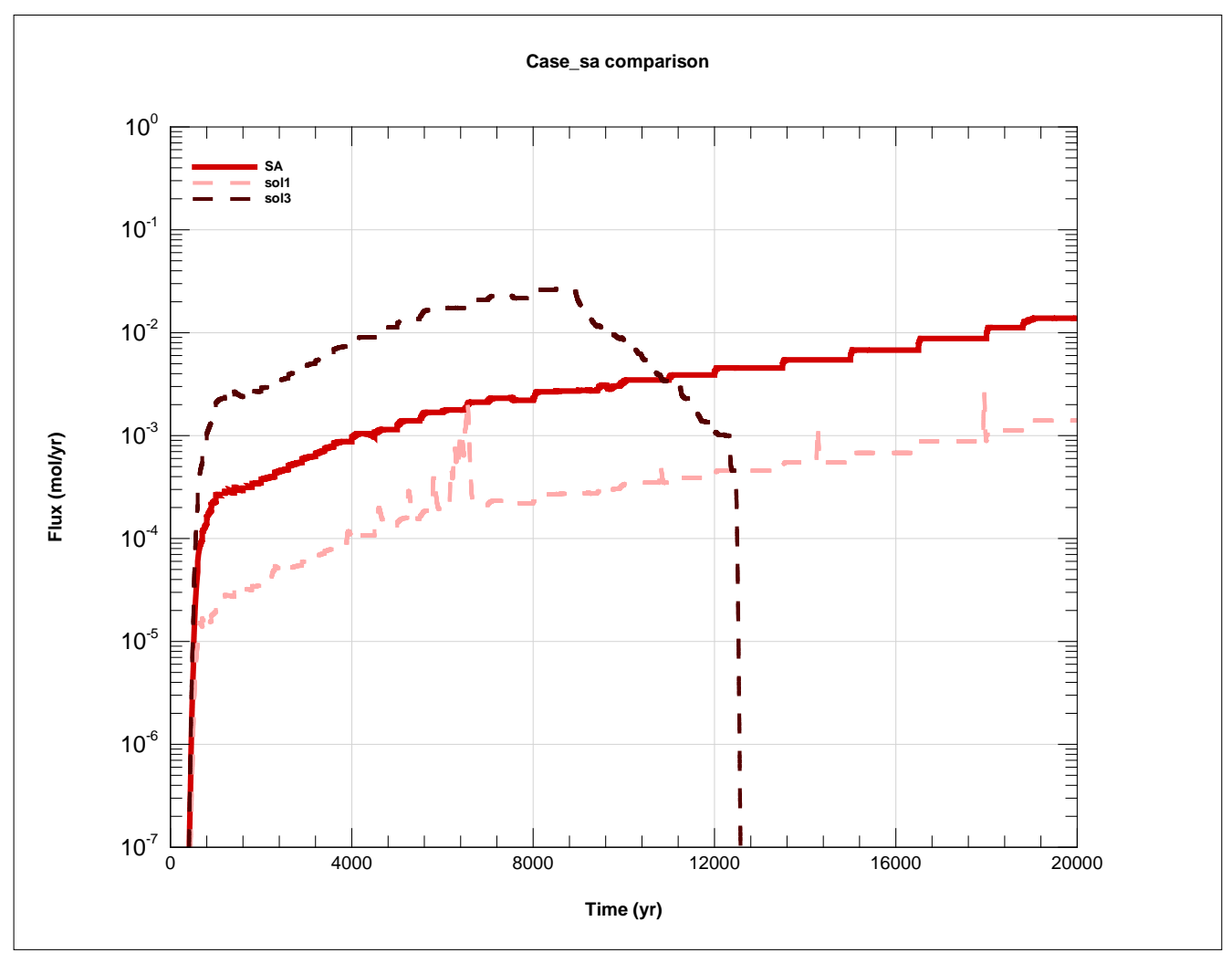

Figure 5-1. Solubility sensitivity for SDU 1.

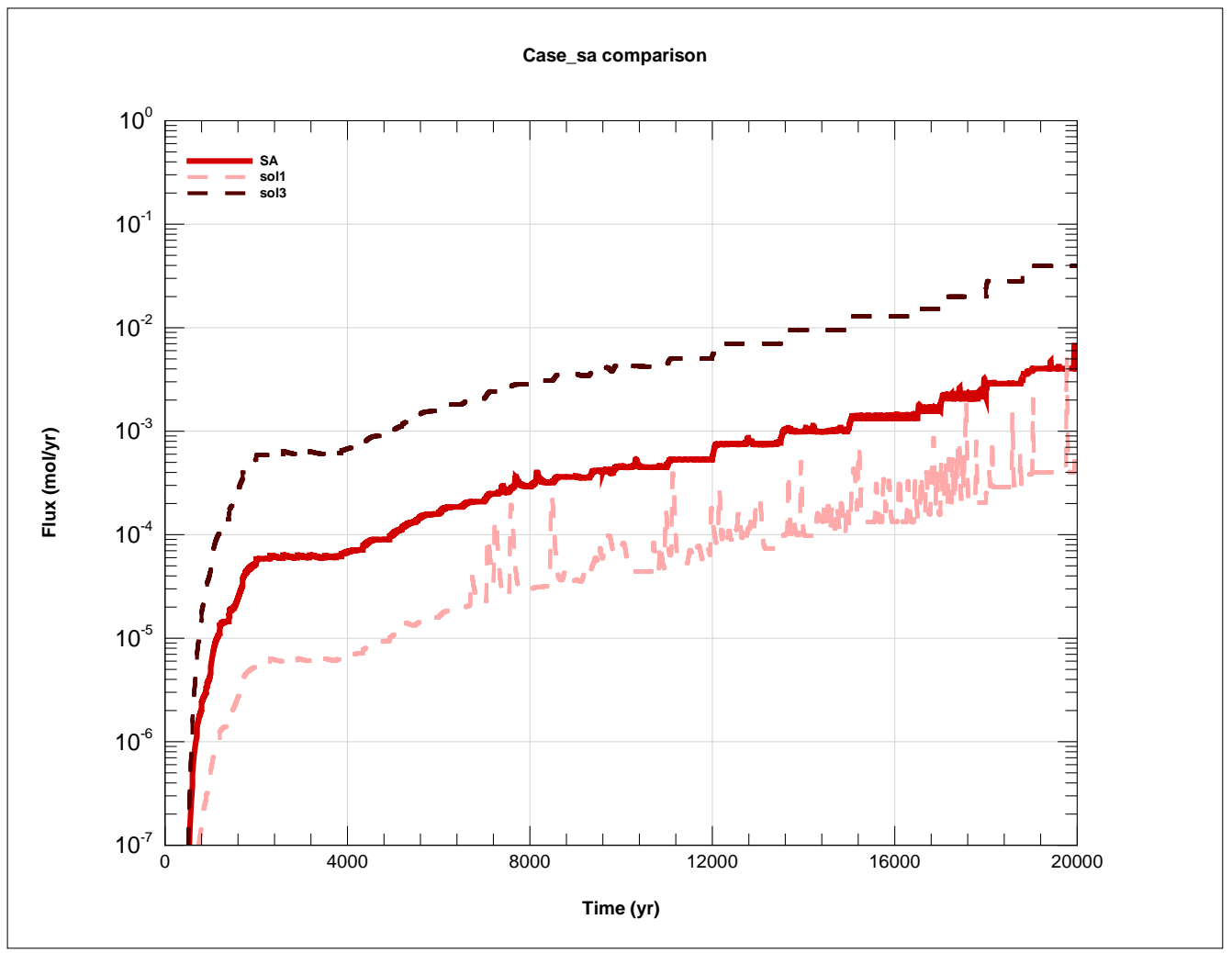

Figure 5-2. Solubility sensitivity for SDU 2. 


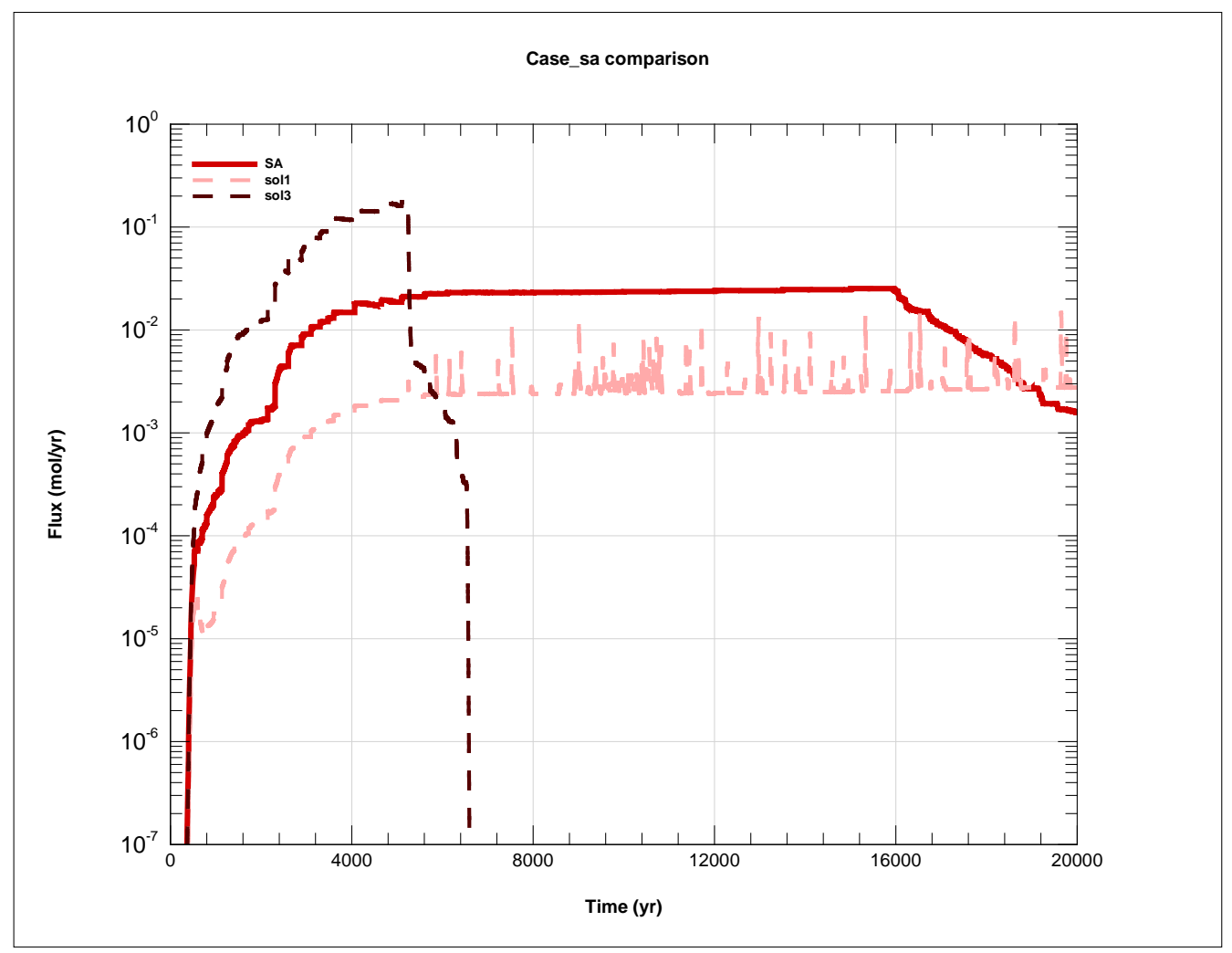

Figure 5-3. Solubility sensitivity for SDU 4.

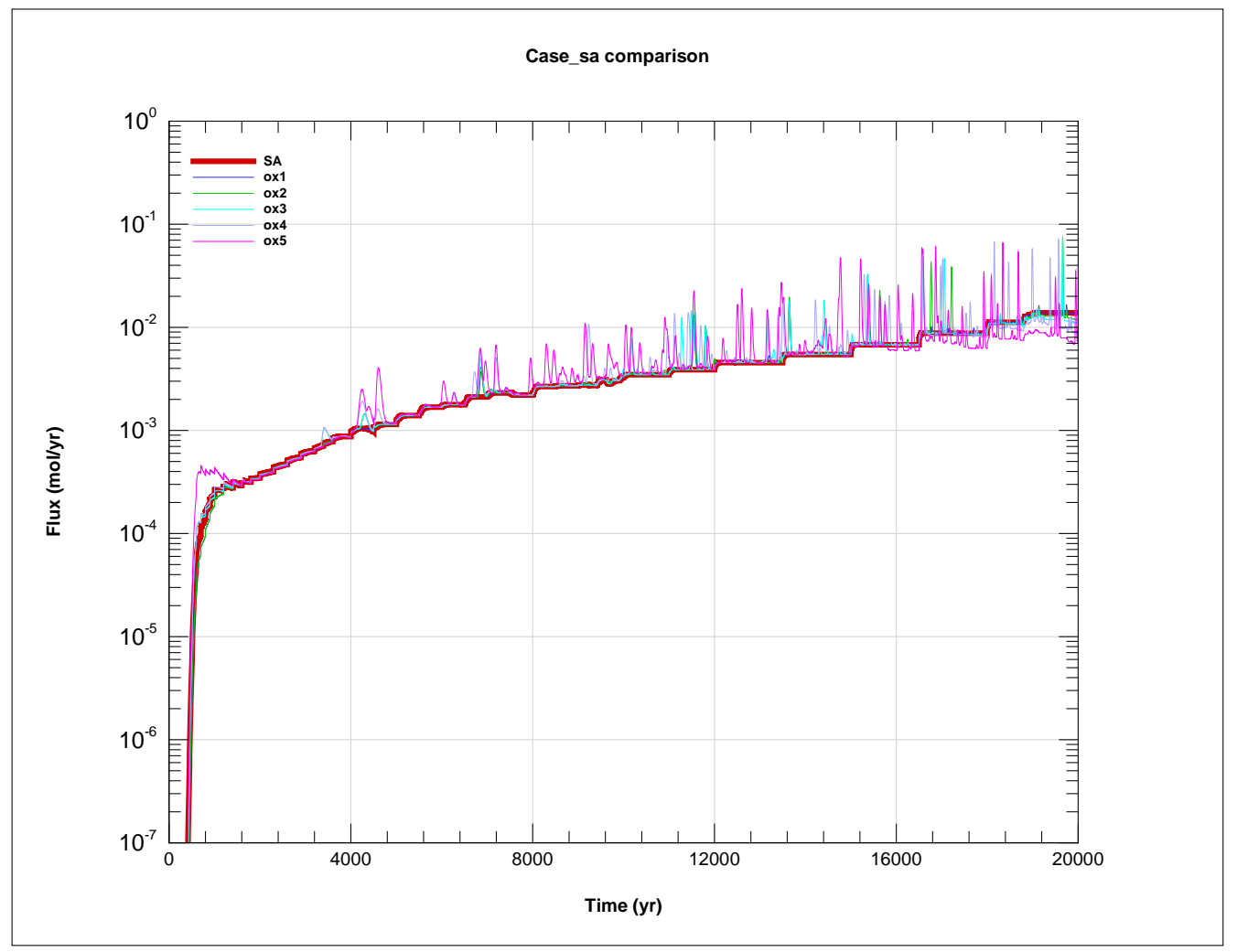

Figure 5-4. Oxygen sensitivity for SDU 1. 


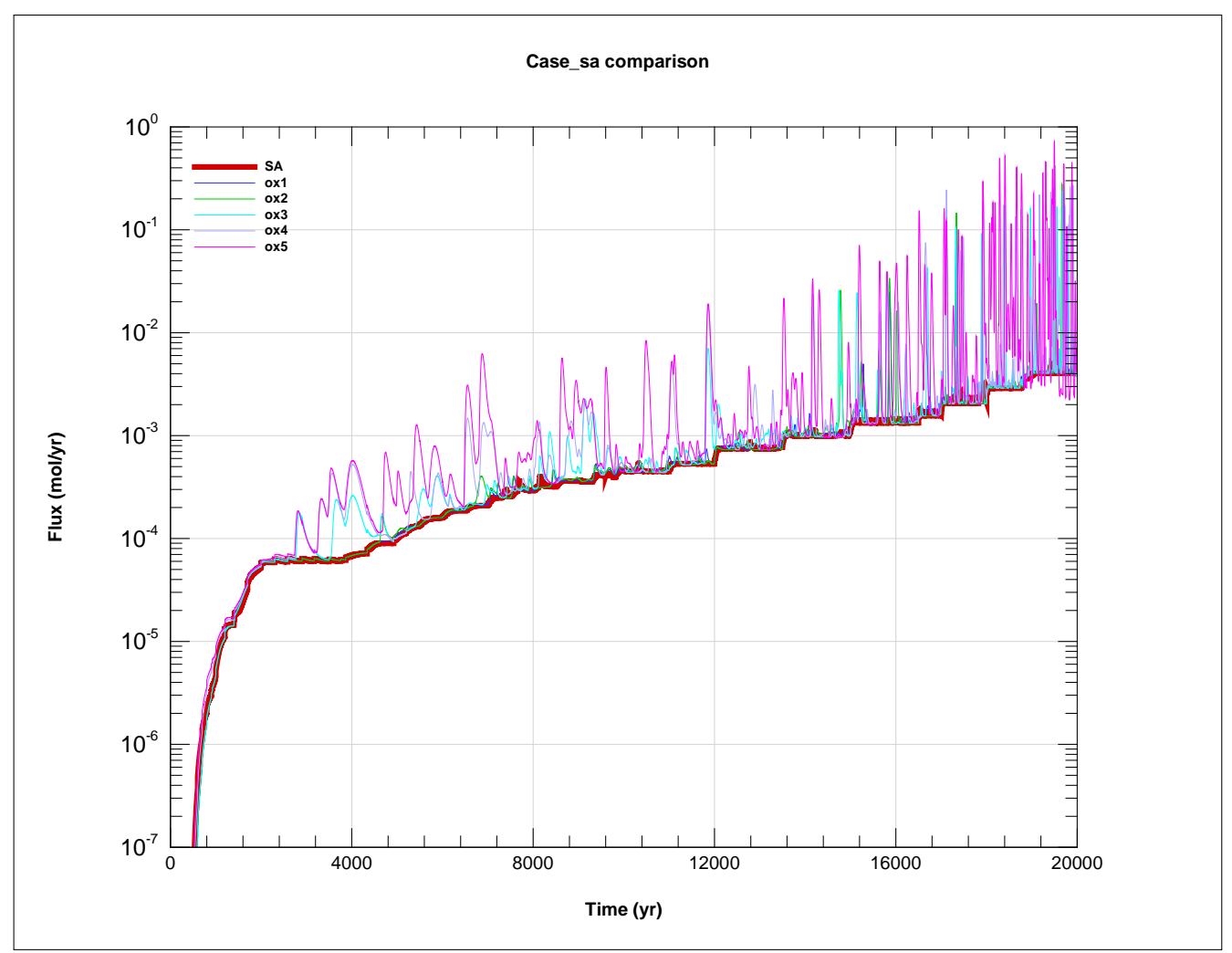

Figure 5-5. Oxygen sensitivity for SDU 2.

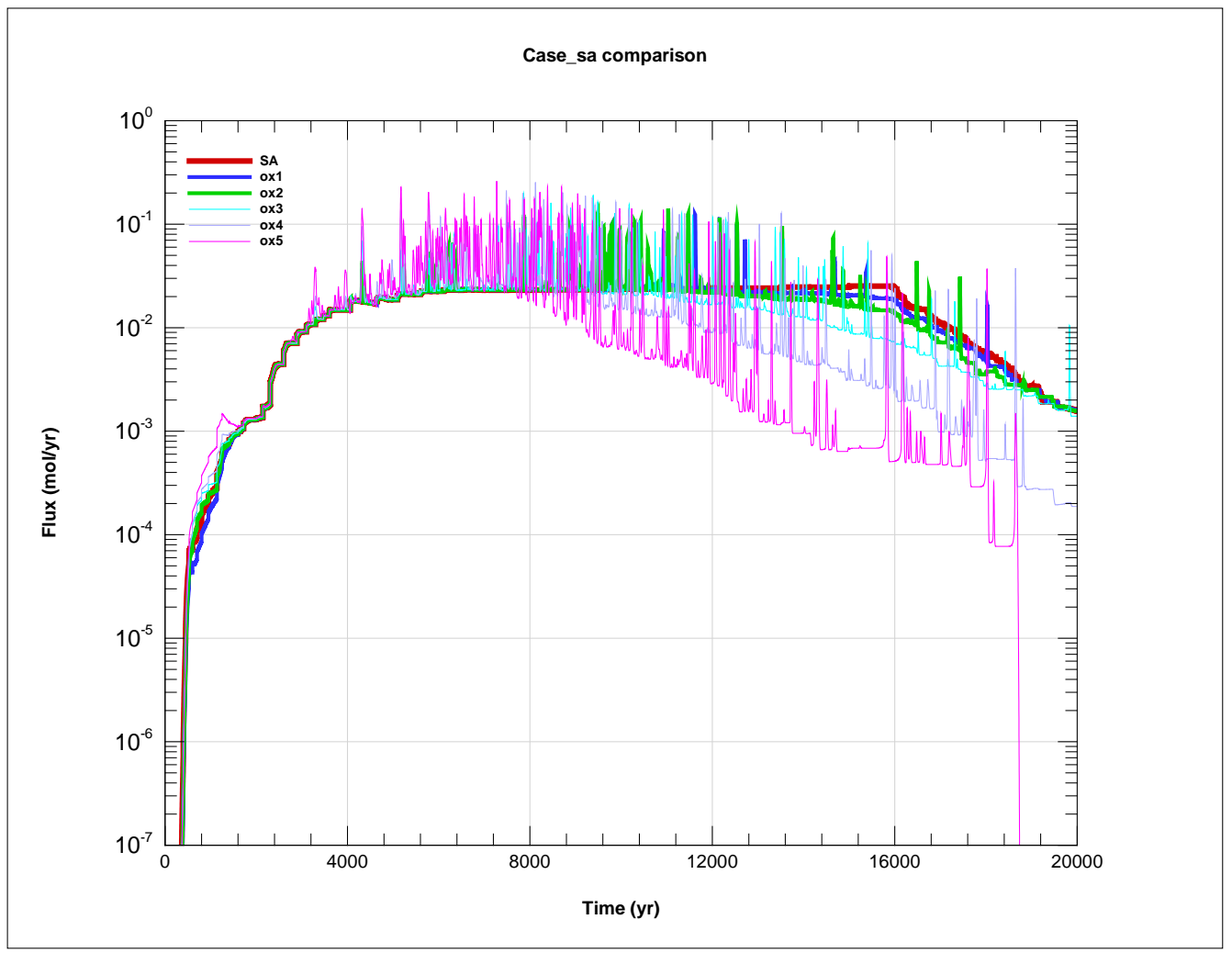

Figure 5-6. Oxygen sensitivity for SDU 4. 


\subsection{REFERENCES}

Altman, S. J., B. W. Arnold, R. W. Barnard, G. E. Barr, C. K. Ho, S. A. McKenna, and R. R. Eaton., Flow Calculations for Yucca Mountain Groundwater Travel Time (GWTT-95), Sandia Report SAND96-0819, September 1996.

Dixon, K., Moisture Retention Properties of High Temperature Cure ARP/MCU Saltstone Grout, SRNL-STI-2011-00661, Rev. 0, December 2011.

Durner, W., Hydraulic conductivity estimation for soils with heterogeneous pore structure, Water Resour. Res., 30(2), 211-223, 1994.

Flach, G. P., J. M. Jordan, and T. Whiteside, Numerical Flow and Transport Simulations Supporting the Saltstone Disposal Facility Performance Assessment, SRNL-STI-200900115, Rev. 1, June 2009.

Flach, G. P., Oxidation of Fractured Cementitious Materials in Performance Assessments, SRNL-L4321-2011-00004, March 24, 2011.

Flach, G. P., Relationship Between Dual-Domain Parameters and Practical Characterization Data, Ground Water, Vol. 50, No. 2, pages 216-229, 2012.

Flach, G. P., and F. G. Smith III, Degradation of Cementitious Materials Associated With Saltstone Disposal Units, SRNL-STI-2013-00118, March 2013.

Haggerty, R., S. A. McKenna, and L. C. Meigs, On the late-time behavior of tracer test breakthrough curves, Water Resour. Res., 36(12), 3467-3479, doi:10.1029/2000WR900214, 2000.

Haggerty, R., Harvey, C.F., Freiherr von Schwerin, C., Meigs, L., What controls the apparent timescale of solute mass transfer in aquifers and soils? A comparison of diverse experimental results, Water Resources Research, doi: 10.1029/2002WR001716, 2004.

Kaplan, D. I. and T. Hang, Estimated duration of the subsurface reducing environment produced by the Z-Area Saltstone Disposal Facility (U), WSRC-RP-2003-00362, Rev. 2. January 2003.

Kaplan, D. I. and D. Li, Solubility of Technetium Dioxides $\left(\mathrm{TcO}_{2}-\mathrm{C}, \mathrm{TcO}_{2} \cdot 1.6 \mathrm{H}_{2} \mathrm{O}\right.$ and $\mathrm{TcO}_{2} \cdot 2 \mathrm{H}_{2} \mathrm{O}$ ) in Reducing Cementitious Material Leachates: A Thermodynamic Calculation, SRNL-STI-2012-00769, Rev. 1, February 2013.

Phifer, M. A., M. R. Millings, and G. P. Flach, Hydraulic Property Data Package for the E-Area and Z-Area Soils, Cementitious Materials, and Waste Zones, WSRC-STI-200600198, September 2006.

Mualem, Y., A new model for predicting the hydraulic conductivity of unsaturated porous media, Water Resour. Res., 12(3), 513-522, doi:10.1029/WR012i003p00513, 1976. 
Painter, S.L. and R.T. Pabalan, Estimated Longevity of Reducing Environments in Grouted Systems for Radioactive Waste Disposal, Center for Nuclear Waste Regulatory Analyses, San Antonio, Texas, October 2009.

Peters, R. R., and E. A. Klavetter, A continuum model for water movement in an unsaturated fractured rock mass, Water Resour. Res., 24(3), 416-430, doi:10.1029/WR024i003p00416, 1988.

Priesack, E. and W. Durner, Closed-Form Expression for the Multi-Modal Unsaturated Conductivity Function, Vadose Zone Journal, vol. 5, 121-124, 2006.

Pruess, K., On water seepage and fast preferential flow in heterogeneous, unsaturated rock fractures, Journal of Contaminant Hydrology 30, 333-362, 1998.

Sheppard, R. E., PORFLOW Input to Support the Development of the SDF FY13 Special Analysis, SRR-CWDA_2013-00064, Rev. 1, April 30, 2013.

Šimůnek, J., N.J. Jarvis, M.Th. van Genuchten and A. Gärdenäs, Review and comparison of models for describing non-equilibrium and preferential flow and transport in the vadose zone, J. Hydrol. 272:14-35, 2003.

Smith, F.G., PORFLOW Modeling for a Preliminary Assessment of the Performance of New Saltstone Disposal Unit Designs, SRNL-STI-2012-00445, Rev. 1, September 6, 2012.

Smith, F. G., B. T. Butcher and G. P. Flach, Design Checking of PORFLOW Modeling Supporting the Saltstone FY13 Special Analysis, SRNL-L3200-2013-00022, June 4, 2013.

Smith, R. W., and J. C. Walton, The role of oxygen diffusion in the release of technetium from reducing cementitious waste forms, Mat. Res. Soc. Symp. Proc. vol. 294, 1993.

SRR Closure \& Waste Disposal Authority, Performance Assessment for the Saltstone Disposal Facility at the Savannah River Site, SRR-CWDA-2009-00017, Rev. 0, October 2009.

SRR Closure \& Waste Disposal Authority, Comment Response Matrix for Nuclear Regulatory Commission RAI-2009-02 Second Request for Additional Information (RAI) on the Saltstone Disposal Facility Performance Assessment (SRR-CWDA-2009-00017, Revision 0, dated October 29, 2009), SRR-CWDA-2011-00044, Rev. 1, August 2011.

SRR Closure \& Waste Disposal Authority, FY2013 Special Analysis for the Saltstone Disposal Facility at the Savannah River Site, SRR-CWDA-2013-00062, Rev. 0, June 2013.

van Genuchten, M. T., A closed-form equation for predicting the hydraulic conductivity of unsaturated soils, Soil Science Society America Journal, vol. 44, no. 5, pp. 892-898, 1980. 
Wang, J. S. Y., and T. N. Narasimhan, Hydrologic Mechanisms Governing Fluid Flow in a Partially Saturated, Fractured, Porous Medium, Water Resour. Res., 21(12), 18611874, doi:10.1029/WR021i012p01861, 1985.

Zinn, B., and Harvey, C. F., When good statistical models Of aquifer heterogeneity go bad: A comparison of flow, dispersion and mass transfer in Multigaussian and Connected Conductivity Fields, Water Resources Research, 39(3) ,1051, 2003. 


\section{Appendix A - PORFLOW input file for a one cell slag oxidation simulation.}

\section{Problem specification, analytic solution, and PORFLOW simulation result:}

\begin{tabular}{|c|c|c|}
\hline \multicolumn{3}{|l|}{ Infiltrating liquid properties } \\
\hline \multirow[t]{2}{*}{ Darcy velocity } & 10 & $\mathrm{~cm} / \mathrm{yr}$ \\
\hline & 3.17E-07 & $\mathrm{cm} / \mathrm{s}$ \\
\hline \multirow[t]{2}{*}{ Dissolved oxygen concentration } & 1.06 & meq-/L \\
\hline & $1.06 \mathrm{E}-03$ & $\mathrm{meq}-/ \mathrm{mL}$ \\
\hline \multirow[t]{2}{*}{ ReOx rate } & $3.36 \mathrm{E}-10$ & $\mathrm{meq}-/ \mathrm{cm}^{2}-\mathrm{s}$ \\
\hline & $1.06 \mathrm{E}-02$ & $\mathrm{meq}-/ \mathrm{cm}^{2}-\mathrm{yr}$ \\
\hline \multicolumn{3}{|l|}{ Solid properties } \\
\hline \multirow[t]{2}{*}{ Thickness } & 0.01 & $m$ \\
\hline & 1 & $\mathrm{~cm}$ \\
\hline Porosity & 0.5 & - \\
\hline Solid density & 2.50 & $\mathrm{~g} / \mathrm{mL}$ \\
\hline Bulk density & 1.25 & $\mathrm{~g} / \mathrm{mL}$ \\
\hline Slag concentration & 1.000 & meq-/g \\
\hline ReOx capacity & 1.25 & $\mathrm{meq}-/ \mathrm{cm}^{2}$ \\
\hline \multicolumn{3}{|l|}{ Slag oxidation times } \\
\hline Time to exhaust capacity & $3.72 E+09$ & $\mathrm{~s}$ \\
\hline Calculated time: & 118 & $\mathrm{yr}$ \\
\hline PORFLOW time: & 118 & yr \\
\hline
\end{tabular}

PORFLOW produced the same oxidation time of 118 years using the added command: CONVergence for SPECies in COUPled mode with a maximum of 2 iterations

\section{PORFLOW input file:}

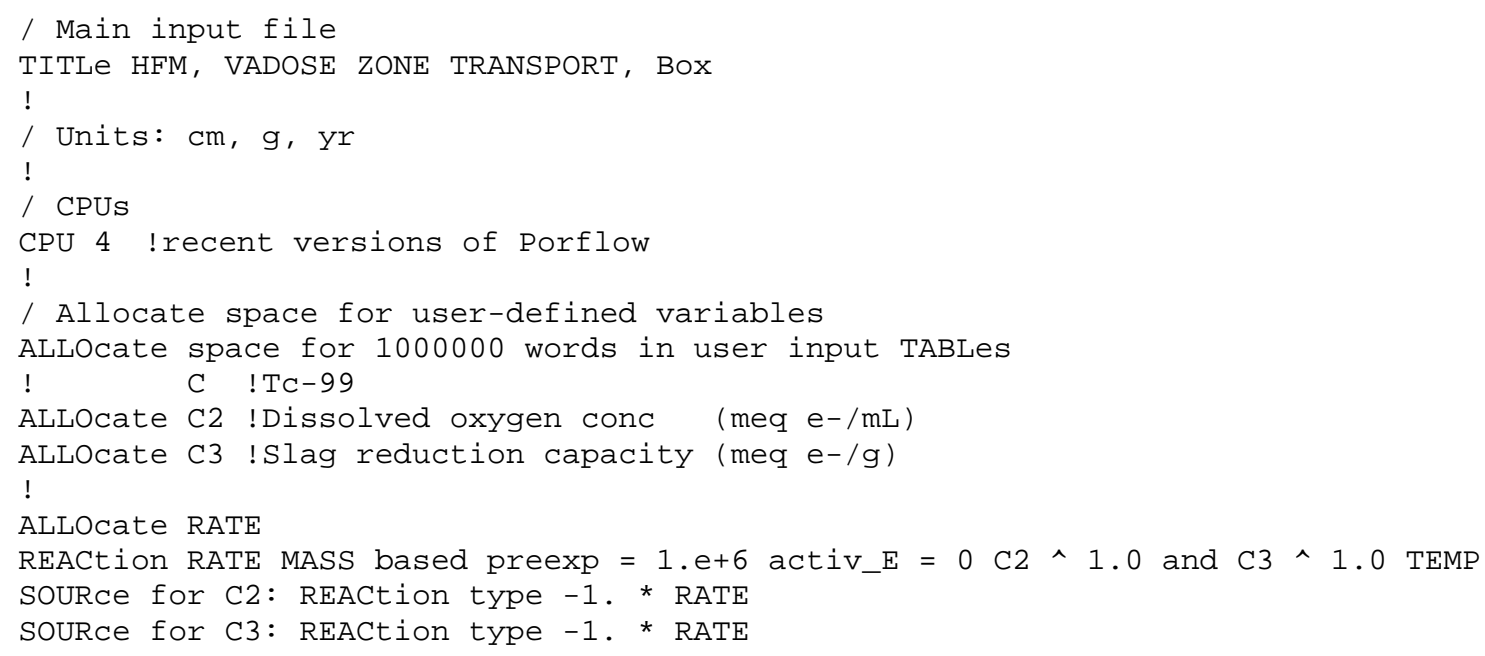




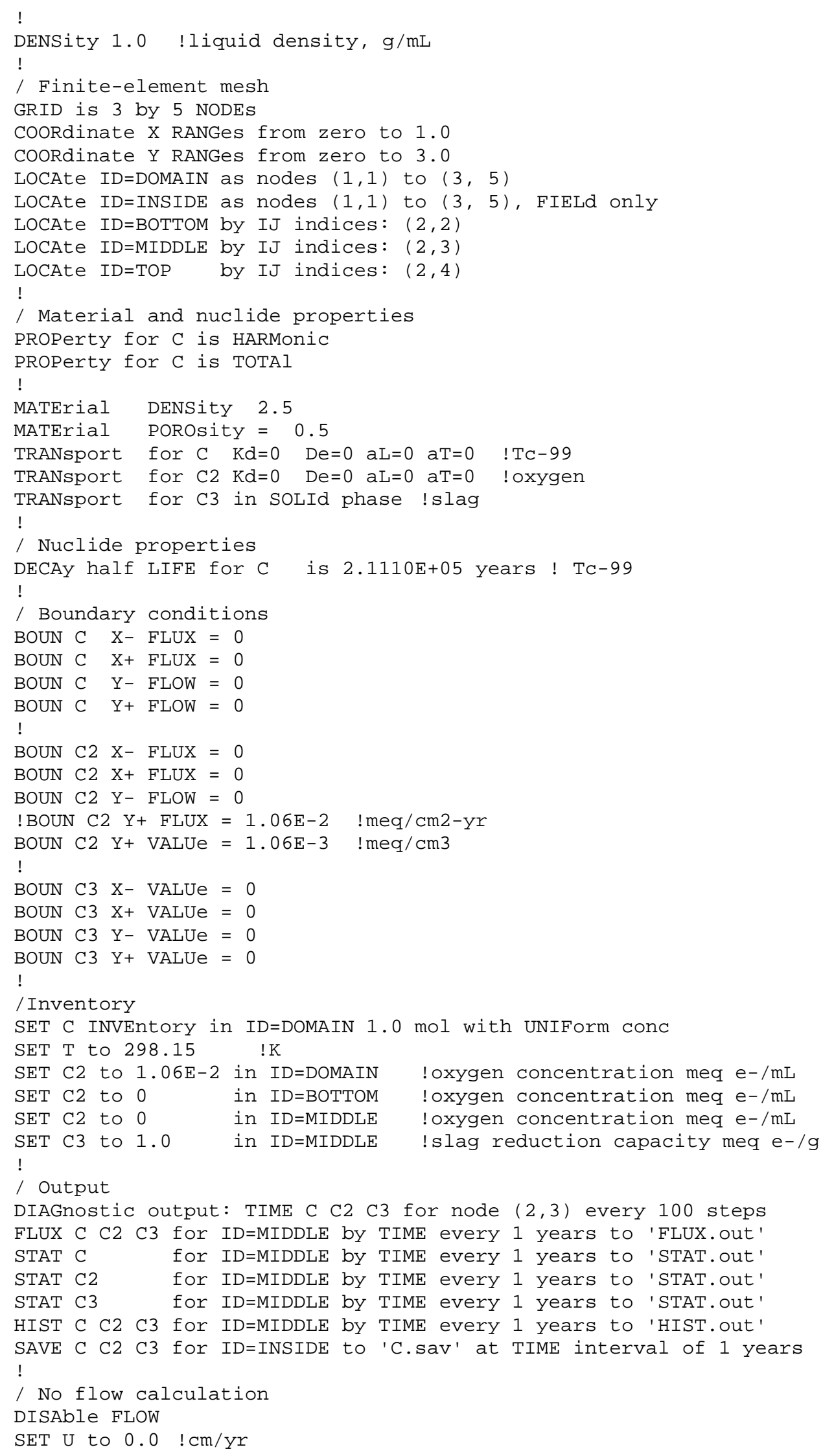


SRNL-STI-2013-00280, REVISION 0

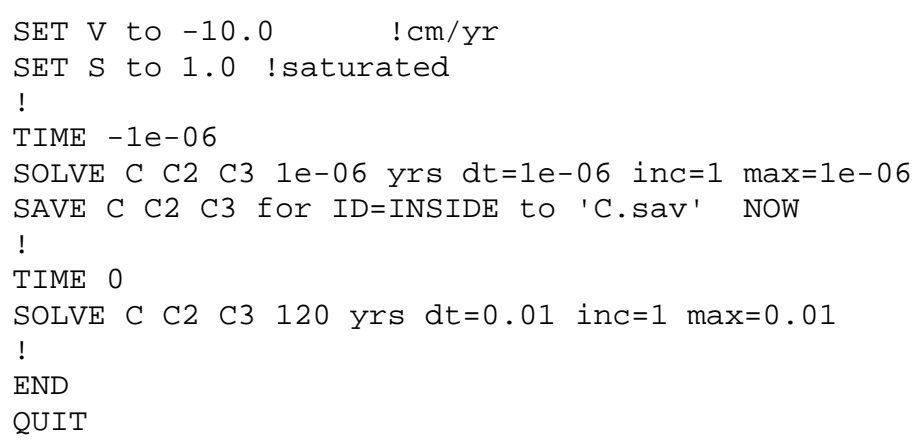




\section{Appendix B - PORFLOW input file for a 1D slag oxidation simulation.}

\section{Problem specifications, analytic solutions, and PORFLOW simulation results:}

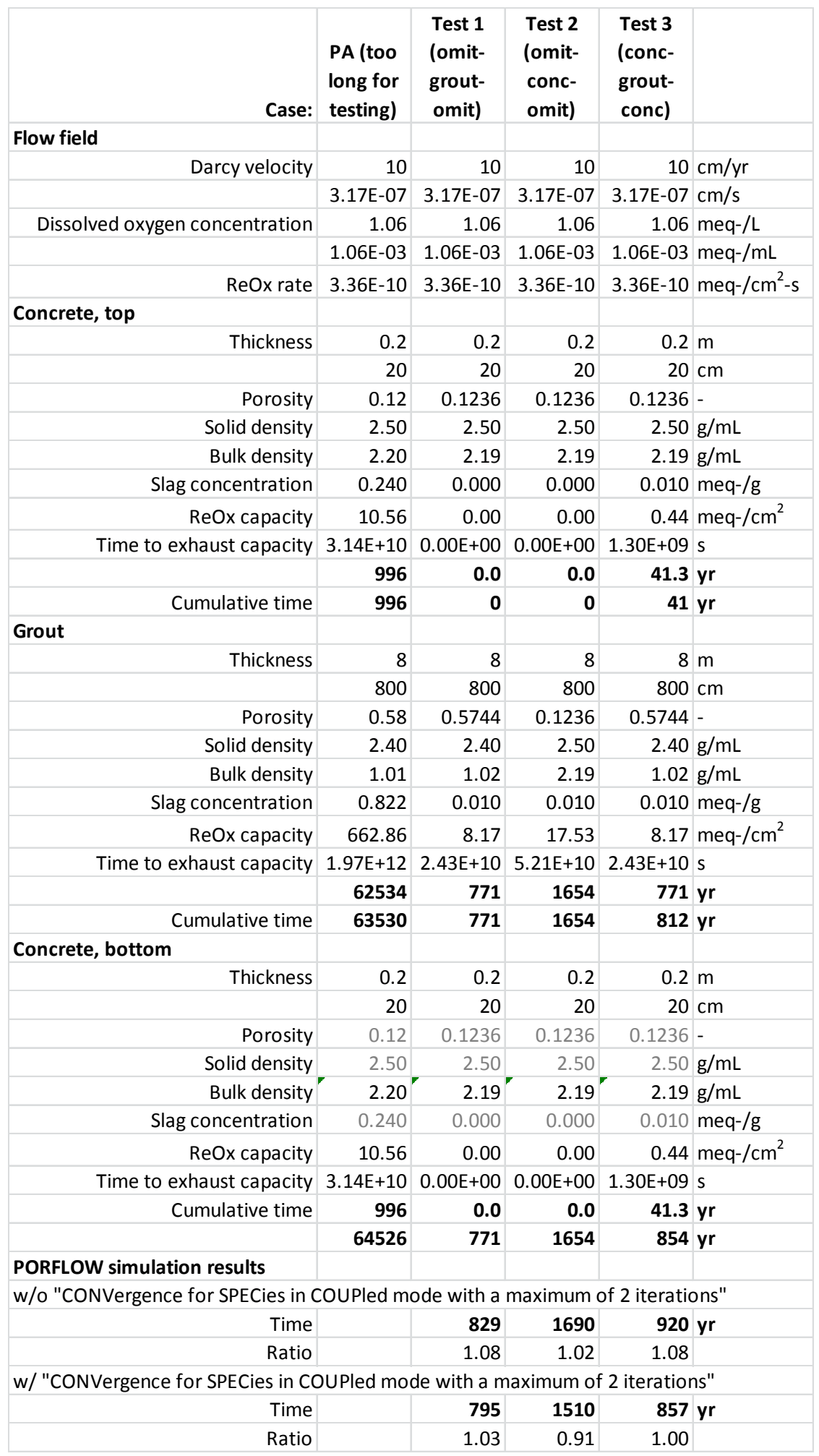


SRNL-STI-2013-00280, REVISION 0

\section{PORFLOW input file for Test 3, no SPECies COUPling:}

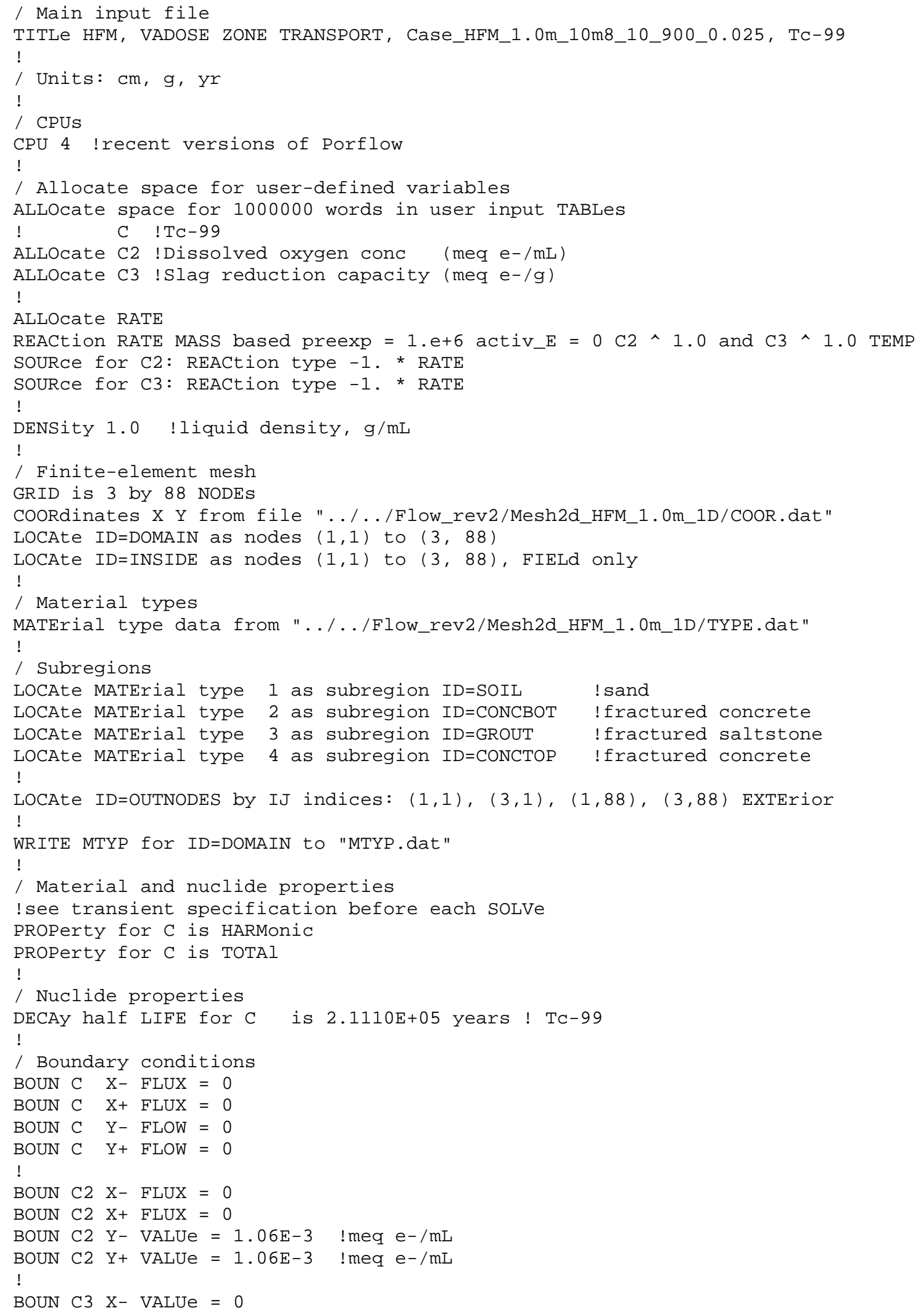




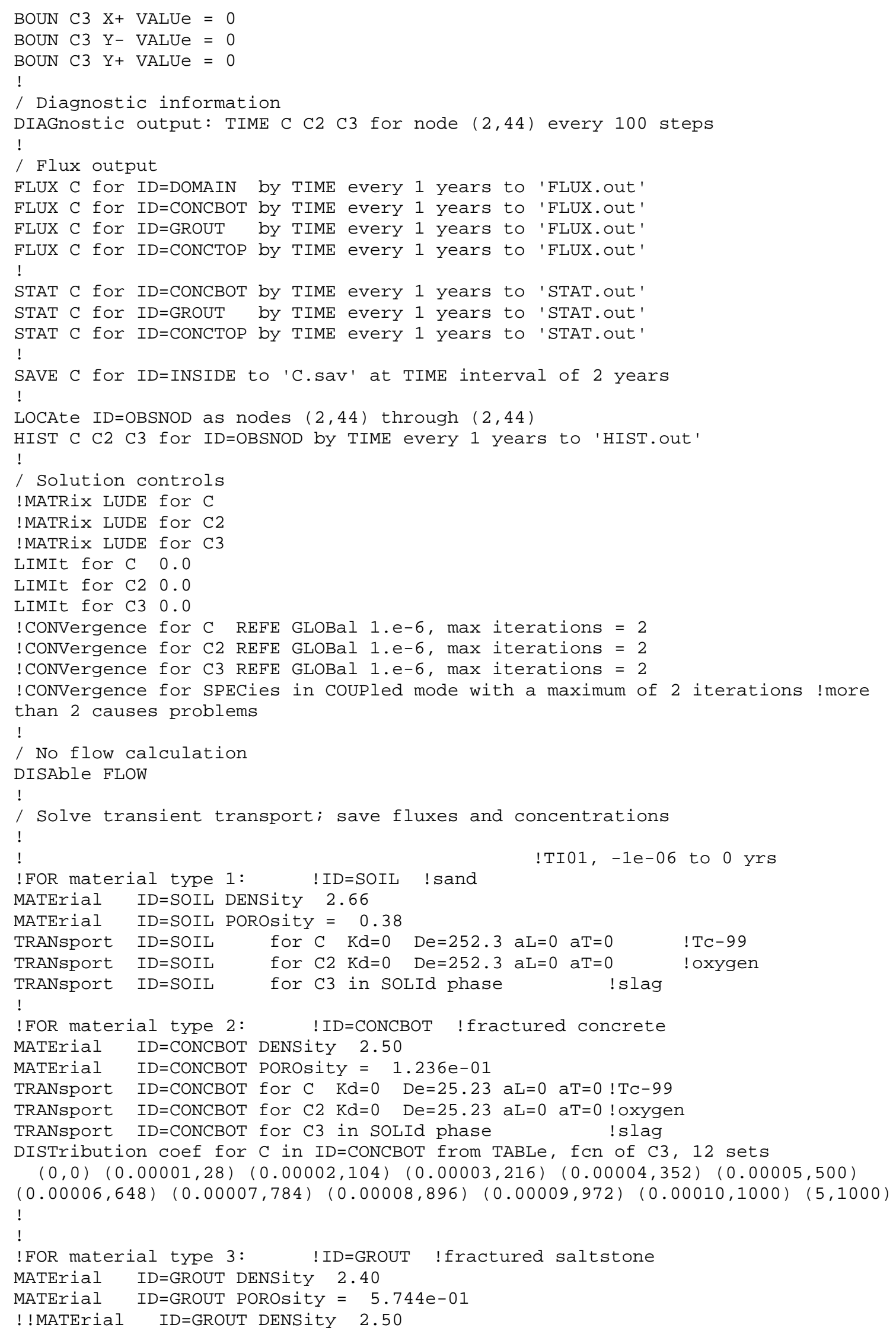


SRNL-STI-2013-00280, REVISION 0

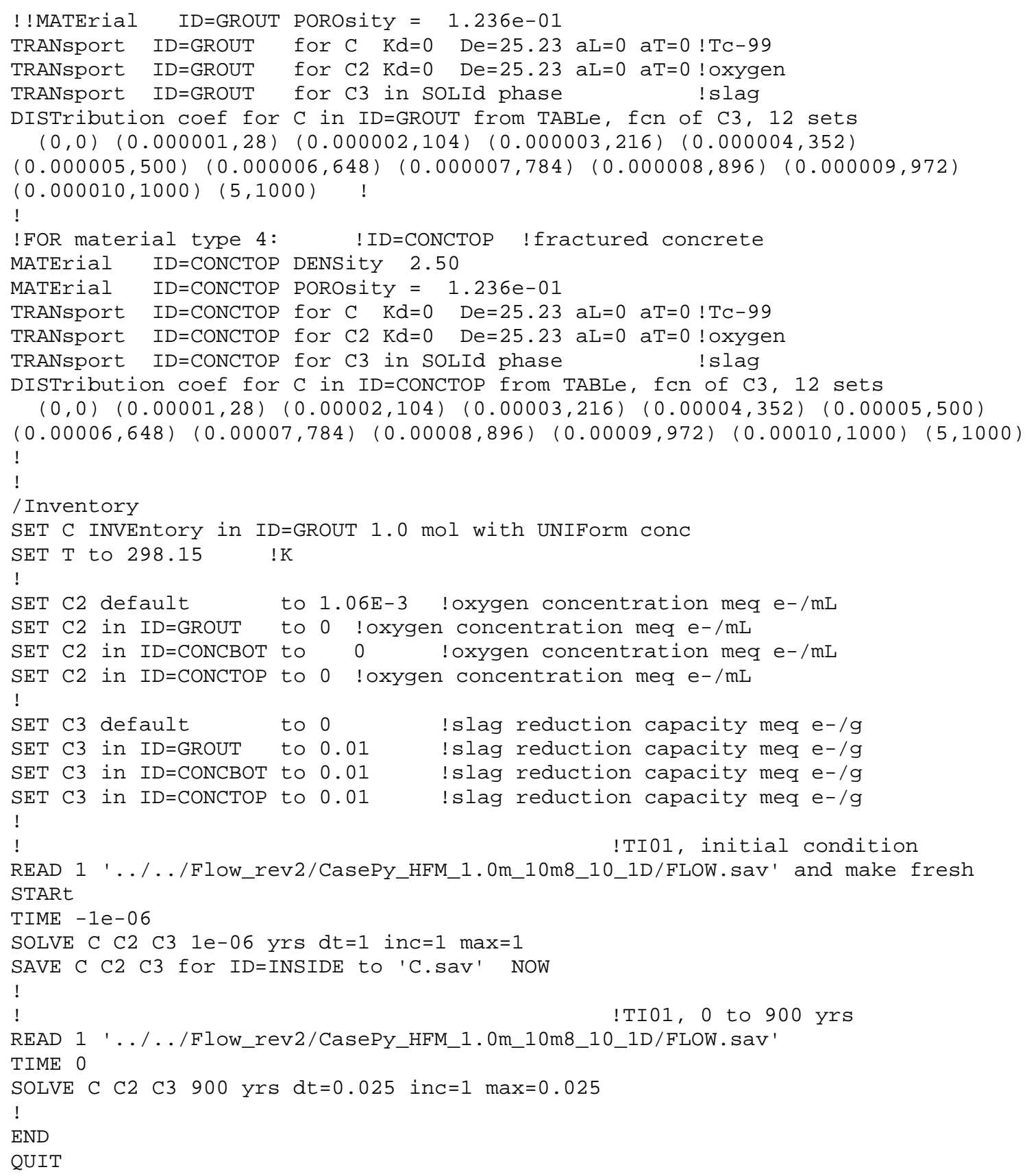




\section{Appendix C - PORFLOW input file for a 2D slag oxidation simulation.}

\section{Problem specification:}

\begin{tabular}{|c|c|c|}
\hline parameter & value & units \\
\hline sorption coefficient for oxidized conditions, $\mathrm{Kd}_{\mathrm{Ox}}$ & 0.01 & $\mathrm{~mL} / \mathrm{g}$ \\
\hline sorption coefficient for reduced conditions, $\mathrm{Kd}_{\mathrm{Re}}$ & 1000 & $\mathrm{~mL} / \mathrm{g}$ \\
\hline \multirow[t]{3}{*}{ saturated liquid phase oxygen concentration, $\mathrm{C}_{\mathrm{Ox}}$} & 1.06 & meq e-/L \\
\hline & 0.00106 & meq e-/mL \\
\hline & 1060 & meq e- $/ \mathrm{m}^{3}$ \\
\hline reduction capacity, $\mathrm{r}_{\mathrm{Ox}}$ & 0.01 & meq-/g \\
\hline porosity, $n$ & 0.58 & - \\
\hline effective diffusion coefficient, $D_{e}$ & 8.0E-07 & $\mathrm{cm}^{2} / \mathrm{s}$ \\
\hline solid density, $\rho_{\mathrm{s}}$ & 2.4 & $\mathrm{~g} / \mathrm{cm}^{3}$ \\
\hline bulk density, $\rho_{b}$ & 1.008 & $\mathrm{~g} / \mathrm{cm}^{3}$ \\
\hline \multirow[t]{2}{*}{$2 \mathrm{nD}_{\mathrm{e}} \mathrm{C}_{\mathrm{Ox}} / \mathrm{r}_{\mathrm{Ox}} \rho_{\mathrm{b}}$} & $9.76 \mathrm{E}-08$ & $\mathrm{~cm}^{2} / \mathrm{s}$ \\
\hline & 3.08E-04 & $\mathrm{m}^{2} / \mathrm{yr}$ \\
\hline retardation for oxidized conditions, $\mathrm{R}_{\mathrm{Ox}}$ & 1.017379 & \\
\hline retardation for reduced conditions, $\mathrm{R}_{\mathrm{Re}}$ & 1738.931 & \\
\hline
\end{tabular}

\section{PORFLOW input file:}

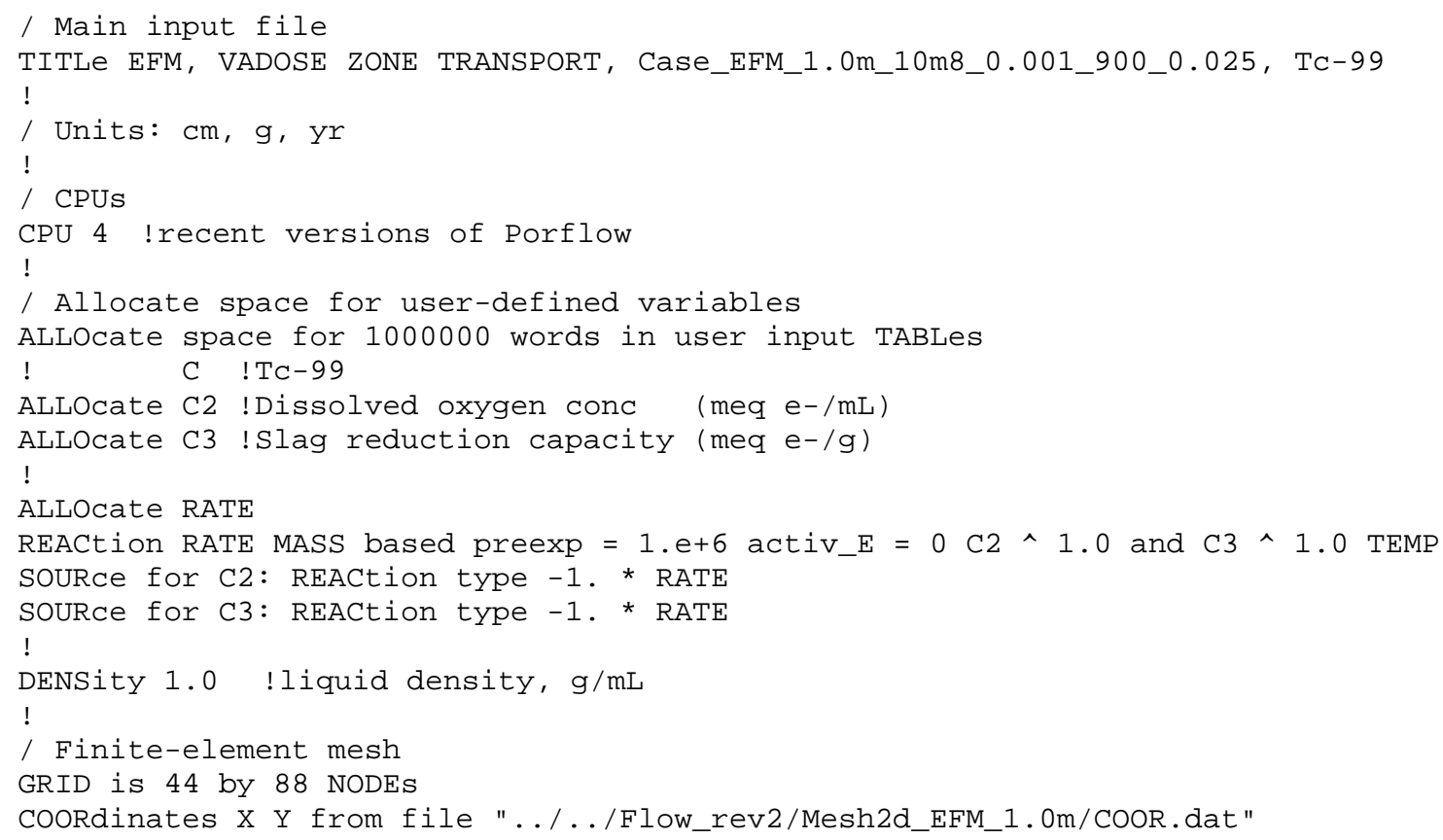


SRNL-STI-2013-00280, REVISION 0

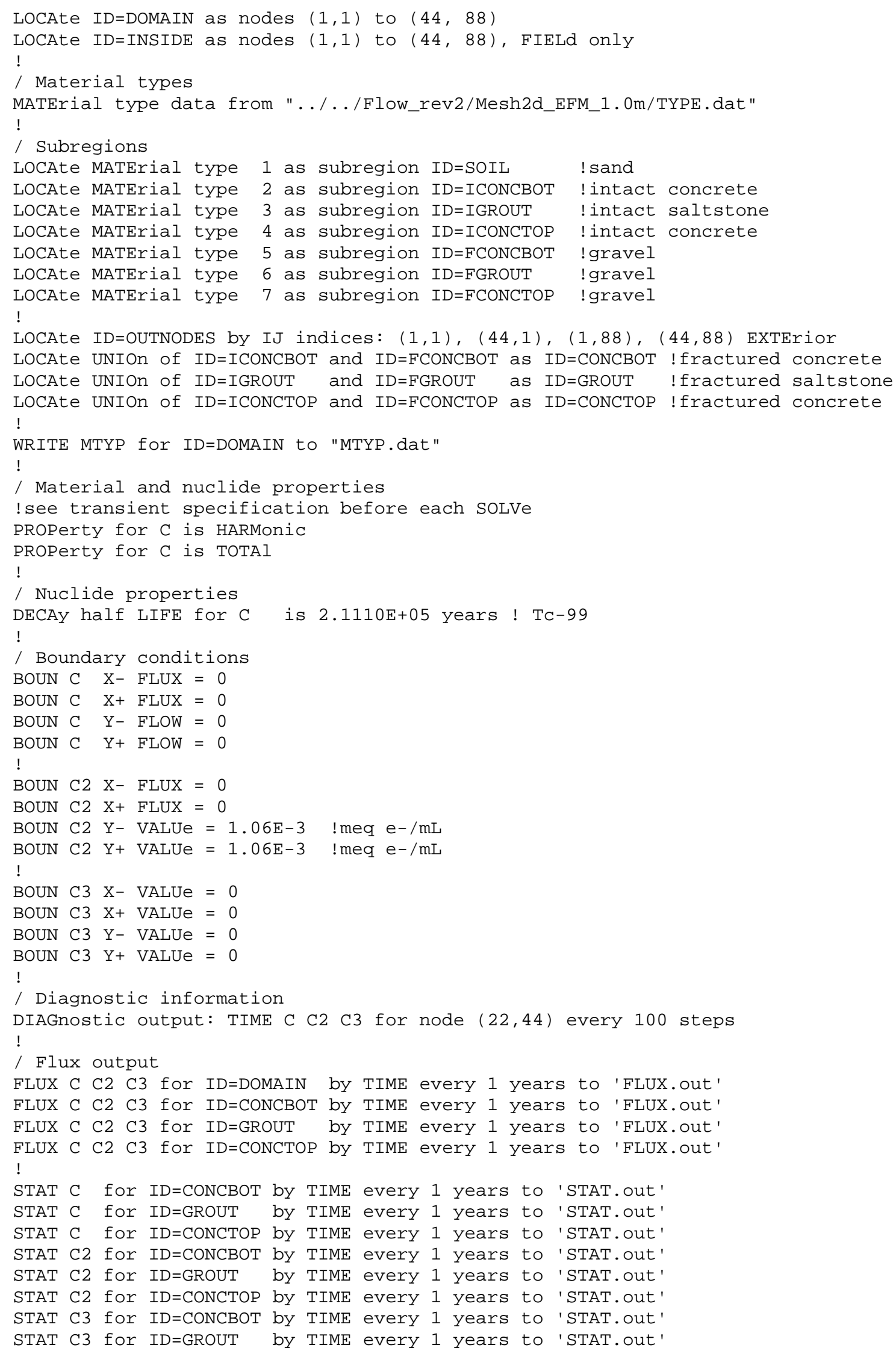




\section{SRNL-STI-2013-00280, REVISION 0}

STAT C3 for ID=CONCTOP by TIME every 1 years to 'STAT. out'

SAVE C C2 C3 for ID=INSIDE to 'C.sav' at TIME interval of 2 years

LOCAte ID=OBSNOD as nodes $(22,44)$ through $(22,44)$

HIST C C2 C3 for ID=OBSNOD by TIME every 1 years to 'HIST.out'

!

/ Solution controls

!MATRiX LUDE for $\mathrm{C}$

!MATRIX LUDE for C2

!MATRiX LUDE for C3

LIMIt for $C \quad 0.0$

LIMIt for C2 $\odot . \Theta$

LIMIt for C3 0.0

! CONVergence for $C$ REFE GLOBal 1.e-6, max iterations $=2$

! CONVergence for C2 REFE GLOBal 1.e-6, $\max$ iterations $=2$

! CONVergence for C3 REFE GLOBal 1.e-6, max iterations $=2$

! CONVergence for SPECies in COUPled mode with a maximum of 2 iterations !more

than 2 causes problems

!

/ No flow calculation

DISAble FLOW

!

/ Solve transient transport; save fluxes and concentrations

! !TI01, -1e-06 to $\odot$ yrs

!FOR material type 1: IID=SOIL ! sand

MATErial ID=SOIL DENSity 2.66

MATErial ID $=$ SOIL POROsity $=0.38$

TRANsport ID $=$ SOIL for $C \quad K d=0 \quad D e=252.3 \quad$ LL $=0$ aT $=0 \quad$ !TC -99

TRANsport ID=SOIL for $\mathrm{C} 2 \mathrm{Kd}=0$ $\mathrm{De}=252.3$ aL=0 $\mathrm{aT}=0$ ! oxygen

TRANsport ID=SOIL for C3 in SOLId phase !slag

!FOR material type 2: !ID=ICONCBOT ! concrete

MATErial ID=ICONCBOT DENSity 2.50

MATErial ID $=$ ICONCBOT POROsity $=0.12$

TRANsport ID =ICONCBOT for $C \quad K d=0 \quad D e=25.23$ aL=0 aT=0 !TC -99

TRANsport ID=ICONCBOT for $\mathrm{C} 2 \mathrm{Kd}=0$ De=25.23 aL=0 aT=0 !oxygen

TRANsport ID=ICONCBOT for C3 in SOLId phase !slag

DISTribution coef for $C$ in ID=ICONCBOT from TABLe, fcn of C3, 12 sets

$(0,0)(0.00001,28)(0.00002,104)(0.00003,216) \quad(0.00004,352)(0.00005,500)$

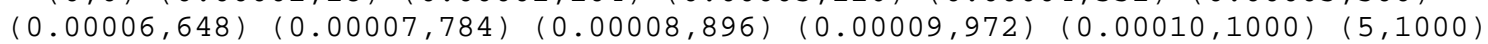

!

!FOR material type 3: IID=IGROUT !saltstone

MATErial ID=IGROUT DENSity 2.40

MATErial ID =IGROUT POROSity $=0.58$

TRANsport ID =IGROUT for $\mathrm{C} \quad \mathrm{Kd}=0 \quad \mathrm{De}=25.23$ aL=0 $\mathrm{aT}=0 \quad$ !TC -99

TRANsport ID=IGROUT for $\mathrm{C} 2 \mathrm{Kd}=0$ De=25.23 aL=0 aT=0 !oxygen

TRANsport ID=IGROUT for $\mathrm{C3}$ in SOLId phase !slag

DISTribution coef for $C$ in ID=IGROUT from TABLe, fen of C3, 12 sets

$\begin{array}{llllll}(0,0) & (0.000001,28) & (0.000002,104) & (0.000003,216) & (0.000004,352)\end{array}$

$(0.0000005,500)(0.0000006,648)(0.000007,784)(0.0000008,896)(0.0000009,972)$

$(\odot .0 \odot \odot \odot 10,10 \odot \odot)(5,100 \odot)$

!FOR material type 4: !ID=ICONCTOP ! concrete

MATErial ID=ICONCTOP DENSity 2.50

MATErial ID $=$ ICONCTOP POROSity $=0.12$

TRANsport ID=ICONCTOP for $\mathrm{C} \quad \mathrm{Kd}=0 \quad \mathrm{De}=25.23 \quad \mathrm{aL}=0$ aT=0 !TC -99

TRANsport ID=ICONCTOP for $\mathrm{C} 2 \mathrm{Kd}=0$ De=25.23 aL=0 aT=0 !oxygen

TRANsport ID=ICONCTOP for C3 in SOLId phase !slag

DISTribution coef for $C$ in ID=ICONCTOP from TABLe, fon of C3, 12 sets 


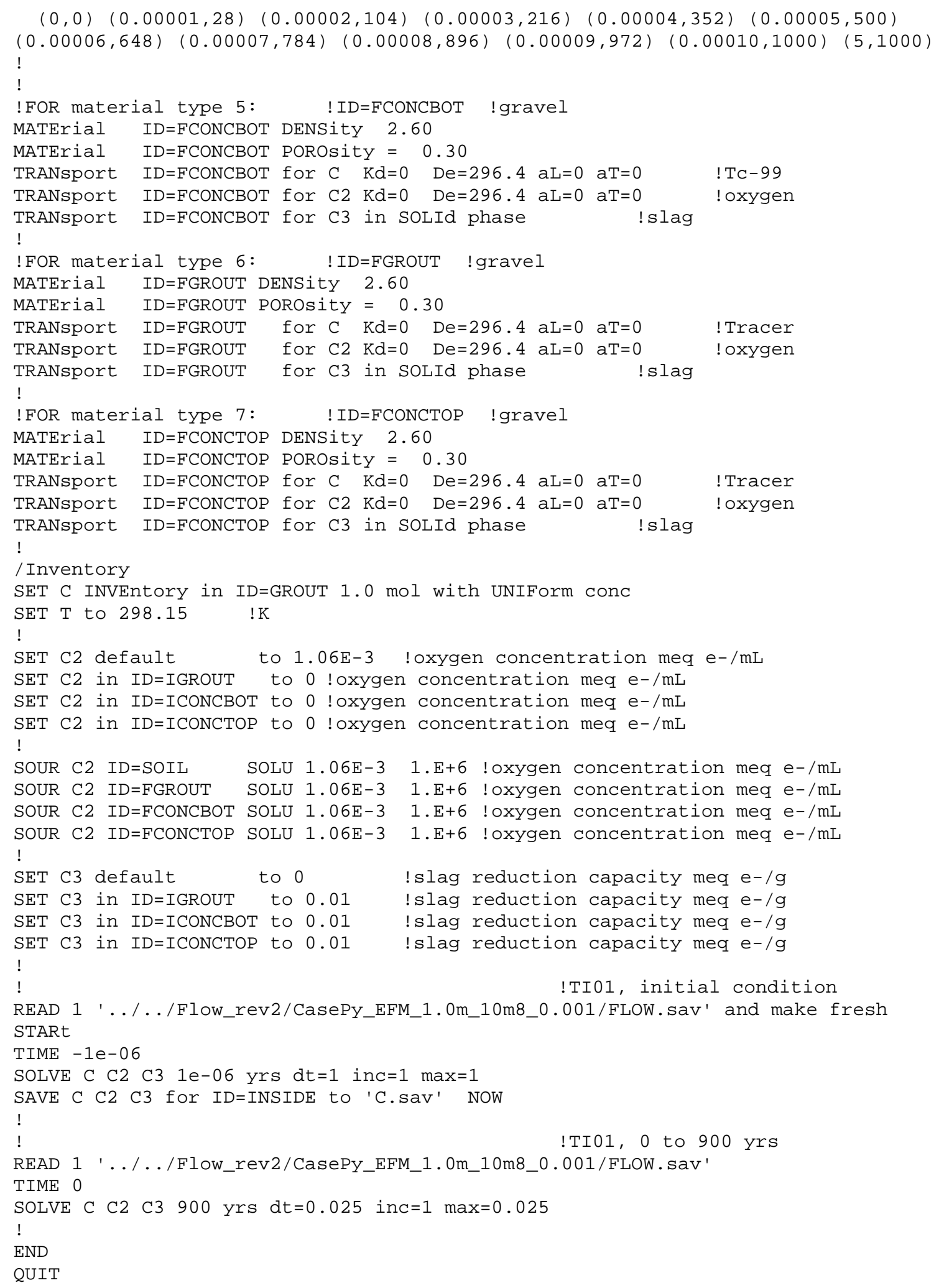




\section{Appendix D - Example implementataion of combined redox and solubility controls on Tc-99 transport.}

\section{PORFLOW input file snippet with highlights:}

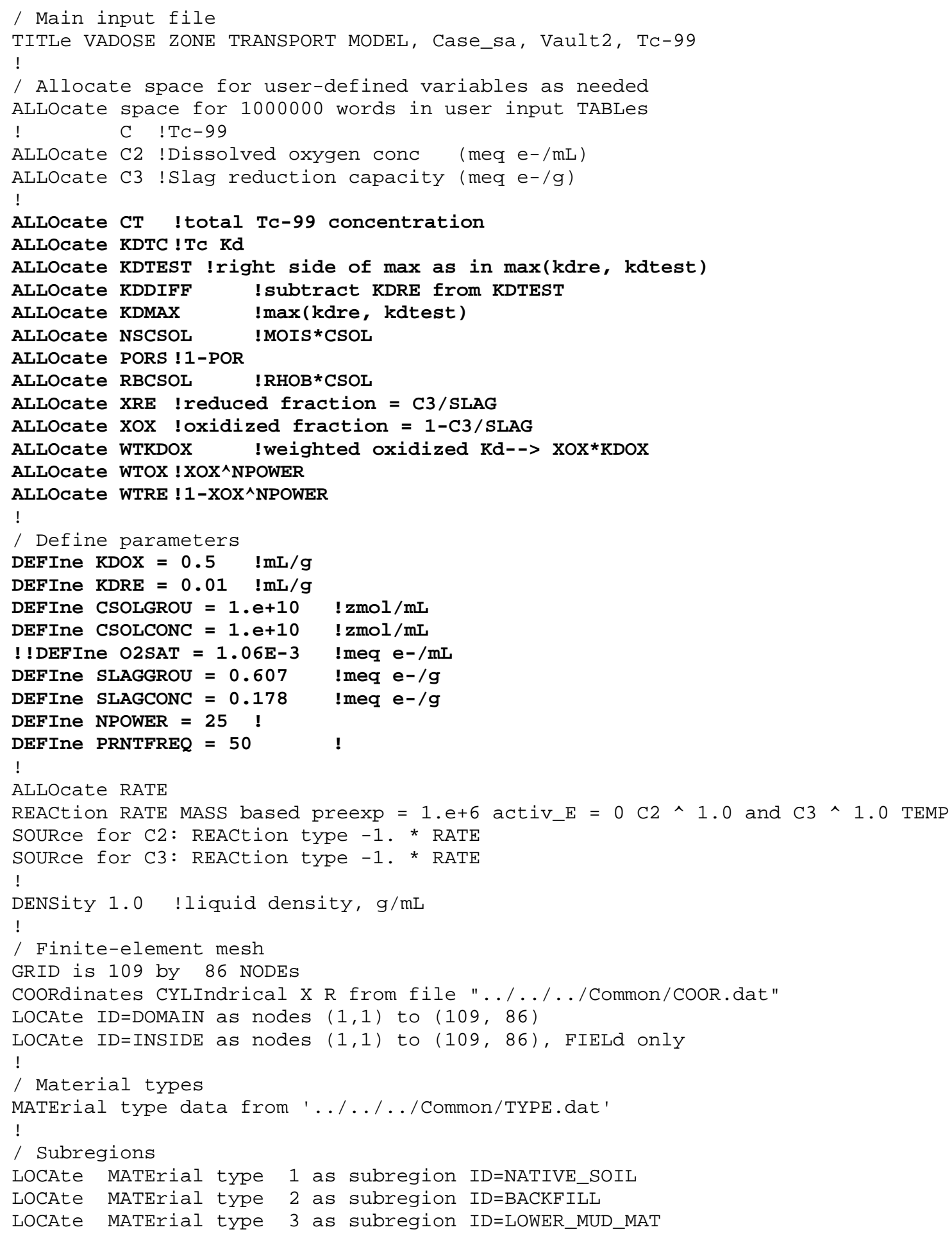


!!!!! LOCAte MATErial type 4 as subregion ID=SHOT_CRETE

LOCAte MATErial type 5 as subregion ID=UPPER_MUD_MAT

LoCAte MATErial type 6 as subregion ID=FLOOR

LOCAte MATErial type 7 as subregion ID=SALTSTONE

LOCAte MATErial type 8 as subregion ID=CLEAN_GROUT

LOCAte MATErial type 9 as subregion ID=HDPE

LOCAte MATErial type 10 as subregion ID=SHEET_DRAIN

LoCAte MATErial type 11 as subregion ID=WALL

!! LOCAte MATErial type 12 as subregion ID=DIAPHRAGM

LoCAte MATErial type 13 as subregion ID=FLOOR_HDPE_GCL

LOCAte MATErial type 14 as subregion ID=ROOF

LOCAte MATErial type 15 as subregion ID=ROOF_HDPE_GCL

LOCAte MATErial type 16 as subregion ID=SAND_DRAIN

!! LOCAte MATErial type 17 as subregion ID=CRACK

!! LOCAte MATErial type 18 as subregion ID=COLUMN

LOCAte MATErial type 19 as subregion ID=JOINT

LOCAte MATErial type 20 as subregion ID=FF_ROOF

LoCAte MATErial type 21 as subregion ID=FF_GROUT1

LOCAte MATErial type 22 as subregion ID=FF_GROUT2

LOCAte MATErial type 23 as subregion ID=FF_GROUT3

LOCAte MATErial type 24 as subregion ID=FF_GROUT4

LoCAte MATErial type 25 as subregion ID=FF_GROUT5

LOCAte MATErial type 26 as subregion ID=FF_GROUT6

LOCAte MATErial type 27 as subregion ID=FF_GROUT7

LOCAte MATErial type 28 as subregion ID=FF_GROUT8

LOCAte MATErial type 29 as subregion ID=FF_GROUT9

LOCAte MATErial type 30 as subregion ID=FF_GROUT10

LOCAte MATErial type 31 as subregion ID=FF_GROUT11

!! LOCAte MATErial type 32 as subregion ID=FF_GROUT12

!! LOCAte MATErial type 33 as subregion ID=FF_GROUT13

LOCAte MATErial type 34 as subregion ID=FF_FLOOR

!! LOCAte MATErial type 35 as subregion ID=COL_BOTTOM

!! LOCAte MATErial type 36 as subregion ID=0X_CRACK

!! LOCAte MATErial type 37 as subregion ID=TOP_SALTSTONE

LOCAte MATErial type 38 as subregion ID=FF_ROOF_HDPE

LOCAte MATErial type 39 as subregion ID=FF_FLOOR_HDPE

LOCAte MATErial type 40 as subregion ID=FF_LOWER_MUD

LOCAte MATErial type 41 as subregion ID=FF_UPPER_MUD

!

LOCATe ID=OUTNODES by IJ indices: $(1,1),(1,92),(106,1),(106,92)$ EXTErior

!

LOCATE UNIOn of ID=SALTSTONE and ID=CLEAN_GROUT as ID=TMP1

LOCATE UNIOn of ID=TMP1 and ID=SHEET_DRAIN as ID=GROUT

!

LOCATE UNIOn of ID=FLOOR and ID=ROOF as ID=TMP3

LOCATe UNIOn of ID=TMP3 and ID=WALL as ID=TMP4

LOCATe UNIOn of ID=TMP4 and ID=UPPER_MUD_MAT as ID=TMP5

LOCATe UNIOn of ID=TMP5 and ID=FLOOR_HDPE_GCL as ID=TMP6

LOCATe UNIOn of ID=TMP6 and ID=RO0F_HDPE_GCL as ID=TMP7

LOCATE UNIOn of ID=TMP7 and ID=HDPE as ID=VAULT

!

LOCATe UNIOn of ID=GROUT and ID=VAULT as ID=VAULT_OUT

!

LOCAte by EXCLuding ID=VAULT_OUT from domain to make ID=NOT_VAULT

!

!

LOCAte UNIOn of ID=TMP5 and ID=FF_UPPER_MUD as ID=TMP10

LOCATE UNIOn of ID=TMP10 and ID=FF_FLOOR as ID=RECONC !

LOCATe UNIOn of ID=GROUT and ID=SHEET_DRAIN

LOCATE UNIOn of ID=TMP11 and ID=FF_GROUT1

LOCATe UNIOn of ID=TMP12 and ID=FF_GROUT2

LOCAte UNIOn of ID=TMP13 and ID=FF_GROUT3

as $\mathrm{ID}=\mathrm{TMP} 11$

as ID $=$ TMP12

as $\mathrm{ID}=\mathrm{TMP} 13$

as ID=TMP14 
LOCATE UNIOn of ID=TMP14 and ID=FF_GROUT4 LOCATe UNIOn of ID=TMP15 and ID=FF_GROUT5 LOCATe UNIOn of ID=TMP16 and ID=FF_GROUT6 LOCATE UNIOn of ID=TMP17 and ID=FF_GROUT7 LOCAte UNIOn of ID=TMP18 and ID=FF_GROUT8 LOCATE UNIOn of ID=TMP19 and ID=FF_GROUT9 LOCATE UNIOn of ID=TMP20 and ID=FF_GROUT10 LOCATE UNIOn of ID=TMP21 and ID=FF_GROUT11 ! LOCAte UNIOn of ID=REGROU and ID=RECONC as ID=RECEME

! / Material and nuclide properties !see transient specification before each SOLVe PROPerty for C C2 C3 is HARMonic PROPerty for C C2 C3 is TOTAl ! / Nuclide properties DECAy half LIFE for $\mathrm{C}$ is $2.1110 \mathrm{E}+05$ years ! TC-99 !

/ Boundary conditions

BOUN C $X-F L O W=0$

BOUN C $X+$ FLOW $=0$

BOUN C $Y-$ FLUX $=0$

BOUN C Y+FLUX $=0$

BOUN C2 $X$ - VALUe $=1.06 \mathrm{E}-3$

BOUN C2 $X+$ VALUe $=1.06 \mathrm{E}-3$

BOUN C2 $Y-$ FLUX $=0$

BOUN C2 $Y+F L U X=0$

BOUN C3 $X$ - VALUe $=0$

BOUN C3 $X+$ VALUe $=0$

BOUN C3 Y-VALUe $=0$

BOUN C3 $Y+$ VALUe $=0$

$!$

/ Diagnostic information

DIAGnostic output: TIME C C2 C3 for node $(23,2)$ every 100 steps !

/ Flux output

FLUX $C$ for ID=DOMAIN by TIME every 1 years to 'FLUX.out'

FLUX $C$ for ID=SALTSTONE by TIME every 1 years to 'FLUX.out'

FLUX $C$ for ID=GROUT by TIME every 1 years to 'FLUX.out'

FLUX C for ID=VAULT_OUT by TIME every 1 years to 'FLUX.out'

FLUX $C$ for ID=VAULT by TIME every 1 years to 'FLUX.out'

FLUX $C$ for ID=NOT_VAULT by TIME every 1 years to 'FLUX.out'

STAT $C$ for ID=SALTSTONE by TIME every 1 years to 'STAT.out'

FLUX C2 for ID=DOMAIN by TIME every 1 years to 'FLUX.out'

FLUX C2 for ID=SALTSTONE by TIME every 1 years to 'FLUX.out'

FLUX C2 for ID=GROUT by TIME every 1 years to 'FLUX.out'

FLUX C2 for ID=VAULT_OUT by TIME every 1 years to 'FLUX.out'

FLUX C2 for ID=VAULT by TIME every 1 years to 'FLUX. out'

FLUX C2 for ID=NOT_VAULT by TIME every 1 years to 'FLUX.out'

STAT C2 for ID=SALTSTONE by TIME every 1 years to 'STAT.out'

FLUX C3 for ID=DOMAIN by TIME every 1 years to 'FLUX.out'

FLUX C3 for ID=SALTSTONE by TIME every 1 years to 'FLUX.out'

FLUX C3 for ID=GROUT by TIME every 1 years to 'FLUX.out'

FLUX C3 for ID=VAULT_OUT by TIME every 1 years to 'FLUX.out'

FLUX C3 for ID=VAULT by TIME every 1 years to 'FLUX.out'

FLUX C3 for ID=NOT_VAULT by TIME every 1 years to 'FLUX.out'

STAT C3 for ID=SALTSTONE by TIME every 1 years to 'STAT.out'

SAVE C C2 C3 for ID=INSIDE to 'C.sav' at TIME interval of 25 years LOCAte ID=OBSNOD as nodes $(23,2)$ through $(23,2)$

HIST C C2 C3 for ID=OBSNOD by TIME every 0.1 years to 'HIST.out' ! 


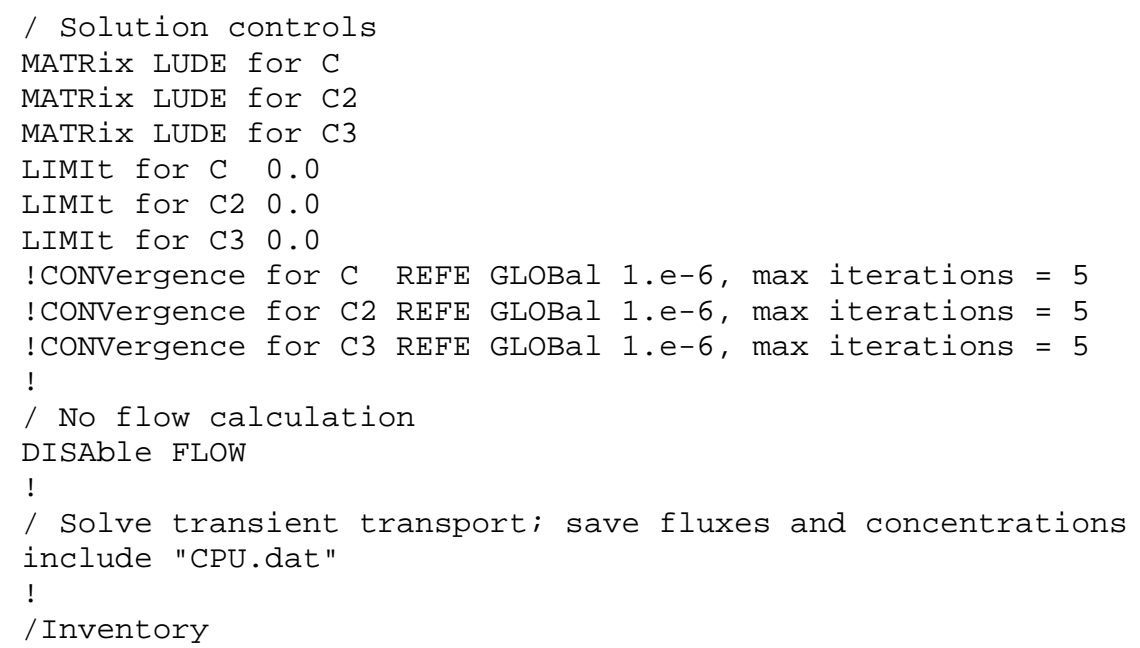


SRNL-STI-2013-00280, REVISION 0

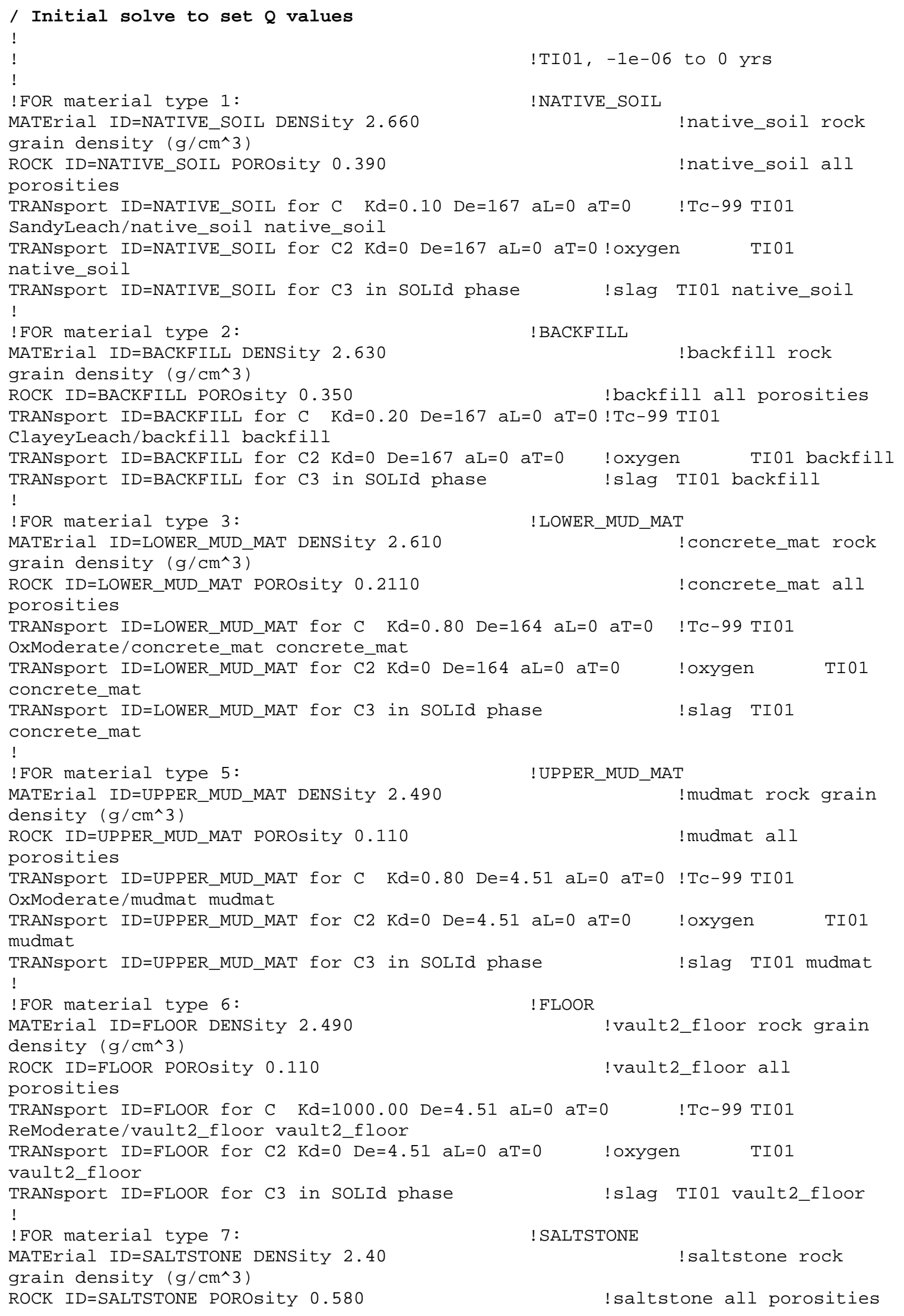


SRNL-STI-2013-00280, REVISION 0

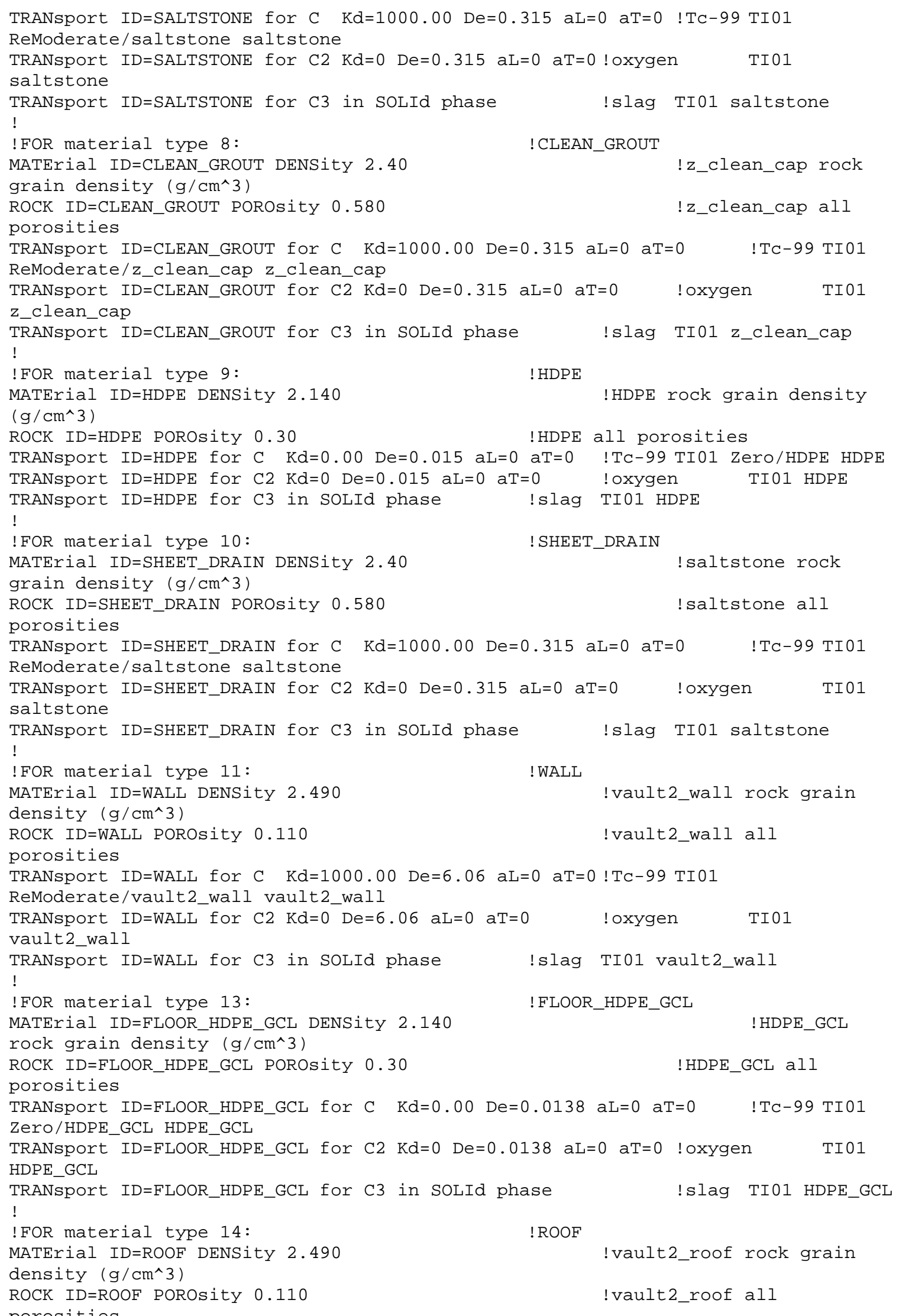

porosities 
SRNL-STI-2013-00280, REVISION 0

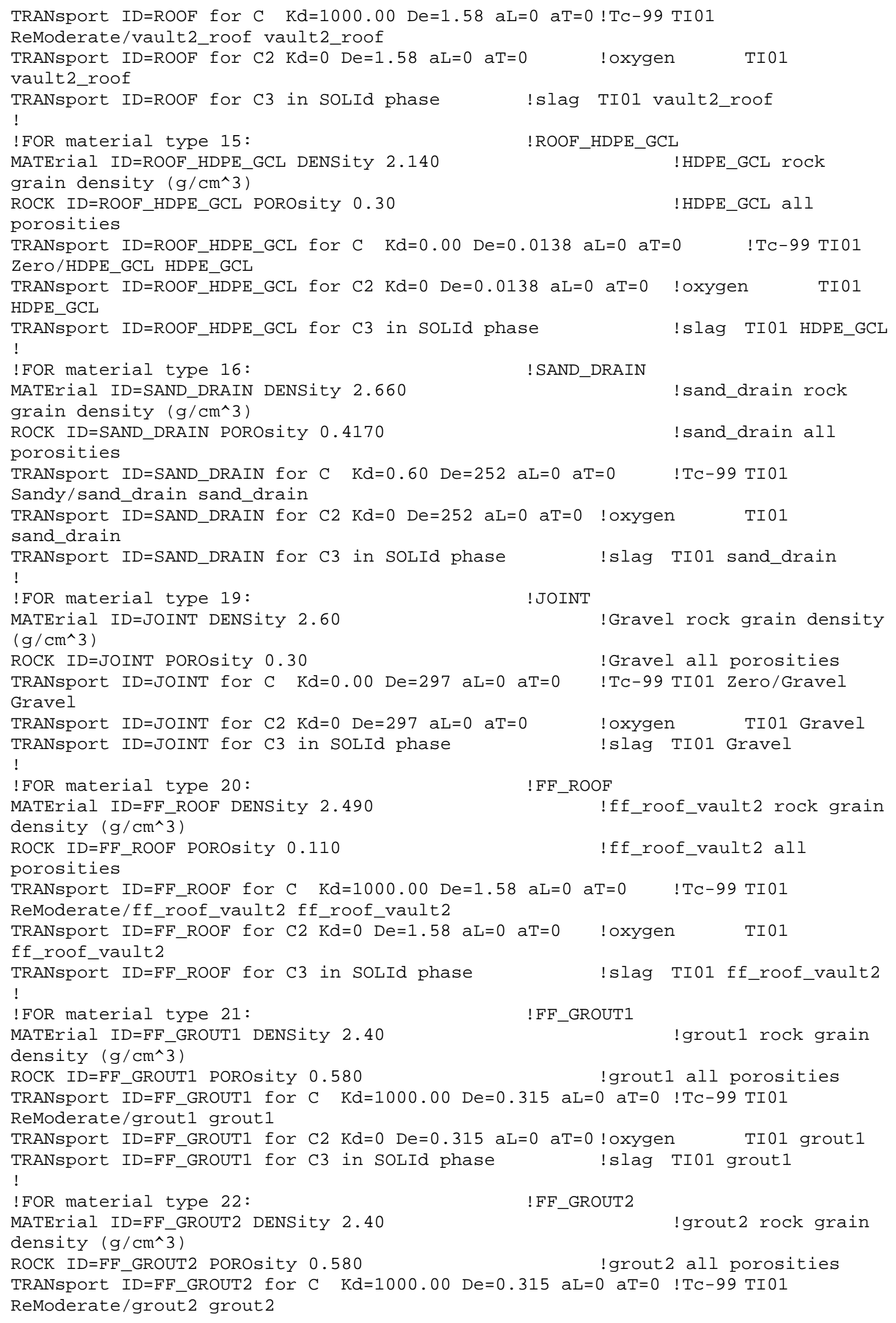


SRNL-STI-2013-00280, REVISION 0

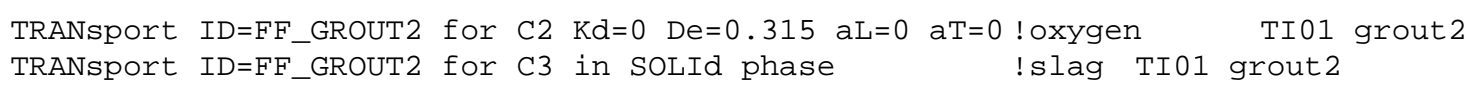

!FOR material type 23:

MATErial ID=FF_GROUT3 DENSity 2.40

!FF_GROUT3

density $\left(\mathrm{g} / \mathrm{cm}^{\wedge} \overline{3}\right)$

ROCK ID=FF_GROUT3 POROsity $\odot .580$

!grout3 rock grain

TRANsport ID=FF_GROUT3 for $\mathrm{C} K \mathrm{Kd}=1000.00 \mathrm{De}=0.315 \mathrm{aL}=0 \mathrm{aT}=0$ !TC-99 TIO1

ReModerate/grout3 grout3

TRANsport ID=FF_GROUT3 for $\mathrm{C} 2 \mathrm{Kd}=\odot \mathrm{De}=\odot .315 \mathrm{aL}=\odot$ aT=๑ ! oxygen TI01 grout3

TRANsport ID=FF_GROUT3 for C3 in SOLId phase !slag TIO1 grout3

!FOR material type 24:

MATErial ID=FF_GROUT4 DENSity 2.40

!FF_GROUT4

density $(\mathrm{g} / \mathrm{cm} \wedge \overline{3})$

ROCK ID=FF_GROUT4 POROsity $\odot .580$

! grout4 rock grain

TRANsport ID=FF_GROUT4 for C $\mathrm{Kd}=1000.00 \mathrm{De}=0.315 \mathrm{aL}=\odot$ aT=0 !TC $-99 \mathrm{TIO1}$

ReModerate/grout4 grout4

TRANsport ID=FF_GROUT4 for $\mathrm{C} 2 \mathrm{Kd}=\odot \mathrm{De}=0.315 \mathrm{aL}=\odot$ aT=0 ! oxygen TI01 grout4 TRANsport ID=FF_GROUT4 for $\mathrm{C} 3$ in SOLId phase !slag TIO1 grout4 !

!FOR material type 25:

!FF_GROUT5

MATErial ID=FF_GROUT5 DENSity $2.40 \quad$ !grout5 rock grain density $\left(\mathrm{g} / \mathrm{cm}^{\wedge} \overline{3}\right)$

ROCK ID=FF_GROUT5 POROsity 0.580

!grout5 all porosities

TRANsport ID=FF_GROUT5 for C $\mathrm{Kd}=1000.00$ De=0.315 aL=0 aT=0 !TC -99 TIO1

ReModerate/grout5 grout5

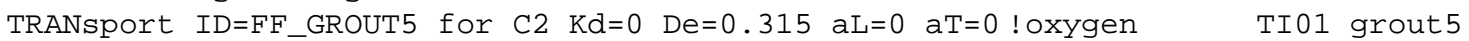
TRANsport ID=FF_GROUT5 for $\mathrm{C} 3$ in SOLId phase !slag TIO1 grout5

!FOR material type 26 :

MATErial ID=FF_GROUT6 DENSity 2.40

!FF_GROUT6

density $(\mathrm{g} / \mathrm{cm} \wedge \overline{3})$

ROCK ID=FF_GROUT6 POROsity 0.580

!grout6 rock grain

TRANsport ID=FF_GROUT6 for C $\mathrm{Kd}=1000.00 \mathrm{De}=0.315$ aL=0 aT=0 !TC -99 TIO1

ReModerate/grout6 grout6

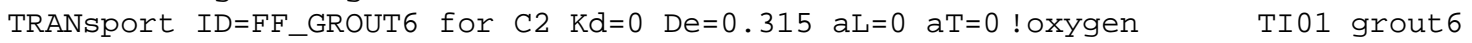

TRANsport ID=FF_GROUT6 for $\mathrm{C3}$ in SOLId phase !slag TIO1 grout6

!FOR material type 27:

MATErial ID=FF_GROUT7 DENSity 2.40

!FF_GROUT7

density $(\mathrm{g} / \mathrm{cm} \wedge \overline{3})$

ROCK ID=FF_GROUT7 POROsity 0.580

! grout7 rock grain

TRANsport ID=FF_GROUT7 for $\mathrm{C} \mathrm{Kd}=100 \odot .0 \odot \mathrm{De}=0.315 \mathrm{aL}=\odot$ aT=○ !TC-99 TI01

ReModerate/grout7 grout7

TRANsport ID=FF_GROUT7 for $\mathrm{C} 2 \mathrm{Kd}=\odot \mathrm{De}=\odot .315 \mathrm{aL}=\odot$ aT=๑ ! oxygen $\quad$ TI01 grout7

TRANsport ID=FF_GROUT7 for $\mathrm{C} 3$ in SOLId phase !slag TIO1 grout7 !

!FOR material type 28:

!FF_GROUT8

MATErial ID=FF_GROUT8 DENSity 2.40

density $\left(\mathrm{g} / \mathrm{cm}^{\wedge} 3\right)$

ROCK ID=FF_GROUT8 POROsity 0.580

!grout8 rock grain

ReModerate/grout8 grout8

TRANsport ID=FF_GROUT8 for $\mathrm{C} 2 \mathrm{Kd}=0 \mathrm{De}=0.315 \mathrm{aL}=0$ aT=0 ! oxygen TIO1 grout8 TRANsport ID=FF_GROUT8 for $\mathrm{C} 3$ in SOLId phase

!slag TI01 grout8

!FOR material type 29:

MATErial ID=FF_GROUT9 DENSity 2.40

! FF GROUT9

density $\left(\mathrm{g} / \mathrm{cm}^{\wedge} 3\right)$

ROCK ID=FF_GROUT9 POROsity 0.580

!grout9 rock grain

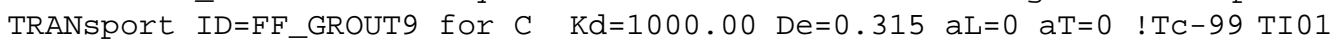

ReModerate/grout9 grout9 
SRNL-STI-2013-00280, REVISION 0

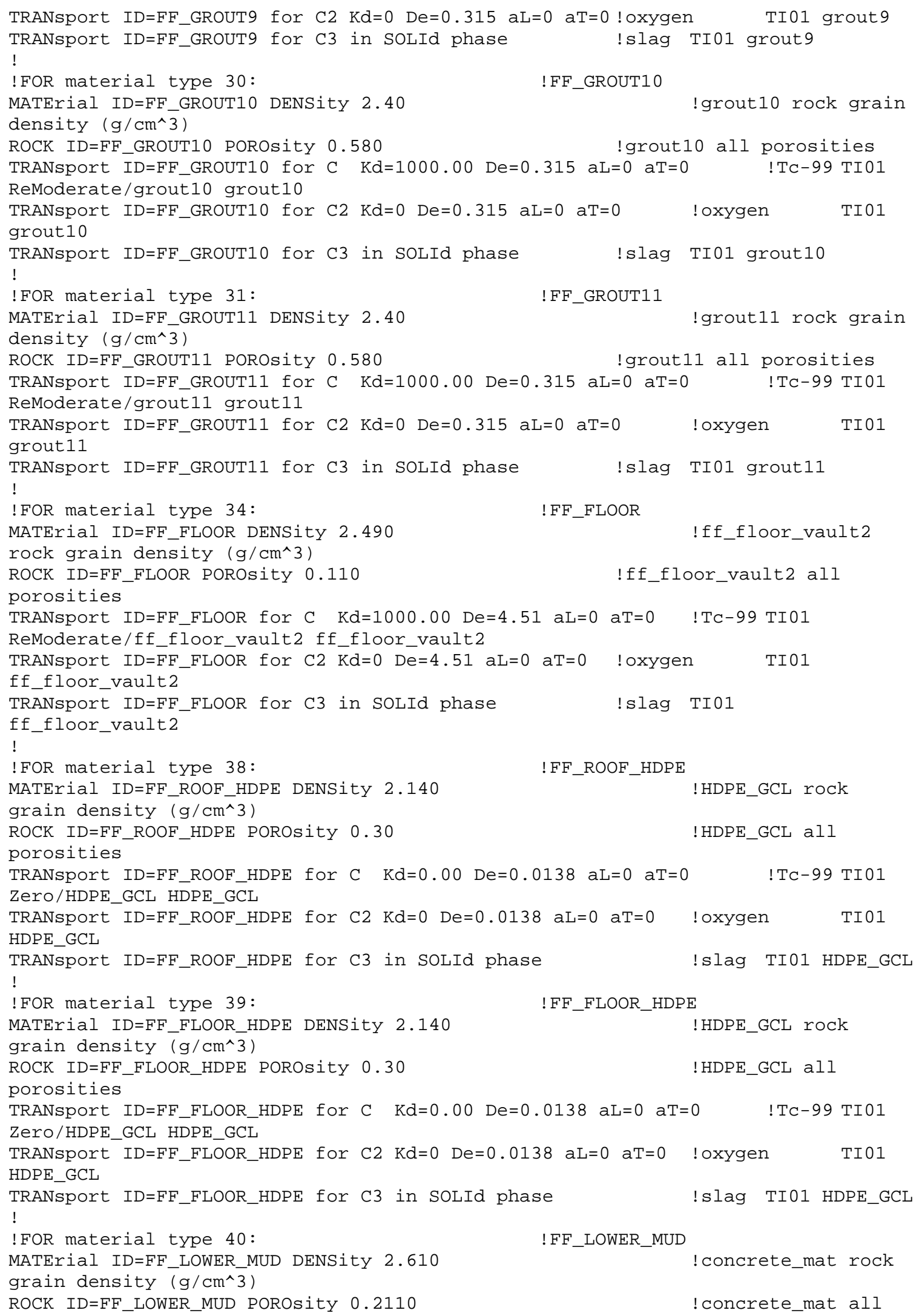




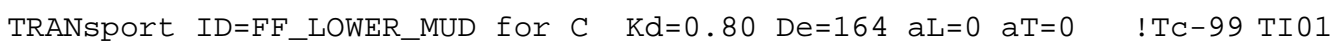

OxModerate/concrete_mat concrete_mat

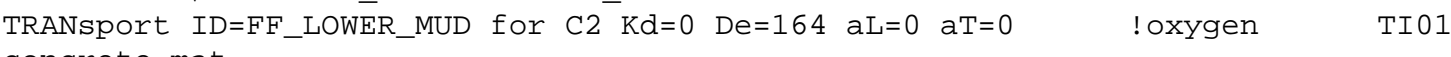
concrete_mat

TRANsport ID=FF_LOWER_MUD for C3 in SOLId phase !slag TIO1 concrete_mat

!

!FOR material type 41:

MATErial ID=FF_UPPER_MUD DENSity 2.490

! FF_UPPER_MUD density $\left(\mathrm{g} / \mathrm{cm}^{\wedge} 3\right)$

ROCK ID=FF_UPPER_MUD POROsity 0.110

porosities

TRANsport ID=FF_UPPER_MUD for $C \quad K d=\odot .80 \quad \mathrm{De}=4.51$ aL $=\odot$ aT=0

OxModerate/mudmat mudmat

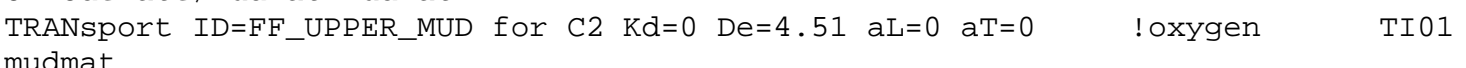

TRANsport ID=FF_UPPER_MUD for C3 in SOLId phase !slag TIO1 mudmat

!

READ 1 '../..././Flow/Case_sa/TIO1/FLOW.sav' and make fresh STARt

TIME $-1 \mathrm{e}-06$

!

SOLVE C C2 C3 1e-06 yrs $\mathrm{dt}=0.05$ inc $=1$ max $=0.1$

WRITe VOL QF QC QC2 QC3 in ID=INSIDE to "VOLMASS_oyr.out"

SAVE C C2 C3 for ID=INSIDE to 'C.Sav' NOW

/ Set variable values

SET XRE in ID=RECEME by ALWAys REPLacing

SET XRE in ID=REGROU by ALWAys DIVIding

with LINEar fon $0 .+1 . *$ c3

SET XRE in ID=RECONC by ALWAys DIVIding

with constant value SLAGGROU

SET $X O X$ in ID=RECEME by ALWAys REPLacing

SET WTOX in ID=RECEME by ALWAYS REPLacing

with CONStant value SLAGCONC

$\wedge$ NPOWER + O.)

SET WTRE in ID=RECEME by ALWAys REPLacing

SET CT in ID=RECEME by ALWAys REPLacing

SET CT in ID=RECEME by ALWAyS DIVIding

SET PORS in ID=RECEME by ALWAyS REPLacing

SET RBCSOL in ID=REGROU by ALWAYS REPLacing

SET RBCSOL in ID=RECONC by ALWAYS REPLacing

with LINEar fon $1 .+-1 . *$ XRE

with (POWEr fon 1. * (XOX + 0.)

SET RBCSOL in ID=RECEME by ALWAys MULTiplying with LINEar fon $0 .+1 . *$ RHOS

SET RBCSOL in ID=RECEME by ALWAys MULTiplying with LINEar fcn $0 .+1$. * PORS

SET NSCSOL in ID=REGROU by ALWAyS REPLacing with LINEar fcn $0 .+$ CSOLGROU *

MOIS ! CSOLGROU is a constant

SET NSCSOL in ID=RECONC by ALWAyS REPLacing with LINEar fon 0 . + CSOLCONC *

MOIS ! CSOLCONC is a constant

!

! KDTEST $=(\mathrm{m} / \mathrm{V}-$ theta $*$ csol $) /($ rhob*csol $):$

SET KDTEST in ID=RECEME by ALWAys REPLacing with LINEar fon $0 .+1 . *$ CT

SET KDTEST in ID=RECEME by ALWAys SUBTracting with LINEar fcn $0 .+1$. * NSCSOL SET KDTEST in ID=RECEME by ALWAys DIVIding with LINEar fcn $0 .+1$. * RBCSOL !

! KDMAX $=\max ($ KDRE, KDTEST) :

SET KDDIFF in ID=RECEME by ALWAys REPLacing with LINEAR fon $0 .+1$. * KDTEST SET KDDIFF in ID=RECEME by ALWAys SUBTracting with constant value KDRE !KDRE is a constant

SET KDDIFF in ID=RECEME by ALWAys REPLacing with LINEAR fen $0 .+1$. KDDIFF $^{\circ}$

POSItive values only

SET KDMAX in ID=RECEME by ALWAys REPLacing with LINEar fon KDRE + 1. *

KDDIFF ! KDRE is constant

!

! get the final $\mathrm{Kd}$ :

SET WTKDOX in ID=RECEME by ALWAys REPLacing with LINEar fcn 0 . + KDOX * WTOX

! KDOX is a constant

SET KDTC in ID=RECEME by ALWAys REPLacing with LINEar fon $0 .+1$. * WTRE

SET KDTC in ID=RECEME by ALWAys MULTiplying with LINEar fon $0 .+1$. * KDMAX 
SET KDTC in ID=RECEME by ALWAys ADD LINEar fon $0 .+1$ * WTKDOX ! if I used ADDing rather than ADD porflow got very confused ! HISTory of ID=RECEME for VOL QF QC QC2 QC3 C C2 C3 to "CONC.out" every PRNTFREQ years by TIME

HISTOrY of ID=RECEME for C3 XRE WTOX WTRE CT PORS RBCSOL NSCSOL WTKDOX KDTEST KDMAX KDTC for ID=RECEME to "VARIABLES.out" every PRNTFREQ years by TIME HISTOry of ID=RECEME for STORage of $C$ to "STORAGE.out" every PRNTFREQ years by TIME

HISTOry of ID=RECEME for MTYP POR S MOIS to "MOIS.out" every PRNTFREQ years by TIME!

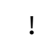

TRANsport ID=FL00R for $C \quad K d=1000.00$ De=4.51 aL=0 aT=0 !TC-99 TI01

! FLOOR !vault2_floor rock grain !vault2_floor all 
SRNL-STI-2013-00280, REVISION 0

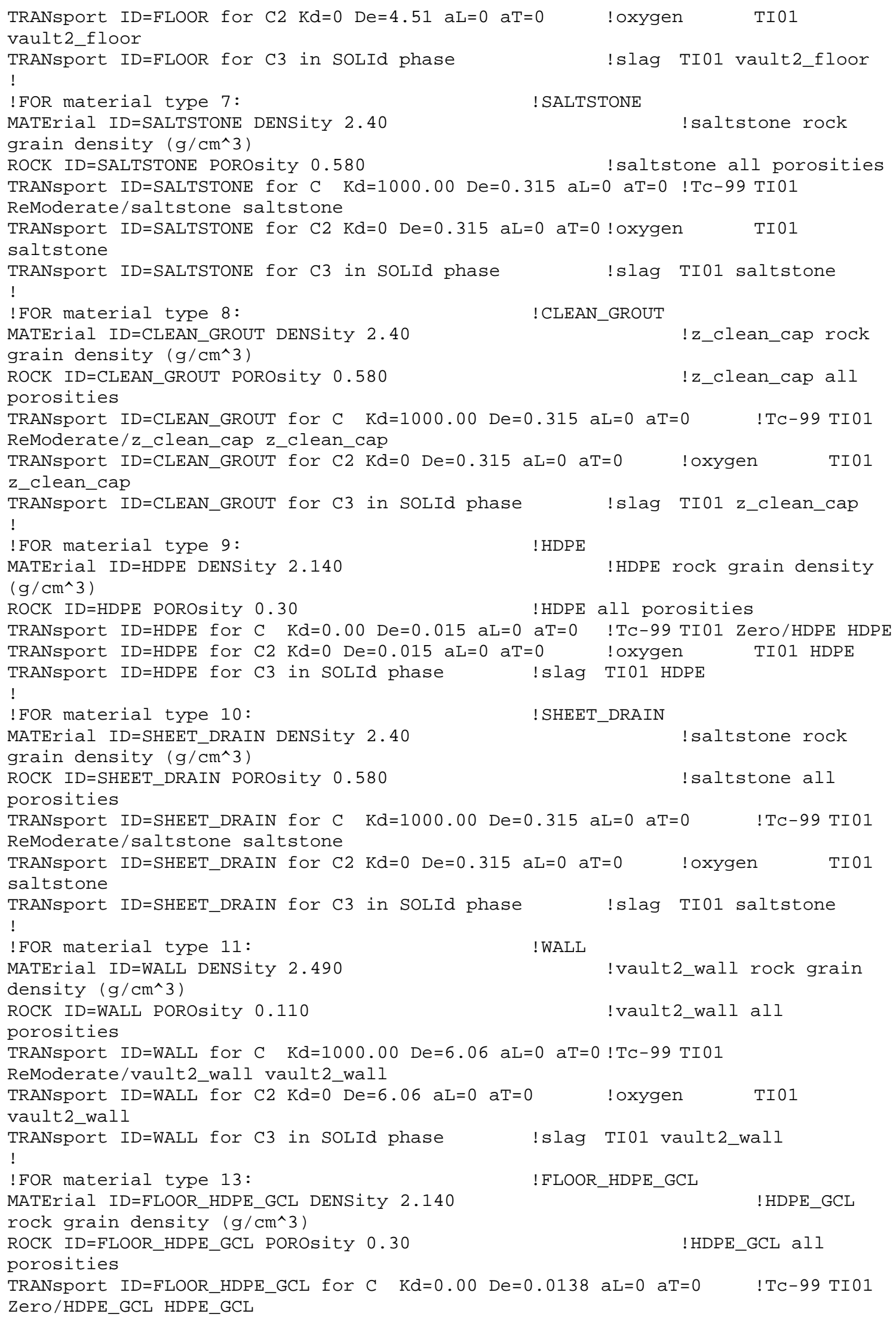


SRNL-STI-2013-00280, REVISION 0

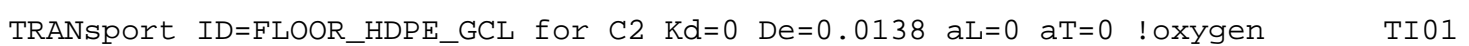
HDPE_GCL

TRANsport ID=FLOOR_HDPE_GCL for C3 in SOLId phase !slag TIO1 HDPE_GCL !

!FOR material type 14:

MATErial ID=ROOF DENSity 2.490 !vault2_roof rock grain

density $\left(\mathrm{g} / \mathrm{cm}^{\wedge} 3\right)$

ROCK ID=ROOF POROsity 0.110

! vault2_roof all

porosities

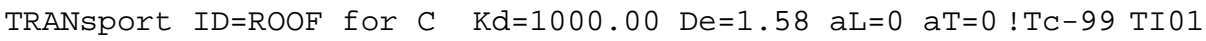

ReModerate/vault2_roof vault2_roof

TRANsport ID=ROOF for $\mathrm{C} 2 \mathrm{Kd}=\odot \mathrm{De}=1.58 \mathrm{aL}=\odot$ aT=○ !oxygen TI01

vault2_roof

TRANsport ID=ROOF for C3 in SOLId phase !slag TIO1 vault2_roof !

!FOR material type 15:

MATErial ID=ROOF_HDPE_GCL DENSity 2.140

! ROOF_HDPE_GCL

grain density $\left(\mathrm{g} / \mathrm{cm}^{\wedge} 3\right)$

ROCK ID=ROOF_HDPE_GCL POROsity $\odot .30$

! HDPE_GCL rock

porosities

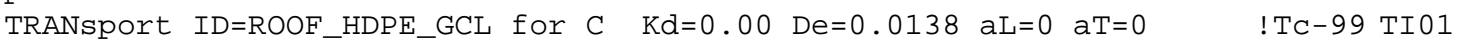

Zero/HDPE_GCL HDPE_GCL

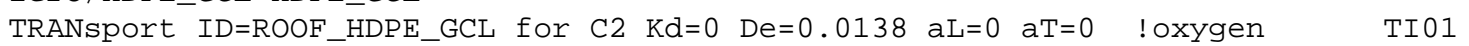

HDPE_GCL

TRANsport ID=ROOF_HDPE_GCL for C3 in SOLId phase !slag TIO1 HDPE_GCL !

!FOR material type 16:

MATErial ID=SAND_DRAIN DENSity 2.660

! SAND_DRAIN

grain density $(\mathrm{g} / \mathrm{cm} \wedge 3)$

ROCK ID=SAND_DRAIN POROsity $\odot .4170$

!HDPE_GCL all

porosities

TRANsport ID=SAND_DRAIN for C $\mathrm{Kd}=0.60$ De=252 aL=0 aT=0 !TC-99 TI01

Sandy/sand_drain sand_drain

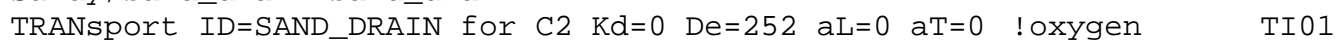

sand_drain

TRANsport ID=SAND_DRAIN for C3 in SOLId phase !slag TIO1 sand_drain !

!FOR material type 19:

! JOINT

MATErial ID=JOINT DENSity 2.60

$\left(\mathrm{g} / \mathrm{cm}^{\wedge} 3\right)$

ROCK ID=JOINT POROSity 0.30

! Gravel rock grain density

TRANsport ID=JOINT for C $\mathrm{Kd}=\odot . \odot \odot \quad \mathrm{De}=297 \mathrm{aL}=\odot$ aT $=\odot$

! Gravel all porosities

Gravel

TRANsport ID=JOINT for C2 $\mathrm{Kd}=\odot \mathrm{De}=297 \mathrm{aL}=\odot$ aT=○ !oxygen TI01 Gravel

TRANsport ID=JOINT for $\mathrm{C} 3$ in SOLId phase

! slag TI01 Gravel

!FOR material type 20:

MATErial ID=FF_ROOF DENSity 2.490

density $\left(\mathrm{g} / \mathrm{cm}^{\wedge} 3\right)$

ROCK ID=FF_ROOF POROsity 0.110

!Tc-99 TI01 Zero/Gravel

porosities

TRANsport ID=FF_ROOF for $C \quad K d=1000.00 \quad \mathrm{De}=1.58$ aL=0 aT=0 !TC-99 TI01

ReModerate/ff_roof_vault2 ff_roof_vault2

TRANsport ID=FF_ROOF for $\mathrm{C} 2 \mathrm{Kd}=0 \quad \mathrm{De}=1.58$ aL=0 $\mathrm{aT}=0$ !oxygen $\quad$ TIO1

ff_roof_vault2

TRANsport ID=FF_ROOF for C3 in SOLId phase

! FF ROOF

!ff_roof_vault2 rock grain

!ff_roof_vault2 all

!FOR material type 21:

MATErial ID=FF_GROUT1 DENSity 2.40

density $\left(\mathrm{g} / \mathrm{cm}^{\wedge} 3\right)$

ROCK ID=FF_GROUT1 POROsity $\odot .580$

!slag TI01 ff_roof_vault2

TRANsport ID=FF_GROUT1 for C $\mathrm{Kd}=1000.00 \mathrm{De}=0.315 \mathrm{aL}=\odot$ aT=0 !TC -99 TIO1

ReModerate/grout1 grout1 
SRNL-STI-2013-00280, REVISION 0

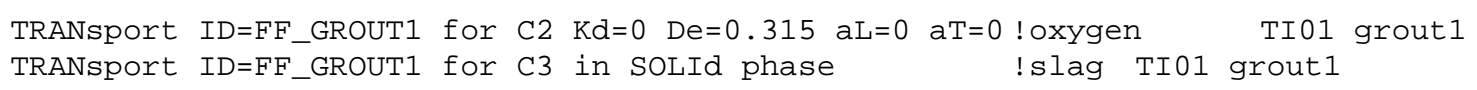

!FOR material type 22:

MATErial ID=FF_GROUT2 DENSity 2.40

!FF_GROUT2

density $\left(\mathrm{g} / \mathrm{cm}^{\wedge} 3\right)$

ROCK ID=FF_GROUT2 POROsity $\odot .580$

!grout2 rock grain

TRANsport ID=FF_GROUT2 for $\mathrm{C} K \mathrm{Kd}=1000.00 \mathrm{De}=0.315 \mathrm{aL}=0 \mathrm{aT}=0$ !TC-99 TIO1

ReModerate/grout2 grout2

TRANsport ID=FF_GROUT2 for $\mathrm{C} 2 \mathrm{Kd}=\odot \mathrm{De}=\odot .315 \mathrm{aL}=\odot$ aT=๑ ! oxygen TI01 grout2

TRANsport ID=FF_GROUT2 for C3 in SOLId phase !slag TIO1 grout2

!FOR material type 23:

MATErial ID=FF_GROUT3 DENSity 2.40

!FF_GROUT3

density $(\mathrm{g} / \mathrm{cm} \wedge \overline{3})$

ROCK ID=FF_GROUT3 POROsity $\odot .580$

! grout3 rock grain

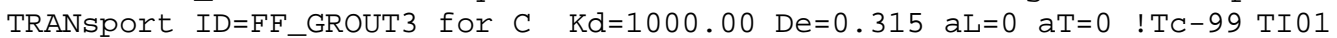

ReModerate/grout3 grout3

TRANsport ID=FF_GROUT3 for $\mathrm{C} 2 \mathrm{Kd}=\odot \mathrm{De}=0.315 \mathrm{aL}=\odot$ aT=0 ! oxygen TI01 grout3 TRANsport ID=FF_GROUT3 for C3 in SOLId phase !slag TIO1 grout3

!

!FOR material type 24:

! FF GROUT4

MATErial ID=FF_GROUT4 DENSity 2.40

density $\left(\mathrm{g} / \mathrm{cm}^{\wedge} 3\right)$

ROCK ID=FF_GROUT4 POROsity 0.580

!grout4 rock grain

TRANsport ID=FF_GROUT4 for C $\mathrm{Kd}=1000.00 \mathrm{De}=0.315 \mathrm{aL}=0$ aT=0 !TC-99 TI01

ReModerate/grout4 grout4

TRANsport ID=FF_GROUT4 for $\mathrm{C} 2 \mathrm{Kd}=0$ De=0.315 aL=0 aT=0 ! oxygen $\quad$ TI01 grout4 TRANsport ID=FF_GROUT4 for $\mathrm{C} 3$ in SOLId phase !slag TIO1 grout4

!FOR material type 25:

MATErial ID=FF_GROUT5 DENSity 2.40

!FF_GROUT5

density $\left(\mathrm{g} / \mathrm{cm}^{\wedge} 3\right)$

ROCK ID=FF_GROUT5 POROsity 0.580

!grout5 rock grain

TRANsport ID=FF_GROUT5 for C $\mathrm{Kd}=1000.00 \mathrm{De}=0.315 \mathrm{aL}=\odot$ aT=0 !TC -99 TIO1

ReModerate/grout5 grout5

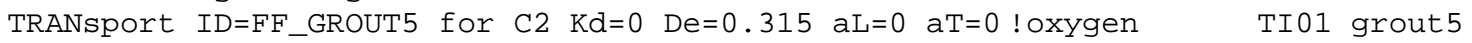

TRANsport ID=FF_GROUT5 for $\mathrm{C3}$ in SOLId phase !slag TI01 grout5

!FOR material type 26:

MATErial ID=FF_GROUT6 DENSity 2.40

!FF_GROUT6

density $\left(\mathrm{g} / \mathrm{cm}^{\wedge} 3\right)$

ROCK ID=FF_GROUT6 POROsity 0.580

grout6 rock grain

TRANsport ID=FF_GROUT6 for $\mathrm{C} \mathrm{Kd}=100 \odot .0 \odot \mathrm{De}=0.315 \mathrm{aL}=\odot$ aT=0 !TC-99 TI01

ReModerate/grout6 grout 6

TRANsport ID=FF_GROUT6 for $\mathrm{C} 2 \mathrm{Kd}=\odot \mathrm{De}=\odot .315 \mathrm{aL}=\odot$ aT=๑ ! oxygen TI01 grout6

TRANsport ID=FF_GROUT6 for $\mathrm{C} 3$ in SOLId phase !slag TI01 grout6 !

!FOR material type 27:

!FF_GROUT7

MATErial ID=FF_GROUT7 DENSity 2.40

!grout7 rock grain density $\left(\mathrm{g} / \mathrm{cm}^{\wedge} 3\right)$

ROCK ID=FF_GROUT7 POROsity 0.580

! grout7 all porosities

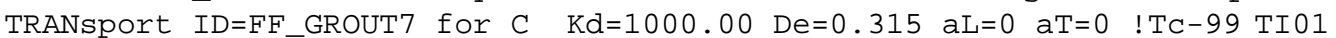

ReModerate/grout7 grout 7

TRANsport ID=FF_GROUT7 for $\mathrm{C} 2 \mathrm{Kd}=0$ De=0.315 aL=0 $\mathrm{aT}=0$ ! oxygen $\quad$ TI01 grout7 TRANsport ID=FF_GROUT7 for C3 in SOLId phase

!slag TI01 grout7

!FOR material type 28:

MATErial ID=FF_GROUT8 DENSity 2.40

! FF GROUT8

density $\left(\mathrm{g} / \mathrm{cm}^{\wedge} 3\right)$

ROCK ID=FF_GROUT8 POROsity 0.580

!grout8 rock grain

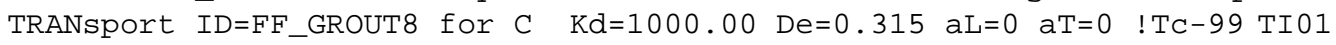

ReModerate/grout8 grout8 
SRNL-STI-2013-00280, REVISION 0

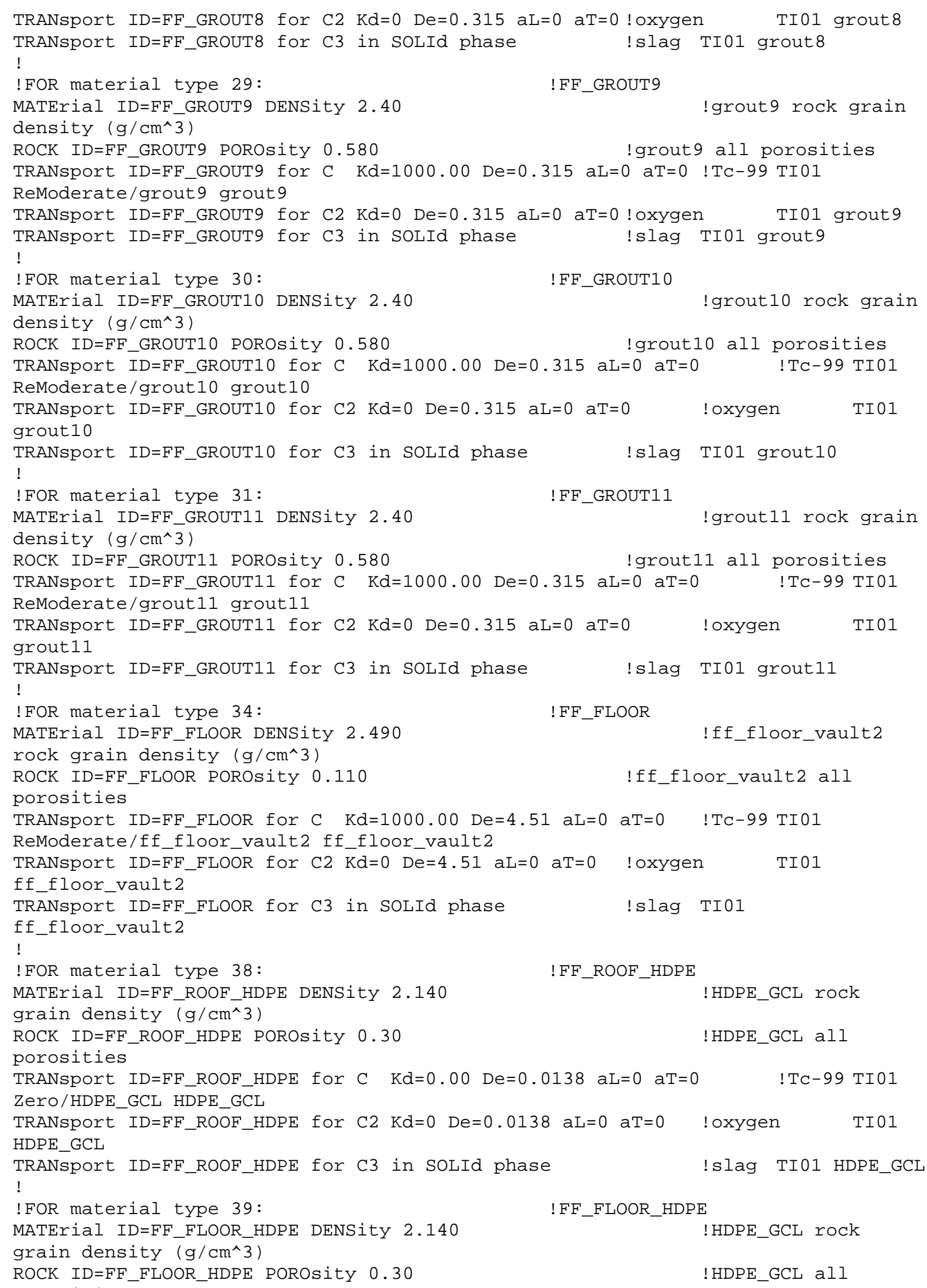


SRNL-STI-2013-00280, REVISION 0

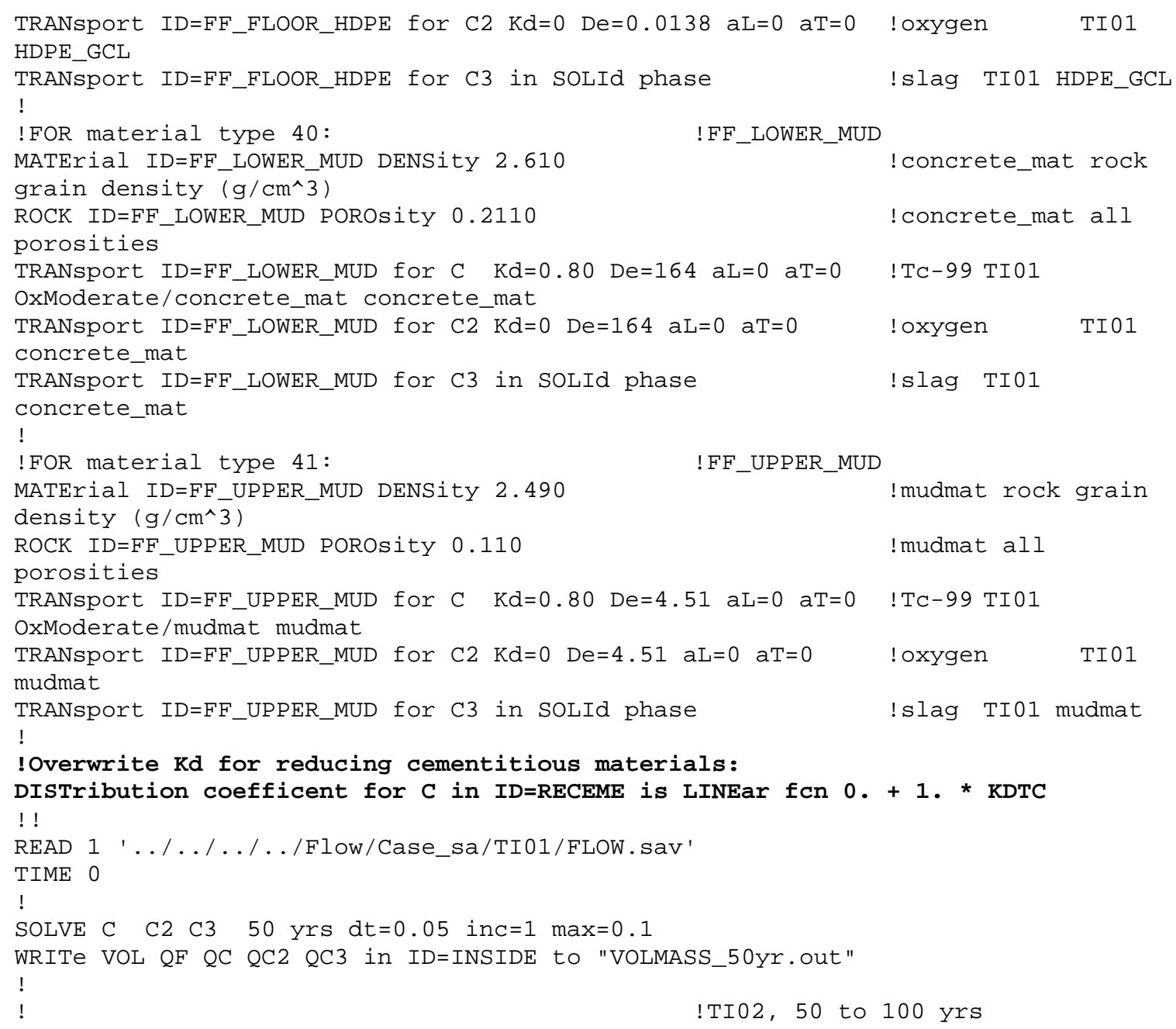




\section{Appendix E - Test cases for PORFLOW implementation of combined redox and solubility controls on Tc-99 transport.}

Problem specifications:

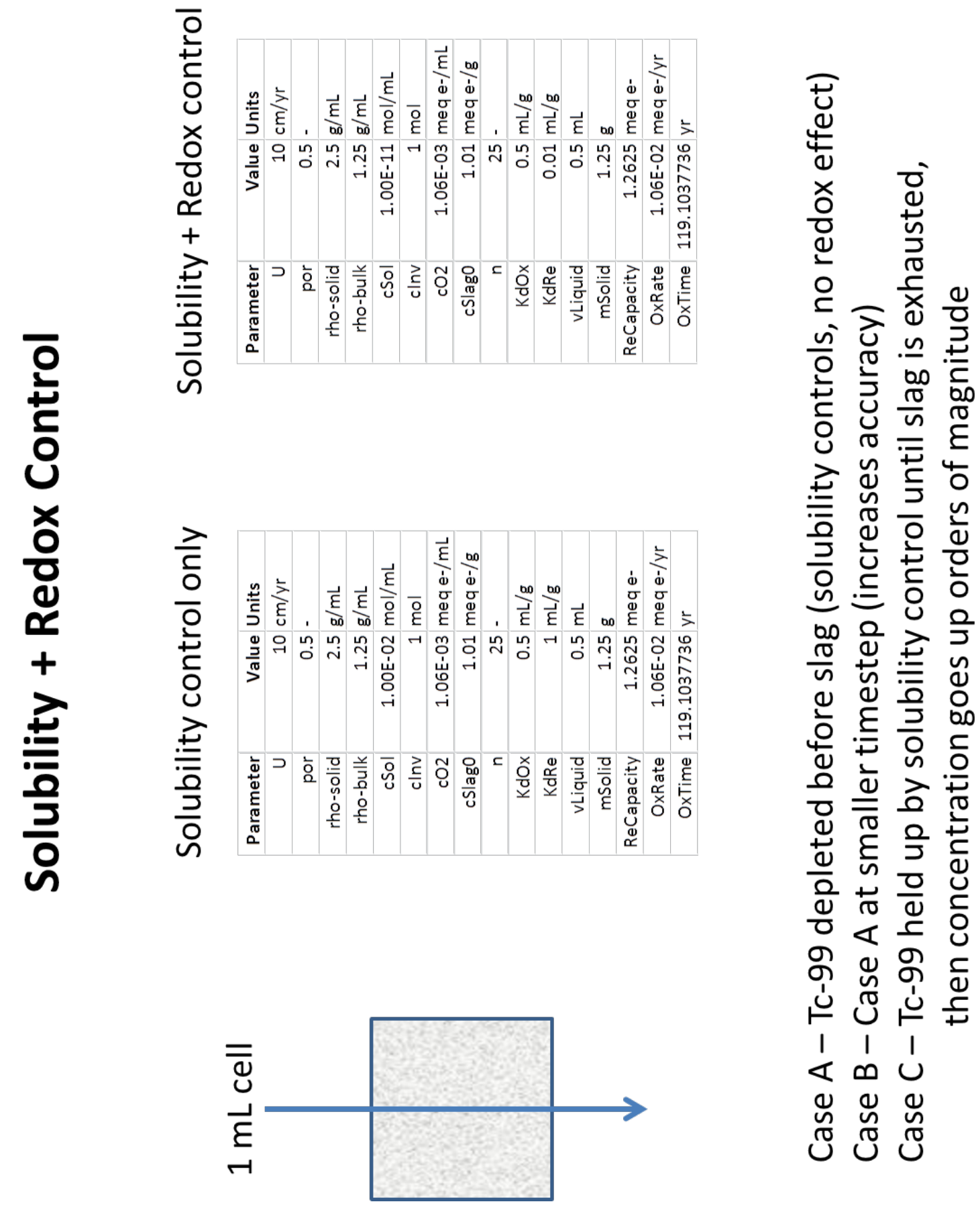




\section{PORFLOW input file - Case A:}

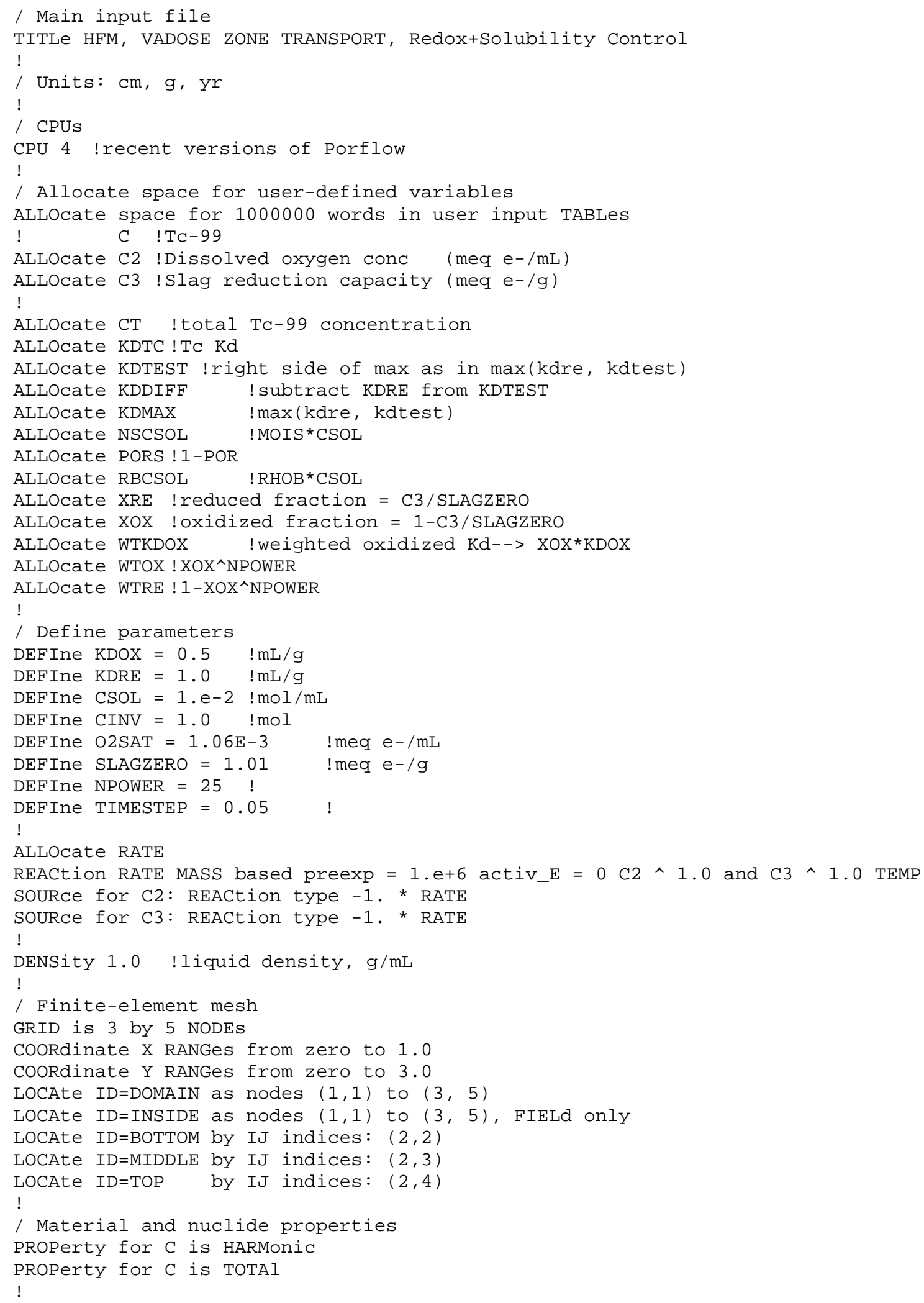




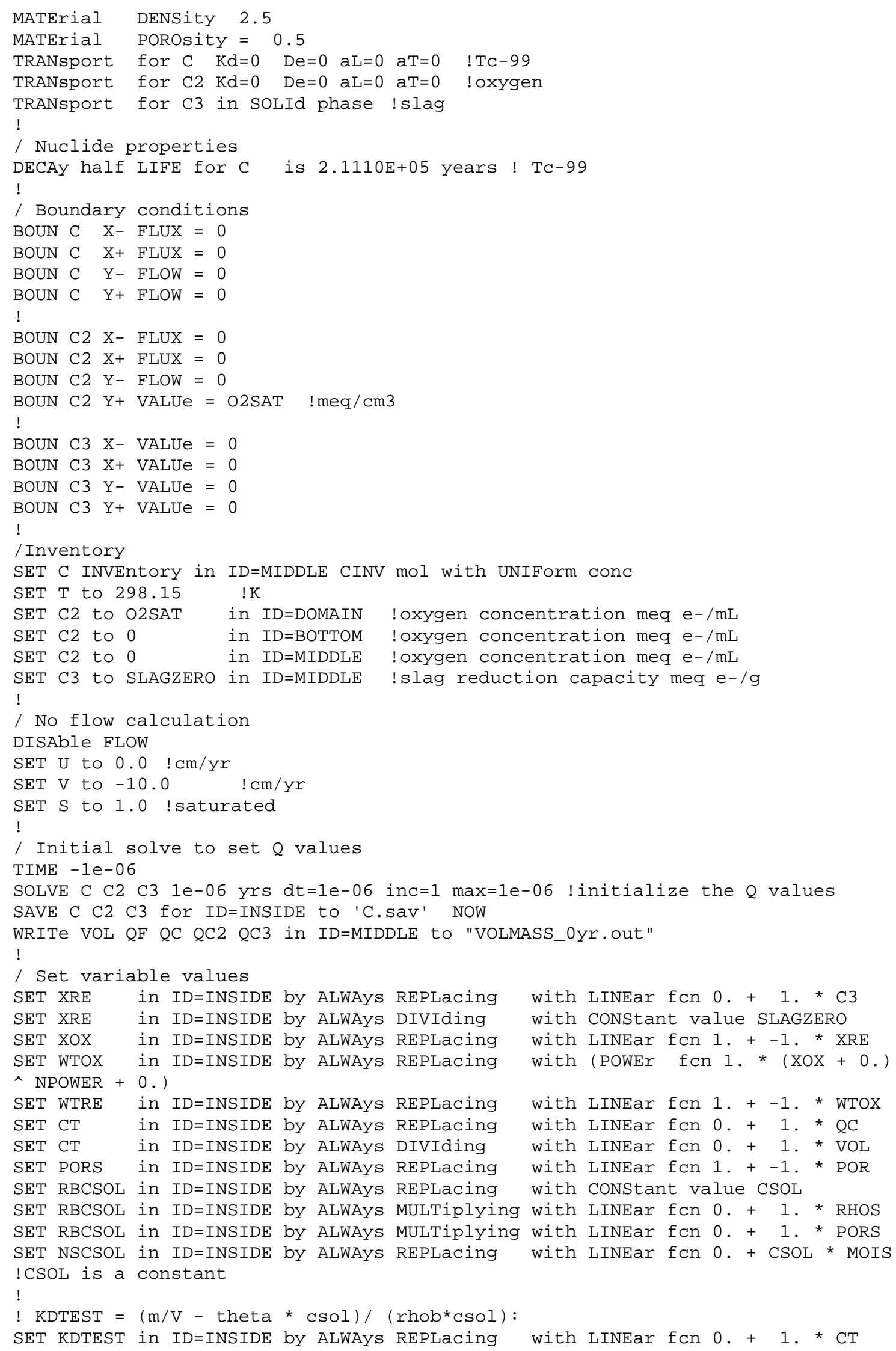


SRNL-STI-2013-00280, REVISION 0

SET KDTEST in ID=INSIDE by ALWAys SUBTracting with LINEar fcn $0 .+1 . *$ NSCSOL SET KDTEST in ID=INSIDE by ALWAys DIVIding with LINEar fen $0 .+1$. * RBCSOL !

! $\mathrm{KDMAX}=\max (\mathrm{KDRE}, \mathrm{KDTEST})$

SET KDDIFF in ID=INSIDE by ALWAyS REPLacing with LINEAR fon $0 .+1$. * KDTEST SET KDDIFF in ID=INSIDE by ALWAys SUBTracting with constant value KDRE !KDRE is a constant

SET KDDIFF in ID=INSIDE by ALWAys REPLacing with LINEAR fon $\odot .+1$. * KDDIFF

POSItive values only

SET KDMAX in ID=INSIDE by ALWAys REPLacing with LINEar fon KDRE +1 . * KDDIFF ! KDRE is constant

!

! get the final $\mathrm{Kd}$ :

SET WTKDOX in ID=INSIDE by ALWAyS REPLacing with LINEar fcn $\odot .+$ KDOX * WTOX

!KDOX is a constant

SET KDTC in ID=INSIDE by ALWAyS REPLacing with LINEar fon $0 .+1$. * WTRE

SET KDTC in ID=INSIDE by ALWAys MULTiplying with LINEar fcn $0 .+1$. * KDMAX

SET KDTC in ID=INSIDE by ALWAyS ADD LINEar fcn $\odot .+1$. * WTKDOX ! if I used

ADDing rather than ADD porflow got very confused

! Tc-99 custom Kd:

DISTribution coefficent for $C$ in ID=INSIDE is LINEar fon $\odot .+1$. * KDTC !

/ output

DIAGnostic output: TIME C C2 C3 for node $(2,3)$

FLUX C2 for ID=MIDDLE to 'FLUX.out'

FLUX $C$ for ID=MIDDLE to 'FLUX.out'

STAT $C$ for ID=MIDDLE to 'STAT. out'

STAT C2 for ID=MIDDLE to 'STAT.out'

STAT C3 for ID=MIDDLE to 'STAT. out'

HIST C C2 C3 for ID=MIDDLE to 'HIST. out'

HIST $C$ for ID=MIDDLE to 'STOR.out' STORage

HIST C2 for ID=MIDDLE to 'STOR.out' STORage

HIST C3 for ID=MIDDLE to 'STOR.out' STORage

SAVE C C2 C3 for ID=INSIDE to 'C.sav' every 1 years by TIME

every 100 steps

every 1 years by TIME

every 1 years by TIME

every 1 years by TIME

every 1 years by TIME

every 1 years by TIME

every 1 years by TIME

every 1 steps

every 1 steps

every 1 steps

!

HIST VOL QF QC QC2 QC3 C C2 C3 for ID=MIDDLE to 'CONC.out' every TIMESTEP years by TIME

HIST C3 XRE WTOX WTRE CT PORS RBCSOL NSCSOL WTKDOX KDTEST KDMAX KDTC for

ID=MIDDLE to 'VARIABLES. out' every TIMESTEP years by TIME

HIST STOR C in ID=MIDDLE to "STOR. out" every 1 years by TIME

!

/ Solve transient transport

TIME $\odot$

SOLVE C C2 C3 120 yrs dt=TIMESTEP inc=1 max=TIMESTEP

WRITe VOL QF QC QC2 QC3 in ID=MIDDLE to "VOLMASS_120yr.out"

SOLVE C C2 C3 5 yrs dt=TIMESTEP inc=1 max=TIMESTEP

WRITe VOL QF QC QC2 QC3 in ID=MIDDLE to "VOLMASS_125yr.out"

!

END

QUIT

\section{PORFLOW input file - Case B:}

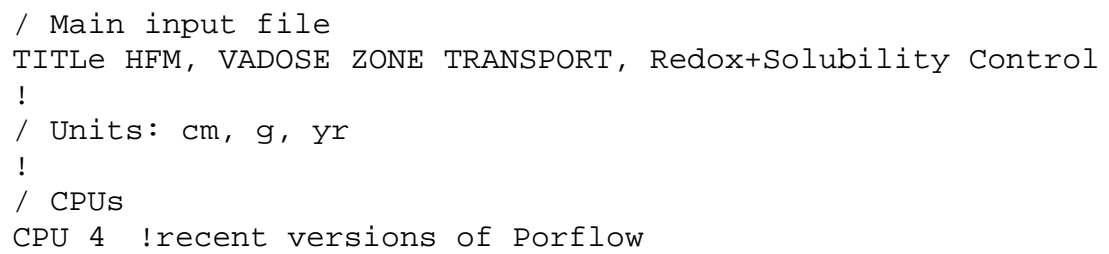




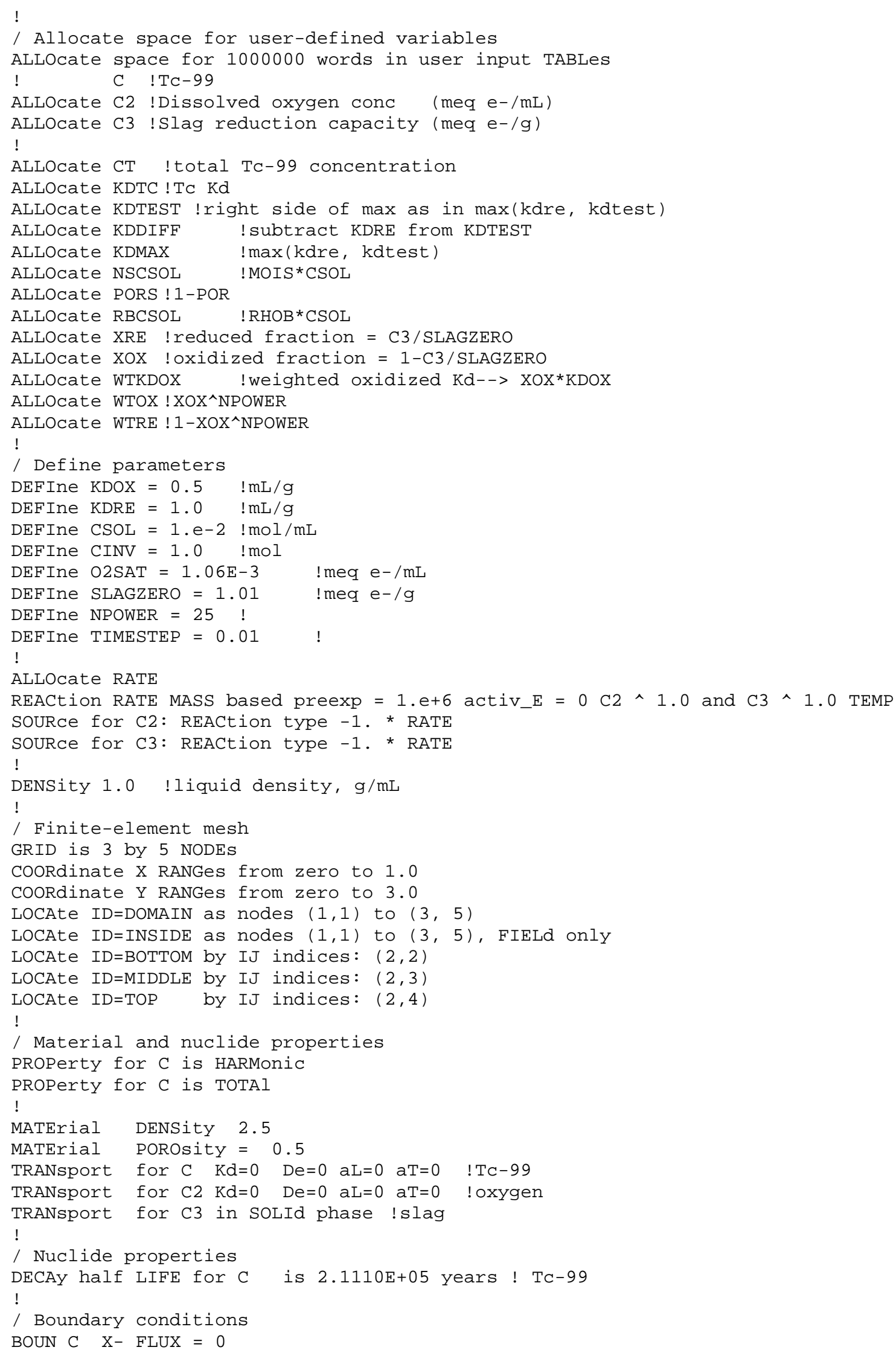




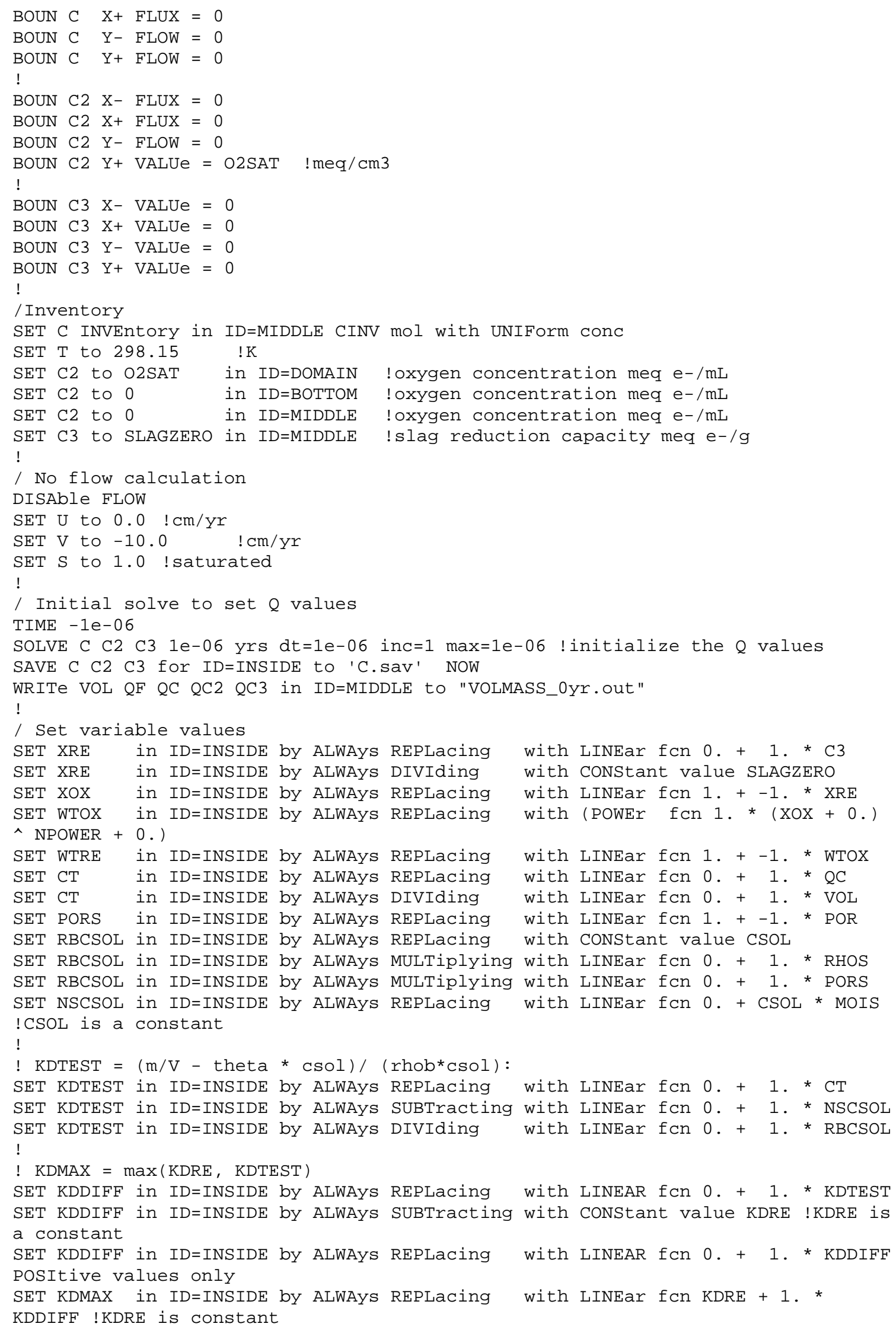




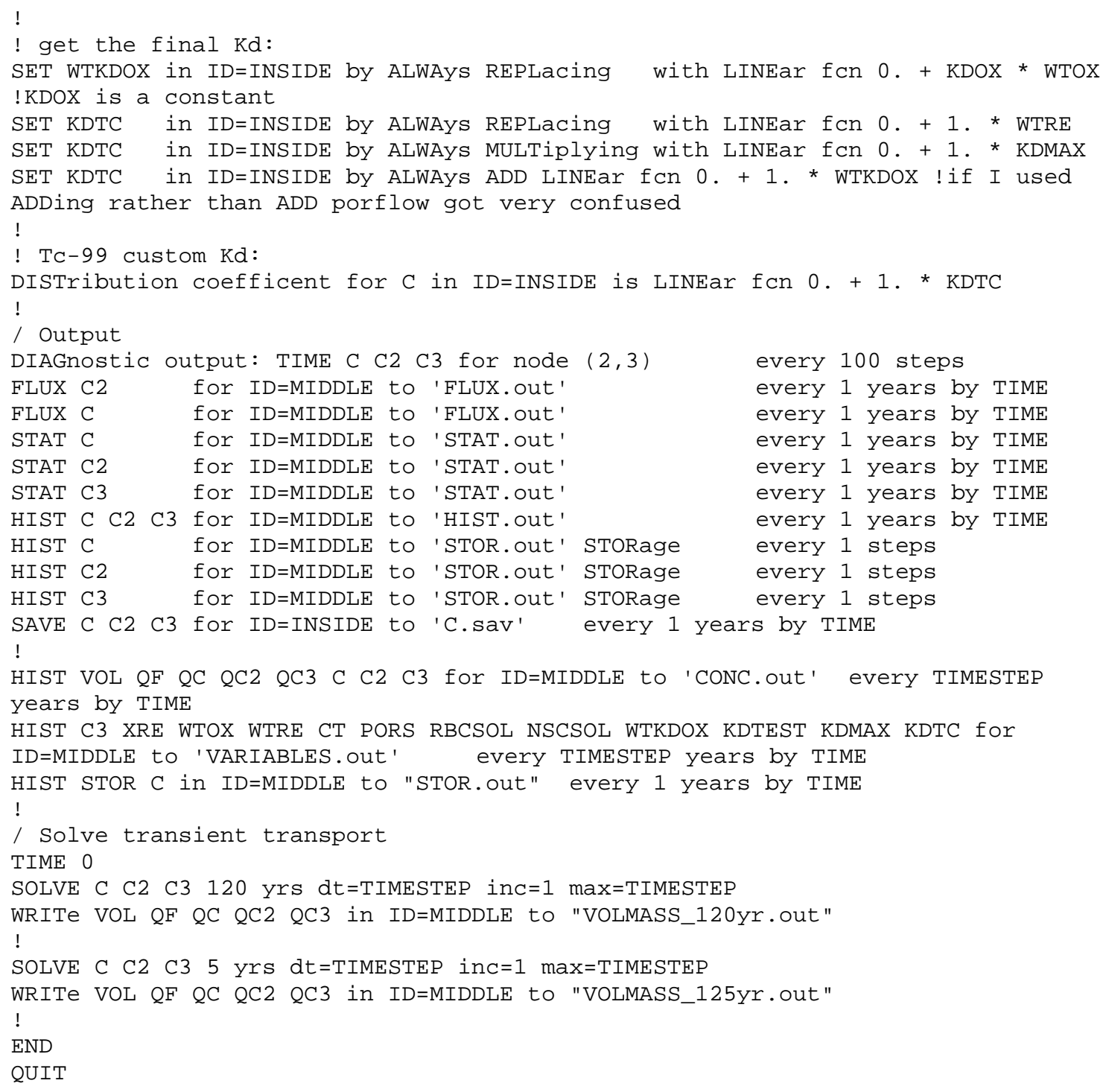

\section{PORFLOW input file - Case C:}

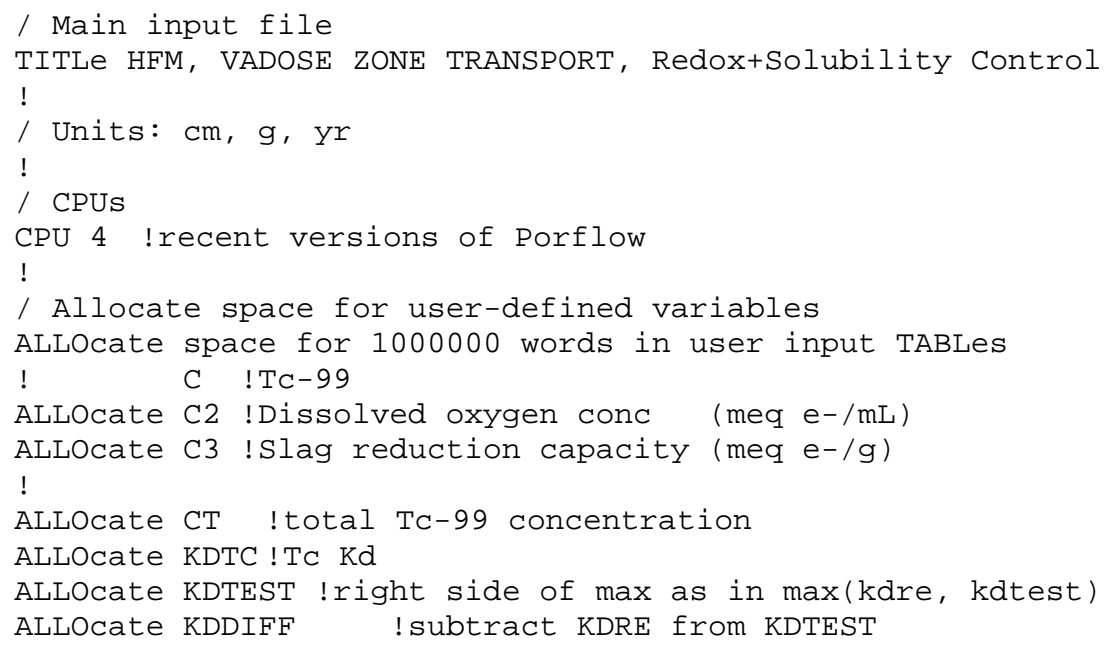




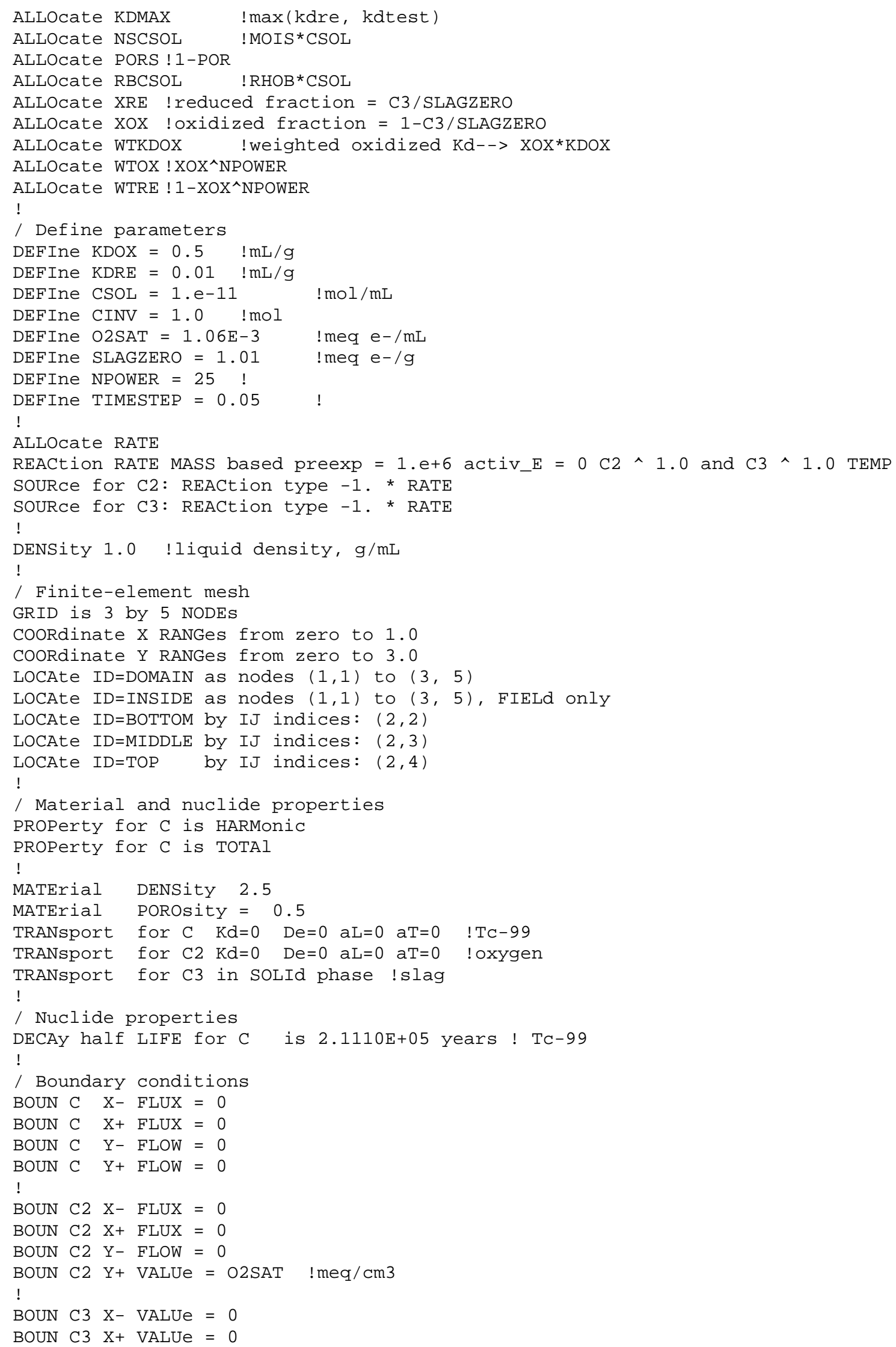




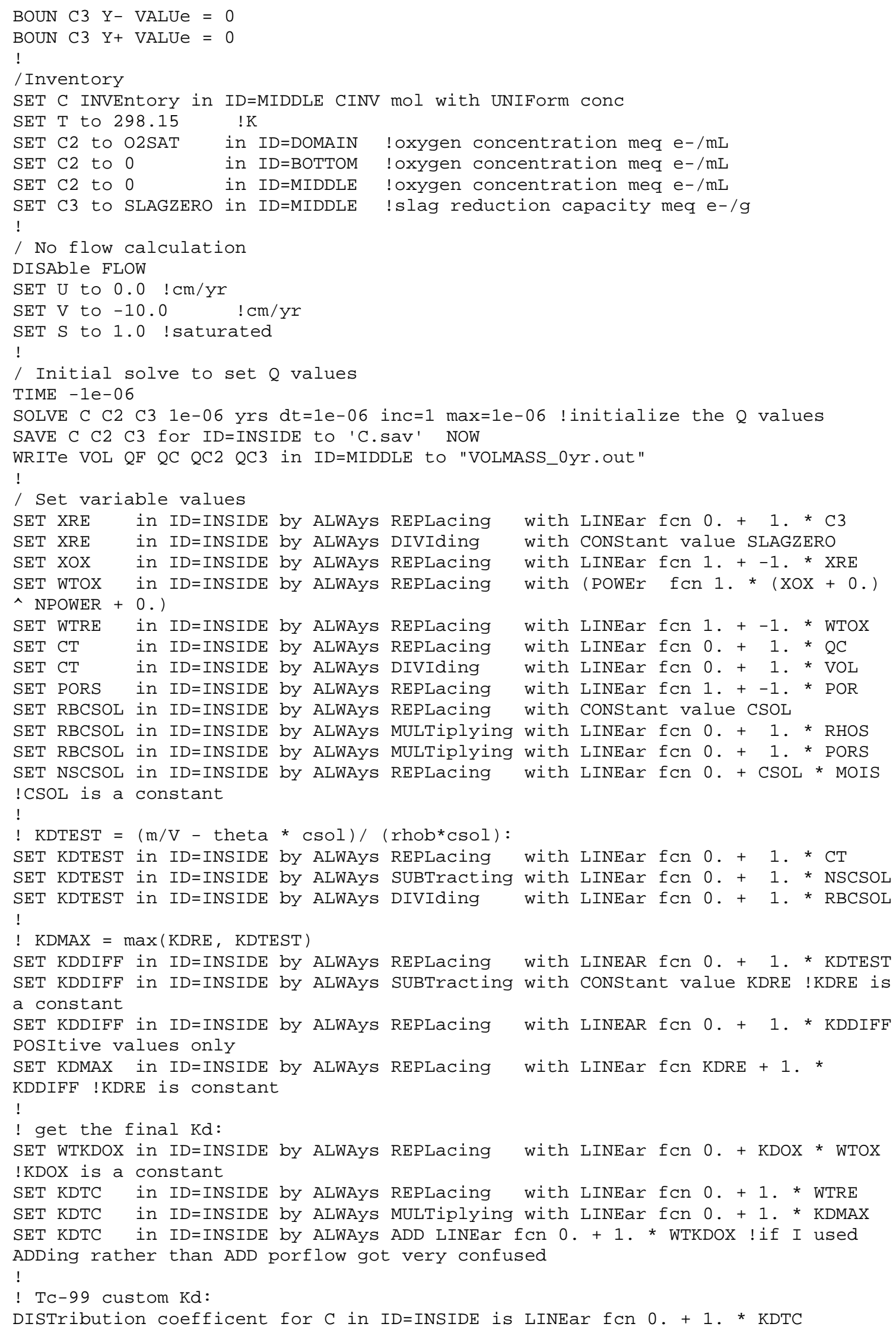


SRNL-STI-2013-00280, REVISION 0

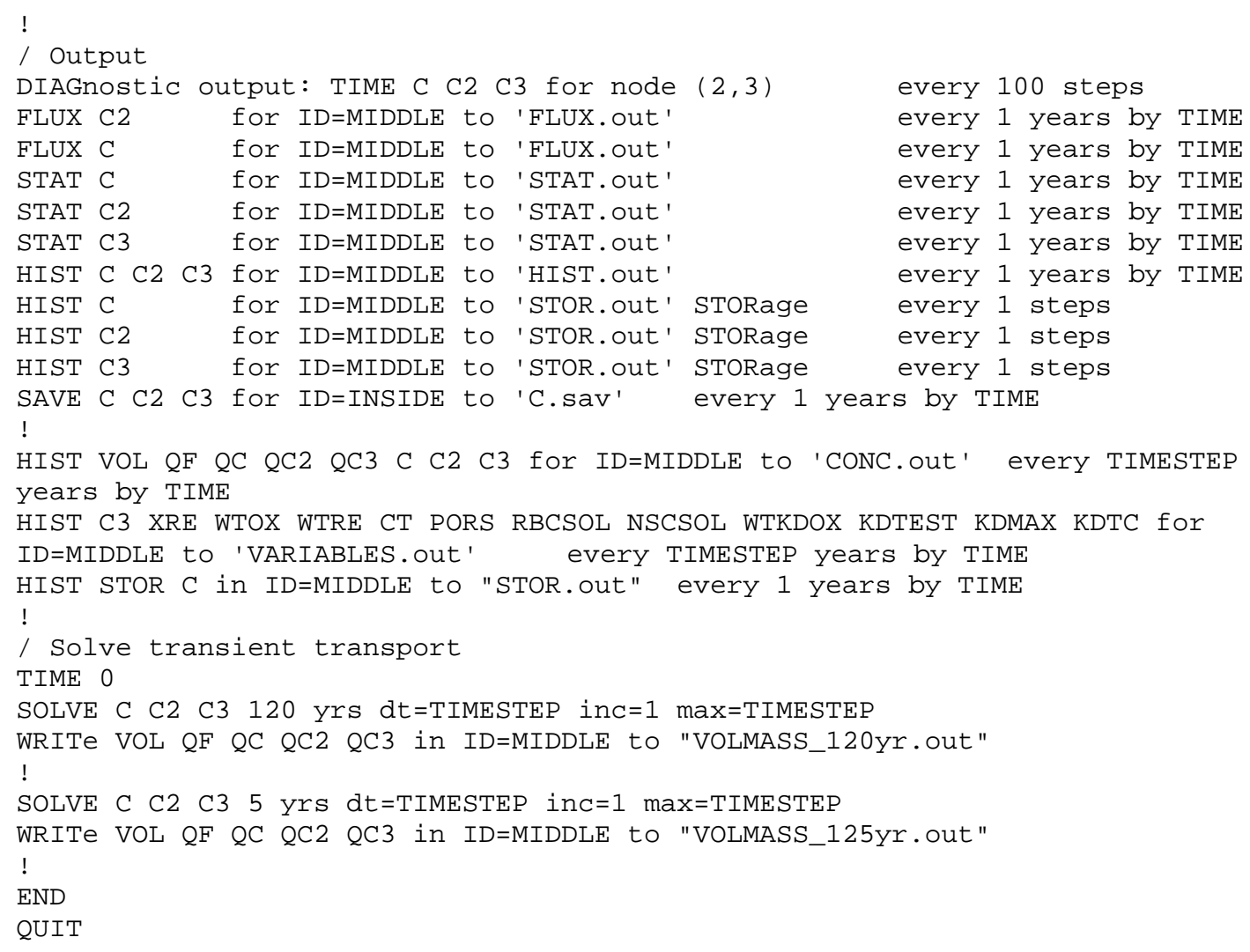




\section{Distribution:}

R. S. Aylward, 773-42A

H. H. Burns, 773-41A

B. T. Butcher, 773-43A

T. W. Coffield, 705-1C

D. A. Crowley, 773-43A

W. B. Dean, 705-1C

G. P. Flach, 773-42A

M. B. Gorensek, 703-41A

J. C. Griffin, 773-A

M. K. Harris, 703-41A

J. M. Jordan, 703-41A

C. A. Langton, $773-43 \mathrm{~A}$

P. L. Lee, 703-41A

B. H. Lester, 705-1C

S. L. Marra, 773-A

M. A. Phifer, 773-42A

K. H. Rosenberger, 705-1C

R. R. Seitz, 773-43A

R. E. Sheppard, 705-1C

F. G. Smith, III 703-41A

G. A. Taylor, 773-43A

C. Wilson (1 file copy \& 1 electronic copy), 773-43A - Rm. 213 